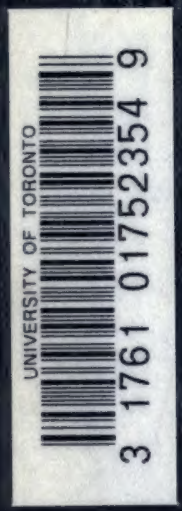

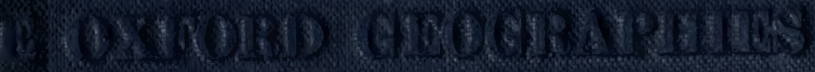

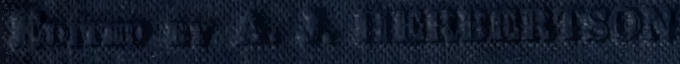

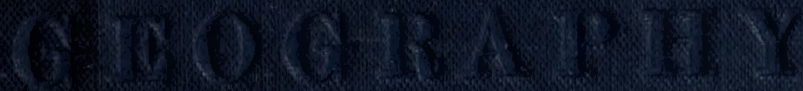

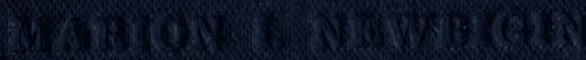



6001.

Pauna

\section{THE OXFORD GEOGRAPHIES}

Edited by A. J. HERBER'TSON

\section{ANIMAL GEOGRAPHY}

\section{THE FAUNAS OF THE NATURAL}

REGIONS OF THE GLOBE

BY

\section{MARION I. NEWBIGIN \\ D.Sc. (LOND.)}

LECTURER IN ZOOLOGY AND BIOLOGY IN THE EDINBURGH SCHOOL. OF MEDICINE FOR WOMEN

EDITOR OF THE ' SCOTTISH GEOGRAPHICAL MAGAZINE'

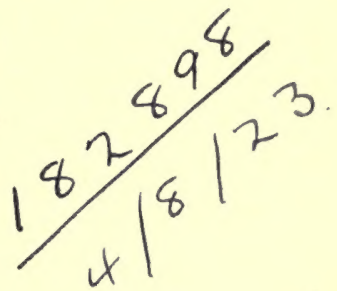

OXFORD

A'T THE CLARENDON PRESS 


\section{OXFORD UNIVERSITY PRESS}

LONDON EDINBURGH GLASGOW NEW YORK

TORONTO MELBOURNE BOMBAY

HUMPHREY MILFORD M.A.

PUBLISHER TO THE UNIVERSITY 


\section{PREFACE}

Wiтhin the last few years, as is well known, botanical geography has made great strides. The intimate relation between the vegetative covering and the physical conditions has been in many cases thoroughly worked out, and all the more modern geographical text-books give at least some indication of the results obtained. On the other hand, the more difficult subject of the relation between the animals of the various natural regions and their surroundings has been much less fully treated by geographers. The facts have still mostly to be sought in zoological text-books, where they are treated from another point of view, and many even of the most recent geographical text-books show uncertainty of treatment when dealing with the animals of tropical forest and arctic tundra. The present book is an attempt to put the main facts connected with the distribution of animals in a form acceptable to the geographical student, and has been written by one whose approach to geography was first made from the biological side.

The sources of the illustrations are indicated beneath each, and I am greatly indebted to the various gentlemen named for permission to reproduce their photographs. Special acknowledgement should be made to Sir Thomas Carlaw Martin, Director of 
the Royal Scottish Museum, and Mr. Eagle Clarke, Keeper of the Natural History Collection there, for permission to photograph a number of specimens in the collection.

For the index I am indebted to my sister, Miss Florence Newbigin.

\section{MARION I. NEWBIGIN.}

Edinburgh, 1913. 


\section{CONTENTS}

PAGE

Introduction: The Natural Regions of the Globe $\quad 9$ CHAPTER

I. The Tundra and its Fauna . . . . 15

II. The 'Taiga, or Coniferous Forest, and its Fauna . 36

III. Steppe faunas and the Temperate Steppes of Asta and North America . . . . 52

IV. Mountain Faunas $\quad$. $\quad$. $\quad$. 72

V. The Fauna of the Tropical Forest . . . 92

VI. Tropical Savanas and Deserts . . . . 121

VII. Special Features of Island Faunas . . . 144

VIII. The Distribution of Animal Life in the Sea . 156

IX. The Animals of Lakes and Rivers. Cave Faunas 182

X. Zoogeographical Regions . . . . . . 208

Appendix. Outline Classification of Animals • 226

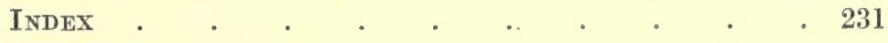


Digitized by the Internet Archive in 2007 with funding from Microsoft Corporation 


\section{LIST OF ILLUSTRATIONS}

FIG.

1. Tundra in Northern Russia

2. Ptarmigan .

3. Wapiti

4. Elk

facing 40

5. Virginian Deer

6. Three-toed Woodpecker

7. Camels

61

8. American Bison .

facing $\quad 62$

9. Prairie Marmot .

10. Sage-cock .

11. Swiss Alp .

12. Snow Leopard

facing $\quad 80$

13. Yak .

14. Alaskan Wild Sheep

15. Takin

16. Kiang

83

17. Bharal

84

18. Serow

19. Musk-deer .

21. Rain-forest in North Borneo

22. Congo Tropical Forest

23. Red Howling Monkey

24. American Monkey

101

25. Black Lemur

102

26. Puma and Cubs

27. African Elephant

108

28. Indian Elephant

109

29. African Flying Squirrel

30. Brazilian Tree Porcupine

31. Quica Opossum .

32. Sloth

33. Phalanger . 
FIG.

PAGE

35. Gnu .

facing 130

36. Giraffe

37. Jerboa (Central Asia).

.. 131

38. Jerboa (Egypt) . . . . . . . . . . $\quad 134$

39. Cactus Wren . . . . . . . . 141

40. Kiwi .

facing 150

41. Seal Rookery in Copper Island . . . . . 162

42. Seals on shore of Copper Island . . . , , 163

43. Kittiwake Gulls . . . . . . . . 164

44. Penguins . . . . . facing 164

45. Clouded Leopard . . . . . . . . $\quad$. 218

46. Okapi . . . . . . . . . . 219

47. Bower Bird . . . . . . . . 224

48. Lyre Bird . . . . . . . , , 225 


\section{INTRODUCTION}

\section{THE NATURAL REGIONS OF THE GLOBE}

THE modern interest in the facts of the distribution of animals, as indeed the modern interest in so many of the problems connected with biology, dates from the publication of the Origin of Species. Darwin in his famous voyage on the Beagle was much struck by the curious phenomena of distribution which that voyage brought before his eyes, and it was these phenomena which helped to direct his attention to that line of thought which resulted ultimately in the publication of his theory of Natural Selection. The two facts which especially struck him were the two set forth in the chapters on distribution in the Origin of species. These are, first, that similarity of physical conditions does not necessarily result in a similar fauna, and conversely. For example, there is considerable uniformity in the fauna of South America throughout its length and breadth, even though we find there every variety of physical conditions, from the cold deserts of the high Andes to the luxuriance of the Brazilian forest, or from the burning deserts of Chile to the grassy plains of the Argentine. On the other hand, there is very little resemblance between the animals of the grassy plains of South America and those of Africa, despite the similarity in physical conditions. The second point which struck him was that the resemblances or differences between the faunas of two areas are directly 
proportioned to the nature of the barrier which separates the two regions. Transverse mountain chains, such as the Himalayas or Atlas, separate two different faunas. Similarly, lands separated by a broad and deep belt of ocean may have quite different faunas; those separated by a shallow and narrow strait may have almost identical animals. Such facts led him to believe that each species originated in a particular region, and spread out from that region till it was stopped by some barrier to further distribution. The remarkable features of the animals of isolated regions can be explained on this hypothesis as the result of descent with modification from the original forms.

One result of the direction thus given to the study of distribution has been to make the division of the globe into zoogeographical regions, and the study of the faunas of the different regions, of supreme importance, and it is this aspect which is studied in most books on the subject. But, obviously, another and more truly geographical point of view is possible. We may study the animals of the natural regions of the globe as forming a part of the features of those regions, and in this case attention is directed rather to the adaptations displayed by the animals, than to their zoological relationships.

In deliminating the natural regions of the globe the botanists have played a large part, for they have shown that the existence of the great plant associations depends upon the climate, the relief, and so forth of the region. To the practised eye a collection of plants from e.g. the Mediterranean region gives a great deal of information in regard to the region. For example, the small silvery leaves of such plants, and the other devices for husbanding water, together with the occur- 
rence of many bulbous plants, speaks to a climate where dry and wet seasons alternate, and so on. The dependence of the more active animal upon its surroundings is less intimate than that of the passive plant, but even here the characters of the animals of a region tell us something of the physical features of that region. That we find in Brazil, for example, animals so thoroughly adapted to the arboreal life as sloths, marmosets, monkeys, and so forth, suggests at once that dense forest occurs in the region. That Africa has an enormous number of antelopes-enormous both as regards species and individuals-suggests the existence in that continent of open plains, and so with other regions.

The botanists recognize three great plant formations, which roughly divide the surface of the land among them. These are woodland, grassland, and desert. Such a simple division would help us little in the case of animals, but as all animals depend ultimately for their food upon plants, a modification of this classification may serve as a framework in the study of animal distribution. There is, for example, a considerable difference in the life conditions of animals which live in regions where the winter cold periodically checks plant growth, as compared with those where no such temperature check occurs. This gives us a first distinction between the animals of cold or temperate regions and those of tropical regions. In both of these forest, grassland, and desert occur, but it is possible to pick out certain well-defined types in order to study their faunas separately. Thus, among the various forms of temperate forest, the Taiga or coniferous forest of Asia and North America has a well-defined assemblage of animals showing some interesting adaptations. 
Again, both in Asia and in North America we have vast areas of natural grassland forming well-defined Steppe areas, which possess a characteristic fauna. The great mountain chains of the earth's surface are peopled by faunas having certain special features, and the vast area of coast-line which fringes the Arctic sea forms a cold desert or tundra, whose fauna has many peculiar features. As natural regions with a cold winter climate then, we have to consider (1) the Tundra, (2) the Taiga or coniferous forest, (3) the Steppe, best developed in the northern hemisphere, and (4) Mountain regions.

Where the temperature is permanently high, and the precipitation great, we have (5) luxuriant Tropical Forest, with its characteristic fauna, differing according as the forest occurs in Africa, Asia, or South America, but showing in all cases certain special adaptations. Again, in warm or tropical regions where the temperature is still high, but the rainfall small and unequally distributed throughout the year, we have a thinning of the forest into that type of grassland, or grassland mingled with wood, which the botanists call Savana. As the rainfall diminishes the savana thins out into desert, so that we may conveniently consider (6) Savanas and Warm Deserts together.

This still leaves to be considered the fauna of ( 7 ) Islands, which show some special features, and also the animals of aquatic habitat, which we must consider separately, according as they live (8) in the sea, or (9) in fresh water.

Such a scheme is obviously incomplete, in that it does not cover the whole surface of the globe. It omits, for example, any consideration of the fauna of the deciduous forest which covers so much ground in 
Europe and North America, and of the animals of the Mediterranean or scrub forest, found round the Mediterranean Sea, in California, and elsewhere. We shall find, however, that such regions have for the most part a transitional fauna, made up of units from the surrounding regions, and that further they have been much altered by man's interference. It is true that the effects of this interference are often interesting, for while some animals die out as civilization spreads, others, like the rats, the common sparrow, the cockroaches, some parasites, and so on, adjust themselves to the altered conditions, and prosper under civilization as they never did in former days. But a consideration of these points would take us too far from our immediate subject. We shall therefore confine ourselves to a consideration of the nine natural regions already given, and fill up whatever gaps this method may leave by a final consideration of the zoogeographical regions into which zoologists have divided the globe. But as the greater part of this book is thus devoted to the geographical aspect of animal distribution, a word or two may be added in further explanation of the difference between the two points of view, the zoological and the geographical.

To the zoologist it is a fact of great interest that the sloths, ant-eaters, and armadillos should occur in South America, and nowhere else. But the geographer is more interested in the fact that the sloth is a purely arboreal animal, fitted only for life in the dense forest, while the armadillo, for example, shows adaptations to quite other habitats. The difference between the sloth of the Amazon forest and the squirrel of the Siberian taiga, again, means something very different to zoologist and geographer, for the latter 
sees in it a reflection of the difference between the two forests, which interests the other less, and only incidentally.

References. A realization of the connexion between the study of the facts of animal distribution and the general theory of evolution may best be obtained from Darwin's Origin of Species and Wallace's Darwinism. Wallace's classical work on Geographical Distribution (two vols., London, 1876) should also be consulted. An interesting discussion of the purely geographical standpoint will be found in the chapters on animal geography in de Martonne's Traité de Géographie Physique (Paris, 1909), which gives copious references. 


\section{CHAPTER I}

\section{THE TUNDRA AND ITS FAUNA}

ONE of the well-marked natural regions of the world is the Tundra, that treeless area which fringes the margin of the far northern seas, and is characterized by its climate, its plants and animals, and to some extent also by its topography. Originally applied only to the treeless lands of Northern Asia, lying to the north of the forest or taiga, the term is now by extension given to all areas of similar character, occurring alike in the Old and New Worlds. In the southern hemisphere the tapering of the land-masses, and their cessation in relatively low latitudes, make the development of true tundra impossible. It is true that considerable land-masses occur within the Antarctic area, in latitudes lower than those in which the northern tundra finds its limit, but the climate and the absence of a direct connexion between these areas and the continents have prevented the development of the characteristic tundra plants and animals. In the Antaretic land-mass flowering plants are, with two exceptions, absent, and mosses and lichens are only slightly developed. Associated with this we have a complete absence of land mammals - a very striking difference from the northern tundra.

The boundaries of the tundra are well marked. As already indicated, on the continents the southern boundary is the beginning of the forest zone. This limit is, roughly speaking, marked out by the July isotherm of $50^{\circ}$. Wherever the mean temperature of the hottest month exceeds $50^{\circ} \mathrm{F}$., there the tundra 
dies away into forest. The result is that the continental tundra forms a band of very varying width. The mildness of the Western European climate pushes the tree limit up within the Arctic Circle, and reduces the tundra zone to a narrow band to the north of Scandinavia. Thence it extends through European Russia into Siberia, and reappears again at the other side of the Bering Strait to extend across Arctic America. Here to the east it revenges itself for its conquest by the forest in Western Europe by pushing the forest zone far to the south, so that a band of tundra extends down the coast-line of Labrador, and even into $\mathrm{New}$ foundland.

The northern limit of the continental tundra is the polar sea, but the tundra type reappears on the margin of the land-masses lying within that sea. The islands of the American archipelago, Baffin Land, Greenland, the northern shore of Iceland, Spitsbergen, Franz Josef Land, Nova Zembla, the New Siberian Islands, \&c., are all fringed by a band of tundra. Its northern extension may indeed be gathered from the fact that the reindeer, one of the most characteristic tundra animals, was hunted by the Sverdrup expedition in King Oscar Land, which extends to about $80^{\circ} 30^{\prime}$ $\mathrm{N}$. lat. In these regions the sea again forms one of the boundaries of the tundra zone. The other boundary is formed by the presence of eternal ice and snow. Generally it may be said that tundra occurs wherever the melting of the snow is sufficient to expose a surface upon which land plants may grow.

The climate throughout this great area naturally varies, but the special features are the following. Nowhere does the mean temperature of the warmest month exceed $50^{\circ} \mathrm{F}$, and it is often much below this. 
The precipitation is everywhere small, except in the south-western extremity of Greenland. Elsewhere the mean never exceeds $10^{\prime \prime}$ per annum, and may be much less. The winters especially are remarkable for the clearness and dryness of the atmosphere and the virtual absence of precipitation. The result is that, contrary to what might be expected, the snow does not form everywhere a thick mantle, and the frequency of strong winds helps to diminish its thickness in places, a fact which greatly aids the obtaining of food by such herbivorous mammals as the reindeer and muskox. During the short summer precipitation is frequent, though slight, and fog and mist are common. The subsoil is permanently frozen, and there is thus no ground water. This renders all erosion mechanical, and as springs are absent the rivers are fed only by the melting of ice and snow, and are temporary, being frostbound in winter.

There are only two seasons-winter and summerand the winter extends far into the months which are spring elsewhere, so that March or even April may be the coldest month. It is apparently these months which take the largest toll of animal life, for Nordenskiöld notes that the reindeer are in better condition in the depth of winter than in the spring months. Summer comes with extraordinary rapidity, and with its coming life suddenly bursts into activity. Thus all the flowers bloom at once, giving rise to the local luxuriance noticed by many explorers. The rapidity of development is of course aided by the virtually continuous daylight. As the rays of sunlight have a very oblique direction, local conditions count for much in promoting the growth of plants, and therefore the occurrence of land animals. Thus a slope where the ice-cold water 
drains away as the snow melts is favourable to plant growth, while level ground is very unfavourable. A sunny exposure also exerts much influence. The Sverdrup expedition noted that the Arctic hare is practically limited to the regions where large valleys open out into fiords, for only here is vegetation abundant enough to supply its needs.

As regards topography one must note that the tundra, like the semi-arid lands of other latitudes, is characterized by a very youthful condition of drainage. As already stated, the rivers are temporary, chemical erosion does not occur, and therefore the process of carving up the land into hill and valley goes on very slowly, and the land is imperfectly drained. The imperfect drainage is aided by the fact that the extreme coldness of the soil is unfavourable to bacterial life, and thus humus accumulates and favours the growth of bog mosses as contrasted with higher plants. These hold up the water like a sponge, and so hinder drainage. When Nansen and his party left the inland ice of Greenland they descended to a little tarn, whose water drained by a stream to the distant fiord. In their descent, as the leader notices, they found that the main streams had often transverse tributaries, which greatly hindered progress. The picture may be taken as characteristic of the tundra. Lakes fed by melting ice, streams showing a very undeveloped drainage system-these are characteristic features, which, aided by the climate, account for the very local development of a covering of vegetation, and therefore for the curiously local appearance of animals.

Without discussing the plants of the tundra in detail we may note those points which are of special importance for animal life. The first of these is the great 
abundance of mosses and lichens, which do not die down in winter, and are therefore permanently available as pasture for the herbivorous mammals. It is well known that the lichen popularly called reindeer moss (Cladonia rangiferina), which occurs over wide areas, forms a very important part of the winter food

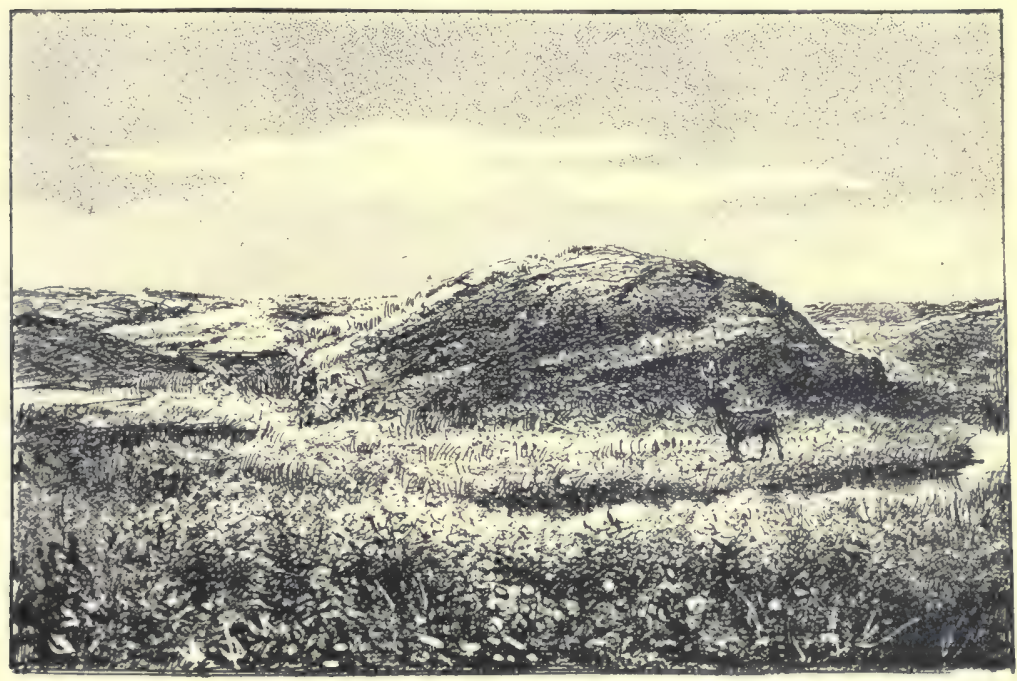

FIG. 1. The Tundra in Northern Russia, summer conditions. The illustration shows the undifferentiated nature of the drainage, and shows also that at this season pasturage is freely available for herbivorous mammals.

of the reindeer. Other areas are clad in hair moss (Polytrichum), or bog moss (Sphagnum). Among the higher plants we may note the presence of dwarf willows, birches, alders, \&c., whose branches stick up through the snow, and whose buds and seeds are of great importance as part of the food of the ptarmigan and the snow-bunting. In the more favourably situated regions berry-bearing shrubs occur, such as crowberries, 
whortleberries, \&c., again forming an important part of the available food supply. Again, as in the case of the Swiss alps (p. 74), the vegetative growth of the plants is checked by the natural conditions, and thus, though stunted in appearance, they are relatively rich in proteids and fats, and relatively poor in cellulose, which makes their nutritive value high. With all that can be said, however, the land offers but little food, and the vast majority of the tundra animals depend partly or wholly upon the sea, and are therefore necessarily confined in their distribution to the margin of the sea. The German expedition to Greenland made large collections of both birds and mammals, and observed the habits of all as closely as possible, and the conclusion arrived at is that only four of the mammals can be said to be permanently dependent upon the land for food; these four being the reindeer, the musk-ox, the Arctic hare, and the lemming. Of the many birds known to visit Greenland, only two can be said to be at once permanent residents and wholly dependent upon the land for food. These are the redpoll (Linota hornemanni) and the ptarmigan (Lagopus hyperboreus). All other birds and mammals are either partially migratory or depend to some extent at least upon the harvest of the sea. Even of the land plants the last statement is partly true, for it is said that the phanerogams are especially abundant about the breeding-places of the sea birds, on ground enriched by their droppings, and such birds feed in the sea. Again, even of the four mammals named, the reindeer, according to Nordenskiöld, does not disdain seaweed in times of scarcity. Everywhere over the globe animals depend ultimately upon plants, which alone can fix inorganic matter in organis form, but it may be said to be the special 
character of the tundra animals, like the fewer animals of the Antarctic area, that it is marine plants, rather than terrestrial ones, which form the basis of their food supply.

Having thus summarized the conditions of life in the tundra we may give some account of the fauna, beginning with the ungulates among mammals. The reindeer (Rangifer tarandus) is widely spread throughout the region, though nowhere very abundant as individuals. On the continent of America there is a marked distinction between those forms which haunt the forests, the so-called woodland caribou, and the smaller forms, with larger antlers, which occur in the tundra. The latter, the barren-ground forms, seem to migrate southwards towards the forest in winter, but this is impossible with the herds which occur in the Arctic islands. In King Oscar Land and the adjacent regions the Sverdrup expedition found the animal widely distributed but not abundant, apparently on account of persecution by the Arctic wolf. The absence of this animal in Spitsbergen perhaps accounts for the greater abundance of the reindeer there. It occurs also in the suitable parts of Greenland, where the wolf is again absent. On the continent of Asia the reindeer occurs in summer in suitable localities in the tundra region, but here also it seems migratory, and thus not wholly dependent upon the tundra for food.

The musk-ox (Ovibos moschatus), the second large herbivore of polar regions, has a much more limited distribution. Found fossil in Europe and Asia, it is now limited to the American side of Aretic regions. On the continent of America its eastward distribution is limited by the Mackenzie River, but it is apparently abundant in the northern parts of Greenland, in 
Grinnell Land, and in the adjacent regions. It is non-migratory, finding food throughout the year by scraping away the thin covering of snow. A markedly social animal, the herds seem capable of defending themselves against the Arctic wolf, which attacks chiefly young stragglers.

To this short list we should perhaps add the fact that the mammoth occurs in the tundra in the subfossil condition in Asia and also in Alaska.

Rodents are represented in the tundra by the Arctic hare (Lepus glacialis), which is very abundant in suitable localities. Even in winter it finds food enough in the grasses which project through the snow. Its greatest enemy is the wolf, which seems to feed largely upon it, but in spite of the abundance of that animal in King Oscar Land the Arctic hare is stated to be very abundant there. Another important rodent of the tundra is the lemming (Myodes torquatus), which is sometimes extraordinarily abundant. Absent from Spitsbergen, it occurs elsewhere on both sides of the Arctic region. Perhaps because of the paucity of vegetation in its natural habitat, this northern lemming does not show the enormous fertility of the Norwegian form, nor does it seem to migrate in the same fashion. In some regions, as in Nova Zembla, it is, however, remarkably abundant. While the other herbivorous animals named find their food in winter either by scraping away the snow, or by nibbling the protruding shoots, the lemming, a much smaller animal-it is not much bigger than a mouse-lives in winter beneath the snow, making runs and burrows in the underlying ground. When the snow melts in spring these runs appear, ramifying over the surface in all directions. The Norwegian lemming (M. lemmus) is also circum- 
polar, but does not extend so far to the north as the other species.

In the tundra, as elsewhere, the presence of large herbivores naturally attracts their enemies the large carnivores, necessarily fewer in number, and usually of greater intelligence. As masterful and highly organized animals the large carnivores do not as a rule show a very close adaptation to one type of country only, nor are they, as a rule, like such herbivorous animals as the musk-ox, driven by stress of competition to the unfavourable parts of the surface. The carnivores which occur in the tundra, therefore, do not as a rule form an integral part of its fauna; rather are they intruders from other regions. Thus the wolf (Canis lupus), absent in Greenland, in Spitsbergen, \&c., occurs in Arctic Asia and Arctic America, and extends also into such regions as Grinnell Land and King Oscar Land. Its near ally, the Eskimo dog, is a very important animal in Greenland and elsewhere. Very insufficiently fed by its master, the catholicity of its appetite may be gathered from the fact that it will eat fish, shell-fish, seaweed, and refuse.

Much more truly Arctic than the wolf is the Arctic fox (Canis lagopus), widely distributed in the polar regions of both the Old and New Worlds. Its food consists of birds, especially the ptarmigan, but it is constrained to add to this refuse and even seaweed. Lemmings are also an important part of its diet where they occur, and by some it is believed to store the bodies of these for the winter, when it is often hardpressed. Two other land carnivores occur in the tundra, but both are immigrants from their natural home further south. These are the ermine (Mustela erminea), which follows the lemming to the coasts of the Arctic 
sea, and the glutton (Gulo luscus), a forest mammal, which just reaches the tundra.

Among the mammals which find their food in the sea, we must place the polar bear. As its name ( $C r s u s$ maritimus) indicates, this animal haunts the margin of the sea, where it is found among the drift and floe ice, on the look out for its natural prey, seals and the walrus. It is thus not in any true sense a tundra animal, although occurring round the margin of the tundra region throughout its extension. Of the many kinds of seals also, we can only say here that though they breed on the shore they are not in any sense tundra animals.

We may pass next to the birds of the tundra. In regard to these it is noticeable that large numbers of migrants occur, especially sea birds and those which haunt the vicinity of the shore or of fresh water. These come north to breed in the relative security of the tundra, and also probably because they find the long northern daylight an advantage, for it lengthens the period during which the search for food can be carried on. As winter approaches, these birds travel southwards, fleeing from the increasing cold and darkness. It is unnecessary to give lists of these migratory forms. All travellers to tundra regions, whether to the mainland areas or to the lands of the polar sea, speak of many kinds of gulls, of skuas, of kittiwakes, of geese, of various forms of ducks, including the eider, of auks and guillemots, of sandpipers, terns, petrels, and so forth, none of which can be regarded as definitely characteristic of the tundra, though their summer abundance at certain special localities is one of the features of the region. It is.otherwise with the true land birds, which, though relatively few in number, help to give its characteristic facies to the region. First 
among these we must place the ptarmigan (Lagopus), of which more than one species occur in the tundra. In Greenland, in Aretic America and the adjacent

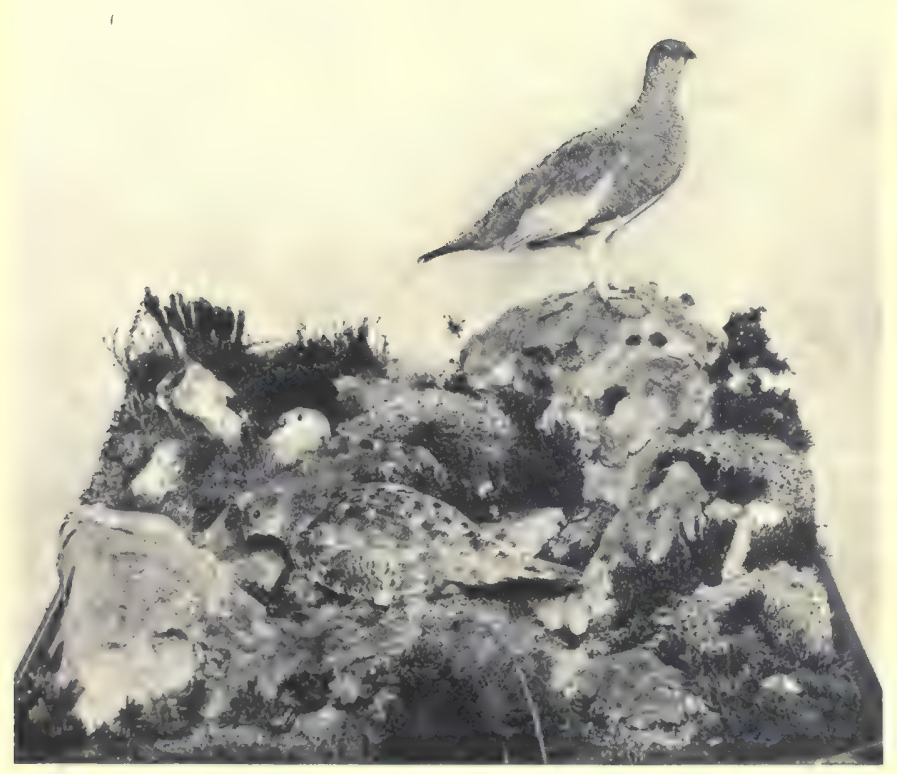

FIG. 2. The Ptarmigan, with nest, young, and eggs, showing the stony uplands where the bird breeds in Highland Scotland. (From a specrmen in the Royal Scottish Museum.)

regions, in Spitsbergen, in Northern Asia, these birds occur, sometimes in considerable numbers. In the slow 
agony of the last march of de Long and his companions after the wreck of the Jeannette, it was by the help of the ptarmigan and reindeer shot that the final catastrophe was postponed so long. After Nansen and his companions arrived in safety at the east coast of Greenland, their crossing of the inland ice completed, they whiled away their months of waiting for a ship by the help of ptarmigan shooting. Sverdrup and his companions shot many for food during their Arctic expedition, and similarly almost every expedition which has landed in tundra regions has noted the presence and characters of the birds.

The ptarmigan share with the Arctic fox, the stoat or ermine, and not a few other northern forms the peculiarity of displaying a seasonal change of colour. This change doubtless aids these varied animals in escaping from their enemies, or in stealing unperceived upon their prey. Like many other tundra animals also, the ptarmigan is social, being found in flocks, except at the pairing season. This is no doubt associated with the fact that food is only obtainable in certain areas, separated by extensive barren regions. Though in most favourable tundra regions ptarmigan are to be found throughout the year, a certain amount of migration occurs. Thus in Greenland they are commoner in the south in winter than in summer. Needless to say, ptarmigan are not peculiar to the tundra, for they extend far to the south of the region.

The only songster of the tundra is the snow-bunting (Plectrophenax nivalis), which is very widely distributed, and is spoken of by most explorers, who welcome its twittering song in spring. There is no doubt that it is largely a migrant, nesting in the north, and turning southwards in the autumn. Occasionally, however, 
it appears to winter in the Arctic, notably in Greenland.

Wherever in the tundra region lemmings and small birds are to be found, there occurs the snowy owl (Nyctea nivea), though it does not seem to be common except where lemmings are abundant, as in Nova Zembla and parts of the mainland of Northern Asia. The bird has a general resemblance in coloration to a ptarmigan in winter plumage, and often lives in the stony regions frequented by that bird, upon which the owl preys. It is, however, no exception to the rule that the carnivorous animals of these barren regions need to lay the sea under contribution as well as the land, for it eats fish in addition to birds and small mammals. It winters in the tundra, and is a very characteristic bird of the region. Another predatory bird of the Arctic is the Greenland gerfalcon (Falco candicans), a beautiful bird, predominantly white in colour, which inhabits Greenland and Arctic America, and is represented by an at least closely allied species in Northern Asia. It preys upon ptarmigan and other birds, and also upon lemmings, and winters in Greenland. The third predaceous bird of the tundra is the raven (Corvus corax), which is the scavenger of the region, and will eat practically anything from land or sea.

As is to be expected from the unfavourable conditions of life, reptiles and amphibians are absent, and fresh-water fish are not abundant. Representatives of the salmon family occur in some lakes, but there is nothing characteristic.

Among the invertebrates the insects present some interesting points. Except in Spitsbergen and Nova Zembla, mosquitoes are enormously numerous, and form in many regions a terrible plague. It may seem 
curious that they should be abundant in this cold region, but the cause is to be looked for in the undeveloped condition of the drainage system, already mentioned. The absence of any run-off in winter give: the tundra, as we have noted, the characters of a semiarid region, with the result that the water formed in summer by the melting of the snow tends to accumulate in innumerable lakes and pools. In these the mosquito larvae swarm, and the natural checks, e.g. in the shape of small fish who feed on the larvae, must be insignificant. From the pupal stage the adults emerge towards the middle of June, and they are then extraordinarily abundant till the middle of August, when they disappear, after having laid their eggs in the pools. These pools freeze or dry up with the onset of winter, but the eggs or larvae remain uninjured, to hatch or recommence active life with the coming of water in the spring. It is possible that the life-history is lengthened by the cold, but the rapidity of reproduction is certainly not checked, except in the coldest regions. In addition to mosquitoes a considerable number of other flies occur, especially about the houses of the Eskimo, \&c., breeding in the refuse thrown out. Indeed, flies predominate among northern insects, the percentage increasing as we pass northwards. The reason lies apparently in the fact that the larval stage is usually short, and can be run through in the brief period of warmth.

With the exception of the curious parasites known as Strepsiptera, all the other orders of insects are represented, the bees and butterflies fulfilling here their usual rôle as fertilizers of flowers. The very short active period of vegetation has a curious effect upon the development of plant-eating insects. As is well known, in more temperate countries butterflies usually 
lay their eggs in the autumn (except in the case where there are two annual broods), and these eggs pass the winter as eggs, or, if the larvae hatch, they winter in a very undeveloped state. In the spring, activity is early resumed, and the life-history is rapidly passed through, so that the butterflies appear in summer. In Greenland, butterflies do not appear till the middle of July. If they lay their eggs, and these hatch at once, the resulting larvae have, in the colder parts, only some five weeks before winter sets in. Activity does not recommence till at earliest the first week of the following June, and as it cannot be supposed that the animals can pass through larval and pupal life before the onset of cold, they must pass a second winter in the larval state, the butterfly emerging in the following July to lay its eggs and die. This great lengthening of the lifehistory cannot be ascribed wholly to the cold ; we must suppose that it is also due to the fact that caterpillars must necessarily wait in spring until their food plants have made some new growth. This life-history, therefore, again emphasizes the baneful effect on animal life of the scanty development and slow growth in spring of the plants of the tundra.

In addition to insects, a few earthworms occur in the warmer parts, and there are a few land and fresh-water shell-fish and some spiders and mites. In general, however, it may be said that among the invertebrates the insects are the most conspicuous and numerous forms.

As a pendant to this picture of life on the tundra we may add a brief consideration of the animals of the shore, which, as we have noticed, have considerable direct and indirect importance for the land animals. Man in these regions is practically dependent upon the sea for food, for fuel, and for clothing, for the land 
gives him almost nothing. It is a commonplace of physiology that in cold climates his need of fat is great, but in this respect he resembles all the other animals of the region, all of whom seek fatty food, and store up in their bodies reserves of this heat-producing substance. The food from which the larger marine animals obtain their supplies of fat is almost always, directly or indirectly, found in the myriads of small crustacea which haunt polar seas, and whose bodies contain much oil. Arctic seas are indeed specially characterized by their wealth of small crustacea and of marine mammals, and the two facts are closely connected. The crustacea feed the fish of the polar seas, which, though of relatively few species, are often extraordinarily abundant as individuals. The seals and toothed whales feed upon fish. Small crustacea are also devoured by molluscs, of which the mud-haunting forms are devoured by the walrus, and the floating forms by the whalebone whales, so that the crustacea form the basis of the marine foodsupply. They are in their turn fed by the more minute forms of life, especially by the minute plants, such as the diatoms, so abundant in polar seas.

The few survivors of the ill-fated Greely expedition kept themselves alive by the collection of 'shrimps' in the shore-water. These 'shrimps' must have been largely the small crustaceans called amphipods, which are enormously abundant in polar seas, and the fact that they were so utilized may be taken as emblematic of Arctic conditions.

Apart from crustacea, the littoral fauna of the Arctic is fairly rich. A considerable number of large molluses occur, including in the 'gapers' Mya and Saxicava mussel-like forms, which constitute an important part of the food of the walrus. Where molluses abound, 
starfish, which prey upon them, are also abundant, and reach a large size. Where seaweed is abundant, seaurchins occur ; according to Nordenskiöld, west of Nova Zembla they are so numerous as almost to cover the bottom. The mud holds a considerable number of marine worms, and other less striking invertebrates also occur in numbers. Here, however, we must note that if the sea contributes a wealth of food to land animals, yet the land also gives something to the sea. The icebergs which detach themselves from the glaciers carry much rock-waste to the sea, and this forms a fine mud very favourable to animal life, for very many shore animals are mud-eaters. The ice-foot and driftice also contribute to the rock débris spread over the bottom, and the proximity of the glaciers to the shore in many places must mean that the rock-waste is carried by the turbid streams of summer direct to the ocean, instead of being spread over the land, as is for instance so much of the glacial mud of the Alps. In other words, the mud which in Central Europe forms such vast fertile areas as the Plain of Lombardy, is in Arctic regions carried seawards to help to feed the swarming life of the sea. It is this fact which explains the wealth of the Arctic in marine birds and mammals, and its poverty in land forms of either. The poverty of the land is made up for by the wealth of the sea.

The characteristic marine mammals of the extreme north are the walrus and the earless seals, all of which spend a considerable part of their life on shore, especially at the breeding season, and the whales, toothed and whalebone, which never voluntarily come on shore at all. All have, of course, had terrestrial ancestors, and we may see one justification of the evolution of their adaptations to a marine habitat in the fact just 
emphasized-the poverty of the land and the relative wealth of the sea in these northern latitudes. Another cause of the abundance of the seals and their allies in Arctic and Antarctic waters is certainly to be sought in the fact that these animals must come on shore to breed, and suitable regions for this purpose, offering security against attack, except in the case of man, the great enemy of the large mammals, are to be found in the frigid rather than in the temperate or torrid zones.

Of the Arctic seal-like animals, the walrus (Trichechus rosmarus), which is circumpolar, is one of the most interesting forms. As already noted, it is stated to feed chiefly upon molluses, but apparently adds fish, swimming birds, and even seals to these. It seems to pass a considerable part of its life on shore, or at least on floating ice-floes. The massive tusks are used in digging up mussels from the mud, and also in helping the animal to clamber upon the ice.

The true seals are represented by a number of species, five or six occurring in Greenland. The presence of a number of nearly related forms within a limited area means a very perfect adaptation to the natural conditions. Analogous conditions are presented by the many kinds of antelope which are found in the open plains of Africa, and the many kinds of deer in the forests of Asia.

The true seals are very clumsy on land, but are very perfectly adapted for swift movement in the sea. They feed upon fish, to which at times they add shell-fish and crustaceans. In the sea their great enemy is the killer whale, but their enemies on land are much more serious, consisting of the polar bear and man, both of whom take advantage of the animal's relative helplessness on land, and the fact that they must come on shore to 
breed, and that the young must spend the first two or three weeks of their life on shore. Many of the seals are markedly migratory, going south in winter to avoid the intense cold of the north. This is especially true of the Greenland seal (Phoca groenlandica), which seems incapable of making a breathing-hole in the ice, and therefore must have relatively open water in its haunts. On the other hand, the ringed seal (Phoca hispida), which does make such breathing-holes, is almost nonmigratory, living permanently in the coldest regions. These two species will thus not compete with each other, and all the species doubtless show similar minor adaptations, which fit them for different parts of the common environment; but it is not always possible to explain wherein these special adaptations consist. The large bearded seal (Phoca barbata) is another form which makes breathing-holes. The very curious crested seal (Cystophora cristata) is not only migratory but also pelagic in its habits, avoiding the neighbourhood of land, and bringing forth its young on ice-floes. It is a bold species, apparently a swift swimmer, and eats cuttles as well as fish. The common seal (Phoca vitulina) also occurs in Arctic waters.

The cetaceans of the north are numerous, and include some very large animals. Thus among the whalebone forms we have the Greenland whale (Balaena mysticetus), with its enormous head, and its elaborate series of baleen plates, which filter the minute crustaceans and molluses upon which it feeds from the sea water. The huge rorquals (Balaenoptera), though found in practically all seas, often seek the vicinity of northern coast-lines in spring for breeding purposes. Among the toothed whales the narwhal (Monodon monoceros) is a true northern form, and lives largely 
upon cuttles and crustaceans. The white whale (Del ph inapterus leucas) is similarly an Arctic form, remarkable for its habit of ascending rivers for a considerable distance. The killer whale (Orca gladiator), on the other hand, which is a very widely distributed animal. chiefly occurs in the Arctic in summer.

If we sum up the facts in regard to the distribution of tundra animals, and of the marine forms which occur round its seaward margin, we may say briefly that the tundra fauna is virtually uniform throughout. The animals, generally speaking, are either circumpolar at the present time, or have once been circumpolar, and there is no distinction between eastern and western faunas. In other words, the fact that the 'salt, estranging sea' is here more or less ice-bound makes the land areas virtually continuous, and this, combined with the marked uniformity of physical conditions, leads to practical uniformity of distribution, both of plants and of animals. No such similar uniformity exists in regard to the other natural regions of the world. Though the steppes of Asia show a general resemblance in physical conditions to the steppe-like regions of North America, yet their faunas are different. In the same way, the faunas of the similar equatorial forests of South America and Africa are markedly dissimilar, and there is almost no resemblance between the desert fauna of Australia and those of Africa or of America. No resemblance, that is, when the actual affinities of the animals are considered, but necessarily desert animals or forest animals, whatever their affinities, share certain adaptations to forest or desert life.

REFerences. Accounts of tundra animals are to be found in almost all books dealing with the Arctic regions. The following may be mentioned as giving a considerable amount of detail : Manual of the Natural 


\section{THE TUNDRA AND ITS FAUNA}

History, Geology, and Physics of Greenland and the Neighbouring Regions, edited by Professor T. Rupert Jones (London, 1875); The Voyage of the Vega, by A. E. Nordenskiöld (English Translation, London, 1881); Grönland-Expedition der Gesellschaft für Erdkunde zu Berlin, unter Leitung von Erich von Drygalski (Berlin, 1897). The second volume of the last named gives a very full account of the fauna and flora of Greenland by Dr. Ernst Vanhöffen. The animals of polar regions generally are discussed in Dr. Bruce's Polar Exploration (London, 1911). In addition the accounts of their explorations published by Nansen, Sverdrup, the Duke of Orleans, the books dealing with the Jeannette expedition, \&c., may be consulted. Kobelt's Die Verbreitung der Tierwelt (Gemässigte Zone), published at Leipzig in 1902, discusses tundra animals in general, and gives some characteristic views of tundra life. See also Seebohm's Siberia in Asia (1882), and the same author's Address to Section E (Geography) at the Nottingham Meeting of the British Association, 1893. 


\section{CHAPTER II}

\section{THE TAIGA, OR CONIFEROUS FOREST, AND ITS FAUNA}

Strikingly different from the fauna of the tundra is that of the temperate forest, which forms a wide belt in the northern hemisphere, lying just south of the tundra. Here the climate is more favourable, especially in the southern portion, and the flora far more luxuriant. Nevertheless here, as in the tundra, the ebb and flow of plant life is caused by the seasons, that is, by the varying amounts of heat received. In subtropical countries, with their winter rainfall, it is water, not heat, which determines vegetative activity. In the tropics, except where there is a well-marked dry season, vegetative life is practically continuous, but in the temperate forest zone, no less than in the drier steppes, it is the alternation of summer and winter which is of importance. As all animal life in these regions ultimately depends upon land plants, this means that there are periodic alternations of plenty and scarcity. In the forest zone, however, this is less marked than in the steppe zone. In the coniferous forests the trees for the most part keep their leaves all the year round. However deep the snow, the twigs and branches of the trees are exposed, and these twigs and branches very often carry nuts, berries, or seeds, which persist throughout the winter, and thus prolong the summer abundance into the time of scarcity. Further, the forest gives shelter, and thus diminishes 
the rigour of the winter climate. The thick branches may shelter the ground from snow, the covering of dead leaves may protect it from frost; hollow trees and dense bushes offer protection to many small animals. In short, while the forest does not offer the rich pasturage of the steppe in summer, it offers greater advantages in winter, and especially greater reserves of food.

One result of this is that on the whole the habit of migration is less marked in the animals of the temperate forest than in steppe ones. It does occur, but, on the other hand, both tundra and steppe animals may seek the forest in winter, and the greater uniformity of conditions in the forest prevents migration occurring on the same scale as in steppe and tundra, where areas of abundance even in the summer season alternate with others where famine reigns.

As a consequence of the fact that the forest offers a refuge to animals from other areas, we find that its denizens may be divided into two groups. We have forms like the squirrel, the dormouse, the lynx, the woodpecker, the tree-creeper, the tree-frog, and so forth, which are structurally adapted for forest life, and are not at home elsewhere, and we also find animals, like some kinds of deer and wolf and fox, which show no very special adaptations to forest life, but which visit the forest for shelter or for food.

We have already noted that the northern limit of the forest is determined by adequate summer warmth. Its southern limit depends upon much more complicated factors, especially upon the rainfall, and the absence of drying winds in winter, when the coldness of the soil prevents absorption. A small rainfall, limited to the summer months, favours grass rather than trees, and 
their slow rate of transpiration makes conifers more tolerant than broad-leaved trees of unfavourable conditions. The consequence is that in Asia we find a band of predominantly coniferous forest separating the tundra from the steppes of the central region, this forest, which is markedly uniform in character, being called the taiga. Its important trees are the Siberian larch and the Siberian fir ; the Cembra pine, important for its edible seeds, eagerly relished by many animals ; with many minor forms, such as juniper, bird cherry, mountain ash, \&c., important in that they bear edible fruits. In addition the taiga resembles the tundra in its great wealth of berry-bearing bushes, such as cranberries, crowberries, whortleberries, \&c., especially abundant in clearings, and in areas devastated by forest fires.

Lianes and creepers are typically absent, and the taiga as a whole is much less dense than the tropical forest. The result is that we have no animals of purely arboreal habit, such as occur in the equatorial forests, and on the whole arboreal adaptations are few. Very many of the inhabitants of the taiga possess the power of climbing without showing any great modification of structure.

In North America, especially in the eastern part of Canada, a belt of forest of very similar characters occurs. The species of conifers are different, but the general aspect of the forest is the same, and its inhabitants show a general resemblance to those in the Old World. Under the name of taiga animals, therefore, we shall describe the inhabitants of the coniferous forests of both the eastern and western hemispheres.

The important mammals of the taiga belong to three orders; they are ungulates, or rodents, or carnivores. 
There are in addition a few bats and a few insectivores, but the predominant forms belong to the orders named. We shall begin with the ungulates, as including the largest and most obvious of the inhabitants of the forest.

With the exception of the wild boar (Sus scrofa),

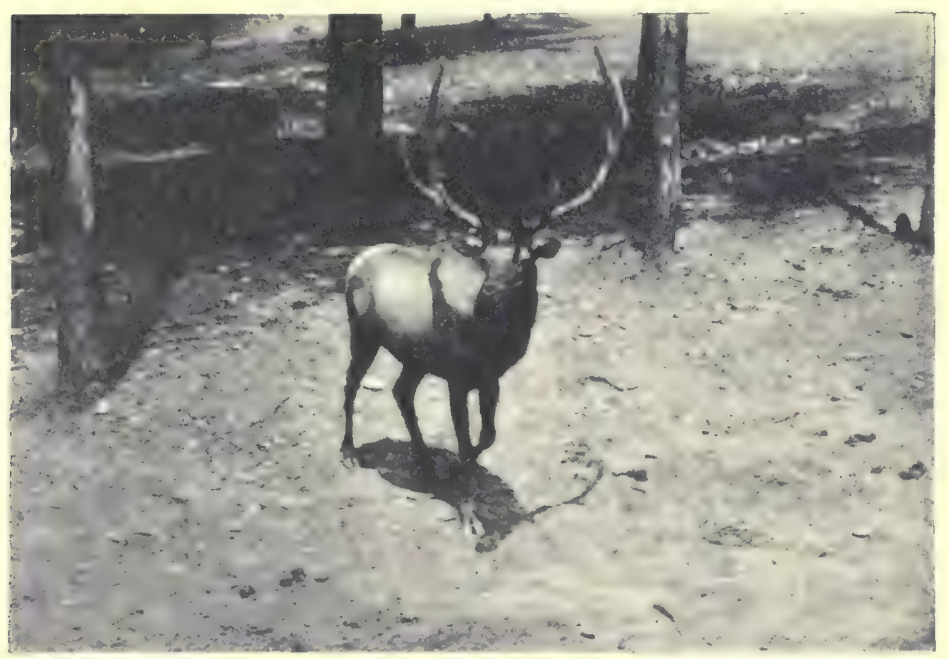

FIG. 3. The Wapiti of the American forests, often miscalled Rocky Mountain 'elk'. (Photo by the Biological Survey, U.S.A.)

which just penetrates the Asiatic taiga from the south, and excluding from consideration such forms as sheep and goats, really mountain animals, we may say that the ungulates of the taiga consist of deer. Deer are typically forest-haunting animals, though some of them feed on the outskirts of the forests, and a few species inhabit open plains, especially in South America, where large hoofed mammals are few. Except in South America, the place of deer on grassy plains is taken by 
antelopes, especially abundant in Africa, where deer are altogether absent. High up on mountains also, their place tends to be taken by sheep, goats, and allied forms. The Eurasiatic continent, which is rich in forests, is rich also in species of deer, but many of these are confined to tropical and subtropical regions, leaving relatively few to occur in the taiga proper. So far as these forms gc there is a close resemblance between the eastern and western halves of the continent.

The fact that deer are characteristic animals in the taiga is in itself sufficient to enable us to draw certain conclusions in regard to the nature of the region. When ungulates occur in tropical forests they are mostly small animals, with narrow compressed bodies, which allow them to glide through the brushwood. Deer are not only big animals, but the broad, spreading antlers of the male would make rapid movement through a dense wood impossible for him. Some authorities regard these antlers as evidence that deer have only recently taken to wooded regions; their presence at least excludes the animals from very dense thickets.

In both hemispheres there are taiga varieties of the reindeer, and both have elk or moose (Alces machlis). In the Asiatic taiga, the red deer (Cervus elaphus) occurs, with closely related forms of similar habits, such as the maral stag ( $C$. maral). Though these forms do not occur in Canada, the wapiti ( $C$. canadensis) is a nearly related species. America has in addition the Virginian deer (Cariacus virginianus), belonging to a group numerously represented further south, and distinguished by the great development and curious structure of the antlers. In the Asiatic taiga the 


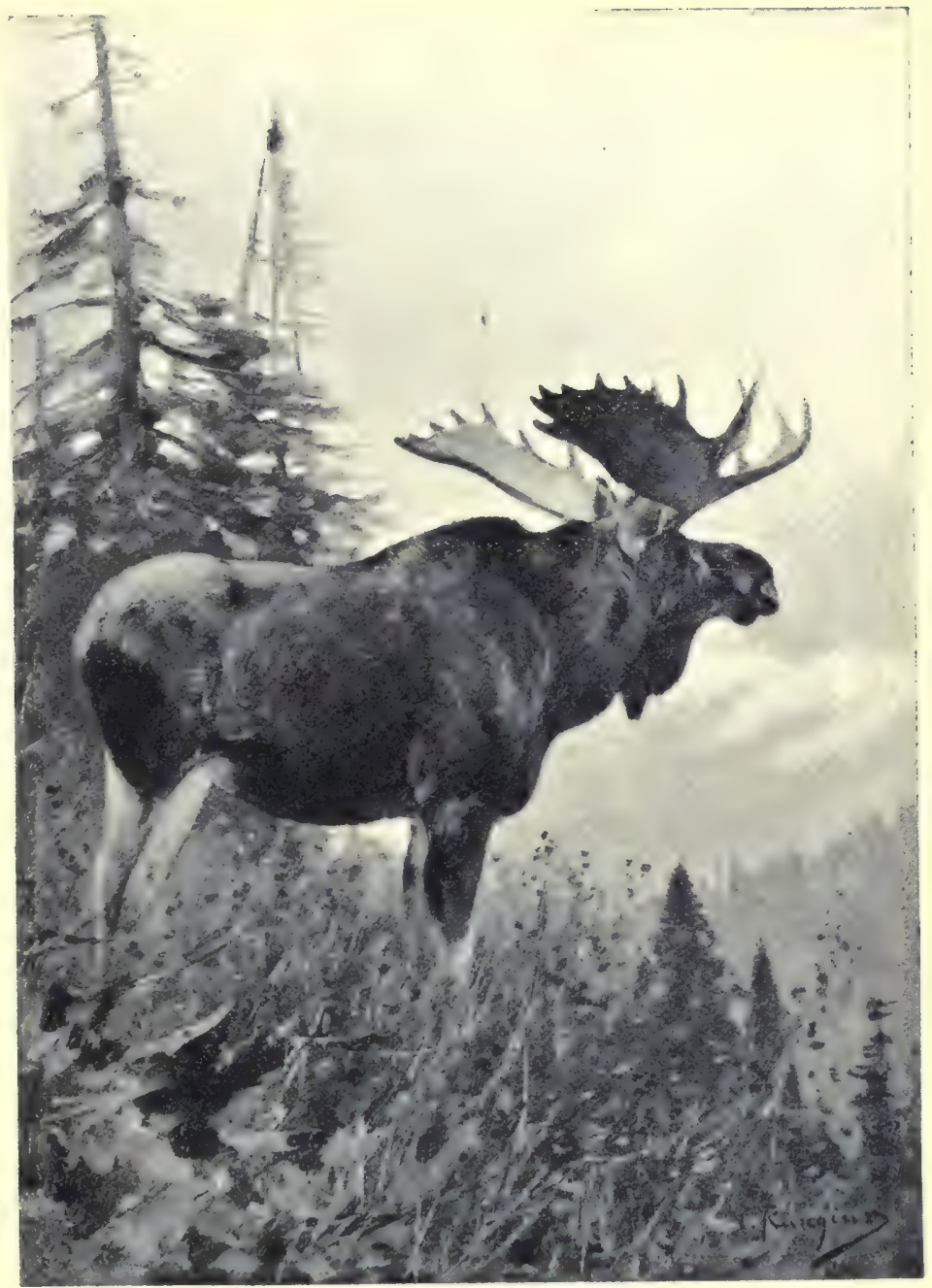

Fig. 4. The Elk or Moose of Alaska. (Photo by the Biological Survey, U.S.A.) 




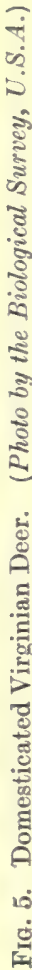


small roedeer (Capreolus caprea) also occurs, and the musk-deer (Moschus) is found occasionally, though its true home lies further south. The last is an aberrant form, almost hare-like in its habits, and much persecuted for the sake of the scent gland of the male (see p. 85).

Most of the animals above mentioned are at least largely forest-feeders. That is, twigs and leaves both of coniferous and deciduous trees, berries, nuts, \&c., bulk largely in their diet, and grass is relatively less important. The most northerly forms of those mentioned are the woodland reindeer and the elk, both very characteristic of the taiga. In North America the woodland reindeer is larger than the tundra form, perhaps because it is better fed, and chiefly haunts marshy ground. Within the forest, as outside of it, it depends largely upon mosses and lichens. In winter it leaves the swamps for the dense forests on the higher ground.

In the Asiatic taiga some interesting observations on woodland reindeer have recently been made by the members of Mr. Carruthers' expedition to Mongolia. Here, on the Sayansk divide, the members of the expedition found traces of a forest-haunting form which spends the summer in the rhododendron scrub, near the upper limit of the forest. In the winter the animals seek the open hill-tops, which are swept bare of snow by the wind, and there feed upon ' reindeer moss'.

The elk in both the Old and New Worlds is a true forest animal, compelled to feed upon trees and bushes by the fact that its long legs and short neck prevent it from grazing on the ground, except where the grass is very long. 
The red deer seem to feed chiefly on the outskirts of the forest or in the open glades, but the American wapiti eats a considerable amount of leaves and twigs. The Virginian deer also eats a large amount of forest produce, sharing with many other animals, both birds and mammals, a great fondness for beech mast, which it obtains in winter by pawing away the snow. It extends into Canada, but its true home is rather further south than the taiga proper.

The most important rodents of the taiga are the various kinds of squirrels, such as the true squirrels (Sciurus), the striped squirrels or chipmunks (Tamias), and the flying squirrels (Sciuropterus); the beaver (Castor); the Polar hare, which extends into the forest region, though it is not common there. The American taiga also lodges the Canadian porcupine, an arboreal animal, the musquash (Fiber), a swamp animal, and the American variable hare in addition to the Polar hare.

The squirrels form a very interesting group, showing progressive adaptation to arboreal life. The Siberian striped squirrel or chipmunk ( $T$. asiaticus) is an example of a ground form which occurs in both North America and Asia, though North America has other species in addition. The chipmunks feed on nuts and seeds, of which they store large quantities for the winter, and, like the true squirrels, they hibernate. They differ, however, in living mostly on the ground, where they often excavate holes. They can climb trees, but are not nearly so agile as the true squirrels. The next stage is represented by the American red squirrel or chickaree ( $S$. hudsonianus), which is a graceful and agile climber, but spends a good part of its time upon the ground, where it sometimes excavates holes. Our 
common British squirrel (S. vulgaris), widely distributed in the more northerly parts of Asia, as is well known, rarely descends to the ground, and has great powers of leaping. It shows interesting colour variations, tending to be darker in colour in the colder parts of its range in summer, and turning white in winter where the climate is severe. It will eat almost any forest product, and hibernates during winter. The final stage in the mastery over the forest is represented by the flying squirrels, which are furnished with a parachute by means of which they can take long leaps from one tree to another, and thus obviate the risks due to a descent to terra firma. Though chiefly inhabitants of the tropical forests of Asia, one species occurs in temperate Asia and one in temperate North America.

The beaver, which haunts the streams flowing through wooded regions, was once widely distributed over the cooler parts of the northern hemisphere. The American species, if not identical with the Eurasiatic one, is at least very nearly allied. Beavers feed upon bark and twigs, and also upon the roots, \&c., of such plants as water-lilies.

While the porcupine of the warmer parts of Asia inhabits rocky country, the porcupine of Canada is a purely arboreal animal in habits, though it does not possess the same adaptations to this mode of life as are exhibited by its southern allies, the tree-porcupines of South America, Mexico, \&c. The Canadian form (Erethizon dorsatus) follows the taiga to its northern limit, and also follows the western coniferous forest to its southern limit. It spends the greater part of its time in the trees, though the nest is usually made on the ground among stones. The food consists of leaves, bark, twigs, beech mast, and other nuts, and the 
animals are stated to defoliate completely the trees they attack.

As regards the carnivores, the special features of the northern forests are the relative poverty in true cats, so abundant in tropical forests generally, and the wealth of arboreal animals of the weasel family, which are most abundant in temperate latitudes, and take there the place of the true cats and civets elsewhere. The bears also are characteristic of temperate forests. though not confined to them.

There is a close resemblance between the carnivores of the American and Siberian taigas. Thus in both are found lynxes, the common wolf, the common fox, bears, martens, the glutton, and among less purely forest forms, weasels, stoats, minks, and badgers. In Siberia, especially in the south, the tiger is sometimes found, while in the Canadian taiga the puma ( $F$ elis concolor) does not occur, although it is common in the coniferous forest of the Rocky Mountains. The wild cat (Felis catus) of the wooded parts of Europe does not occur in the Siberian forest, while it is altogether absent from America. An animal found in the Canadian forests, but with no Old World representative, is the skunk (Mephitis mephitica), a member of a group characteristic of South America, and the only one which ranges far north.

The lynxes are represented by the common lynx (Felis lynx) in Siberia, and by a closely related species (F. canadensis) in the woods of Canada. They are expert climbers, and are true forest animals, but the Canadian form is stated to feed chiefly on hares and birds of the grouse family, so that it must find its food largely on the ground. The common wolf is not specially fitted for forest life; it lives either in the 
woods or in the open, wherever food can be easily obtained. The fox with its burrowing habits is more of a forest animal, but only because in the woods it finds the necessary shelter and abundant food. It has no special adaptations to life there.

In addition to wolf and fox Siberia has another member of the genus Canis, in the form of the Siberian wild $\operatorname{dog}(C$. alpinus), which apparently haunts the high Alpine forests, as well as open country.

The brown bear (Ursus arctos) occurs in the Siberian taiga, as in the woods of the temperate region of the Eurasian continent generally. It can climb, though it is not so agile as some of its relatives, and, like all the bears, it takes a large amount of vegetable food. It is stated to be particularly fond of the edible seeds of the Cembra pine, and climbs the pines in search of them, as well as seeking to rob the peasants' stores. Like its relatives also it is very. fond of honey. In the taiga of North America it is replaced by the black bear (Ursus americanus), of similar habits. The grizzly (U. horribilis) is only found in the western forest. Both the black and brown bears eat fish and other aquatic animals in addition to warm-blooded forms, nor do they disdain insects.

In the Siberian forests two kinds of martens occur, the pine-marten (Mustela martes) and the more valuable sable $(M$. zibellina), with a more northerly range and a more valuable coat. Both are thoroughly arboreal, though both descend to the ground upon occasion. Closely related is the American marten ( $M$. americana), which is of similar habits, while the fisher marten (M. pennanti), in spite of its name, is also largely arboreal. It occurs throughout the greater part of North America, haunting mountain regions in the 
warmer parts of its range. The polecats, of which one (M. eversmannia) occurs in Siberia, the common weasel ( $M$. vulgaris), found both in Northern Asia and in Northern America, and the stoat or ermine ( $M$. erminea) as already indicated, are not definitely forest animals, though they are found there as well as elsewhere. The mink ( $M$. vison) of North America, and the Siberian form ( $M$. siberica) haunt streams and lakes, and are forest animals to the extent that localities suitable to their habits often occur within forest areas.

On the other hand, the wolverene (Gulo luscus), a fierce and voracious carnivore, is chiefly found within the forest, where it preys upon all manner of small mammals and birds, and even attacks weakly or disabled deer.

The common badger (Meles taxus) is found in the Siberian forests, and, though a burrowing form, occurs chiefly in woods. On the other hand, the American form (Taxidea americana) is chiefly a prairie mammal, and feeds largely upon the prairie marmots (see p. 64).

Passing now to the birds, we find that the forest is rich in specially adapted forms, and that in addition there are large numbers of migrants who spend part of their time there. The forest gives relative security during the dangerous period when brooding is taking place and the young are being reared. The absence or paucity of snakes in the northern forest also, and the complete absence of monkeys as well as of the many carnivorous or egg-eating animals which haunt tropical forests, increase the value of the northern forest from the birds' standpoint, and help to account for the number of species found there in summer time. Among forms which are especially abundant in northern forests, or especially adapted to life there, we may 
note the grouse and their allies; the grosbeaks and their relatives the crossbills; the woodpeckers and wryneck; the nutcrackers, jays, and their allies.

Grouse belong to the same family as the ptarmigan, and are especially characteristic of northern latitudes. The abundance of berry-bearing bushes, of which we have already spoken, both in the tundra and in the taiga, is an important factor in their distribution, for these berries constitute a considerable part of their food. In the Asiatic taiga we find the black grouse (Lyrurus tetrix), the larger capercaillie (Tetrao urogallus), and the hazel grouse (Tetrastes bonasia), while in the Canadian forest is found the Canadian grouse (Canachites canadensis), often called a partridge, and also the ruffed grouse (Bonasa umbellus).

The woodpeckers are birds showing remarkable adaptations to an arboreal habitat. The feet are well fitted for climbing, and the most highly specialized forms have stiffened tails, which aid in the climbing process. The beak is powerful and chisel-shaped, enabling the birds to excavate holes in wood, and also to lever off bark, while the long, viscid, worm-like tongue enables them to capture the insects thus exposed. Woodpeckers are very widely distributed, a few only ranging into the northern woods. Among these are the green woodpeckers (Gecinus), found in the temperate regions of the Old World, and the spotted woodpeckers (Dendrocopus), of both Old and New Worlds. Related is the curious wryneck (Iynx torquilla), found in summer in Northern Europe and Asia, which is without the stiff tail and climbing habits of the woodpeckers.

We have spoken of the edible seeds of the Cembra pine, and of the appreciation in which they are held 
by many inhabitants of the Siberian taiga. Though the seeds of other conifers have not the same wealth

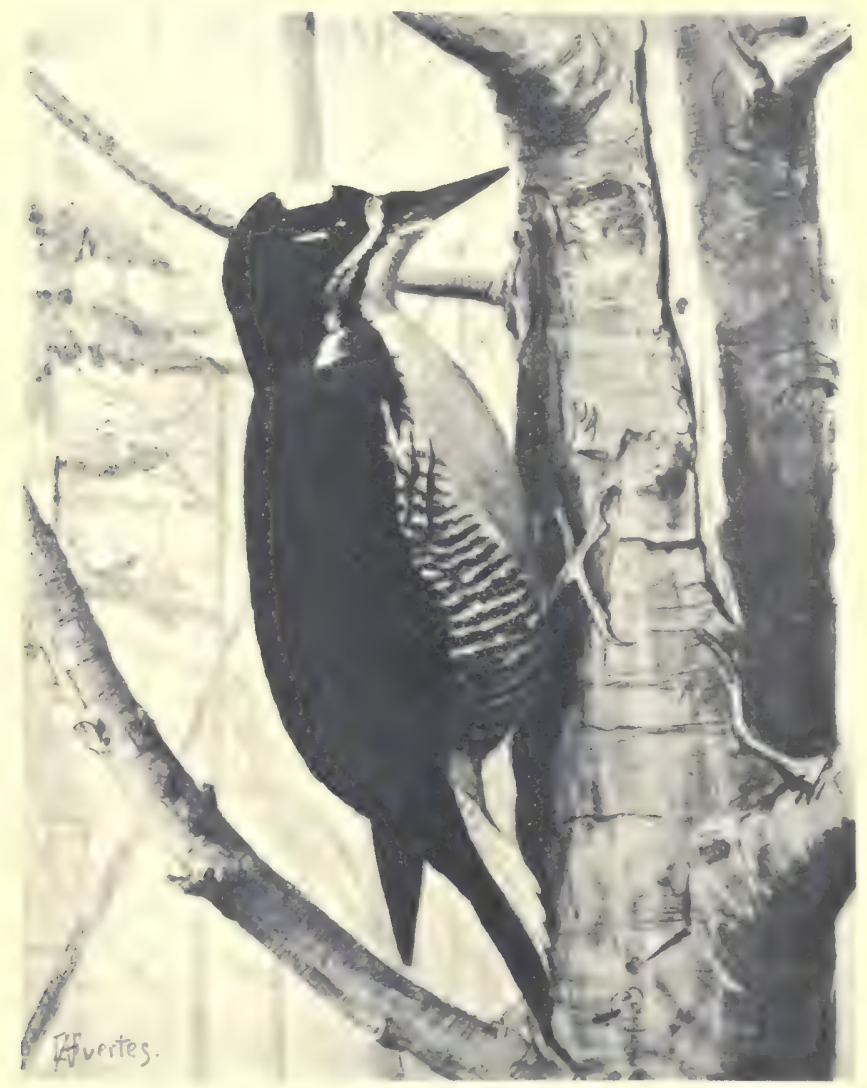

Fig. 6. The Three-toed Woodpecker of North America. Note the characteristic attitude, and especially the position of the tail. (Photo by the Biological Survey, U.S.A.)

of food products, yet they also are edible to many animals, and form a much sought after food supply. In 
both the Siberian and Canadian taiga they form a very large part of the natural food of the pine grosbeak (Pinicola enucleator), a gorgeous bird related to the bullfinch, and of the crossbill (Loxia curvirostra), also with bright-coloured plumage. Pine cones, it will be remembered, ripen slowly, and during the ripening process the seeds are carefully protected by the closing of the scales, so that their extrication is a matter of difficulty. The forester is constrained to apply heat to obtain the seeds without damage, but the crossbills have the beak converted into an instrument by means of which the seeds are readily prized out. More slashing are the methods of the nutcracker ( $N$ ucifraga caryocatactes), which in the Alps, as in Siberia, may be seen breaking the cones of the Cembra pine to pieces with its powerful bill. The western coniferous wood of North America is inhabited by another species. Related to the nutcrackers are the magpies and jays, the latter represented in the eastern taiga by the Siberian jay (Perisoreus infaustus), with soft fluffy plumage of a reddish colour.

Reptiles and amphibians are few in number in the northern forest, the former especially. Among amphibia, frogs and toads haunt the pools and swamps, an important form being the large bull-frog (Rana catesbiana) of North America, which is exceedingly voracious, devouring fish, young. water-birds, \&c., and derives its common name from its noisy croak, which is compared to the roaring of a bull. The tree-frogs (Hylidae), with their usually greenish colour and the curious adhesive pads at the ends of the toes, by means of which they keep their foothold, have a much wider distribution in America than in the Old World. In the Eurasiatic continent the common tree-frog ( $H y l a$ 
arborea) of Europe just reaches the south of the taiga, but the tree-frogs of North America have a more northerly extension.

In insects the northern forests are rich, for the perennial vegetation feeds many herbivirous forms, and many carnivorous or parasitic forms prey upon these. Many of the beetles especially are important pests from the point of view of the forester.

As examples of wood-eating forms we may mention the wood-wasps (Sirex), of which a large species ( $S$. gigas) often appears in summer-houses or other wooden erections in Britain, where it has been introduced with pinewood. The adult female has a boring apparatus, by means of which she bores a hole in trunks of pine trees in order to lay her egg at the bottom of the excavation. The wood-wasps are preyed upon by ichneumon flies, whose delicate senses enable them to find the burrows of the wasps, when they insert their long ovipositors and lay their eggs close to the wasp's egg, so that the resultant larvae may prey upon the wasp larva. There is here a singularly delicate adjustment between host and parasite, comparable to the relation which exists between the length of the proboscis of certain butterflies and the length of the tubes of the flowers which they visit.

Another form which feeds in the pine woods is the pine saw-fly (Lophyrus pini), whose larvae feed upon the needles, sometimes in countless numbers.

Wild bees also occur in the woods, the forms which store up honey extending much further north in the Old World than in the New. In Asia wild honey bees reach the Arctic circle, while in North America, according to Marshall, they scarcely pass latitude $50^{\circ} \mathrm{N}$. The honey is greatly prized by bears, who rob the nests 
without regard to the stings of the bees, from which their thick coats doubtless protect them.

REFERENCES. Kobelt's book, already mentioned, gives a full account of the taiga animals, and descriptions will also be found in Brehm's From North Pole to Equator (in translation, London, 1896). As the inhabitants of the taiga are mostly those characteristic of the temperate regions of the Northern Hemisphere, full accounts of them will be found in the books mentioned at the end of chapter $\mathrm{x}$. Most descriptions of journeys through Siberia also give some account of the taiga animals. 


\section{CHAPTER III}

\section{STEPPE FAUNAS AND THE TEMPERATE STEPPES OF ASIA AND NORTH AIIERICA}

To the south of the coniferous forest of Asia lies a belt of varying width, characterized by the absence or scarcity of trees, and by the periodical growth of grasses and other herbaceous plants. This belt of steppe land is continually merging into desert, the cold desert of the high uplands, or the warm desert of the rainless regions to the south. Similarly, the forest sends long feelers into it, wherever the banks of a water-course, or some favouring condition of soil or local variation of climate, make this possible. As Central Asia generally is a country of high mean elevation, and as it is remote from the sea, the climate is continental in character, very hot in summer and very cold in winter. The region is also continually swept by very severe storms, injurious alike to plant and animal life. Further, though the rainfall is always slight, and chiefly confined to the summer period, there is some reason to believe that it is subject to great variation, perhaps cyclical in character.

This very brief description may be said to sum up the main features of regions of temperate steppes, and the peculiar conditions cause them to be inhabited by special types of animals. Some of the conditions which we noted in the tundra are here repeated, for indeed the tundra is but a special type of steppe. Thus in both we have a seasonal and highly local abundance of 


\section{STEPPE FAUNAS OF ASIA AND AMERICA 53}

food, and also a seasonal and local scarcity. If the rains of early summer are abundant in the steppe there is an extraordinarily rapid awakening into life on the part of the steppe plants, resulting in a great abundance of food for the herbivores of the region. If the rains fail, scarcity reigns, and it comes in any case as soon as the favourable season is past; that is, alike in the height of summer and in the depth of winter. But local conditions produce minor variations in climate, altitude being one of the most important of these conditions. For this reason there are frequent alternations of famine and plenty, alike in time and space. Like the tundra animals then, the steppe animals tend to be social, to move about in flocks from one region of abundance to another. But as the wealth of the steppe is greater than that of the tundra, they are far more numerous, and far more diverse. Like the tundra animals as a whole, they attempt to escape unfavourable conditions by migration, and as these migrations must be rapid, to prevent death by starvation occurring between one region of pasturage and the next, the steppe animals are mostly swift, with special adaptations to ensure rapidity of movement.

The herbivores, always, as we have seen, necessarily the majority, are far more exposed in the open steppe than in the forest, and therefore they are either burrowers, or have singularly keen senses, enabling them to perceive danger from afar. The social instinct also is here of great aid. In some cases, as with the wild asses, the strength of the male enables him to protect the females and young from attack. As the safety of the species depends in this case upon the strength of the male, we find that he must win and keep his post as leader and defender by his strength, and that he is 
deposed by a younger male so soon as his powers begin to fail.

Again, the social instinct is an aid in another way. The more helpless forms, such as the rodents, usually appoint sentinels when they feed, these sentinels giving warning of the approach of danger in time for the party to seek safety in flight or underground. In the forest, where food is more uniformly distributed and the natural shelter greater, social animals are less frequent.

Another marked feature of steppe animals is their great fertility, seen alike in the steppe rodents and in insects like the locusts. This is associated with the risks of the natural habitat-risks of drought and consequent lack of food, risks of storm, risks associated with winter cold and summer heat. In Central Asia the dreaded 'buran' or hurricane may practically exterminate all life within a given area, except such animals as can find a refuge underground. As such storms are frequent, great natural fertility is necessary to repeople the devastated regions. Similarly, a season of deficient rainfall, or a series of such seasons, must kill out large numbers of animals.

We have already seen that this fertility of steppe animals is associated with strong migratory instincts. Now no natural barriers separate steppe regions from the neighbouring areas of forest, of desert, of semidesert, and so forth. We find then, as a special character of steppe animals, the fact that they tend periodically to overrun the means of subsistence within their own region, and therefore to flow out into the neighbouring regions. The direction of the winds and the position of Europe on the western border of a great continent give it a moist climate, and led to its being forest-clad 
almost throughout till man interfered, though the steppe region of Asia is continued into it through Southern Russia and part of Hungary. We find then that since the close of the glacial period Europe has been continually liable to incursions of steppe animals from Asia, some of which, like the hamster, have kept their hold, while others, like the saiga antelope, rapidly died out.

Another character of the animals of the temperate steppe is the prevalence of hibernation among them. The tundra is too cold for hibernation to be practised to any great extent, and the shelter and presence of food even in winter in the forest makes it relatively infrequent there. But the animals of the steppe can only find in burrows and in sleep protection against want of food and extremes of temperature, so that here both aestivation and hibernation may occur. The squirrels in the fir woods wake whenever the temperature rises in winter, just as the fir-tree itself becomes active whenever the temperature permits. But the plants of the steppe disappear beneath ground so soon as their brief period of activity is over, and their quiescence is reflected in that of many of the steppe animals.

Large areas of land almost devoid of trees, and clothed, at least at times, with grasses and herbs, occur in many other temperate regions besides Asia and South-eastern Europe. A great area of land of this type extends from the border of the Canadian forest southwards through the United States in the region west of the Mississippi river, nearly to the Gulf of Mexico. Similar areas occur in the Argentine and in Patagonia in South America, in South Africa, and in the south-eastern part of Australia. By extension the term steppe can be applied to all these regions, and 
there are other large areas in Africa and in the north of South America where open park-like country occurs, with trees scattered among the grass, and such land has some of the characters of a steppe. Again, all the great deserts of the world are fringed by semi-arid areas, displaying the general characters of a steppe.

The great interest of the steppe areas is that, especially in Asia and Africa, they are the natural home of very many of the great ungulates, the most highly specialized of which are steppe animals. In North America the steppe lands, within the human period at least, have been inhabited only by few species of wild ungulates, but of these few the bison was represented by countless numbers of individuals until it was exterminated by the white man. In South America, within the human period, but prior to the immigration of the white, large ungulates were almost absent. No horse, no relative of cattle or sheep or antelope cropped the herbage of the great plains, but their place in nature was taken by enormous numbers of rodents, which reached here a size not attained elsewhere. Again, in Australia no ungulate whatever occurred, and the natural pasture was utilized by marsupials or pouched animals, of which the most important grasseating form is the kangaroo.

That South America has few native ungulates and Australia none are two of the most interesting facts in geographical distribution, but the fact that ungulates introduced by the white man into both countries have flourished apace makes it unnecessary for us to suppose that any natural obstacle to their presence there existed. We may then say generally that the steppe regions of the world are the regions which form the natural home of the ungulates most valuable to man. 
It is the steppes of the more remote parts of the world which now support the vast herds of sheep, horses, and cattle necessary for the wants of civilized communities. Further, as steppe regions do not require to be cleared of trees, and, where the rainfall is sufficient, often produce abundant crops, we find that it is in the steppe regions that the cultivation of cereals is being most vigorously pushed at the present time. The regions of dense population are mostly regions of abundant rain, and therefore were once forest regions. Formerly these watered lands were liable to be periodically flooded by the overflow of the fertility of the steppes. This great tide is now being gradually regulated, and the steady stream of wheat, of wool, of meat, and so forth, which pours into the civilized world, is the biological equivalent of the flocks of rodents and the flights of locusts which the steppe sent out in earlier days, and of the hordes of wandering nomads which came later.

To this general account we may add a few words on the special conditions, climatic and other, found in the steppes of temperate Asia, the region to which the following description specially refers. Steppe conditions reign over that great area of Central Asia which is practically ringed by mountain chains, as well as to the west of it, but the fauna throughout this area is not uniform. The mountain chains themselves have their own characteristic animals, and the plateau of Tibet, with special conditions of climate, has a peculiar fauna of its own. Excluding Tibet and the mountain chains then, we have a great steppe and desert area which extends from the eastern base of the Pamirs to the Khingan Mountains, and is separated from the forest region to the north by the great area of elevated ground in which the Siberian rivers arise, and from the 
wooded regions of China to the south-east by mountain chains. Through the Dzungarian Gate this area, to which the general name of Desert of Gobi or Shamo may be given, is continuous with the extensive band of steppes which runs through Russian Turkestan to the Aral and Caspian seas, is continued through Southern Russia in Europe into Hungary, and is bounded to the south-west by the plateau of Persia. But uniform conditions do not reign throughout this great area, which shows many alternations of fertility and aridity. Thus the snows of the Pamirs water much of Russian Turkestan through the Amu Daria and the Syr Daria, and this westerly region as a whole has a much milder winter climate than the easterly region, permitting of the extension into it of animals really peculiar to the southern steppe and desert regions, those characterized by the absence of severe winter cold.

Climatically, as we have seen, the general features of the steppes of temperate Asia are the great range of temperature, the hot summers and the bitterly cold winters, and the small precipitation, which tends to occur in late spring or early summer, giving a dry winter and a dry summer and autumn, which makes the growth of trees virtually impossible. The frequency of dry east winds in winter is an important feature in checking the growth of perennial plants, except such as die down to the ground. As indications of the nature of the climate, we may note that at Orenburg the mean January temperature is $4^{\circ} \mathrm{F}$., and the mean July $70^{\circ} \mathrm{F}$., while the mean annual precipitation is only $17^{\prime \prime}$, with a June maximum, but no absolutely dry month. Further to the east much lower winter temperatures occur ; thus Sven Hedin found temperatures of $-17^{\circ} \mathrm{F}$. in the Tarim basin, and the river here is frozen for three 
and a half months every year. Even the Amu Daria, in a western region of relatively mild winters, is frozen for about a month every year. The steppe animals are thus subjected to very unfavourable natural conditions, but the high summer temperature, especially during the rainy season, means a great intensity of life for a short period.

In giving a brief account of steppe animals, we shall limit ourselves chiefly to the steppes of Central Asia just described, and, as before, will begin with the ungulates, here especially important.

Perhaps the most characteristic of the steppe ungulates is the saiga antelope (Saiga tartarica), an ungainly animal with rather short legs, the male having a peculiar swelling on the face, which makes it appear hook-nosed. The animal occurs in thousands in the Kirghiz steppes, and the fact that its yellowish coat becomes almost white in winter suggests the severity of the climate in its home. Formerly it had a much wider distribution to the west, its remains having been found even in Southern England, as well as in Belgium and Southern France. In the historic period it has been gradually retreating eastwards, thus losing the ground which its ancestors conquered in the ages when steppe conditions were more widely spread than at present. The antelopes are also represented in the steppes by two kinds of gazelles, the so-called Persian gazelle $(G$. subgutturosa), which extends to the Gobi desert, and the Mongolian gazelle (G. gutturosa), a somewhat larger animal; but, generally speaking, the gazelles are more characteristic of the warmer deserts to the south.

No less than three kinds of horse-like animals haunt the Asiatic steppe-the tarpan or wild horse (Equus caballus), Prejevalski's horse (E. prejevalskii), and the 
kiang or wild ass (E. hemionus). The tarpan is now limited to the regions of the steppe most remote from human influence. Like its allies it goes about in small troops under the leadership of an old male, and has extraordinarily acute senses and great swiftness. In winter its coat is so thick as to form a kind of fur, and it obtains food by scraping away the snow from the ground. It is almost uniform in coloration, and of a dun colour. Prejevalski's horse is of a similar colour above, but is almost white underneath. Such a dun tint is common in steppe and desert animals, and is doubtless protective. In the kiang there is a dark stripe down the back, and traces of striping on the limbs, but the body is of a uniform darkish colour, instead of being striped as in the African zebras. The kiang (see Fig. 16) inhabits the higher parts of the steppes, and occurs at great heights in Tibet.

Still another group of ungulates is represented in the steppes by the Bactrian or two-humped camel (Camelus bactrianus), which with its long hair, moderately short legs; and hard feet is as well fitted for the hilly and rocky regions of the steppes, as is the one-humped camel for the sandy deserts to the south. The animal feeds largely upon the bitter saline plants of the steppes, and will drink saline and brackish water, so that it is a typical inhabitant of the salt steppe. The two humps allow for the storage of fat when the animal is well fed, and thus permit it to withstand periods of semi-starvation. Its appetite is, moreover, remarkably catholic, for, according to Prejevalski, it will devour all sorts of animal matter if vegetable food fails.

Taking antelopes, horses, and camel as representatives of the ungulates of the steppes, we may pass on to the consideration of the rodents, which are numerous 
both as to individuals and as to species, and often show some curious adaptations to steppe life.

A point of very considerable interest in regard to the steppe rodents is that there is much general resemblance between those inhabiting Asia and those of North America. This is the more remarkable in that there is no resemblance in regard to the ungulates of

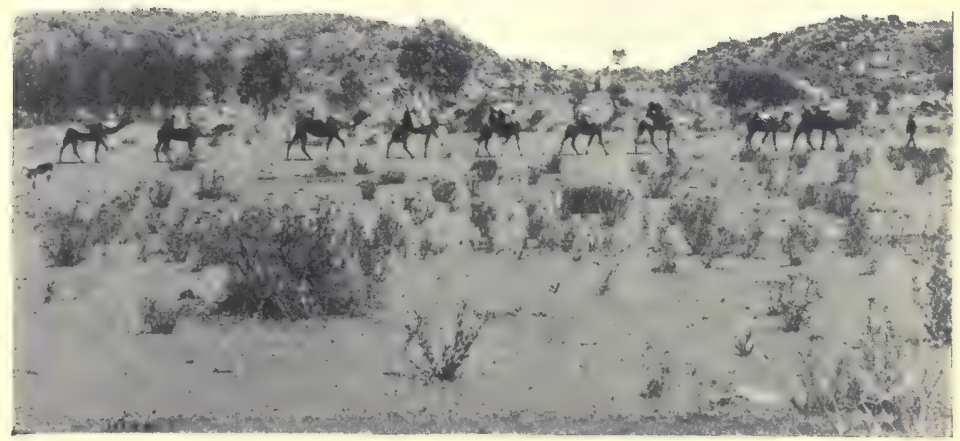

Frg. 7. Transport Camels in the Australian Desert.

the two regions. The prairies of North America have no antelope, no camel, no wild horse nor ass. Their chief ungulate was formerly the bison (Bos americanus), while the bison of the temperate regions of the old World was a forest-dwelling animal, found in Europe, but not in the steppes of Asia. The other important ungulate of the North American prairies is the prongbuck (Antilocapra americana), an animal related to the antelopes, but differing markedly in the fact that the 
horns are shed annually and are branched. The contrast between the living, or recently exterminated, ungulates of the Old and New Worlds is the more remarkable when we find that America has many fossil horses, though no living ones.

In proof of the statement just made as to the resemblance between the steppe rodents in the Old and New Worlds, we may note that marmots occur in both regions, that the susliks of Asia are represented by the forms called gophers in America, which belong to the same genus, and that the jumping mouse of the American prairies takes the place of the jerboas and their allies in the Old World. As the adaptation to steppe life is similar, we shall refer chiefly in the following description to the rodents of the Asiatic steppes.

The susliks (Spermophilus) are related to the squirrels, but the common steppe form ( $S$. citillus) differs in the very short tail and the minute ears, both adaptations to the terrestrial and burrowing habit, and markedly contrasted with the long tail and large tufted ears of the common squirrel. Like other steppe rodents the susliks are social and burrowing animals, hibernating in winter, but storing in autumn a large collection of roots, seeds, berries, \&c., for winter use. Like the squirrels, they are not averse to a certain amount of animal food, taking small birds and their eggs when occasion offers, and also small rodents belonging to other genera.

The marmots (Arctomys) form an interesting genus, with representatives both on mountains and in the steppes. We shall see later that it is not unusual to find relationships between steppe and mountain animals, a fact which has a double significance. In the first place, just as the tundra forms a steppe because it is too remote from the Equator for tree growth to occur, 


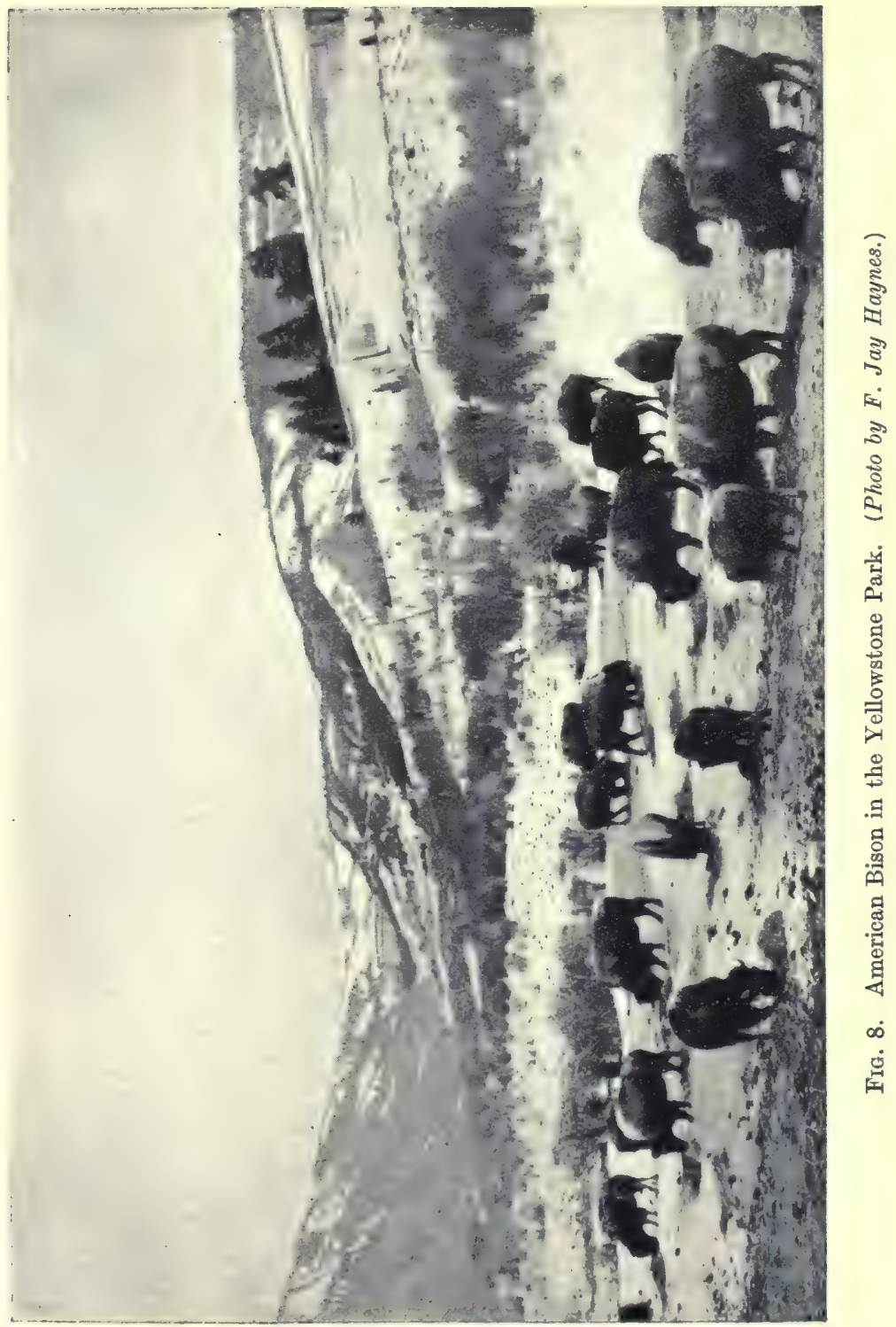




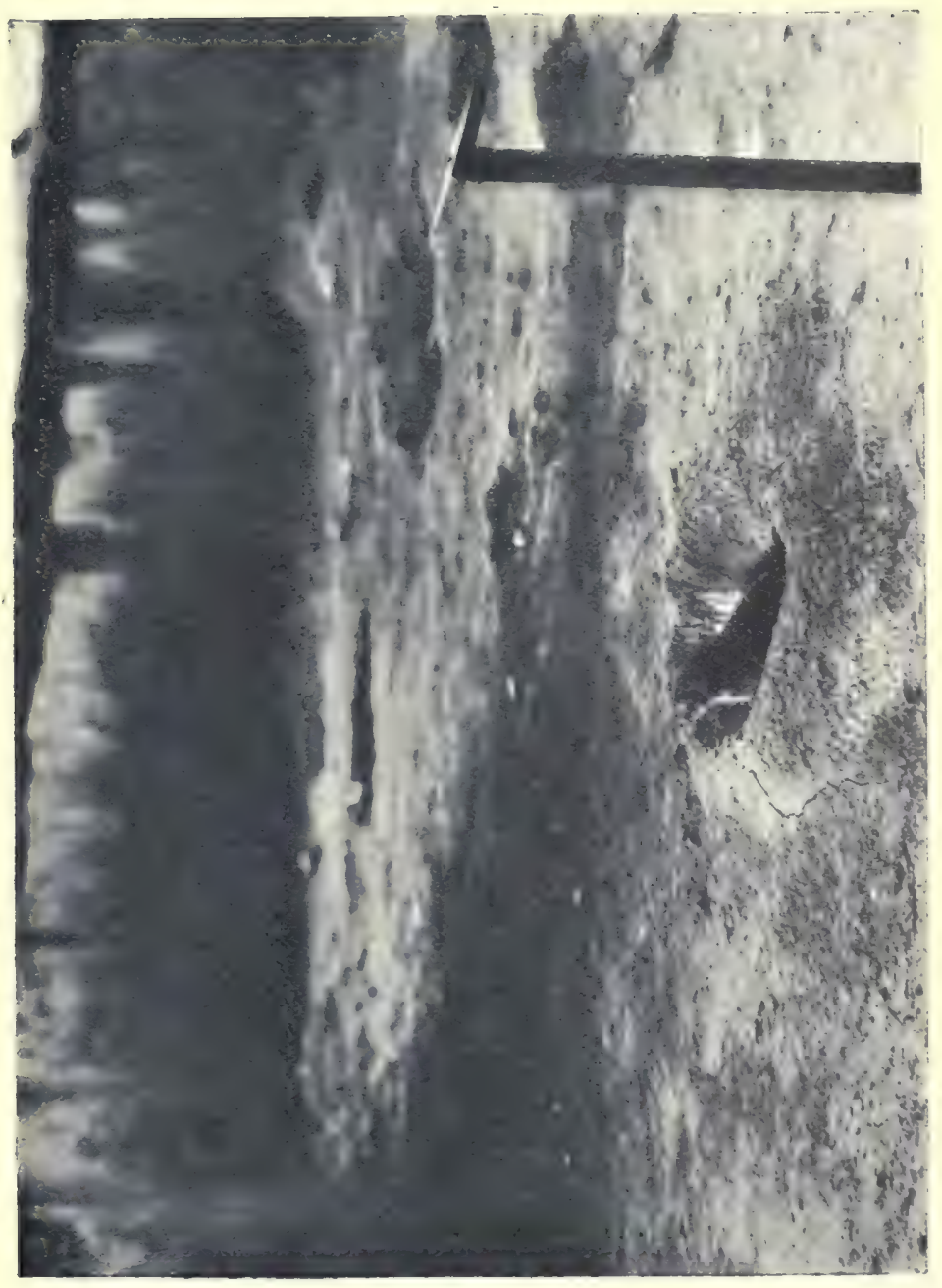

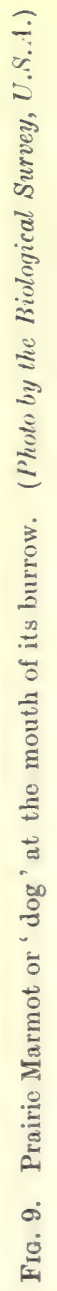


so the upper parts of mountains form steppes because the elevation prevents forest growth. Again, it is believed that in those parts of the world recently subjected to glaciation there was a period, after the retreat of the ice, when the climate was unsuited to trees, leading to a wide extension of steppe conditions. This brought in its turn a wide extension of steppe animals, which, with the gradual improvement of the climate, and the return of forest-haunting forms, were driven up the mountain sides to the Alpine regions. If this be so, then the shrill whistle of the Alpine marmot, so common a sound in the mountainous regions of Switzerland in summer, not only recalls the conditions of the Asiatic steppes, but also brings back a time when much of Europe was in the condition in which the steppes are to-day. The Alpine marmot is now limited to the Alps, Pyrenees, and Caucasus, the time being far past when it also inhabited the low ground. On the other hand, the bobac $(A$. bobac), the characteristic marmot of the Asiatic steppes, extends into Europe as far as the eastern frontier of Germany.

Marmots are rather clufmsy animals with heavy bodies, short limbs, and usually short tails. The shortness of the limbs must greatly limit the range of vision, and the animals have very markedly developed that habit of sitting up on the hind limbs to take a wider view which is common in relatively short-legged animals. The shortening of the fore-limbs here gives greater purchase in burrowing, the burrows being extensive. The food appears to be entirely vegetable, and the animals hibernate much more profoundly than the susliks. Bobacs occur in very large colonies, and tunnel the ground in all directions with their burrows. According to Kobelt, the result of these excavations is 
to modify the condition of the soil, so that special plants appear in the 'marmot gardens', which can thus be recognized from afar. The hemp-leaved nettle and wild rhubarb occur especially here, and the presence of the large leaves of these plants among the lyme grass (Elymus) of the steppes is a very obvious feature, while the loosening of the soil by the burrows makes progress for horsemen very difficult over the 'gardens'.

The interesting point is that rodents of similar habits seem to inhabit steppe regions in general. Thus the prairie marmot (Cynomys ludovicianus), a related form inhabiting the prairies of North America (Fig. 9), has similar habits, while the viscacha of the pampas of Argentina, though not very nearly related, shows also a general resemblance in habits, and also modifies the herbage in the regions of its occurrence.

A different, though no less perfect, adaptation to steppe life is shown by the jerboas or jumping mice.

In speaking of the marmots we noted that for rapid and efficient burrowing, short fore-legs are necessary. but, on the other hand, if the hind-legs are also short, the animal's range of vision is small, and its speed cannot be great. On the other hand, if the legs are elongated to give speed, then feeding on the ground and drinking become difficult, as is seen in the giraffe (Fig. 36). The jerboas show a curious form of compromise to these varying needs, generally parallel to that shown by the kangaroo, which is, however, not a burrowing animal. In the jerboas the fore-limbs are short, thus permitting the animal to burrow, but the hind-legs are enormously long (Figs. 37 and 38), and the tail also long and capable of helping in the support of the body. The animal therefore progresses by leaps, the fore-legs not touching the ground at all. In feeding, 
a crouching position is adopted, the food being carried to the mouth by the fore-limbs. As in rodents in general, the food consists largely of roots, seeds, berries, \&c., and not wholly of grass, as in the kangaroo and in most ungulates. The curious elongation of the hind-legs gives such speed that the jerboas can escape their enemies by flight, while on the other hand the bobacs at once seek their burrows on an alarm, and make underground tunnels to the feeding-grounds, so that they are never far from an open burrow. Another very interesting structural point in regard to the jerboas is the reduction of the number of toes from five to three on the hind-foot. Among the ungulates we find a similar reduction, carried however much further, for the horse and its allies have only one toe on each foot. This reduction gives speed, and is an adaptation to swift movement over a relatively hard surface.

The commonest jerboa of the steppes is Alactaga decumana, the five-toed jerboa as it is called, because the lateral toes are present on the hind-feet, though they are minute and functionless. Another peculiarity of the hind-foot, which it shares with other jerboas, is the fusion of the bones which form the sole of the foot in man, that is of the metatarsal bones. As a result a very strong bone called the cannon bone is formed, quite comparable to the cannon bone in the antelopes and their allies, though it is formed in a different way. This also is an adaptation to ensure swift movement over firm ground, for it gives the necessary rigidity during the taking of the long leaps. Though the head and body together of this animal only measure some seven inches, it is stated that it cannot be overtaken by a horse, so extraordinarily rapid is its speed. Like the other steppe rodents the jerboas are social, forming 
burrows in companies. With the vegetable food they mingle insects and the eggs and young of birds, especially of the steppe lark.

The jerboas of the genus Dipus chiefly inhabit the hot deserts further south, but some species, notably D. sagitta, extend into the steppes. Though the habits of the members of this genus are generally similar to those of the preceding in their coloration and in their intolerance of rain or damp, they are essentially inhabitants of arid regions (cf. p. 133).

In the steppe region are also found the hamsters (C'ricetus), with a western extension into Europe. But though originally doubtless steppe animals, the hamsters, like the brown and black rats, though to a less extent, have attached themselves to man, and find it more profitable to plunder his fields and gardens, than to depend upon the precarious vegetation of the steppes. They are remarkable for the size and elaboration of their burrows, in which they store quantities of corn. \&c., for winter use.

Another characteristic genus of the steppe is Lagomys, the genus which includes the picas, tailless hares or whistling hares as they are variously called. These animals are smaller than a rabbit, and are for the most part mountain animals, living high up among rocks and stones in the mountains of Central Asia. In Siberia, however, they are found on lower ground, and even extend into the tundra region. They form a very important part of the food of the carnivores of the high steppe, replacing here the lemming of the tundra. In Mongolia, $L$. ogotona occurs in large colonies, and at the approach of winter stores up large quantities of hay near the openings of the holes. According to Prejevalski, these haystacks may weigh 10 kilogrammes 
(22 pounds), and are sufficiently numerous for it to be worth while for the Mongolians to bring their cattle to feed upon the pica's stores, and so dispense with the trouble of storing fodder on their own account. Like some other of the steppe animals, the picas are remarkably resistant to thirst, and can live in localities far from water, where no rain nor dew occurs for months at a time.

As to the carnivores of the steppe, the tiger, though usually regarded as a tropical animal, extends far to the north, and occurs in steppe regions, perhaps in more than one variety. When nobler game fail, it does not disdain the rodents, notably the picas. The special cat of the steppe is, however, the manul cat (Felis manul), a beautiful animal with a bushy tail, about the size of the common cat, and apparently allied to the wild cat of Europe, but, unlike it, a steppe animal. Its main food consists of the steppe rodents, and also of the ground-nesting birds. The steppe has also its special fox, the corsac fox (Canis corsac), which also feeds chiefly upon the steppe rodents. Here as elsewhere the ubiquitous wolf also occurs.

In regard to the birds of the steppe it is noticeable that they tend to acquire swiftness in running, thus showing parallelism with the mammals. This is carried further in the birds of the warm deserts of the world, where we have in ostrich, rhea, emu, \&c., examples of birds without any power of flight, but of great fleetness of foot. The reason for this tendency is possibly that the steppe or desert does not, like the forest, offer safe places upon which to rest. As the birds are exposed to danger so soon as they alight, whịch is necessarily upon the ground, fleetness is a great advantage to them. 
As examples of steppe birds, we may name first the bustards, of which the largest form, the great bustard (Otis tarda), has been compared in build and habits to the ostrich of the Saharan desert. Bustards, though good fliers, are fleet of foot, and show a preference for open country. They do not seem to drink, and take both animal and vegetable food. In addition to the form mentioned, the little bustard $(O$. tetrax) and the ruffed or Macqueen's bustard (Hubara undulata) also occur, the latter preferring running to flying, and having the habit, common among steppe animals, of squatting down when undisturbed, so as to take full advantage of its protective coloration, but stretching itself to its (considerable) height on an alarm in order to increase the range of vision over the plain.

Pheasants, which are bush-haunting birds, just enter the region, but Pallas's sand-grouse (Syrrhaptes paradoxus) is characteristic, both the young and the adult showing a delicately patterned type of coloration which is eminently fitted to conceal them in their natural habitat. The young are precocious, being able to run as soon as hatched. This is necessary in birds whose eggs are laid in a mere depression scratched in the loose soil. In the steppes the bird is said to feed chiefly on the seeds of a member of the Chenopodiaceae called Agriophyllum, and it assembles in large flocks in places where this plant of the salt wastes is abundant. The plant is also relished by horses and camels, and its seeds are used as food by the nomads as well as by the sand-grouse. The sand-grouse shares with many steppe animals the peculiarity of being periodically very abundant, when it makes incursions on lands adjacent to its normal habitat. Flocks of it have appeared at various times in Europe, reaching even the British 
Isles. The bird differs from the bustard in that water is necessary to it, and it makes regular daily visits to particular drinking-places.

Very characteristic of the Asiatic steppes are the birds belonging to the genus Podoces, sometimes called chough-thrushes, which are members of the crow alliance, though their exact position is doubtful. Though capable of flight, they only fly with reluctance, but run swiftly, feeding upon insects and seeds, and nesting in bushes or sometimes on the ground. They haunt the desert regions where bushes of saxaul and tamarisk grow, and do not seem to drink, while the more grassy regions of the steppes often swarm with the Siberian lark (Melanocorypha calandra).

In the American prairies game birds are represented by the prairie-hen (Tympanuchus americanus), a form related to the grouse; also by the sage-cock (Centrocercus urophasianus, Fig. 10), which feeds upon 'sagebrush ' (Artemisia tridentata) in the western states, just as Pallas's sand-grouse feeds upon Agriophyllum in the Asiatic steppes; and by the prairie-chicken (Pedioecetes phasianellus). All these can fly rapidly and powerfully, but only rise when hard pressed, preferring to run along the ground, or squat among the herbage, as means of escaping notice.

In the steppes of both the Old and New Worlds such forms as curlews, plovers, snipe, ducks, geese, and so on, with many of the smaller singing-birds, are abundantly represented in the breeding-season, but do not show any very notable adaptations to steppe life.

Reptiles in the steppes and adjacent deserts are not numerous in species, but the individuals are often very abundant. In that part of the desert of Gobi which is called Alashan, lizards belonging to the genera Phryno. 
cephalus and Eremias are very abundant, and show special adaptations to desert life, e.g. in coloration, in swiftness, in the power of burrowing, and so forth. So abundant are they in summer that they attract flockis of the demoiselle crane (Grus virgo), which feeds upon

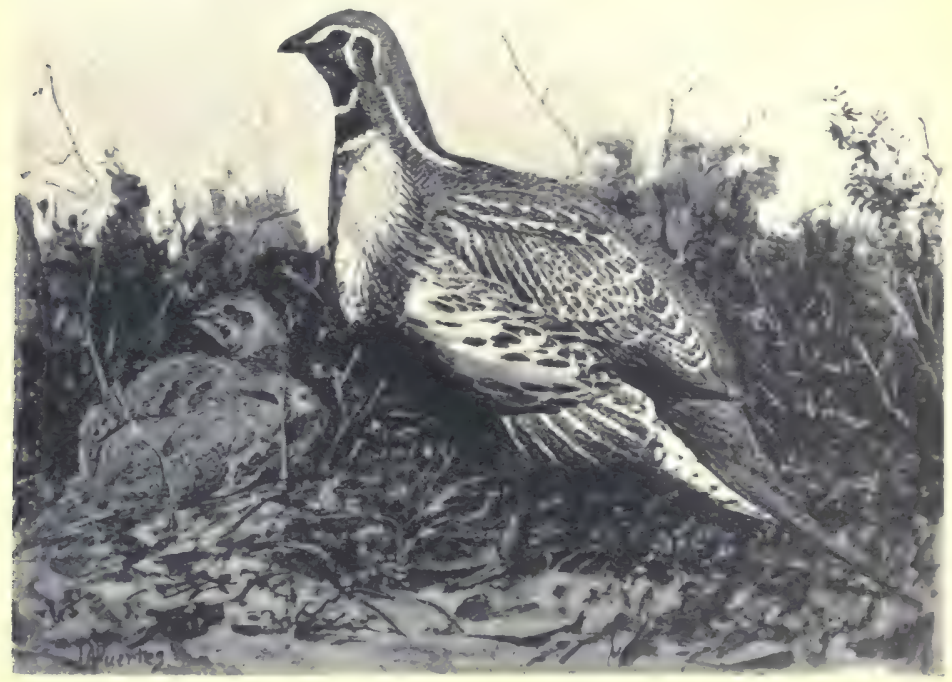

Fig. 10. Sage-cock. (Photo by the Biological Surrey, L.S.A.)

them. They are also greedily consumed by birds of prey, and even by such mammals as wolves and foxes and domesticated dogs. In the steppes and deserts of Turkestan there occurs a curious gecko (Teratoscincus scincus), which has lost the disks on the digits by which its allies climb, and has acquired curious fringes, which enable it to run over the loose sand. Among snakes we find the small sand-snake (Eryx jaculus), a harmless 
form, which extends into Greece, and is interesting from the way in which it buries itself in the sand by means of its snout; and the poisonous Trigonocephalus halys, dangerous to cattle but not to man, as well as vipers and others.

Amphibians are limited to the regions in the vicinity of water, and offer no special features. As regards insects we need only note that grasshoppers and locusts are very abundant, open grassy plains being the natural home of these insects, from which the locusts make periodical raids upon cultivated lands.

Referexces. The works of Kobelt and Brehm already mentioned give accounts of steppe animals, and reference should also be made to any of the natural histories, e.g. the relevant volumes of the Cambridge Natural History (London), edited by Shipley and Harmer, or The Royal Natural History (1893-6), six vols., edited by Lydekker, where details will be found of the different animals mentioned. A series of articles in the American Naturalist, especially 'Cursorial Adaptations in Mammals', by Lull (1904), and 'Fossorial Adaptations in Mammals', by Shimer (1903), will be found interesting in this connexion. Of the various books published as the result of travels and giving accounts of the life of the steppes, mention may especially be made of Prejevalski, Wissenschaftliche Resultate der nach Centralasien unternommenen Reisen (Leipzig, 1889). See also the books mentioned at the end of chapter iv. 


\section{CHAPTER IV}

\section{MOUNTAIN FAUNAS}

THE animals of mountain and plateau regions show some interesting conditions which make it worth while to consider them separately. Taking mountains first, we may note that elevated ranges may be divided into three regions, each of which presents peculiar biological features. The lowest region is usually clad in forests, conifers predominating as we ascend. At a point which varies with the exposure, the slope, and other factors, even on a single mountain, tree growth ceases, and there comes a zone with steppe characters. The width of this band and its nature vary greatly. In e.g. the mountain regions of Europe, it is characterized by the growth of relatively small herbaceous plants, often with large and gorgeously coloured flowers, but with tufted leaves and other indications of checked vegetative growth. Many of these plants reappear in the Arctic tundra, but the fact that they are specially abundant in the Alps has led to them being called Alpine plants, whether they occur in the Alps proper, on the hills of Scotland or Norway, in the Himalayas, or in the Caucasus.

In tropical regions, e.g. in Africa, this steppe area with its Alpine plants is replaced by a band where the plants show desert characters; the Lobelias, Senecios, and tree-heaths of the upper zone of Ruwenzori and Mount Kenya form good examples. In all regions where the mountains attain sufficient elevation, above the steppe or desert zone comes that of eternal snow, where 
the exposed rocks are at most scantily clad in mosises and lichens.

Without discussing in detail the characters of mountain climates, we may note that it seems probable that the upper limit of the forest corresponds roughly to the zone of maximum precipitation. In ascending a mountain the rainfall increases up to a certain point, beyond which it begins to diminish. With certain modifications, due to inversions, \&c., the temperature diminishes steadily as we ascend. The relatively narrow alpine zone on, e.g., the Alps is due to the fact that the vertical distance between the zone of maximum precipitation and the snow-line is short. In tropical regions the snow-line is pushed far upwards, much above the zone of maximum precipitation, and the wide interval thus produced between the forest and the snow allows for the development of a broad band of gradually increasing aridity, where the surface is clad in plants of definitely drought-resisting type, the low temperature increasing the need for xerophytic characters by diminishing the power of absorbing water.

Plateau regions, such as the great plateau of Tibet and the far less extensive plateau of Spain, may be said to correspond to the steppe zone on an ordinary mountain. Plateaux of great altitude and great horizontal extension tend to show some of the characters of a cold desert, thus giving us the special conditions which reign in Tibet, but the conditions tend to be less extreme than in small and isolated areas of great elevation. Plateaux differ from other steppes or deserts in the peculiar nature of the relief, which demands special agility upon the part of the animals inhabiting them, but gives to those possessing such agility a certain 
security, due to the rugged nature of the surface. Further, the peculiar climatic conditions, together probably with the rapidity of mechanical erosion, promote the growth, in certain localities at least, of

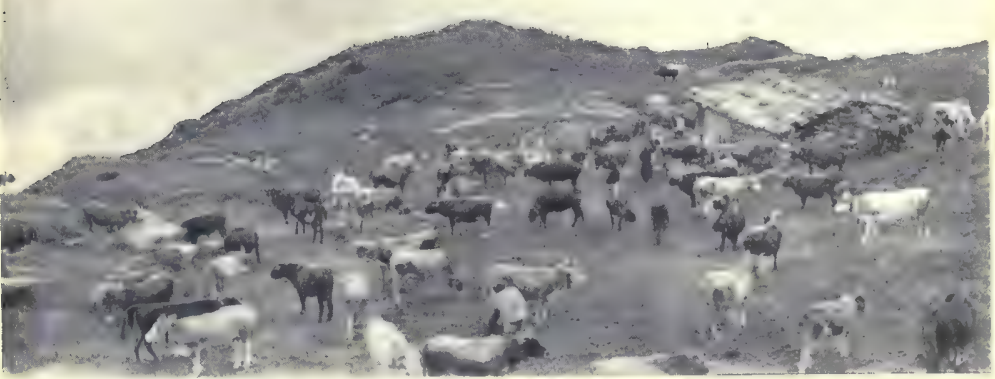

Fig. 11. A Swiss Alp. The absence of trees, the presence of a close short turf and of low bushes (mostly berry-bearing), are very characteristic of the upper regions of the Alps as well as of many other mountain and plateau regions. The richness of the pasture is suggested by the number of cows

particularly nourishing fodder plants. A large part of the pastoral industry of Switzerland is due to the pasturage obtainable on the high mountain shelves or alps. In Tibet, though wild herbivores exist in flocks of thousands, according to some observers, yet there is pasturage enough to spare to feed the domesticated animals upon which the community largely depends. 
The relatively rich pasturage, and the relative security, account for the fact that mountains and plateaux have a considerable number of peculiar herbivores, especially ungulates. The ungulates of mountains belong to more than one group, but in the Old World. at least the two genera of sheep (Ovis) and goat (Capra), which appeared late in geological time, include animals which are especially adapted for mountainous districts. Just as deer are typically forest animals, and antelopes typically steppe or savana animals, so sheep and goats are the typical inhabitants of elevated regions. In the case of sheep, at least, domestication has produced so many changes in character, that it is somewhat difficult to realize the extraordinary agility of the wild animals, and their other special adaptations to life in mountainous and elevated regions. The thick coat protects them against cold, and the fact that the young-necessarily few in number in animals with such a habitat-are able to follow the mother anywhere within a very short time after birth is an important adaptive character. Like steppe animals in general, wild sheep are social, and like many such animals they seem mostly to appoint sentinels while feeding. Their powers of leaping are very great, and they seem able to scale apparently inaccessible cliffs.

While wild sheep, like domesticated forms, chiefly graze upon the ground, the equally agile goats depend largely upon the shoots, leaves, and twigs of bushes and small trees, and as the trees in their native habitats are mostly xerophytic, it is noticeable that the goats have very catholic tastes, not disdaining the resinous, hairy, or spiny plants native to high steppes. From the difference in diet the goats usually occupy ground which is more scarped and rocky than that favoured 
by sheep, and they have apparently even greater powers of climbing and leaping.

As will be explained later, other types of ungulates also show adaptations to mountain life, especially in those regions which have no wild goats or sheep. Just as the two latter types of animals are of relatively recent origin, so it is probable are the adaptations to mountain life shown by other mountain ungulates. Indeed the fleeing to the mountains appears to be the latest phase in the long struggle between herbivores and carnivores. There is evidence that the herbivores acquired swiftness as the carnivores acquired intelligence and strength. As a general rule the latter seek to capture their prey by ruse rather than by direct pursuit, and in the open steppes and plains their task is relatively easy. To escape them, apparently, no less than to utilize the rich mountain pastures, some herbivores sought the heights, and there the carnivores can hardly be said to have followed them, there being few large flesh-eaters at great elevations. Indeed the chief flesh-eating animals of the mountain ranges of the globe are the vultures and their allies, always conspicuous in such regions.

For convenience' sake we shall take a rapid systematic survey of the animal kingdom in studying mountain animals, but it may be noted first that as forest, steppe, and tundra are all represented on mountains, it is natural that animals from all these regions should occur there.

For example, in the Himalayas we find that those truly arboreal animals, the Primates or monkeys, are represented high up in the region of coniferous forests, where, doubtless, like the ungulates, they find relative security from the great carnivores. The characteristic 
monkey of the Himalayas is one of the langurs, a group of slender-limbed, leaf-eating forms widely distributed over South-eastern Asia. The particular species is Semnopithecus schistaceus, and the animal occurs at heights up to 12,000 feet. All who have seen it in its native home speak of the peculiar effect of the animal among the snow-covered pines and deodars there, and the number of forms found on the lower ground in India and the adjacent region proves that the acquisition of the mountain habitat in this case must be recent. The Himalayan form is very closely related to the common sacred monkey of India, and while sharing with its allies the usual adaptations to arboreal life - to be described later-it does not seem to show any special fitness for mountain life. Better adapted for life at high elevations is the Tibetan langur (S. roxellanae), which lives in the forested regions of the east of Tibet, especially in the vicinity of Lake Kuku Nor, and also extends into China. It is found at elevations of over 10,000 feet, and migrates to some extent according to the seasons, but never descends to the region of cultivated land, the district plundered so frequently by the low ground forms. The Tibetan langur is somewhat stouter in build and shorter in the limbs than the other forms, and has a curious tiptilted nose, whose use is unknown, unless it has anything to do with facilitating respiration at these high altitudes. The hair is very long, and the skin is greatly prized by the Chinese on this account. The animal is stated to live chiefly on 'fruits', but no doubt the seeds of the mountain trees are also important. As the other monkeys of China are species of Macacus, there can be no doubt that the Tibetan form has found its way into China from the south, through the moun- 
tain barrier. Its presence is thus an indication that mountains do not necessarily form a barrier to distribution, even to animals reputed to be so sensitive to cold as monkeys.

The macaques also include one mountain form, Macacus tibetanus, which seems to occur in much the same region as the Tibetan langur, and also extends into China proper, in Sechwan and the south of Kansu. The narrow and broken mountain chains of this region, according to recent observers, have a damp climate, quite different from that of Tibet proper, and into the valleys the monsoon forest insinuates itself, taking with it part of its characteristic fauna, notably the two monkeys named. The macaques differ from the langurs in their diet, for they eat insects and other forms of animal food in addition to fruits and seeds. As this food is much more portable than leaves, they have cheek-pouches in which it may be stored, these being absent in the langurs, which have large sacculated stomachs, comparable to the stomachs of some ungulates.

The Himalayan and Tibetan langurs and the Tibetan macaque appear to exhaust the members of the Primates which haunt mountains. None of the New World forms seem to be specially fitted for life at high altitudes, and though some of the African baboons inhabit rocky regions at some elevation, none seem to be peculiar to high mountains or plateaux.

The insectivores have various mountain representatives, some showing peculiarities of distribution. The Alpine shrew (Sorex alpinus) inhabits the upper parts of the lofty mountain regions of Central Europe; the Himalayan swimming shrew (Chimarrogale himalayica) inhabits the lower slopes of the Himalayas, where it 
haunts streams and feeds upon aquatic insects and their larvae, tadpoles, and small fish; the desman (Myogale pyrenaica) of the Pyrenees inhabits the banks of streams in that mountain range, and spends a considerable part of its time in the water; the Tibetan mole-shrew (Uropsilus soricipes) is a small cursorial animal, seeming to be intermediate between moles and shrews. The insectivores are, however, losers in the battle of life, and there is nothing remarkable in the fact that peculiar forms are found in mountain ranges, when we remember the shifts the members of the group have been put to in order to survive in a world where the mammals as a whole have better developed brains and greater differentiation of structure than they can boast of.

Carnivores, as we have seen, are not very abundant. The forms which inhabit the neighbouring regionsforest or steppe-may extend also into the mountain regions, but peculiar forms are not numerous, the bear alliance being that with most mountain representatives.

Of the cats the most characteristically mountain form is the ounce or snow leopard (Felis uncia, Fig. 12), a beautiful animal with very thick fur, greyish above, with black spots, and pure white below. In Ladak it is said to ascend as high as 18,000 feet in summer time, and not to descend lower than 9,000 feet in winter. It attacks wild goats and sheep, and also rodents, but its habits are not well known. In the New World the puma (Felis concolor, Fig. 26), though not specifically a mountain animal, attains a considerable height in the Rocky Mountains, and is stated to prey upon the Bighorn sheep.

Of other cat-like carnivores extending into mountainous regions, we may note that the lynx of the 
northern forests extends in a special variety, or species (Lynx isabellina), into the plateau of Tibet, where it shows some adaptations to rocky and barren country, instead of to forest-covered ground. The Indian wild $\operatorname{dog}$ (Canis deccanensis) shows a similar extension of habitat from the forests of India into the wastes of Tibet. It is a social animal, the packs hunting down wild sheep, antelopes, \&c. In the Himalayas and Tibet also, the common fox is replaced by a variety with thick fur and a very large brush.

We come next to the bears, of which several occur in mountain regions. Thus the Himalayas and Tibet have special varieties of the brown bear, which, like bears in general, is very resistant to cold on account of the thickness of its coat. Its very indiscriminate appetite also makes it possible for it to exist on many different kinds of ground. The Atlas Mountains have a closely related form, and in the Rocky Mountains the large and powerful grizzly bear (Ursus horribilis) occurs at considerable elevations, though also descending to the plain. In the wooded regions of the Himalayas occurs the black bear (Ursus torquatus), chiefly a vegetable feeder and an excellent climber, which in the Himalayas does not voluntarily quit the forest. It is not known in Tibet, and differs from most bears in the short and thin coat. The necessary resistance to cold is apparently obtained by the great oiliness of the skin, especially in autumn, when the animal is very fata means of providing for the winter time of scarcity. The Andes of South America contain another mountain bear, in the shape of the spectacled bear (Ursus ornatus). Africa south of the Sahara has no bear.

That forested region of Eastern Tibet which lodges the Tibetan macaque and the Tibetan langur has still 


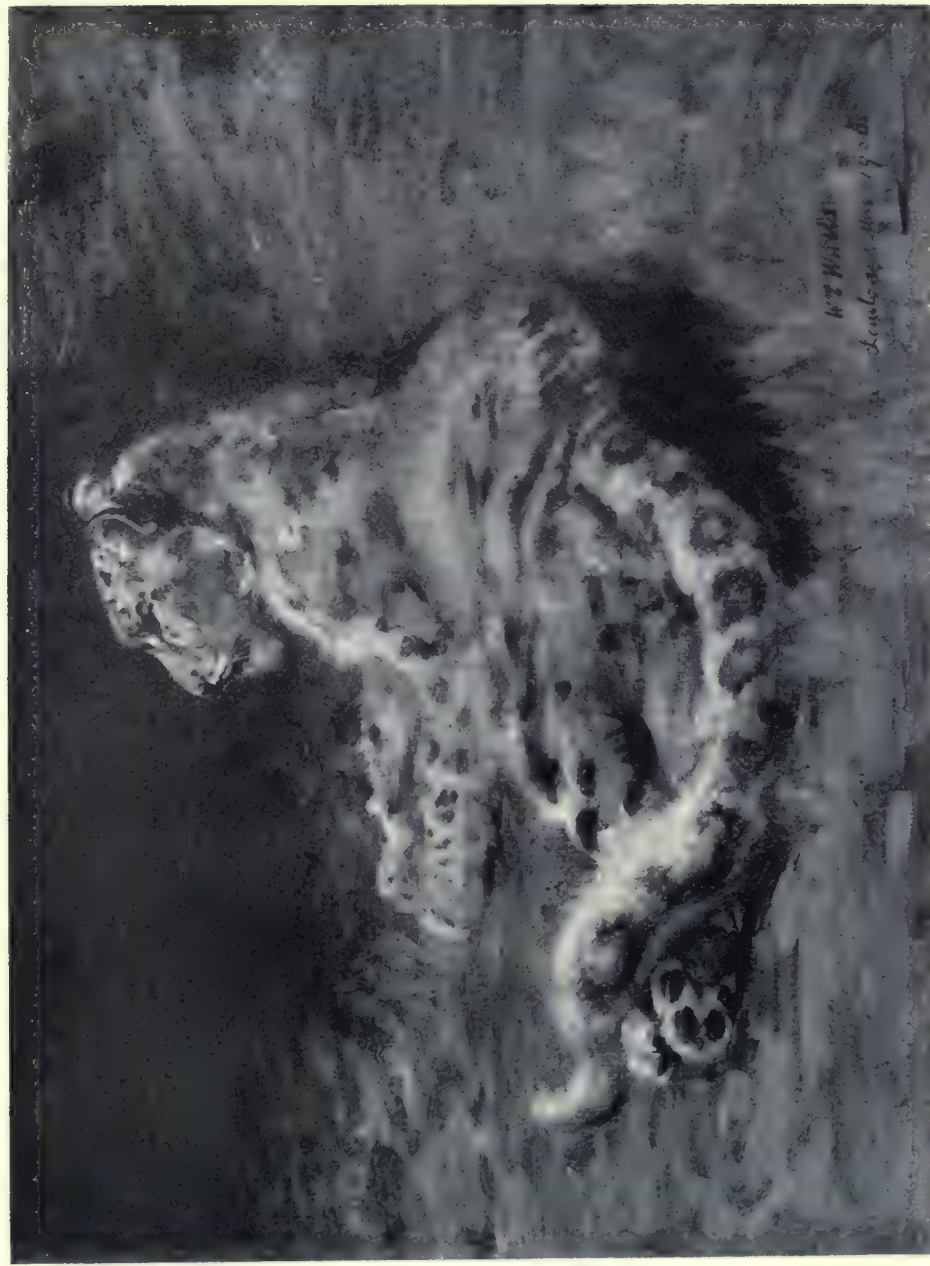

Oै 


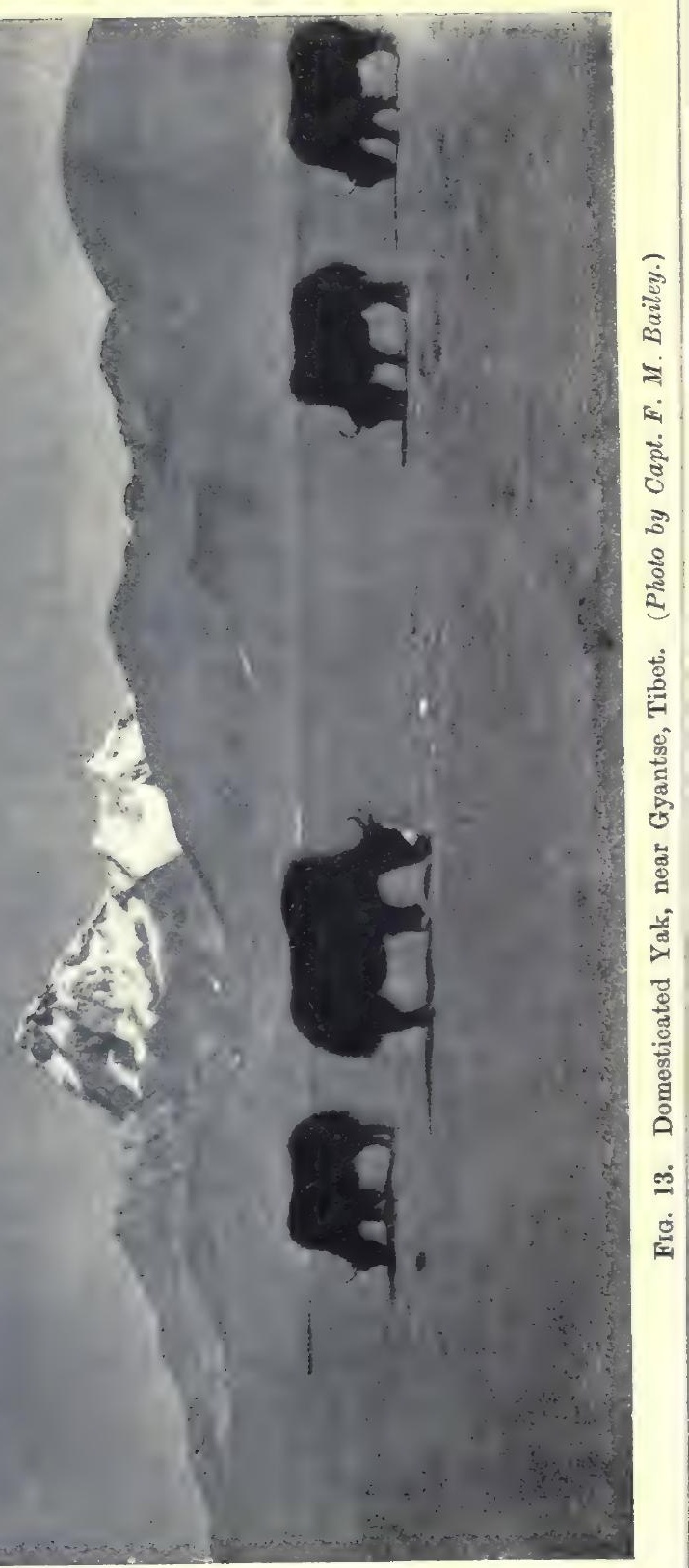


another remarkable form in the parti-coloured bear (Aeluropus melanoleucus). It is curiously marked in black and white, has a very thick close fur, and enormously powerful jaws. The latter feature is remarkable in view of the fact that the animal seems to be purely vegetarian in tastes. It is said to inhabit the bamboo thickets which in this region ascend the damp valleys up to a height of nearly 10,000 feet. The young shoots of bamboos form the greater part of its food, and it is stated to be an excellent climber.

A curious little animal called the panda (Aelurus fulgens), once believed to be related to Aeluropus, occurs at considerable elevations in the south-eastern Himalayas and feeds chiefly on vegetable matter, especially bamboo shoots. The panda is an arboreal animal, somewhat fox-like in appearance, and is now believed to be most nearly related to the carnivorous raccoons of America, which are forest animals, sometimes, as in the case of the forms called coatis (Nasua), ascending to a considerable elevation above sea-level.

The comparative rarity of large and fierce carnivores helps to explain, as we have seen, the abundance of ungulates in mountain regions. Beginning with the cattle, we may note that just as one form-the muskox-is admirably adapted for life on the tundra, so another-the yak of Tibet-is perfectly fitted for life at a great elevation. This animal, the Bos grunniens of zoologists, is characterized by its long hair, and by its great agility and hardiness. It ascends to a height of 20,000 feet above sea-level, and while impatient of heat, is extraordinarily resistant to cold, and is capable of thriving on the coarsest of herbage. As is well known, the animal is used as a beast of burden in Tibet, on account of its great endurance. Travellers have often 
described the way in which the animals push their way through snow, or across glaciers, or through icy glacial torrents. They present a remarkable instance of adaptation to very unfavourable conditions, but in this connexion it is important to remember the great extent of the plateau of Tibet, and its great uniformity.

The yak is the only member of the cattle group with special adaptations to mountain life. Passing to the sheep we find that there are eleven well-defined wild species. Of these, eight inhabit various mountain chains and plateaux in Asia, one, the Indian urial, extending to relatively low ground in the Punjab and Sind; one form is found in the Rocky Mountains, but this, the Bighorn, is so closely related to the wild sheep of Kamchatka as to suggest a former land connexion across the Bering Strait. Of the remaining two species, one, the mouflon, occurs in mountain regions in Sardinia and Corsica, and the other, the Barbary sheep, is found on the southern slopes of the Atlas Mountains in Africa. We are thus justified not only in saying that sheep are definitely mountain animals, but also that the home of the genus is the mountainous regions of Central Asia, only the urial extending south of the Himalayas. The habits of all are generally similar, and have been already alluded to. To the preceding description we may add a brief note on the wild sheep called argali, of which one form (Ovis ammon) is found at moderate elevations in Mongolia, while the other (Ovis hodgsoni) occurs at great heights on the Tibetan plateau. Both are large animals, reaching the size of a small donkey, and having short and close hair. The food consists of grass, mingled in winter with mosses and lichens, and, like the reindeer of the tundra, the animals in winter seek exposed positions where the wind sweeps away 


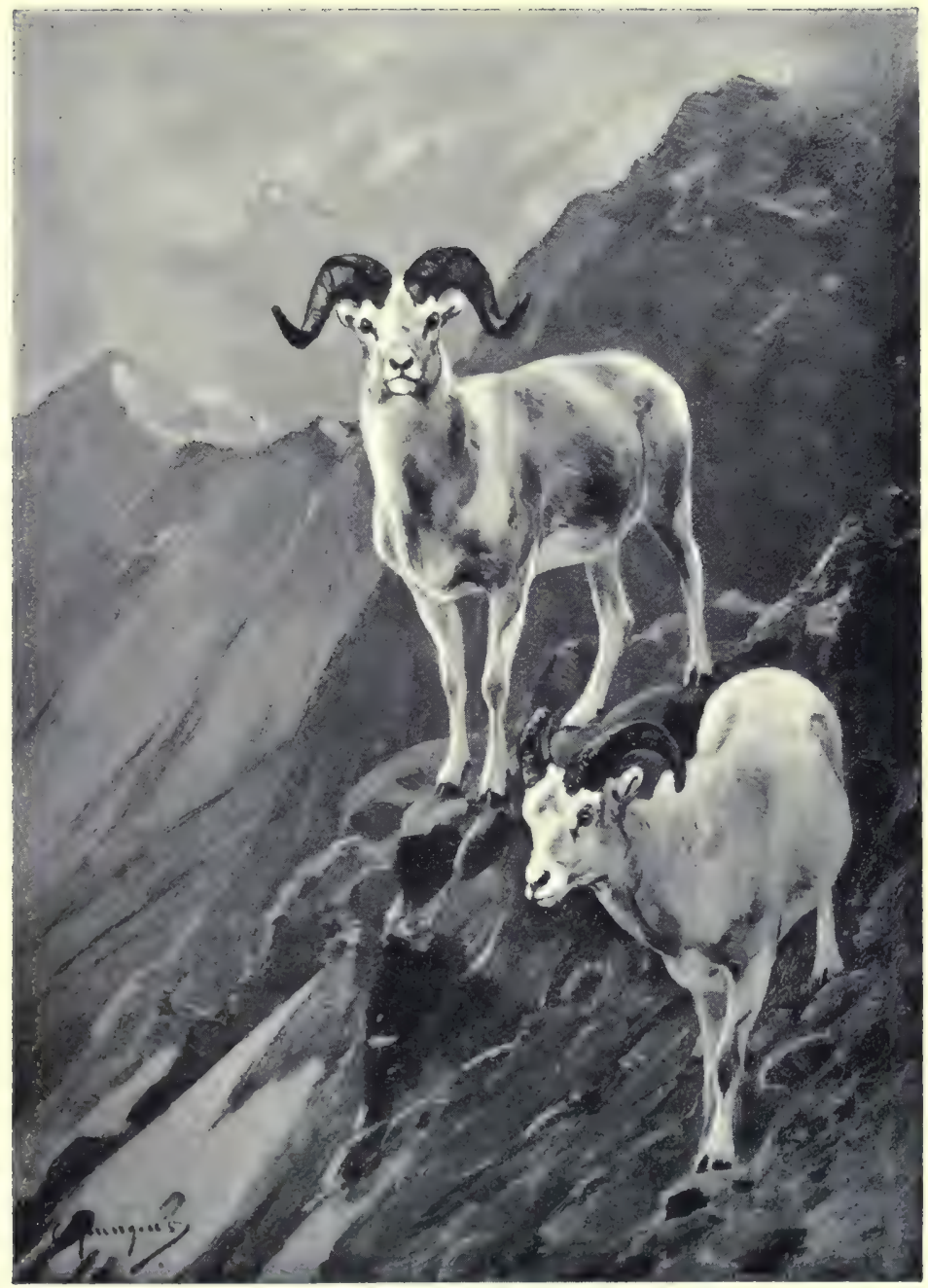

Fig. 14. The Alaskan Wild Sheep (Ovis dalli), a form closely related both to the American Bighorn and to the wild sheep of Kamchatka. (Photo by the Biological Survey, U.S.A.) 


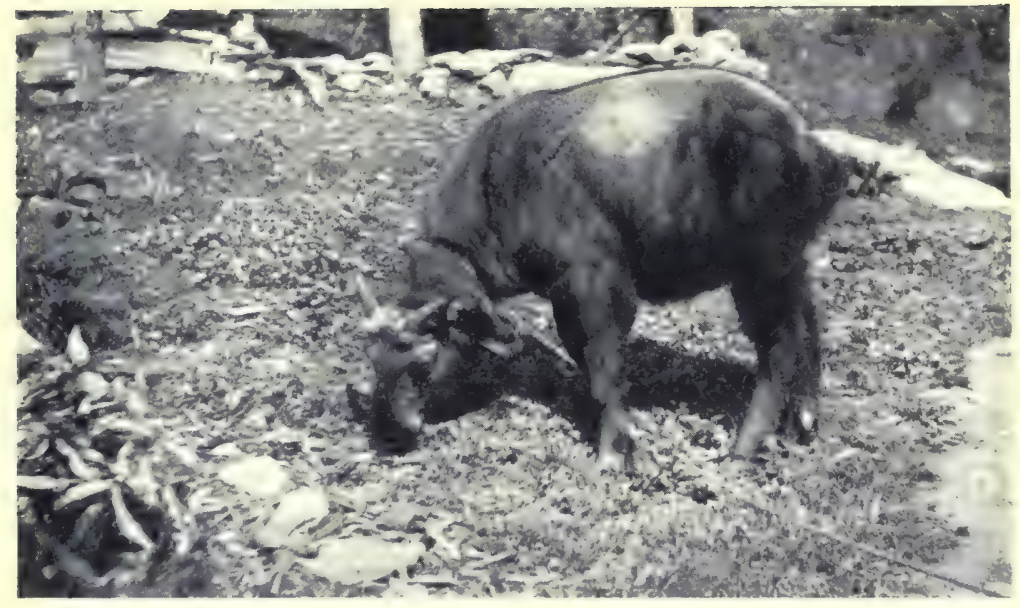

FIG. 15. A young Takin in captivity in Tibet. The large lateral hoofs are a special feature. (Photo by Capt. F. M. Bailey.)

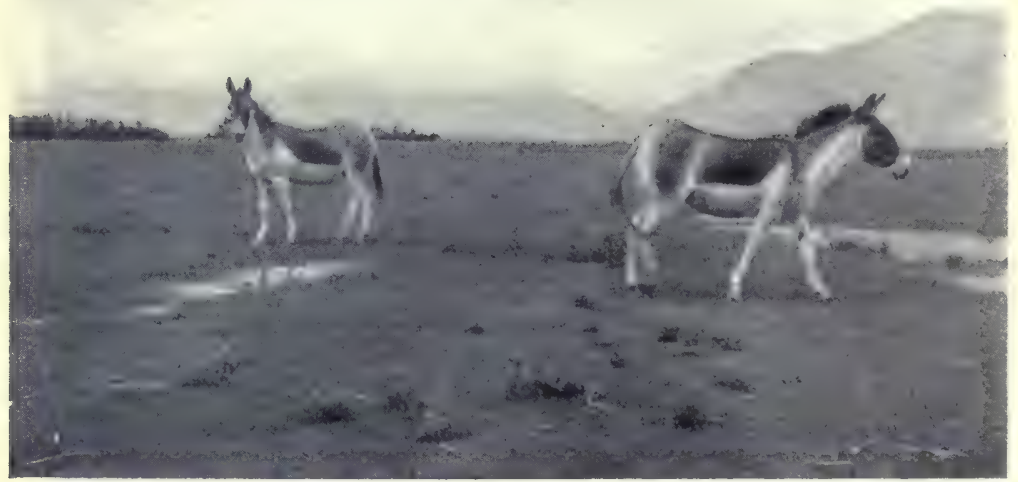

FIG. 16. Half-wild Kiang, near Gyantse, Tibet. The type of country is very characteristic. (Photo by Capt. F. M. Bailey.) 
the snow. In the male the horns are large and massive, while the female has smaller and thinner structures. Like all their allies, the animals are very wary and agile.

The goats are mostly distinguished from the sheep by the presence of a beard on the chin, and by the strong odour of the males. They also are mountain animals, their distribution showing a remarkable analogy to that of the sheep, except that there is no true American goat. Some ten species of wild goat occur in the Old World, and of these, two species, the ibex of Abyssinia and the Arabian wild goat, which extends into Upper Egypt, enter Africa. The remainder occur in the mountain regions of Europe or of Central Asia. In Europe there is a curious tendency for the (isolated) mountain chains to have peculiar species of goats. Thus there is a Spanish wild goat, sometimes called an ibex; the Alpine ibex, now exterminated as a wild animal, is peculiar to that chain, and no less than three species of wild goats inhabit the Caucasus. Of the Asiatic species the most attractive is the markhor (Capra falconeri) of the Himalayas, with long spirally twisted horns in the male, and fringes of hair on the chest and shoulders in addition to the beard. Closely related to the goats are a series of smaller genera, such as Hemitragus, including the tahr of the Himalayas, and another species found in the Nilgiri Hills of Southern India, there being thus a curious separation between the range of the two species. The gorals (Cemas) and serows (Nemorhoedus) are Himalayan and Tibetan forms, which seem to connect the goats with the antelopes, while the takin of Eastern Tibet is a large form with curiously shaped horns. The interest of these genera is merely that they emphasize what has 
been said already as to the number of kinds of ungulates found in Tibet, the Himalayas, and adjacent regions.

Though America has no true goat, there occurs in the Rocky Mountains a white ungulate, about the size of a large sheep, and apparently related to the serow, often called the Rocky Mountain goat. Its hair is very long, and the animal seems to be very resistant to cold, spending its time near the upper limit of the forest, although it also descends at times to sea-level. Nearer the antelopes than the goats is the chamois (Rupicapra tragus), a rather clumsily built animal with short hooked horns, stumpy tail, and feet especially fitted for scrambling about rocks. It is widely but discontinuously distributed over the mountain regions of Europe, but is found fossil on the low ground also.

Of the true antelopes many of the gazelles ascend to considerable elevations, notably the Tibetan gazelle (Gazella picticaudata), which ranges up to 18,000 feet, and is less shy than most gazelles. Tibet has also a peculiar antelope, the chiru (Pantholops hodgsoni), an animal in which the male has a curious swollen nose and long horns. This form occurs at the same heights as the gazelle, sometimes in very large herds. In the distended nose it somewhat resembles the saiga of the Siberian steppes.

Of the vast number of African antelopes some frequent hill regions, notably the rhebok (Pelea capreola) of the south and east, which has the habits of a chamois. Another agile and chamois-like African form is the klipspringer (Oreotragus saltator), found at heights up to 8,000 or 9,000 feet in Abyssinia, and having very small feet, which apparently give it great sureness on the rocks. Both its Dutch and Latin names refer to its jumping powers. 


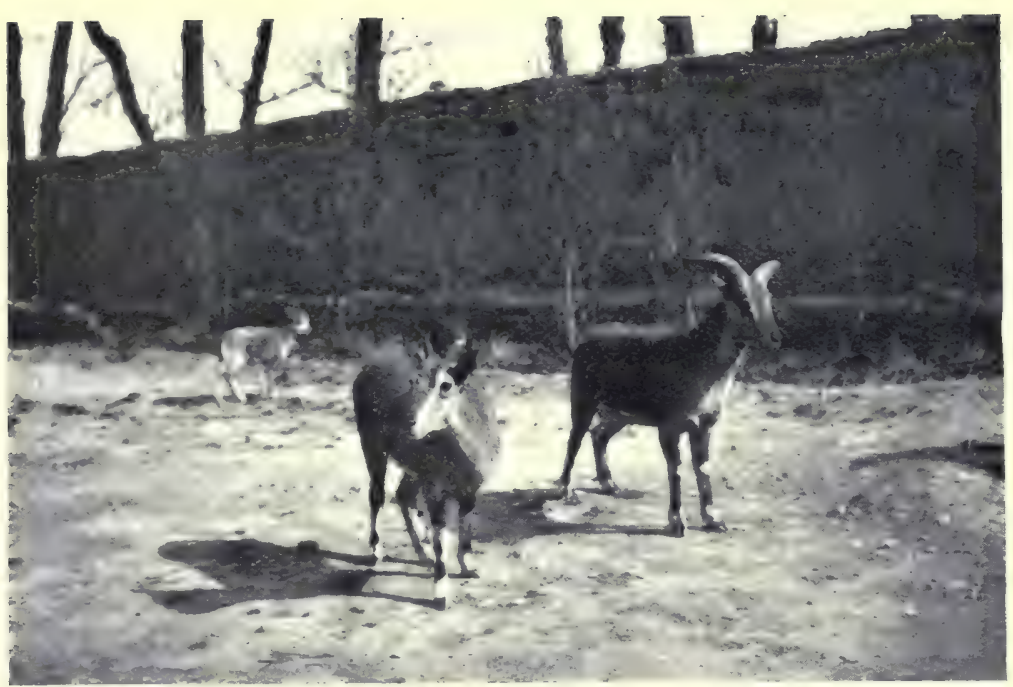

Fra. 17. The Bharal or Burhel, one of the wild sheep of Tibet (Ovis nahura). Note the curious markings on the legs. (Photo by Capt. F. M. Bailey.)

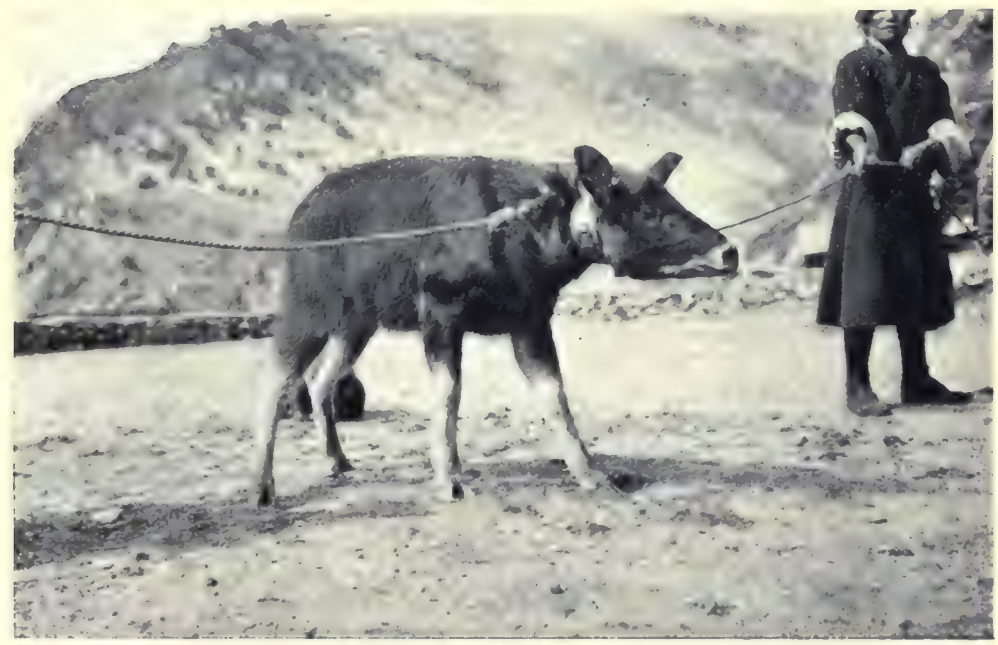

FIG. 18. The Serow of Tibet. (Photo by Capt. F, M. Bailey.) 


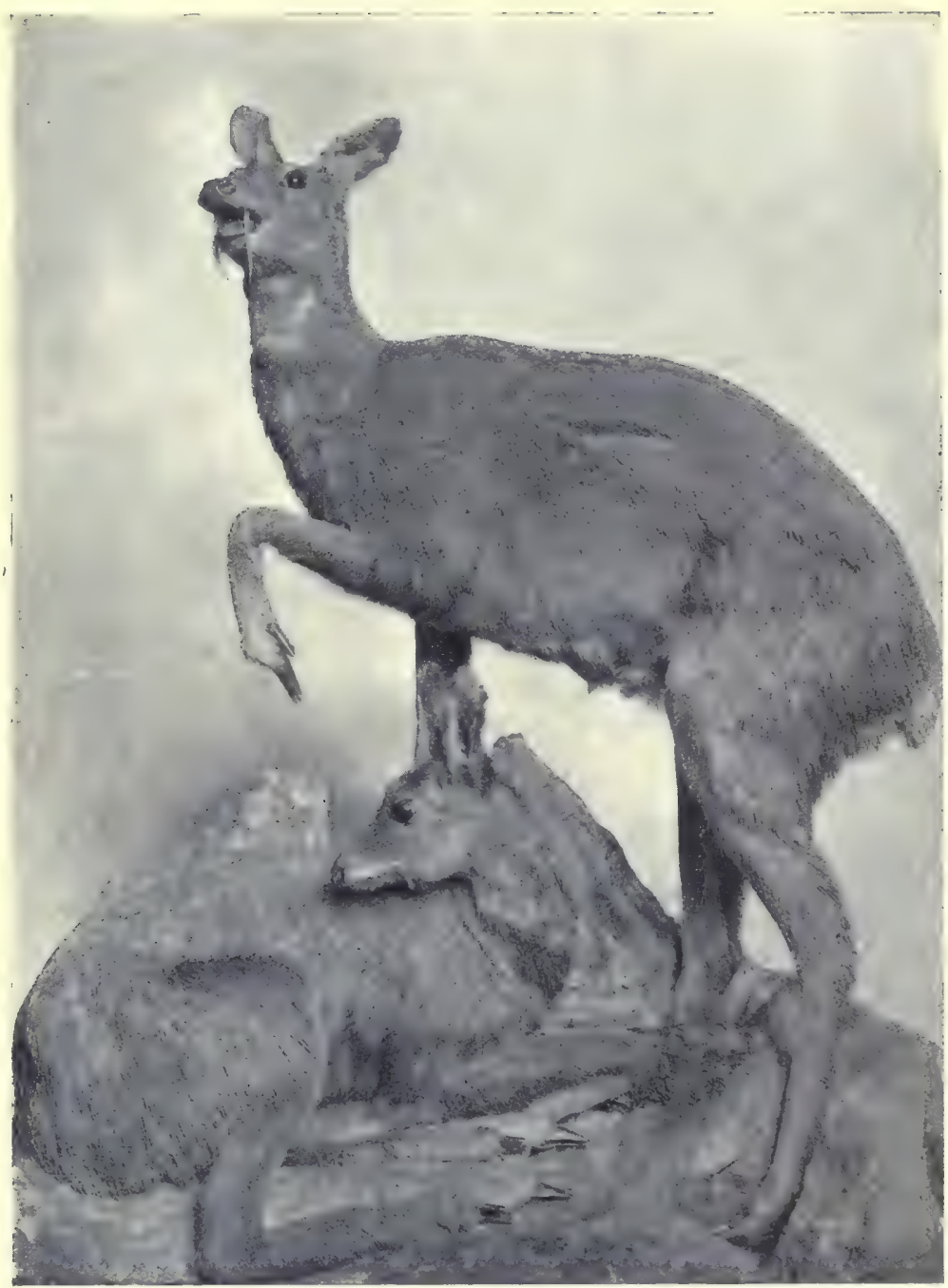

FIG. 19. Musk-deer. Note the large lateral hoofs, the coarse coat, the prominent canines of the male. (From a specimen in the Royal Scottish Museum.) 
Of the deer we may note that the somewhat primitive musk-deer (Moschus moschiferus) occurs at considerable elevations in the Himalayas, being usually found in the birch forest above the zone of pines. From the Himalayas the musk-deer extends northwards into Central Asia and Siberia. It has unusually large lateral hoofs, which apparently assist it in obtaining foothold on hard snow or rocky ground, and feeds largely on twigs and buds. The coat is thick, the hair being long and coarse, and giving much protection against cold. The kiang (p.60) occurs in Tibet as well as in the Mongolian steppe.

As already explained, South America is singularly poor in ungulates, but in the Andes two members of the camel family occur, the guanaco and the vicuna. These animals have very soft feet, and though they ascend to the highest ridges, they avoid equally rocky regions and snow and ice. At the wet season they go high up the mountain sides, but when the vegetation there dries up at the approach of the hot season they descend to valleys watered by springs or perennial streams. The long coat affords protection against cold, and the animals seem never to descend below 6,000 or 7,000 feet in the hotter parts of their range. That this is partly due to intolerance of heat seems indicated by the fact that the guanacos come down to sea-level in Patagonia. The vicuna has a more limited extension, being confined to the district between Southern Ecuador and Central Bolivia. One of the American tapirs also (Tapirus roulini), ascends to an elevation of 7,000 to 8,000 feet above sea-level in Ecuador and Colombia, without, apparently, showing any special adaptations to mountain life. In the Andes of Chile and Ecuador also occur the tiny deer of the genus Pudua, which are no bigger than hares. 
The very aberrant and somewhat primitive ungulates called hyraces (Procavia) show some interesting features as regards adaptation to mountain life. All are small animals, very like rodents in appearance and habits, and resembling most of those animals also in their helplessness and want of swiftness. When small herbivores cannot defend themselves actively, cannot escape by flight, and cannot burrow, only two possible means of escaping their enemies remain. These are to haunt rocky country where the fallen stones and blocks offer natural shelter, or to seek the trees. Both methods are adopted by the hyraces. The common hyrax of Syria gets its name of rock coney from its habit of frequenting rocks, where it pops in and out of the crevices as a rabbit pops in and out of its burrow. As rocky country is more frequent in mountainous regions than elsewhere, we find that the ground hyraces usually occur in elevated districts, though frequenting suitable ground elsewhere in addition. They have four welldeveloped toes on the fore foot, and three on the hind, and the size of the feet, with the spreading toes, enables them to scramble about rocks very easily. The tree hyraces, without any notable difference in structure, show a marked difference in habit in that they live entirely among trees, in which they feed, breed, and sleep. Being relatively hardy they occur at great elevations, e.g. at from 7,000 to 11,000 feet in the forests of Kilimanjaro. In both the ground and tree forms, those attaining a great elevation seem to differ chiefly in their thicker coats. All the hyraces are confined to Africa and the adjacent regions, e.g. Syria and Arabia.

Among the true rodents we find, as already indicated, many mountain species. In the consideration of steppe faunas something was said of marmots (Arctomys), 


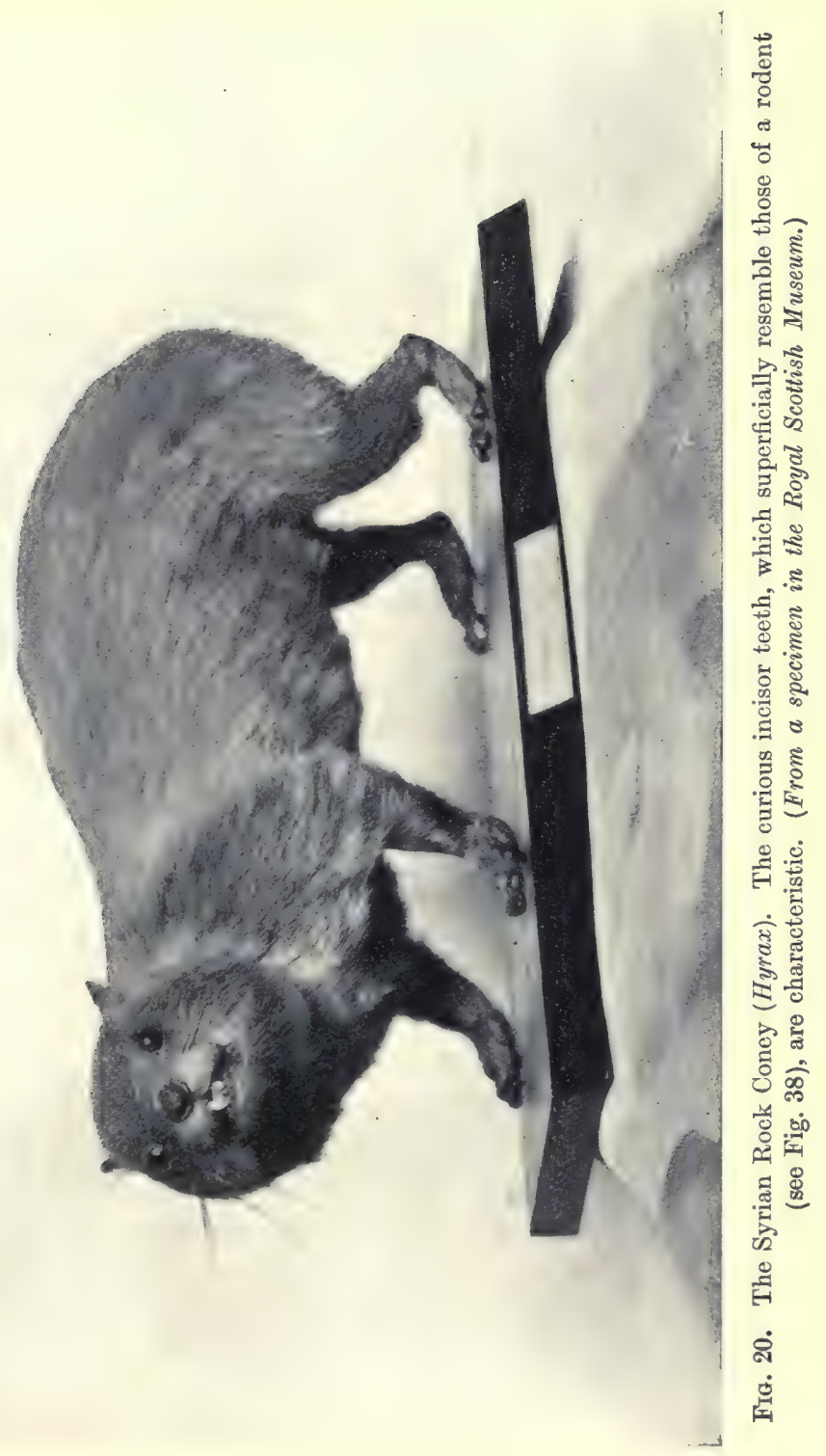




$$
\text { • }
$$


and as these are typical denizens of cold steppes, it is natural that they should occur also in the steppe region of lofty mountain chains. In Europe the Alpine marmot is found in the Alps, the Pyrenees, and the Caucasus, though it once occurred on the low ground also. In Central Asia many kinds of marmots occur, though none extend to the south of the Himalayas. The Himalayan marmot, allied to the bobac of the steppes, is limited to the region above the tree limit, that is, to the barren wastes which most nearly resemble the home of the bobac, the usual elevation being 12,000 to 13,000 feet. In North America we have similarly a Rocky Iountain marmot, resembling in habits the Alpine form.

The voles (Arvicola) are well represented in mountain regions, the genus showing a remarkable tendency to run into varieties, or species, in particular localities. Thus in the Alps and Pyrenees there occurs the very curious Alpine or snow vole (A. nivalis), which is sometimes pure white, but is structurally very near the continental field vole and the bank vole. It differs notably from these forms in its habits, for it lives high up the mountains, even above the snow-line. It has been found on the Finsteraarhorn at a height of 12,000 feet, but on account of its habits is rarely seen. It appears to live actually beneath the snow, making runs beneath it after the fashion of the Aretic lemming, in its search for vegetation. Other mountain species occur in the Himalayas and Tibet.

South America, with its paucity of ungulates, has a considerable number of peculiar mountain rodents. Thus the common chinchilla (Chinchilla lanigera), with its soft thick fur, inhabits the higher parts of the Andes, living in rocky ground, and displaying marvellous agility. A larger form (Lagidium cuvieri) inhabits the 
same regions, and has similar habits. The pacas of the Brazilian woods are represented on the mountains by a smaller type (Coelogenys taczanowskii). Some of the cavies also ascend to mountain regions, notably the Bolivian cavy (Cavia bolivensis), which lives in large societies in the upper part of the Andes, tunnelling the ground in all directions with its burrows.

As to the hare-like rodents, we have already noted that the picas or tailless hares occur at great elevations in the Himalayas in addition to frequenting the Siberian steppes, thus illustrating the same conditions as the marmots. The mountain hare of Europe is closely related to the Arctic hare already discussed (p. 22). Tibet has several species of hares, the most interesting being Lepus hypsibius, which does not descend below 14,000 or 15,000 feet.

Among birds we find that many kinds of birds of prey haunt mountains, though they are not necessarily confined to them. Of wide distribution is the laemmergeier (Gypaëtus barbatus), found in the mountain ranges of Europe, North Africa, and Central Asia, which apparently feeds largely on carrion and animals not killed by itself. The even more widely distributed Golden Eagle (Aquila chrysaëtus), on the other hand, kills its own prey, which consists of rodents, the young of ungulates and game birds. Other forms which may be mentioned are Bonelli's hawk-eagle (Nisaëtus fasciatus), found in the Alps as well as in Asia and North Africa, and the magnificent condor (Sarcorhampus gryphus) of the Andes of South America. In tropical countries some of the parrots range up mountain sides, and in this connexion it is curious to note that the New Zealand kea (Nestor notabilis), which inhabits barren mountain sides, has become virtually a bird of 
prey since the introduction of sheep into that area. At first confining itself to dead sheep, the bird is stated now to kill diving animals with blows of its powerful beak.

As is to be expected from the conditions, game birds are frequent on mountains. Thus in the Alps we find the ptarmigan, and it is also found on the other mountain ranges of Central Europe, on most of which the black grouse or capercaillie is found. In the mountain ranges of South Europe generally the Greek partridge (Caccabis saxatilis) lives. To the pheasant family belong the snow-partridge (Lerwa nivicola) of the Upper Himalayas, and the very large snow-cock (Tetraogallus himalayensis) of the Himalayas and Tibet. Other examples might be given, but these sufficiently indicate the two essential facts-that some of the game birds of the tundra and pine forests extend to the mountain ranges of the interior, and that the great elevated area in Central Asia has its peculiar game birds, as it has its peculiar ungulates and its peculiar rodents.

In regard to other types of birds, a few words may suffice. In the Alps the commonest member of the crow family is the Alpine chough (Graculus alpinus), smaller than the common form, and having a yellow instead of a red beak. In the pine forest of mountains, especially in the Tyrol, occurs the citril finch (Chrysomitris citrinella), while high up on the Alps is found the beautiful black and white snow-finch (Montifringilla nivalis), allied forms of which also occur on the mountains of Central Asia. Both in the Alps and in Central Asia is found the curious wall-creeper (Tichodroma muraria), which lives on insects and spiders, found by probing in rocky crevices. In shape and flight this bird has a remarkable resemblance to a large butterfly, as it hovers over the rocks, using its long 
sharp bill to pick out its prey just as a butterfly uses its proboscis to suck up nectar. In the Alps another frequent bird is the rock-thrush (Monticola saxatilis), a brightly coloured bird, extending up into the barren regions of the mountain sides. In the Alps and Pyrenees also the Alpine accentor (Accentor collaris) is common. With the exception of the hedge-sparrow, most of the accentors are mountain-haunting birds, having strong feet and legs, which fit them for progression over rough ground. Of the summer visitors to the Alps, we may note the Alpine swift (Micropus melba), which is larger than the common form.

Reptiles do not appear to show any special adaptations to mountain life. It is remarkable that the common viviparous lizard (Lacerta vivipara) ascends to a height of 10,000 feet in the Alps, but then this hardy animal also extends into Siberia. The common viper (Pelias berus) also occurs in the Alps, though not at such a great elevation, and it has a similarly wide range.

As regards amphibians, there is some evidence that the mountain habitat tends to produce darkening of the colour. Thus the common frog (Rana temporaria) occurs in the higher parts of the Alps in a dark-coloured variety, and the same thing is said to be true of the common toad (Bufo vulgaris). Similarly the Alpine salamander (Salamandra atra) is black in colour, and unspotted, thus differing markedly in colour from its allies. This form shows a peculiar adaptation to life at considerable elevations, in that it only produces two young at a time, and these pass through the gilled stage within the body of the mother, so that at birth they are lung-breathers like the parents, and not gill-bearing tadpoles. As the animal ascends to an elevation of 9,000 feet, it is obvious that ice-free water for the 
relatively long period of larval development would not be easy to find-hence the adaptation described. In mountáin streams in China and Japan occurs Siebold's giant salamander (Cryptobranchus maximus), reaching a length of over five feet.

Relatively few species of fish occur in mountain streams, doubtless on account of the coldness of the water.

In regard to the lower forms of life we need only note that with the great development of flowering plants during the short period of summer in most mountain regions, we have a great development of insects, especially butterflies. There is a marked general resemblance between the insects of mountains and of polar regions, due doubtless partly to the similar physical conditions which prevail in the two regions.

ReFERENCES. Kobelt's book has a good chapter on mountain animals, and Tschudi's Thierleben der Alpenwelt (ninth edition, Leipzig, 1872) should also be consulted. An account of Alpine animals will also be found in Anderegg's Schweizerische Alpwirtschaft (Berne, 1899). There are a number of works on travel in Tibet and the neighbouring regions which give accounts of various of the characteristic animals. Among these may be mentioned: Demidoff's After Wild Sheep in the Altai (London, 1900); Adventure, Sport, and Travel on the Tibetan Steppes, by W. N. Fergusson (London, 1911) ; P. T. Etherton's Across the Roof of the World (London, 1911). 


\section{CHAPTER V}

\section{THE FAUNA OF THE TROPICAL FOREST}

JUST as the tropical forest as contrasted with the temperate is remarkable for its wealth of species of trees and for the luxuriance of its undergrowth, so its fauna is remarkable for the number of special types. Adaptations to life in the tropical forest occur in almost all groups of animals, and some orders, like the Primates among mammals, are, roughly speaking, fitted for this habitat alone, for relatively few of their members occur outside this region.

We may begin by a few words upon the special conditions which reign here. To begin with, food is abundant all the year round, for there is no seasonal check to vegetation such as occurs in temperate climates. The absence of seasons, in the sense in which they occur in higher latitudes, makes possible the occurrence of many fruit-eating animals, for fruits occur at all seasons. Thus the anthropoid apes are fruit-eaters; the fruit-bats have the same diet, as the name indicates; parrots eat seeds and fruits, and so on. For such forms life in colder climates is impossible.

The constantly high temperature, at least during the day, makes a warm coat unnecessary, so that animals producing valuable furs are relatively rare. The same condition makes reptilian life abundant, for the heat of the sun is available to hatch the eggs. The high temperature also results in abundance of insects, which again feed many other animals.

As the tropical forest is characterized by a very 
luxuriant undergrowth, and by great density, we find not a few arboreal forms which never voluntarily put foot to the ground. This is true of the South American sloths, whose feet are quite unfitted for terrestrial progression, also of some of the monkeys, of forms like the flying lemur, and so forth. Where the forest is less dense than usual, such purely arboreal forms must at times find it difficult to pass from one tree to another, and it is notable that very many different kinds of arboreal animals have some form of parachute, giving them partial powers of flight, or at least of taking long leaps. Thus we have flying frogs (Rhacophorus); a flying lizard (Draco volans); flying phalangers; African flying squirrels, differing in several respects from the forms found in temperate climates; the so-called flying lemur, \&c. The true lemurs do not possess parachutes, but some forms (e.g. Galago) have the ankle greatly elongated, which gives them a very froglike appearance, and enables them to leap from one tree to another.

As regards the structure of the feet, two conditions occur in the more highly specialized forms. Sometimes, as in the sloths of South America, the fingers and toes are converted into hooks, incapable of being separated from one another, and having as their sole function the suspending of the body from the branches of the trees. This condition is suggested also in some of the thumbless monkeys, but in general the monkeys and their allies, together with some other animals, show a character which gives as great security of grip, while conducing to greater freedom of movement and greater agility. This is the modification of one digit on both hands and feet, which is so inserted that it can be opposed to each of the other digits, producing 
the condition described as the opposable thumb and great toe. At the same time the extremities of the digits tend to be flattened, giving more gripping power, and with the flattening of the finger-tips a nail tends to replace a claw. This condition is only gradually acquired in the Primates, the lower forms having pointed fingers, with nails instead of claws. As already suggested also, the hand in certain Primates tends to become hook-like, the thumb being absent or minute. Only in man among the Primates is the great toe not opposable.

But this condition of one (or more) digit being opposable to the other is not confined to the Primates. In the opossums and phalangers, primitive mammals whose young are born in a very undeveloped state, the great toe is also opposable. Again, in parrots among birds, and the chameleon among lizards, a gripping hand and foot is produced by certain digits being opposable to the others.

Still another adaptation to arboreal life is seen in the prehensile tail. This also occurs in widely separated groups. We find it in the chameleon, in the New World monkeys, in opossums, in some of the South American ant-eaters, in the South American tree-porcupines, in the kinkajou, and so forth. Like the hookshaped hand it tends rather to occur in relatively sluggish forms than in those whose agility is sufficient to enable them to recover easily from a false movement. Thus Brehm notes that the 'five-handed' New World monkeys are not nearly such good climbers as the four-handed monkeys of the Old World, which never have prehensile tails.

Some minor adaptations to the arboreal life may next be touched upon. As great freedom of movement. 
of the limbs is necessary, we note that these are not tied down to the body by skin, as in most quadrupeds. A comparison of such animals as dog or cat with monkey or man will make this point clear. Again, as the arms are of very great importance in arboreal animals, we find that they are proportionately very long. In the sloth, in the monkeys and lemurs, this is very noticeable. With the loss of other arboreal characters man has also lost his long arms, these being proportionately very much shorter than in the apes.

Another common feature of arboreal mammals is the presence of collar-bones, which tend to be lost in quadrupeds. This gives such mammals a characteristically broad chest, easily seen on comparing the position of the fore-limbs in, e.g. a sheep, and in a monkey. It is the presence of the clavicle which permits of the upward movement of the arm, so necessary in climbing, a movement impossible to pure quadrupeds like antelopes and deer. Again, in quadrupeds, and notably in the swift ungulates, the two bones of the forearm and the corresponding bones of the foreleg tend to fuse, in order to give a rigid support to the body; but in most arboreal animals they are separate, giving much greater freedom of movement to wrist and ankle, but preventing the animals from acquiring any great speed on the ground, even when their fingers and toes make it possible for them to attempt to run.

Finally, arboreal forms have often only one or two young at a birth, and the mammae are frequently pectoral in position, for only thus can the young be carried without loss of balance by the mother.

To this account of the chief peculiarities of arboreal animals we may add a few words upon the tropical forest considered as a source of food. In the tropical 
forest there is, as already indicated, no seasonal check to vegetation, and therefore no marked variation in the amount of vegetable food available. But there is much evidence to show that the total amount is less than might be expected. The tropical forests of New Guinea yield almost no food for man, so that recent expeditions have had to import every particle consumed, and have at times run almost the same risks of starvation as explorers in the tundra, even when armed with modern weapons. Elsewhere there are few human groups indeed who manage to subsist solely on the products of the tropical forest, and those who do, e.g. the Congo pygmies and the Philippine negritos, seem to be few in number, and yet to suffer from chronic starvation. They do not reach a high state of civilization. The fact that all the more intelligent of the forest animals soon learn to rob man's plantations, or to prey upon his flocks and herds, suggests that the wild mammals are no better off than forest-dwelling man. The reasons why the conditions should be relatively unfavourable in the tropical forests are perhaps a little obscure, but we note among them that the physical conditions most favourable to plant life are not those best suited to the mammalia at least. Further, the enormous number of plant species in the tropical forest diminishes the chance that a particular useful species will occur in numbers. The fact that trees of commercial value only occur in isolated specimens is a great barrier to the exploitation of the tropical forest by man, and it has doubtless also its effect on the wild animals. If there is one Cembra pine loaded with ripe seeds in the taiga, there will almost certainly be many in the vicinity; if the squirrels find one hickory tree in the American woods whose nuts are 
ripe, there will also be many others. On the other hand, just as man has to hunt for individual camphor trees in the Formosan forests, or for individual rubber trees in the Brazilian forest, so must the fruit-eating wild mammals hunt through the forest for the scattered trees whose fruits supply their hunger. This is perhaps part of the reason why the tropical forest seems to the explorer to be deprived of animal life save insects and reptiles, part of the reason why the forest mammals mostly occur in relatively small numbers.

If we consider in systematic order the groups of animals showing adaptation to life in the tropical forest, we naturally begin with the Primates, whose members display practically all those characters which we have described. Their long arms and short legs, their opposable thumbs and great toes, their strong clavicles, in some instances their prehensile tails, their pectoral mammae, and the reduction in the number of young at a birth-all these fit them for life among the trees. On the other hand, their generalized teeth, the number of fingers and toes present, the condition of the bones of the limbs, and other characters, show their descent from relatively primitive ancestors, specialization showing itself chiefly in brain development, and in the fact that the hands are progressively suited for many uses, in addition to their prime function as aids in climbing.

One point of structure is interesting. Most herbivorous, or partially herbivorous, animals are specially exposed to danger when feeding, for large quantities of vegetable food must be taken. Many of the ungulates have an arrangement whereby the hastily swallowed food can be stored within the alimentary canal, careful mastication taking place later. In most of the monkeys, on the other hand, food can be temporarily stored in 
cheek-pouches, to be chewed and swallowed later. This arrangement is far from universal-it is absent in all the New World monkeys and in some Old World forms, but it is nevertheless common.

As, with the exception of baboons, and of the Tibetan and Himalayan forms already mentioned, all Primates are denizens of the tropical forest, it is impossible to name all the members of the order here-a few examples only can be picked out.

Apart from man, the highest living forms are the anthropoid apes, of which there are four living kindsthe gorilla and chimpanzee from West Africa, the orang in Sumatra and Borneo, the gibbons from South-East Asia. Like man himself, and like most Primates except the lemurs, the anthropoid apes are diurnal in habit, not nocturnal, like many mammals. The gorilla and chimpanzee resemble man in the region which they inhabit in having dark skins and hair; the body is of course much more hairy than in man. The gorilla, which has a very limited distribution, is a dweller in dense forest regions, and is an extraordinarily powerful animal. It is purely vegetarian and fruit-eating, sharing a taste for some fruits with the negroes of the region, and also consuming some which the negroes do not care for. The fact that it robs human plantations shows that food is sometimes scarce, even though the animals appear to be very few in number. Wild plantains and 'palm cabbage' are freely eaten.

The chimpanzee, which extends into Central Equatorial Africa apparently, at least at times, eats some animal food in addition to fruit.

Very different in appearance from the gorilla and chimpanzee is the orang, with its very long arms and its covering of long reddish hair. The way in which 


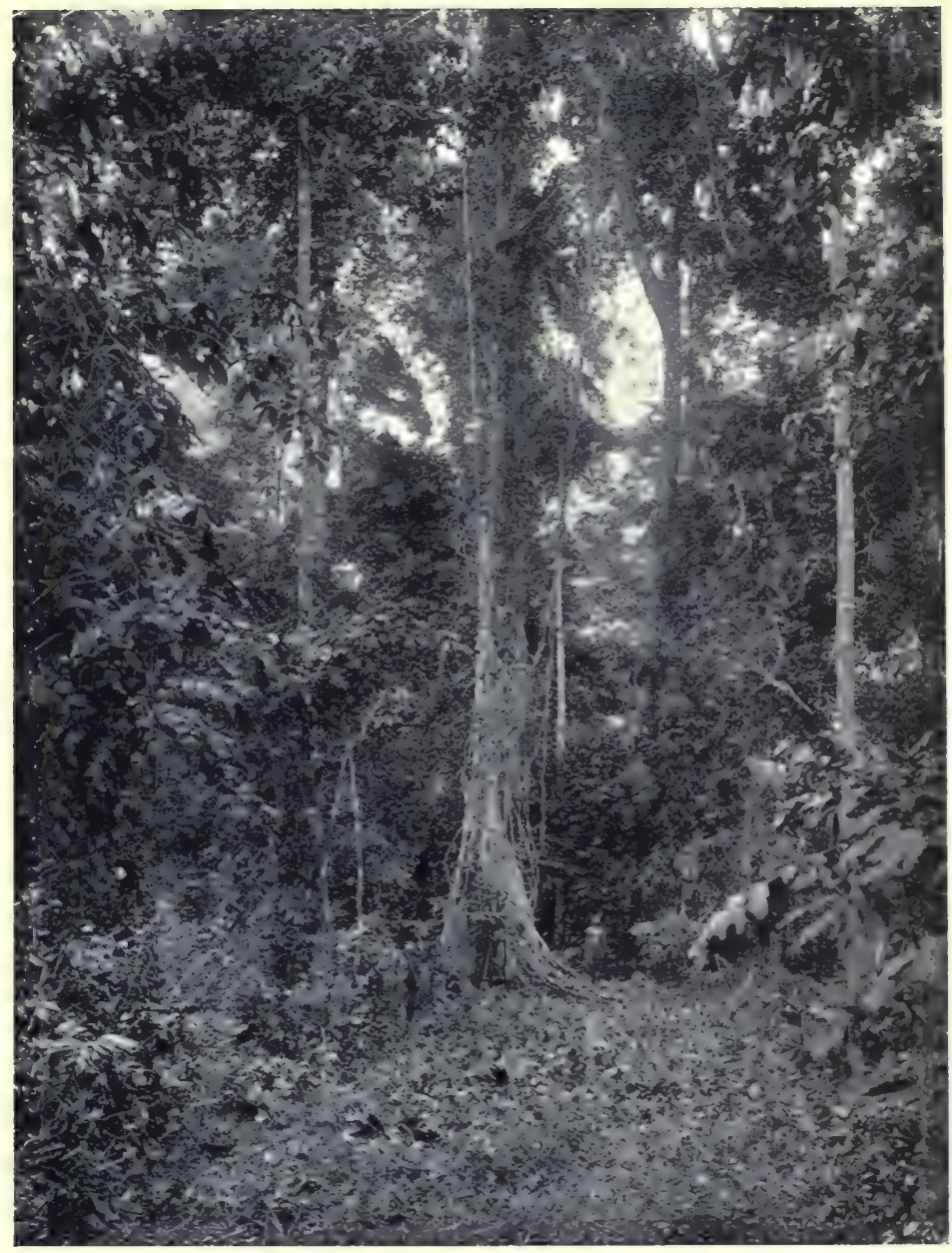

Fig. 22. The Congo Tropiesl Forest (Belgian Government.) 
the knee turns outwards makes it even less fitted for the upright position than its allies, but the resultant inward position of the sole of the foot makes it even more skilful in climbing. The animals are indeed excellent climbers, but are somewhat deliberate in their movements. They do not appear to come voluntarily to the ground, and are fitted for dense primaeval forests. The gibbons are very much more active in their movements ; so active, indeed, as to be able to catch birds on the wing. They mingle with their vegetable food a considerable amount of animal matter, especially eggs and nestling birds. With the other egg-eating animals of the tropical forests they have probably been one factor in determining the migration of so many birds every year to the northern forest, where they can rear their young in comparative security.

The gibbons have even longer arms than the orang, but differ in that they can plant the foot flat upon the ground, and walk, though not rapidly, in the upright position.

Of other forms we may note that the langurs, already mentioned ( $p .77$ ), are long-tailed, leaf-eating monkeys, widely distributed over South-East Asia. Though the arms are relatively short, the animals are exceedingly agile, making their way through the trees with great rapidity. In West Africa the langurs are replaced by thumbless monkeys belonging to the genus Colobus, which are also leaf-eaters, and are remarkable for their long silky hair.

West Africa, the region, it will be recollected, where the tropical forest is best developed, is also inhabited by the monkeys of the genus Cercopithecus, to which the monkey usually carried about by organ-grinders belongs. All have cheek-pouches, and the diet is very 
varied. In Asia the macaques are similar forms, with very large cheek-pouches and a most indiscriminate appetite, animal food entering largely into the diet. The baboons of Africa are much more widely distributed through that continent than most genera of monkeys, but this is associated with the fact that they are not forest animals in the true sense, being chiefly found on rocky ground, and being practically quadrupeds. The shortness of the arms is a drawback in climbing, at which they do not appear to be skilful.

Very different from all the Old World monkeys are those which haunt the equatorial forests of Brazil, and constitute the Platyrrhine or American forms. All these animals are small, none has an opposable thumb, the tail is usually prehensile, and the partition between the nostrils is broad. Examples are the various kinds of capuchins, which have a mixed diet, and share with some Old World forms the habit of plundering cultivated land. In the absence of cheek-pouches they carry away part of their spoil in their hands or under their arms, the arms not being indispensable in climbing, which is carried on largely by the tail. The spider monkeys (Ateles) are comparable to the thumbless monkeys of Africa in the total absence of the thumb. As their name indicates, they have long slender limbs, and are very skilful climbers, the long and markedly prehensile tail playing a great part in the process. The leaf-eating howling monkeys (Mycetes, Fig. 23) may also be named, but a considerable number of other genera occur, some without prehensile tails. Though characteristic of the equatorial forests, these New World monkeys extend northwards into Southern Mexico, and southwards to lat. $30^{\circ} \mathrm{S}$.

Of much more limited distribution are the little 


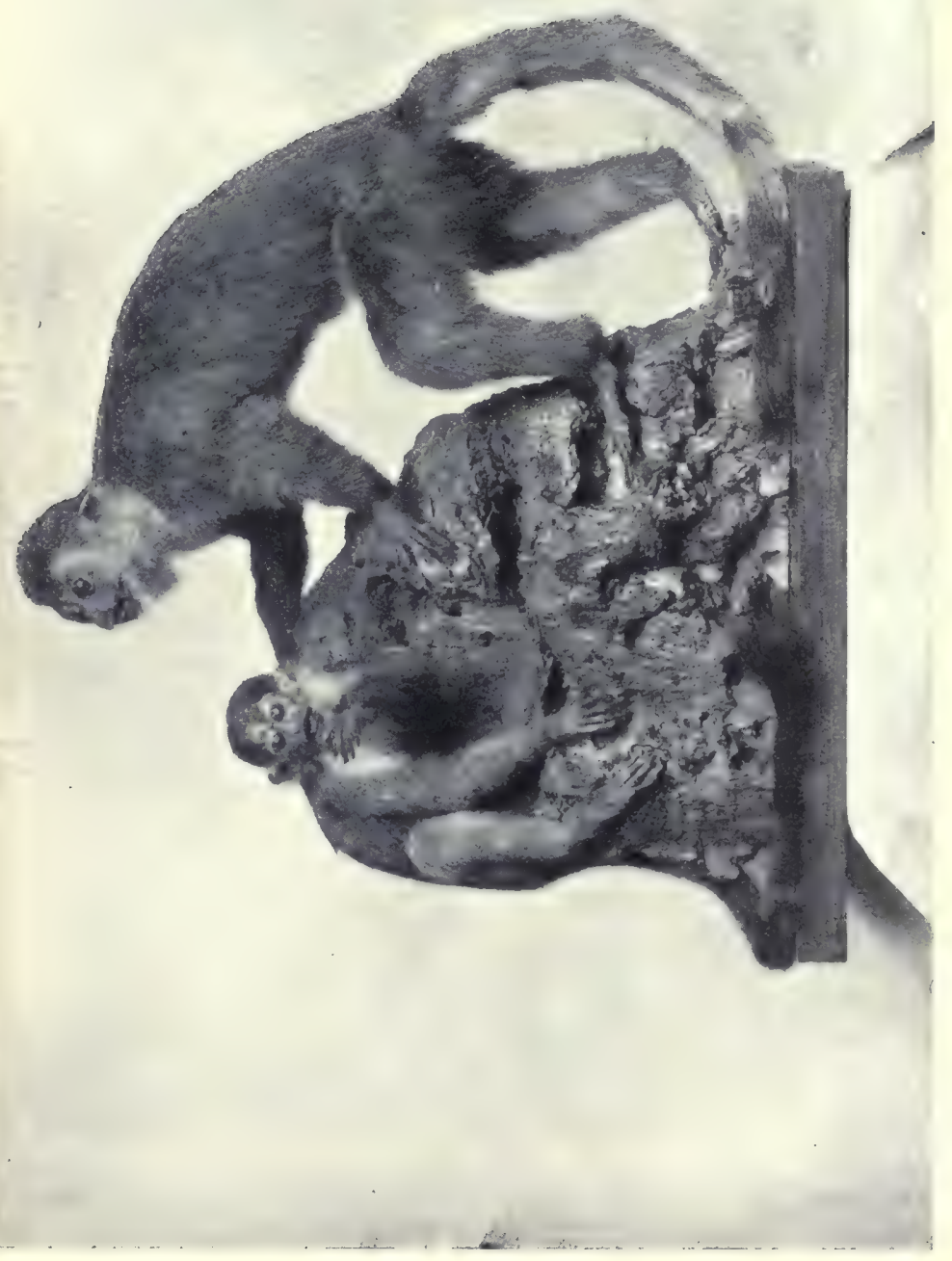


marmosets, which occur only in the tropical forests of South and Central America. These animals are very squirrel-like in appearance, and show much fewer adaptations to the arboreal life than the higher Primates, in spite of the fact that they spend their lives among the trees. Thus the fingers and toes, except the great toe, have pointed claws instead of nails, the hind legs are larger and better developed than the front ones, and the great toe is very small. The tail is nonprehensile. In the absence of the special adaptations shown by their allies, the animals climb like squirrels rather than like monkeys - that is, they do not grip the branches and swing freely from one to another, but stick in their claws and climb along the branch on all fours. The diet consists of fruits and insects.

The lowest members of the Primates are the lemurs, which show some marked peculiarities of distribution, as well as of structure. They are entirely absent from the New World, and in the Old World have apparently been pushed far to the south by the development of better organized forms, or by the attacks of carnivores, for all lemurs are very helpless animals. Existing lemurs occur in the tropical forests of Africa, in the forests of the south-eastern region of Asia, an area which contains many strange and primitive animals, and finally in the island of Madagascar. In Africa and Asia they are few in number, apparently in individuals as well as in species, and are always small in size. In Madagascar there are more than thirty species, and the individuals are abundant in every wood. Here also the animals reach a relatively large size, the largest being about two feet in length, and, as the number of species suggests, they show adaptations to varying conditions of life. The number of species and differentia- 
tion of structure seem to be associated with the fact that the lemurs here are protected by isolation, living as they do on an island where there are no true monkeys nor apes, and where the carnivores of the cat family are absent, members of the less differentiated civet alliance taking their place.

Lemurs are less intelligent than monkeys, and much less highly differentiated, but they are no less definitely adapted to arboreal life. It is therefore the more interesting to find that, just as baboons are monkeys which have abandoned the arboreal life, so in Madagascar we find the ring-tailed lemurs, foxy-looking animals, which live among rocks in regions where trees are virtually absent. We have already spoken of the fact that the galagos of West Africa have an elongated ankle which, though the mechanism is a little different, gives them the power of leaping like a frog. The same peculiarity occurs in the mouse-lemurs (Chirogale) of Madagascar, and is even better developed in the little tarsier (Tarsius) of the Malay region, which progresses by leaping from one branch to another, or from one end of a branch to the other.

We have not hitherto spoken of bats here, because those forms which occur in temperate regions show no special adaptation to any particular type of habitat. It is otherwise with the large fruit-bats, which are practically limited to the tropical regions of the Old World, where they are chiefly found in forests. They are entirely absent from the New World, but in the east extend southwards to the island continent of Australia and to Tasmania, though not to New Zealand. The fruit-bats are larger than the insect-eating forms, the common fruit or fox-bat of India measuring four feet from tip to tip of the wing. Their mastery of the 


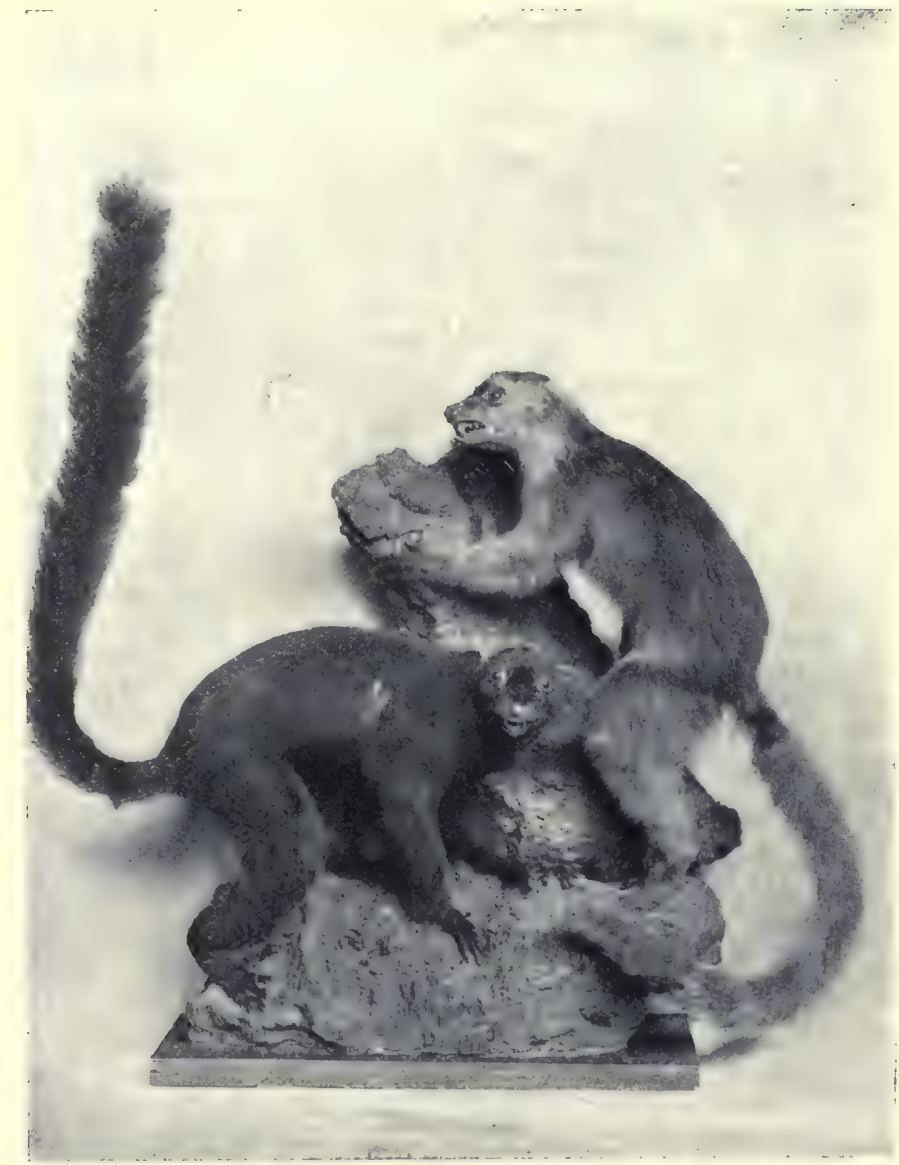

Fig. 25. Male and female of the Black Lemur, Madagascar. The male only is black, the female being brown with a white ruff. Note the opposable thumb and great toc. Though the general shape is monkey-like, the foxy faces should be contrasted with those of monkeys (Figs. 23 and 24). (From a specimen in the Royal Scottish Museum.) 

air is less complete than in the insect-eating forms, the arrangement of the tail apparently preventing them from giving those sharp turns so necessary in an animal which feeds on insects caught on the wing. Further, as the fruit-bats feed in trees they are more arboreal in habitat, being able to scramble about the trees, attaching themselves by the hind feet, and by the strongly hooked thumb of the hand. Similarly the index finger is not reduced to the rudimentary condition seen in other bats, where it is useless, and is here usually furnished with a claw. Fruit-bats spear their food with the claw of the thumb, and have teeth so modified as to allow them to crush pulpy fruits. From the diet the animals must necessarily have been once confined to regions where wild fruits were abundant, but, like some members of the order Primates, they have taken advantage of man's fondness for fruit to extend their range to regions where his plantations can be robbed. In Australia, where wild fruits are somewhat rare, the fruit-bats seem to devour the flowers of the eucalyptus, but the way in which they raid the orchards of the fruit-growers shows that fruit is greatly preferred when it can be obtained.

In the forests of tropical America there occurs an interesting family of bats, the Phyllostomatidae, or vampire bats, some of whose members present a curious analogy to the fruit-eating bats of the Old World. The vampire bats belong to the insect-eating section (Microchiroptera) of bats, but nevertheless some of them eat fruit only. Others eat fruit and insects, while others again are purely blood-suckers.

We have already pointed out that insectivores are peculiarly helpless animals, without the intelligence which enables many of the Primates to escape from 
the consequences of their own incapacity for defence. The tropical forests offer great possibilities in the way of shelter and protection, and it is therefore not remarkable that various forms should show special adaptations to life here. The most striking of these adaptations are those shown by a very aberrant animal, the socalled flying lemur (Galeopithecus), of which two species occur, one in the Malay Peninsula, Borneo, Sumatra, and adjacent regions, and the other in the Philippine Islands. The flying lemur is about the size of a cat, and resembles the flying squirrels of temperate forests in having a parachute of skin extending from the fore to the hind limbs, which enables it to take flying leaps from tree to tree. The membrane is, however, better developed, in that it involves the tail as well as the limbs. The fingers and toes are short and strongly clawed, and they, together with the slightly prehensile tail, enable the animal to swarm up trees, for it cannot fly in the sense of ascending against gravity. It feeds upon leaves, and has strongly cusped front teeth, presumably for the purpose of nibbling the leaves. The animal altogether offers a curious example of adaptation to forest life.

In the same region as the flying lemur, but extending also into the mainland of India and Burma, we find the little tree-shrews (Tupaia), which so far as adaptations go may be said to be comparable to ordinary squirrels, as Galeopithecus is to flying squirrels. The tree-shrews are very like squirrels in appearance, though smaller than most. The feet are naked beneath, with sharp claws to allow the animals to cling to the rough bark, the tail is long and bushy, and the animals use their forefeet like squirrels in feeding, sitting up on their hind-legs and holding the insects or fruits in 
the forepaws. Structurally, of course, the tree-shrews are very different from the squirrels, so that the resemblances are due to adaptation. Their much more limited distribution shows that they have been much less successful than squirrels.

The powerful and intelligent carnivores have many representatives in the tropical forests, though their dominance makes it less necessary for them to acquire purely arboreal habits than for more helpless animals. They haunt the forest for food rather than for protection. Of the large forms the lion is not a forest animal, though occasionally found in forest regions. The tiger, in India especially, is much more frequently found in wooded regions than elsewhere, but this may be partly because it is very impatient of great heat. It is apparently a bad climber. On the other hand, the widely distributed leopard climbs well, being capable of running up a straight-stemmed tree. This is even more true of the South American jaguar, which in swampy regions may be almost purely arboreal in habitat, and preys largely upon monkeys. It shows, however, like the other large cats, considerable adaptability, being found in savanas as well as in forests.

The puma (Fig. 26) does not appear to haunt dense forests, being much more a denizen of open plains or districts with thick reeds and grass. The clouded leopard or tiger (Fig. 45) is an arboreal form found in SouthEast Asia. The smaller cats, with the exception of Madagascar and Australia, are universally distributed, and the tropical forests of all regions have their full share of species.

On the other hand, the less differentiated forms known as civets (family Viverridae) are limited to the warmer parts of the Old World. The habits of the civets are 
varied, but among the arboreal forms we may note the palm-civets or tree-cats (Paradoxurus) of India and West Africa, which have naked feet, a common feature in arboreal animals, and the bear-cat (Arctictis) of South-East Asia, with a prehensile tail.

Though not a few of the dog alliance extend into wooded country, none can be said to hare any special adaptation to forest life.

On the other hand, the bears and their allies, despite their total absence from Africa south of the Sahara, and their general preference for temperate and upland regions, are well represented in the tropics. Thus the forests of South-East Asia contain the small black Malayan bear (Ursus malayanus), which is essentially arboreal and frugivorous in habit. In the forests of India the sloth-bear (Melursus ursinus) is common, and lives in forest regions, though it is a clumsy climber. Of the raccoons, the coatis (Nasua) are found in the forests of South and Central America, and the kinkajou (Cercoleptes caudivolvulus) of the tropical forests of America, a cat-like animal, has as special arboreal characters a prehensile tail, naked feet, and strong claws. It feeds upon small mammals, birds and their eggs, and fruits. The widely distributed weasel family has representatives in the tropical forests, but the animals do not predominate here as they do in the north, and the tropical forms show no special features of interest.

As a general rule ungulates are not abundant in the tropical forests, their bulky bodies not fitting them for life amid dense and tangled undergrowth. The deer of temperate woods are, however, represented in the tropical jungles, though perhaps the majority of the tropical Asiatic deer tend to haunt relatively open country. In Africa, where deer are absent, some of the 
antelopes have become modified for forest life. This is especially true of the little duikerboks (Cephalophus), whose slender bodies enable them to glide through the undergrowth. The African harnessed antelopes (Tragelaphus) also, and the African sable antelopes (Hippotragus) are found in wooded country. In the African tropical forest also is found the rare and little-known okapi, a relative of the giraffe, but with stripes recalling those of a zebra (Fig. 46).

In tropical Asia the sambar and its allies are the chief deer of forests, but the muntjacs (Cervulus) also haunt wooded country, choosing upland regions. In the dense jungles of South-East Asia occur various members of the genus Tragulus, including small, almost rodentlike animals, of primitive structure, called chevrotains. They are the smallest of living ungulates, being only about a foot in height, and their slender legs and bodies enable them to glide through the jungle, and thus to persist despite their generalized structure. An allied form, the water chevrotain, occurs on the west coast of Africa, where it inhabits swampy regions.

In a densely forested region, rivers or swamps, with their special types of vegetation, obviously afford advantages to animals not fitted for arboreal life proper. We find, therefore, that such parts of the forest have special animals. The wild pigs of India and the adjacent regions, the bush pigs of Africa, are examples of forms which haunt the damper parts of forests. Africa has also its hideous wart-hogs (Phacochoerus) while the islands of Celebes and Buru lodge in their forest the curious babirusa with its enormously elongated tusks. America has no true pigs, but the slenderlimbed peccaries replace them, and are similarly inhabitants of the swampy parts of forests. All these 
pig-like animals differ from those ungulates which live on hard ground in the greater number of functional toes, in the way in which these toes spread out to prevent the animal sinking in the mud, and in the absence of the elaborate arrangement which enables a sheep or an antelope to swallow large quantities of partially masticated vegetable food, which is regurgitated and thoroughly masticated later, when the animals feel themselves relatively safe from pursuit.

Among the odd-toed ungulates the tapirs, both the Malayan form and those occurring in South America, are forest animals, haunting much the same regions as do the pigs. The great enemy of the American forms is the jaguar, and the fact that when attacked the animals endeavour to reach thick cover suggests that the forest habitat is partially determined by the need for protection. As in the case of the pigs it is probably partially determined also by the need for finding relatively soft and succulent food, for the teeth of pigs and tapirs have not the elaboration of structure found in the more highly differentiated ungulates.

The rhinoceroses show somewhat different conditions in regard to habitat, for while some haunt more or less open plains, others, like the Javan and Sumatran rhinoceroses of South-East Asia and the common rhinoceros of Africa, are found in forested country, and subsist largely on leaves and twigs. Horses are not forest animals. The elephants, on the other hand, both Indian and African, are found in dense jungles, but in both cases this seems to be largely on account of the animals' great intolerance of heat, for they emerge into the more open regions both at night and during the cooler parts of the day.

Among the rodents, the squirrels and flying squirrels, 


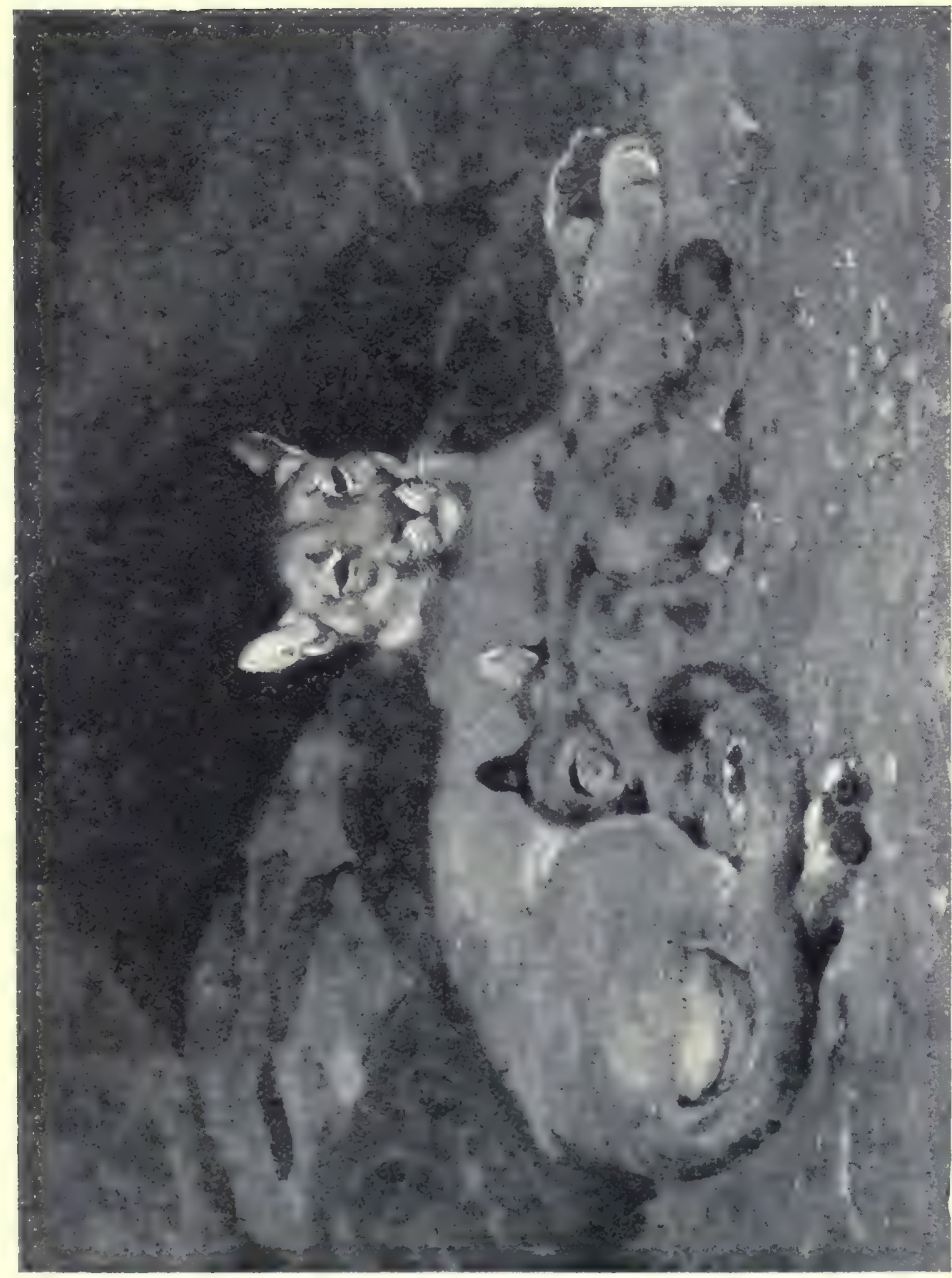

م 00

유

8

घึ. 동

ำ $\stackrel{80}{\circ}$ 


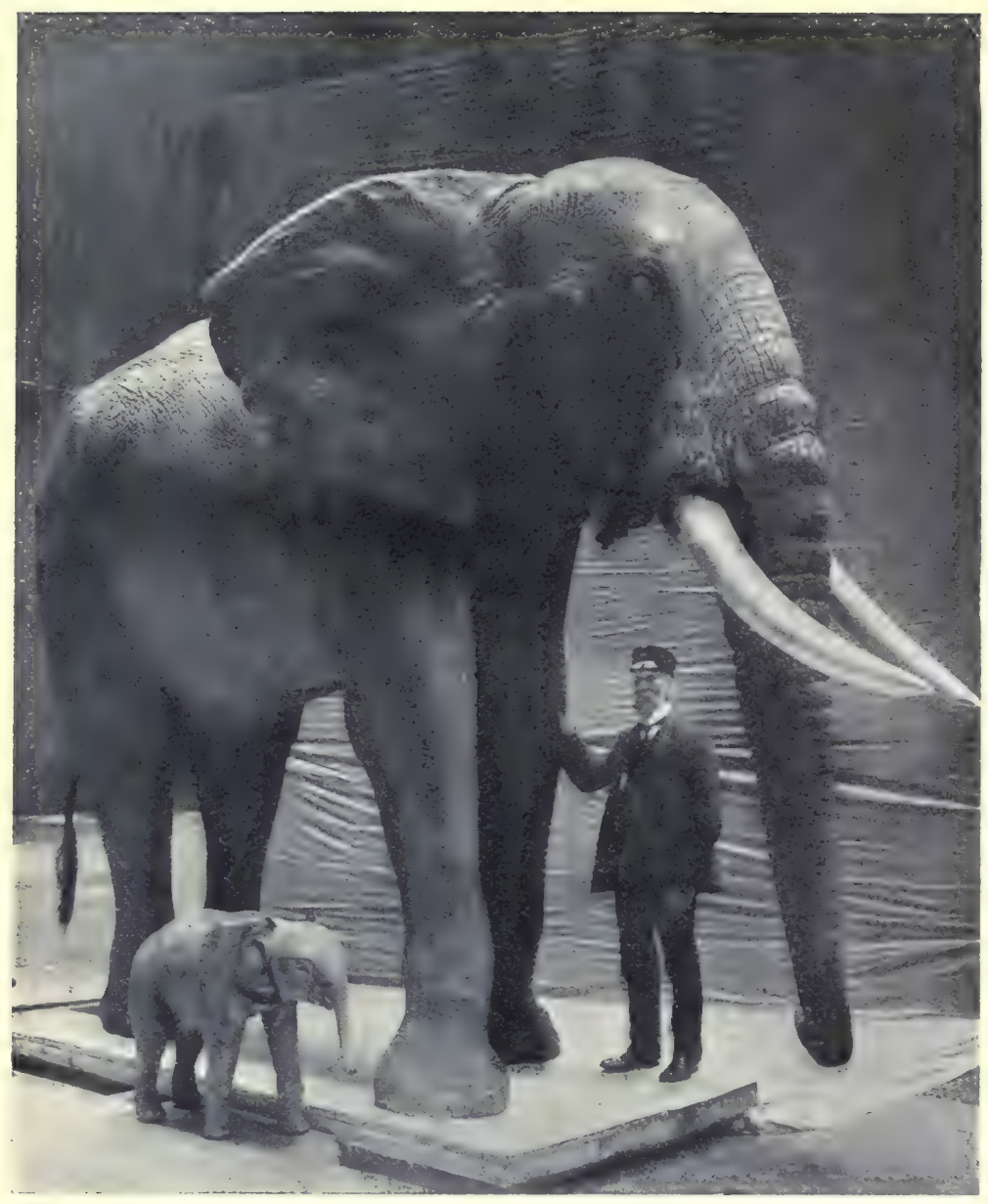

Fra. 27. The African Elephant. (From a specimen in the Royal Scottish Museum.) 
already described in temperate forests, are also found in tropical ones, the squirrels reaching their maximum number in the Malayan region. India and the adjacent regions have large flying squirrels belonging to the

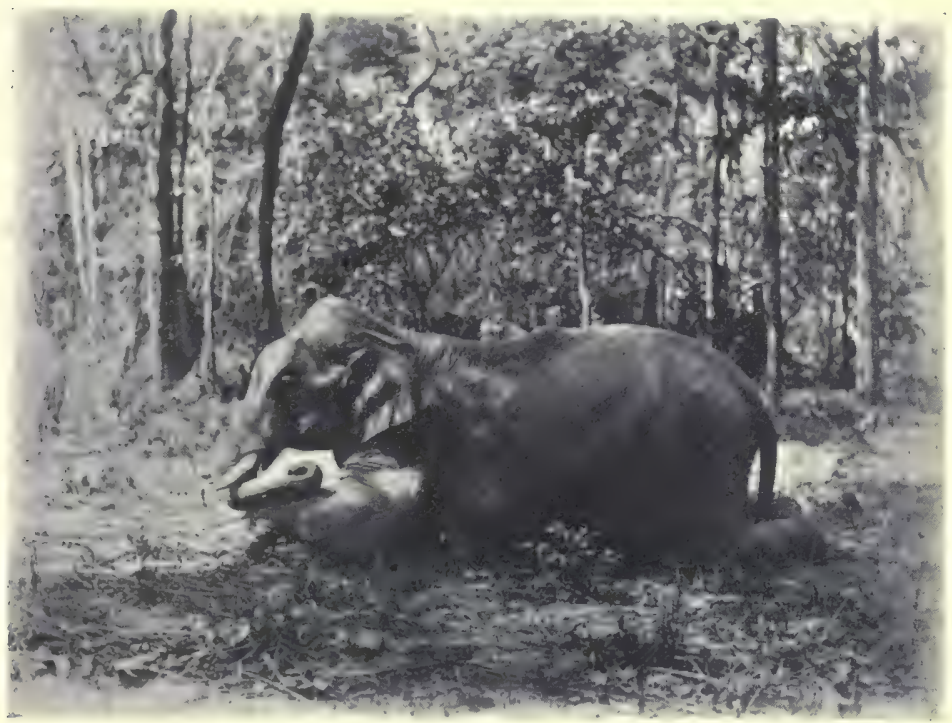

Fig. 28. Elephant in teak forest, Upper Burma. The position brings out the peculiarities of the hind-limbs, which are very different from those of cow or horse. Note especially that the long, straight thigh is not bound down by skin as in the horse, and the true knce appears to be very low down. (Photo by Col. Couchman.)

genus Pteromys, but Africa has forms which belong to quite a different family (Anomaluridae). The Latin name is given on account of the peculiar tail, which has overlapping horny scales on its under surface near the base, stated to be used in obtaining a hold on the bark when the animals are climbing trees, and thus 
offering some analogy to the stiff tail of the woodpecker (p. 47), which has the same function.

We have already spoken of the Canadian porcupine (p. 43) in the taiga. This is represented in the tropical forests of Mexico and Brazil by the treeporcupines of the genus Syntheres, which present some interesting adaptations to arboreal life. The tail is markedly prehensile, and the hind-foot is so inserted as to make it easy for the animals to grasp the branches. The great toe is absent, but its place is taken functionally by a fleshy lobe which can be bent inwards so as to be partially opposed to the toes. The animals are stated not to drink, and probably do not descend voluntarily from the trees (see Fig. 30).

We have already repeatedly emphasized the fact that ungulates in America are few, and that their place in nature is taken there by rodents; there is, therefore, nothing surprising in finding that the rodents called agutis (Dasyprocta) haunt the forests of Brazil and elsewhere, and have become adapted for life in the dense jungle. With their slender limbs and bodies they show a close, though entirely superficial, resemblance to the chevrotains of South-East Asia. The paca (Coelogenys) has similar habits.

With the Edentates we come to a primitive order, whose members have kept their hold in a world which has grown beyond them either by retiring to the depths of the tropical forests, or by acquiring burrowing and concealed habits. In the forests of the Amazon occur the sloths, belonging to the genus Bradypus and Choloepus, perhaps the most truly arboreal of all mammals, for they are quite helpless if removed from the trees among which they pass their whole lives. The fact that they possess practically no adaptation 


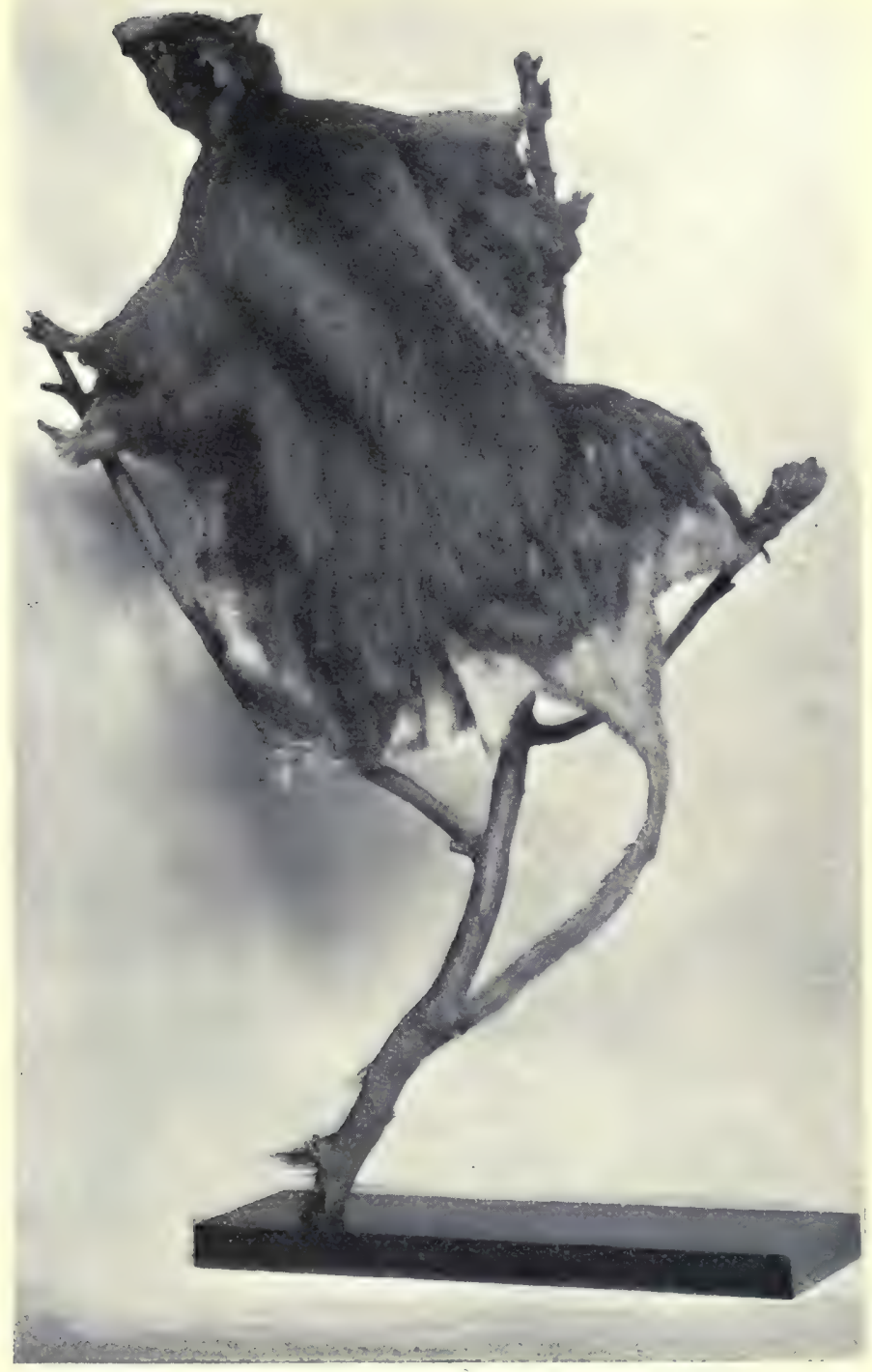

FIG. 29. An African Flying Squirrel (Anomalurus). The characteristic scales on the under-surface of the tail cannot be seen in this specimen, but the bony structure projecting from the elbow, which helps to support the parachute, is well shown. With this figure should be compared that of the Flying Phalanger (Fig. 33). Though not nearly related the animals show a superficial resemblance to one another. (From a specimen in the Royal Scottish Museum). 

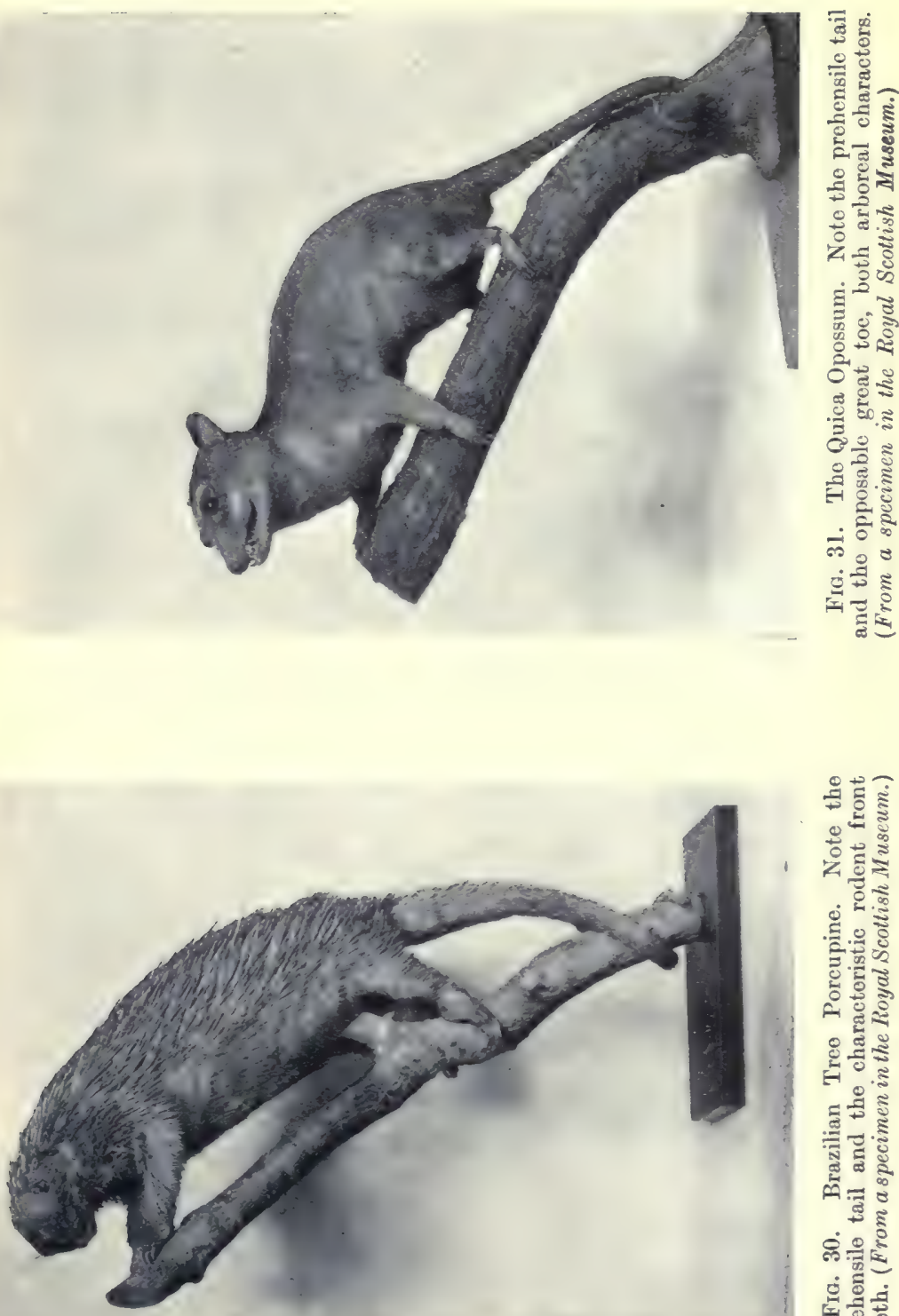

喜 $0=0$
0
0 늘 눈

i $2:$

.

대요

늉 ह

A

०.

$=0$ ह

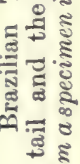

Sํ.

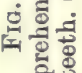


to permit them to pass from one tree to another shows that their natural habitat is the dense forests where tree is bound to tree by lianes.

Among the special features we may note the nature of the coat, the individual hairs having a fluted surface, on which algae lodge, and so give the animals the appearance of a lichen-covered branch. The fingers are converted into mere hooks, the tail is a stump, a common feature in such arboreal animals as have not prehensile tails, or do not require to use the tail as a balancing organ after the fashion of squirrels and tree-shrews (cf. bears, anthropoid apes, \&c.). We have already spoken of the elongation of the forelimbs in the sloths (p. 95). The food consists of leaves and fruits and the animals do not drink. The usual position is hanging back downwards from the branches of trees, and the animals sleep rolled up in a ball with the head tucked between the arms. Like many helpless forms they are active only at night (see Fig. 32 ).

The South American ant-eaters are also forest animals, the large form called Myrmecophaga jubata being strictly terrestrial, while the little two-toed ant-eater (Cycloturus didactylus) is arboreal, and except that it has a prehensile tail and lives upon insects, has a curious adaptive resemblance to a sloth, both in the structure of its limbs and in appearance. The hairy anteaters of South America are replaced in India and Africa by the scaly ant-eaters or pangolins (Manis), but though some of these are partially arboreal, most are found in rocky country, where they burrow in the ground.

Not a few of the marsupials have acquired arboreal habits. Thus the tropical forests of New Guinea and Queensland are inhabited by tree kangaroos, which have 
apparently recently taken to the trees, for they are stated to be slow and clumsy climbers. In other kangaroos the forelimbs are very short, in these forms they are nearly as long as the hind ones, and the tail, though not prehensile, is said to be used in climbing.

Much more definitely arboreal are the phalangers, closely related animals, but as well fitted for life in the trees as most kangaroos are for life on the ground. In the forests of Western Australia occurs the little Tarsipes, a shrew-like animal with a prehensile tail, which sucks honey from flowers with its worm-like tongue, and presumably, like humming birds, obtains insects also in this way. In North Australia and in the islands of the Indo-Malayan region is found the spotted cuscus (Phalanger maculatus). As in the other members of the phalanger family the great toe can be opposed to the others, and the long tail is very markedly prehensile. Cuscuses feed upon leaves and fruit, but like so many of the forest animals will also take birds and other small creatures. There are several species, mostly about the size of a cat. The feet are naked beneath.

Just as we have flying squirrels among the rodents and flying shrews among insectivores, so among the phalangers (Fig. 33) we have also flying types. The great flying phalanger (Petauroides volans) of Queensland and Victoria has both a flying membrane and a prehensile tail ; the squirrel flying phalanger or sugarsquirrel (Petaurus sciureus) has a bushy squirrel-like tail, not prehensile, and a well-developed parachute. It occurs in Eastern Australia. The pygmy flying phalanger (Acrobates pygmaea), in which the total length of head and body does not exceed about $2 \frac{1}{2}$ inches, has a long tail with the hairs arranged at the sides to imitate the vane of a featuer, and a slightly developed 


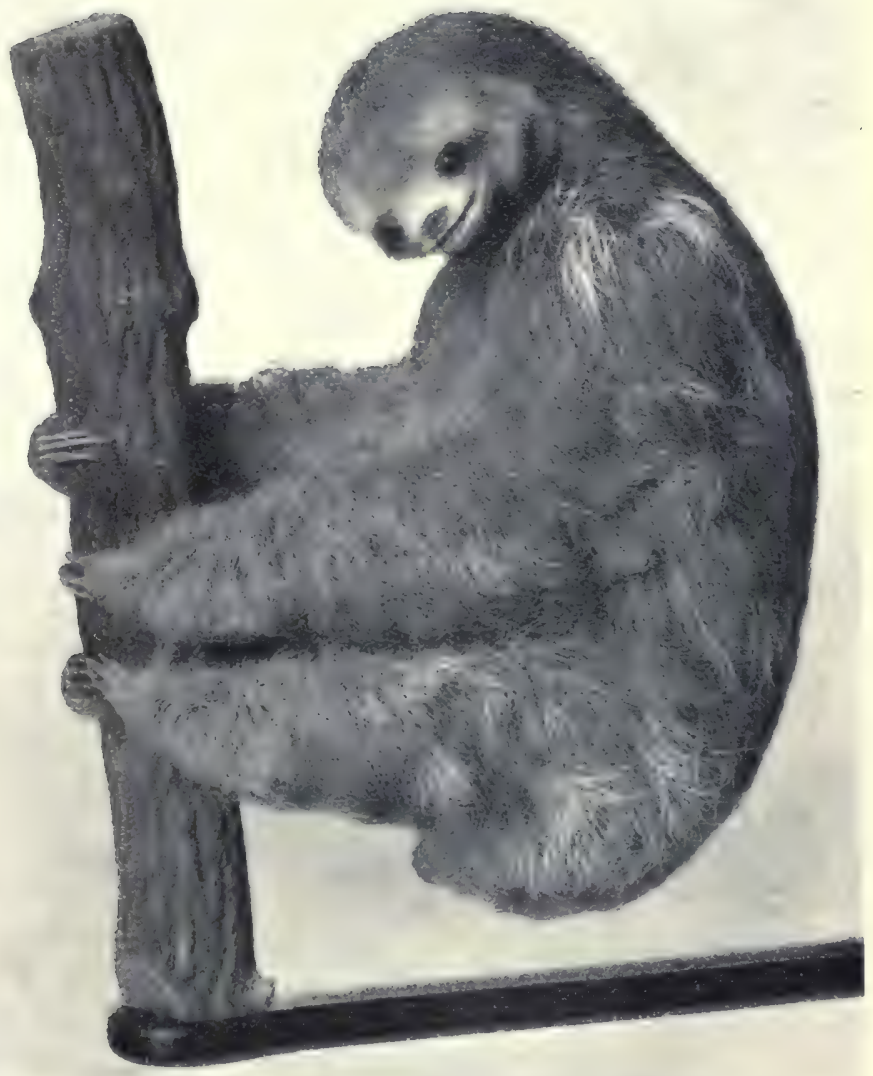

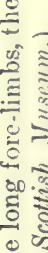

ป

कू

$+$

⿷匚

๘

品. ำ

so

등

ษั

0 क

30

도

ह

E

की

.0

7 .

o 융

흔

다

:.

$g:=$

\$잉

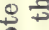

으.

홍

है

ड्षे

के

,

I잉

चू

\%

ํ.

$\triangle 8$

근

है न्न

ค่ เั้

के

近 


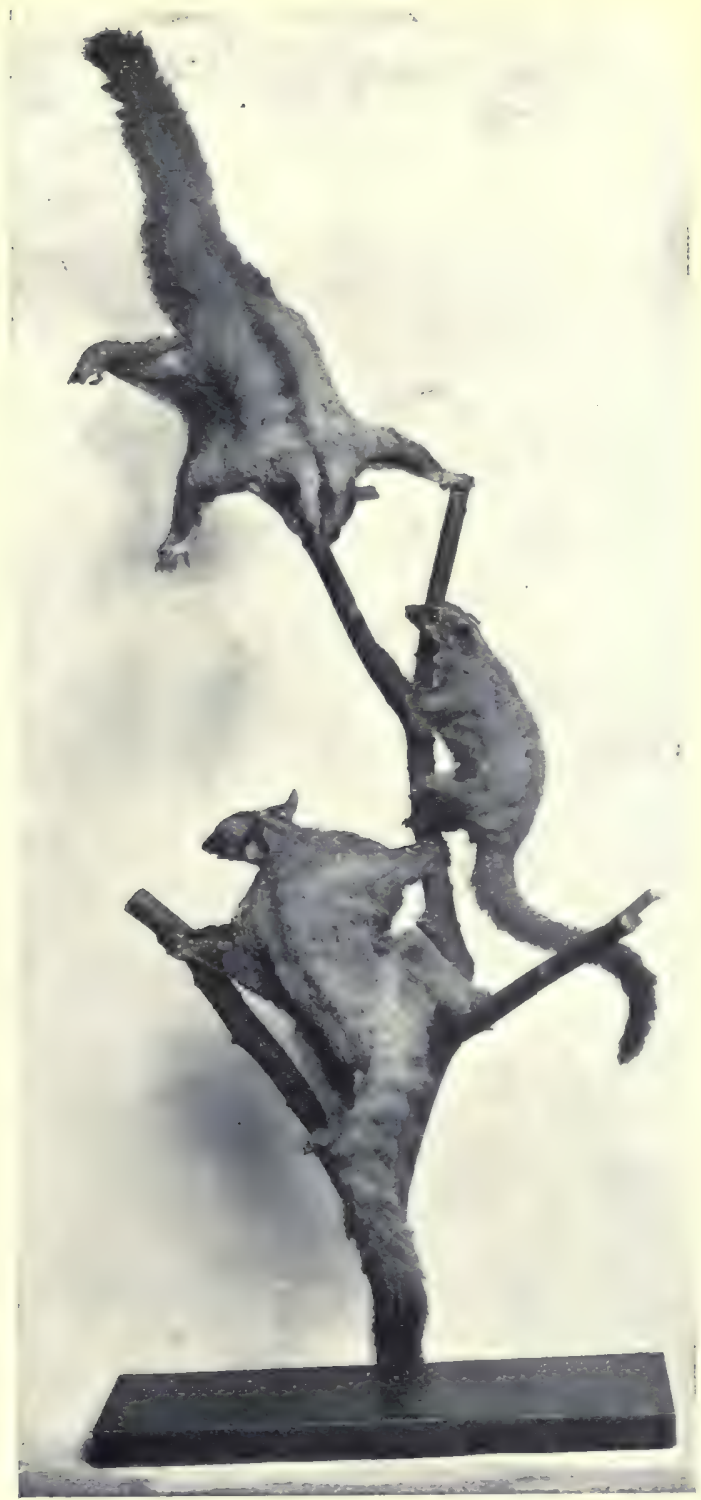

Fro. 33. The Lesser Flying Phalanger of Eastern Australia. (From a specimen in the Royal Scottish Museum.) 
parachute. It is stated to show marvellous agility in leaping from branch to branch, and is doubtless aided by its feather-like tail.

Another member of the phalanger family, the koala or native bear (Phascolarctos cinereus) is very different. from its allies in appearance, and shows some curious adaptations. It is sluggish in its movements, and, as often happens in such cases, the tail has disappeared (cf. bear, sloth, \&c.). In the hand two of the fingers can be opposed to the other three, the condition which occurs in the chameleon. On the foot, as in other phalangers, there are five toes, the great toe being opposable to the others. The animal feeds chiefly upon leaves, but is also stated to descend to the ground in order to dig for roots. Curiously enough, it possesses cheek pouches like an Old World monkey.

The last of the marsupials to be considered are the opossums of South America, small insect-eating animals with opposable great toes and prehensile tails, which, though chiefly South American, are represented in the United States by the widely distributed common opossum (Didelphys marsupialis). They must be added to the very considerable list of peculiar arboreal mammals possessed by South America, for they do not occur outside of the American continent. The majority spend their lives in trees, though some spread to the pampas of Argentine, and they take the place in nature elsewhere occupied by insectivores, which are absent from the South American continent (see Fig. 31).

Birds are so abundant in the tropical forests that we can only pick out for special remark a few which illustrate points of interest. In spite of the gloom of the jungle brilliantly coloured forms are common, a fact well illustrated by the gorgeous birds of paradise, the 
most brightly coloured of animals, which haunt the forests of New Guinea and the neighbouring regions. They spend much of their time in the trees, to whose branches they cling easily with their strong feet.

Among Picarian birds a whole division possesses the climbing foot, that is one in which the first and fourth toes are directed backwards, while the second and third point forwards, and almost all these are arboreal birds. They include the widely distributed woodpeckers, found in tropical no less than in temperate forests, the jacamars, handsome birds found in the South American forests, and the toucans with enormously developed bills and bright colouring. The purely frugivorous plantaineaters of Africa differ in that the fourth toe can be turned backwards or forwards at will, though the birds seem to dwell entirely in the trees. The climbing foot is however best developed in the parrots, which are for the most part thoroughly arboreal. The legs are short, and the short, strong, hooked bill, of which the upper portion is hinged as well as the lower, is used in climbing as well as in cracking hard shells and kernels. Parrots are chiefly tropical, but they extend much further to the south of the tropic of Capricorn than to the north of that of Cancer. As is well known, their colouring is often very striking, green predominating, as it often does among arboreal, fruiteating birds.

Of the parrots, the crested cockatoos are Australian, and the gorgeously coloured macaws with their long tails South American. The little love-birds are African, as is also the familiar grey parrot with a red tail. The parakeets are found in Africa, India, and Australia. Of almost all parrots it may be said, as of the fruiteating mammals, that they show a marked preference 
for robbing man when they can, rather than limiting themselves to wild products.

Not a few of the pigeons are arboreal. We may mention especially the fruit-pigeons, found in SouthEast Asia, and extending southwards to Australia. The bill is distensible at the base to permit the birds to swallow large fruits whole.

Among the mammals we found that in addition to the truly arboreal forms there were a number like the chevrotains and agutis, which took advantage of the shelter afforded by the dense forest, through which their slender bodies permitted them to force their way. Quite similar conditions occur among the game birds, where various members of the pheasant family live in dense thickets, through which their wedge-shaped bodies enable them to travel easily. Such birds fly with considerable reluctance, preferring to trust to the thick cover unless danger approaches too closely. Among such forms we may mention the wood-partridges of the Malay region, the spur-fowl of India and Ceylon, the jungle-fowl, the guinea-fowl of West Africa, and so forth.

Very remarkable is the condition presented by the hoatzin (Opisthocomus) of South America, where the young are hatched with claws on both the thumb and index finger, which they use in climbing about trees, after the fashion of a fruit-bat. The hoatzin is believed by some ornithologists to be related to the game-birds, but is a very primitive form.

Among reptiles the crocodiles and their allies haunt the lakes and rivers of forest regions, where they lie in wait for the forest animals as they come down to drink. A very curious arrangement of the breathing organs enables them to drown their prey by holding the 
animals caught under water till death takes place, the crocodile being meantime protected from choking by the nature of the internal nostrils.

Of the lizards the flying forms (Draco) are interesting. They occur in the Indo-Malayan countries, and their parachute is a lateral fold of skin supported upon the posterior ribs, which are greatly elongated. The mechanism is thus entirely different from that seen in any flying mammal. The body is greatly depressed, and the 'wings' when not in use are folded close to the body.

The iguanas of tropical America and the West Indies are also arboreal forms, but show no special adaptations to this mode of life. They haunt especially trees overhanging water, and are said to have the curious habit of dropping into the water with a splash, sometimes from a great height, if alarmed. The most purely arboreal of the lizards are, however, the chameleons, specially characteristic of Africa, but also found in India and Ceylon, and extending into Europe in Spain. All have prehensile tails, and the hands and feet constitute perfect grasping organs. The limbs are long and slender, the forelegs especially so. The fingers and toes form two groups, two being opposed to the other three. On the fore-limb the first three fingers form an inner bundle opposed to the fourth and fifth, which are outside. In the foot the inner bundle is made up by the first two toes only, the third, fourth, and fifth forming the outer group. The animals are insectivorous, and their power of colour-change is familiar to all.

Of the snakes the tree boas of South America are forest-haunting forms, with prehensile tails, and feed chiefly upon birds. Like their allies the pythons and 
true boas, they are non-poisonous, crushing their prey by the weight of their coils. The huge anaconda (Euneces murinus) of the Amazonian forests is semiaquatic, lurking in pools till its prey approaches the water. It feeds largely on peccaries. The true boas occur both in Madagascar and in tropical South America, and inhabit the dense forests, through which they can glide without difficulty. The beautifully coloured and marked wood-snakes (Herpetodryas) of tropical America represent there the tree snakes (Dendrophis) of the Old World, all of which are arboreal in habit. The American forms feed upon lizards and young birds. In India the very agile whip-snakes (Dryophis) twine their slender bodies round branches of trees, shooting out their heads in order to capture their prey. Most other snakes, including the most poisonous forms, are ground animals, often inhabiting dry and sandy places. An exception is the climbing tree-viper (Trimeresurus gramineus) of India and Burma, with a markedly prehensile tail, and a generally green tint, like the trees among which it lives.

Of the amphibians we have already mentioned the flying frogs of the genus Rhacophorus, which occur in Madagascar, and also throughout South-East Asia. A number of other frogs show more or less well-marked arboreal habits, the commonest adaptation being the development of some form of adhesive disks at the end of the toes, to permit of the animals fixing themselves to the branches of trees. This is seen in the family of Dendrobatinae, whose members occur alike in Madagascar and in tropical America. They are beautifully and often vividly coloured, and some species at least have poison glands in the skin, whose secretion is used in South America as an arrow poison. Such an associa- 
tion of bright colouring with poisonous or noxious qualities is of common occurrence in animals.

The typical tree frogs of the family Hylidae are widely distributed over the globe, but are absent from Africa south of the Sahara, from Arabia, and from India. They have suctorial disks at the ends of their toes, are usually protectively coloured in shades of green, the tints varying with the surroundings, and have glands upon the under surface whereby they can absorb water from the damp leaves on which they rest, and thus obviate the necessity for seeking ponds to moisten the skin. Their breeding habits are often peculiar. Other amphibians are not adapted for the arboreal life.

In regard to fresh-water fish we may note one or two peculiar forms, found in the streams of the tropical forest, or on its seaward margin. The very peculiar double-breathing fishes, which are animals furnished both with lungs and gills, are represented in the tropical streams of Queensland by Ceratodus, in the tropical streams of Africa by Protopterus, and in those of South America by Lepidosiren. None of these animals voluntarily quit the water, but the fact that the two last named can breathe when buried in the mud as well as when swimming in water adapts them for life in tropical regions, where there is often a well-marked alternation of wet and dry seasons.

Even more curious are the habits of the mudskippers (Periophthalmus), which haunt the mangrove swamps and mud-flats on the shores of the Indian and Pacific Oceans and off the coast of West Africa. These are bony fish which are partially adapted for life on land. The anterior fins are curiously modified, so that the fish can climb about the supporting roots of the mangroves, 
and it can also leap and skip over the mud. The eyes are very prominent, are furnished with distinct eyelids, and are protrusible. The fish, which are very tadpolelike in appearance, feed upon insects.

In India and the south-east of Asia generally, another fish is found which can live on land, and voluntarily leaves the water to do so. This is the climbing perch (Anabas scandens), a freshwater form which travels long distances over land by hitching its pectoral fins round plants. The fish is also stated to be able to climb trees. It has a special accessory breathing organ, which enables it to breathe air when out of the water.

In regard to the invertebrates, a special feature of the tropical forests is the great wealth of insects. That this must be so will be clear when we reflect that some of the forest-dwelling primates, the insectivores, many of the marsupials, some carnivores, the edentates, many reptiles and amphibians and so on, eat insects, either solely or in combination with other types of food. Further, the equal temperature allows the insects to go on breeding all the year round, and thus permits a great wealth of individuals to occur, while the special conditions favour a great wealth of genera and species. Apart from the size and beauty of the tropical butterflies, the most impressive of the insects are first the flies, which are often blood-suckers, and then may, as in the case of mosquitoes and tsetse flies, serve as transmittors of the tropical diseases most fatal to man and beast, and second the ants, some of which are extraordinarily destructive to plant life, while others from their numbers and ferocity are the enemies of all other animals. The driver ants of West Africa, which are wandering forms, are stated to devour every living creature in their path which cannot make its 
escape, and will even attack human beings if from any cause these are rendered incapable of defence or flight.

The termites, or so-called white ants, are as a rule less obvious in the dense forest than in more open country, but some species do occur there. Other members of the same order form the beautiful stick and leaf insects, predatory forms which often show a marked resemblance to the vegetation among which they live. As well as with insects the tropical forest swarms with scorpions, spiders, including the large bird-catching form of South America, and ticks, which, like flies, serve for the transmission of deadly diseases. As most of these forms do not, however, show special adaptations to forest life, it is sufficient to merely indicate their abundance, which has a marked effect upon the life of other organisms in forest areas.

We may add that, just as a few fish in tropical climates have taken advantage of the greater opportunities which the land offers as compared with the sea to acquire partially terrestrial habits, so various crabs have become partially adapted for life on land, and wander about in those forest regions which are at no very great distance from the sea. to which they return for breeding purposes.

REFERENCES. In regard to the animals of the African forests, Sir H. H. Johnson's works give very full details, with many figures; see British Central Africa (London, 1897); The Uganda Protectorate (2 vols., London, 1902); Liberia (2 vols., London, 1906). Lydeker's Game Animals of Africa (London, 1908) should also be consulted. Wallace's Malay Archipelago (London, 1869) gives a fascinating account of the animals of that region, and the same author's Tropical Nature (London, 1878) may also be mentioned. Bates's Naturalist on the Amazons (5th ed., London, 1884), and Belt's Naturalist in Nicaragua (2nd ed., London, 1888), give good accounts of South and Central American animals. For details as to the animals, reference should again be made to the natural histories already mentioned. 


\section{CHAPTER VI}

\section{TROPICAL SAVANAS AND DESERTS}

In the tropics the steppes of temperate latitudes are represented by what are called savanas, which are regions where grass occurs, mingled with arborescent or shrubby vegetation. Sometimes we have in these regions scattered trees only; sometimes clumps of trees occur, separated by regions without trees, giving a characteristic park-like appearance to the landscape. Elsewhere the trees follow the courses of the streams, forming the so-called gallery forests. Such savanas occupy large stretches in the tropical regions of Africa, South America, and Australia, and have a highly developed and characteristic fauna.

The typical savana climate is tropical. The rain comes in the hotter season of the year, and there is a well-marked dry season. Where the rain is deficient the savana passes into desert, as we see in passing northwards from the Sudan to the Sahara, or inland from the Australian bush to the central desert. On the other hand, where the rainfall is abundant the trees increase in number, and the savana passes into the tropical rain-forest, through the intervention of the savana wood, with its numerous trees. The period of greatest vegetative activity accompanies or follows the rainy season, and the dry season may witness an almost complete cessation of activity. This, like the similar conditions in the steppes, involves a certain amount of migration among the inhabitants of the region. Further, 
owing to the great power of the sun, bush fires are frequent, and often have devastating effects.

The type of vegetation naturally varies in the different regions in which savanas occur. In Africa the mighty baobab (Adansonia digitata) is conspicuous among the trees. It stores water in its thick trunk,

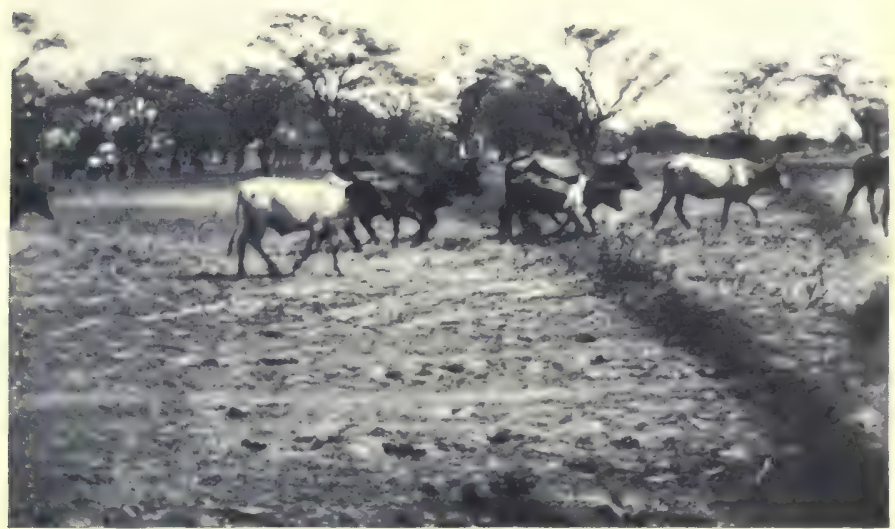

FIG. 34. Savana, with scattered acacias, on the margin of the desert in Kordofan. (Photo by Capt. Lloyd.)

and becomes leafless in the dry season. Other important trees are thorny acacias, whose foliage is relished by the giraffe, various species of cactus-like Euphorbia, palms, and so forth. Various kinds of grasses occur, and often grow to a great height, forming dense thickets, which offer much shelter, while thorny and xerophilous plants are of course frequent. In the savanas of the other 
continents, though the species differ, the general facies is the same-tall grasses, thorny acacias, cactuses or cactus-like forms, and generally plants presenting special features which protect them against periodical drought, while allowing them to take advantage of the periodic tropical downfalls.

Of the great savana regions of the world the African is especially rich in ungulates, notably in antelopes, the Australian in herbivorous marsupials, notably kangaroos and wallabies, while the savanas of South America, a country which has witnessed an extraordinary destruction of mammalian types in recent geological time, were relatively poor in mammalia till the advent of European man.

One of the special climatic features of the savana proper is the periodic abundance of rain. As we pass from the savana to the desert the dry season increases in length, and the rain becomes less, and more uncertain. Vegetation also gradually diminishes as the conditions become less favourable, and the fauna becomes impoverished, the mammalian fauna diminishing first. In the desert proper few organisms can live, but the less unfavourable regions carry a reduced savana fauna, especially of insects and reptiles. The Kalahari, indeed, is said to serve as a reservoir for such insects as locusts, which breed there until starvation forces the swarms to sweep outwards to the better watered lands on the margin of the desert.

No hard and fast line separates savana regions from steppes, this being especially true in South America, where the treeless 'pampas' or steppes of the Argentine south of lat. $32^{\circ} \mathrm{S}$. pass into a savana region further north. It should be noted, however, that in addition to the characters already given, typical savana regions 
are distinguished from the typical steppe region already described in the absence of a severe winter.

Proceeding now to consider the animals of the various savana regions in systematic order, we may note that as a general rule the primates do not occur in such regions, being, as we have seen, mostly fitted by nature for life in the tropical forest. To this rule, however, the baboons form an exception, for, as we have already seen, they are quadrupeds, living in open rocky country. The Arabian baboon (Papio hamadryas) occurs abundantly in the Sudan, where it feeds upon fruits, shoots, buds, and seeds, and finds the necessary shelter in rocky ground. In Angola another species ( $P$. anubis) inhabits very dry country, and feeds largely upon that strange coniferous plant known as Welwitschia.

Among the insectivores we may note especially the jumping shrews, which are confined to Africa, and show a curiously close resemblance to the jerboas among rodents. The jumping or elephant shrews have greatly elongated hind-legs, and move in a series of leaps. They have also curiously elongated snouts, which they use in routing about for the insects on which they feed. The type genus is Macroscelides, and the animals are widely distributed in Africa, being mainly but not exclusively tropical. The elongation of the hind-limbs is interesting, for it is frequent in steppe and savana animals, and has several obvious advantages which have been already discussed (see p. 64).

Of the carnivores, the large cat-like forms, as we have already had occasion to remark, show no very special adaptation to one habitat. The uniform colouring of the lion, however, suggests that it was once a desert animal. In Africa it is abundant in the Kalahari desert, but also extends into savana and steppe 
regions, its distribution being probably determined by the double need of avoiding the proximity of its persistent enemy, man, and of following its natural prey, the larger ungulates. Of the smaller cat-like forms, the mongooses are ground animals, usually haunting open country, and avoiding dense forests. An allied form, the meerkat (Suricata tetradactyla) haunts sandy ground in Cape Colony, where the savanas pass into steppes. Like most of the smaller mammalia of open country this animal is a burrower, making deep holes in the sandy veldt with its sharp foreclaws. Another adaptation to life in this region is shown by the fact that it feeds chiefly upon the bulbs and roots of the veldt plants, which store water in their underground parts during the time of drought. Another steppe or savana form of wider distribution is the aard-wolf (Proteles cristatus), a burrowing animal, with weak teeth, which seems to feed largely upon termites, and inhabits open country throughout the southern half of Africa, with a northern limit apparently in Somaliland, where it has been once found. The hyaenas are also inhabitants of savana country, the spotted hyaena of Africa being often found in the same districts as the lion, upon which it is partly dependent, in that it obtains the remainder of the 'kill', when the nobler animal has satisfied its hunger.

As a rule the members of the dog alliance inhabit open country, as the common habit of hunting in packs suggests. A considerable number occur in the tropics, and may therefore be included in the fauna of deserts and savanas. We may note especially the African jackals, which hunt in packs and feed upon rodents, or the smaller ungulates, or sick or wounded members of the larger species. An interesting desert species is the 
long-eared fox, or fennec, which inhabits the Sahara desert, and is called Canis zerda. This little animal has very large ears and great acuteness of hearing; it is tawny-coloured like the desert sand, and is burrowing and nocturnal in habits. It burrows with great rapidity, being said to appear to sink through the sand. At dusk it becomes active, and sets forth in search of insects, lizards, small birds, rodents, or even fruit if obtainable. The animal is partially social, the burrows being made in company. A very much fiercer animal is the Cape hunting dog (Lycaon pictus), which has a curious and unexplained resemblance to the spotted hyaena. It is widely spread throughout Africa, where it inhabits open country, preying upon the ungulates, which are borne down by sheer weight of numbers. In South Africa the flocks of the white man form a favourite source of food. Though the animals live in holes, the young being born underground, yet on an alarm it seeks safety in flight rather than in the burrow like the fennec. It would appear that the dogs have little or no burrowing power themselves, their holes being either natural or obtained by ejecting the original occupant. So swift are these dogs that they are said to be able to overtake the swiftest antelope. Not a few other dog-like animals haunt the African savanas, but these may serve as types.

Bears, as we have already seen, are absent from Africa south of the Atlas, and one species only occurs in South America, and that in the Andes. As these two countries have the best-developed savanas, it is clear that the animals are unfitted for life in such regions. They are indeed absent alike from temperate steppe and tropical savana and desert. The allies of the bears, such as the raccoons and coatis, are also 
absent from savanas, and the weasel group is not well represented there. Among the few weasel-like forms we may note the South African weasel (Poecilogale) and the Cape polecat (Ictonyx). The latter has a somewhat wide distribution in Africa, and differs from martens and polecats in that it is unable to climb. It has a peculiar resemblance to the American skunks, and like them is protected from possible enemies by its very offensive odour. The animals feed upon small mammals and birds, lizards, and frogs, and are found in rocky districts.

It is when we come to the ungulates, however, that we find the most specialized and abundant of the animals of the African savana. In the reedy swamps throughout the greater part of the continent occurs the so-called Cape buffalo (Bos caffer), which is replaced in the regions richer in trees by the short-horned buffalo (Bos pumilus). Both live in herds, and do not voluntarily quit the vicinity of water, in which they love to bathe. The young are born in the warmer season, and there is never more than one calf at a birth. It is hidden by the mother among long grass, and for about ten days after its birth the mother separates from the herd, and remains within easy reach of her young, which she visits at short intervals. This habit speaks to life in regions where cover is always obtainable, and is in striking distinction to the habits of the mountain ungulates (cf. p. 75), where the young must be able to travel with the herd very shortly after birth.

As we have repeatedly stated, it is the antelopes which characterize specially the savanas of Africa, the diversity of species being as remarkable as the number of individuals, till man interfered. In several points of structure antelopes are more primitive than 
oxen or sheep and goats, and they appear to be older.

Eland are the largest African antelopes, and are distinguished by the presence of horns in both sexes. They were formerly common over the whole of Eastern and Southern Africa. Typical savana animals, they prefer open plains with scattered timber, but extend into the desert on the one hand and into the open savana wood on the other. Like not a few tropical animals they are intolerant of the hot sun, and where possible spend the hours of greatest heat in the shelter of woods, moving back to the grassy plains to feed and drink. Where possible they drink daily, but unlike the buffaloes they can tolerate thirst, and in the Kalahari desert apparently obtain sufficient water by eating water-melons and similar succulent fruits or plants. Like most ungulates they live in herds, and the student of botany will notice that the fodder plants upon which these animals depend (grasses, \&c.) are social also, while in the tropical forests, where social animals are rare, social plants are also infrequent (cf. p. 96).

Kudu (Strepsiceros) are distinguished from eland by the absence of horns in the female, as well as by other characters. They haunt thickets and country covered with bush, and occur in small parties, usually on very rough ground. Their speed is not very great. The preference for bush or thicket-covered country is even more marked in the harnessed antelopes (Tragelaphus), which we have already mentioned as being found even in the tropical forest. On the other hand, the addax from the deserts of North Africa and Arabia, and the gemsbok (Oryx gazella) from the deserts of SouthWestern Africa, are examples of forms which inhabit 
very arid country, and appear capable of going for long periods without tasting water. The horns are very powerful, and the gemsbok is stated to be able to beat off the lion by means of them, but not to be swift, perhaps because it had few enemies till man appeared on the scene. In addition to the gemsbok, other species of the genus Oryx occur in different parts of Africa, all being inhabitants of open country.

The gazelle group, largely represented in the more arid regions of Asia, North Africa, \&c., has a South African member in the springbok, once enormously numerous on the margin of the Kalahari desert. Other African species also occur. An allied form of interesting habits is Waller's gazelle (Lithocranius walleri) from East Africa, which inhabits rocky districts, where thorn-jungle occurs, and has a remarkably long neck, giving it a resemblance to a miniature giraffe. It feeds chiefly upon twigs and leaves, and is stated to rest its forefeet against the trees, in order to reach the foliage.

Among other forms we may notice the pala antelope (Aepyceros melampus), found among the acacia scrub of Southern and South-Eastern Africa, and remarkable for its great swiftness, and for its power of taking long leaps. It prefers the proximity of water. In swampy regions where reeds are plentiful the reitbok and waterbuck antelopes occur, the latter seeking the water or swamps when pursued. On the other hand, hilly and mountainous districts are inhabited by the active rhebok, which resembles a chamois. Of the little klipspringer we have already spoken (p. 84). The steinboks, also small animals, occur in open country or savana wood, but avoid hilly country. They are remarkable for their speed and their close resemblance in colour to the ground. 
The last group of African antelopes includes the large wildebeest or gnu, the hartebeests, and the blessbok. The wildebeests (Connochoetes) are ungainly looking animals, with some resemblance to oxen, which inhabit open country in South and East Africa. The genus Bubalis includes the somewhat stag-like hartebeest, the blessbok, and the bontebok. All the three mentioned are exclusively African, though one member of the genus extends into Syria, and frequent grassy plains, especially those which have so great an extension in Southern Africa.

Generally, we may say that very many of the African antelopes are typical savana animals, but some, like the gemsbok, extend into the desert proper, a few, like the duikerboks, into the tropical forests, while not a few extend their range up the mountains, the klipspringer being a typical example, and some, like the water-buck, frequent the swamps, and seek safety there. Those which inhabit open plains find security in their numbers, the strength and powerful horns of the bucks, and their swiftness. Less powerful and slower forms must haunt country which offers some form of shelter, as e. g. rocky regions, thorny jungle, or swampy districts.

The resistance which these wild forms offer to the diseases carried by tsetse-flies and ticks must have been a factor in their persistence, for these diseases form the greatest obstacles to the introduction of domesticated ungulates into the great plains of Southern Africa. The wild antelopes (cf. negro children and malaria) are apparently tolerant of the parasites of the various diseases, which affect them but little. They thus serve as reservoirs of infection, by means of which introduced forms may be infected. The virtual absence of wild ungulates in South America when it was colonized from 


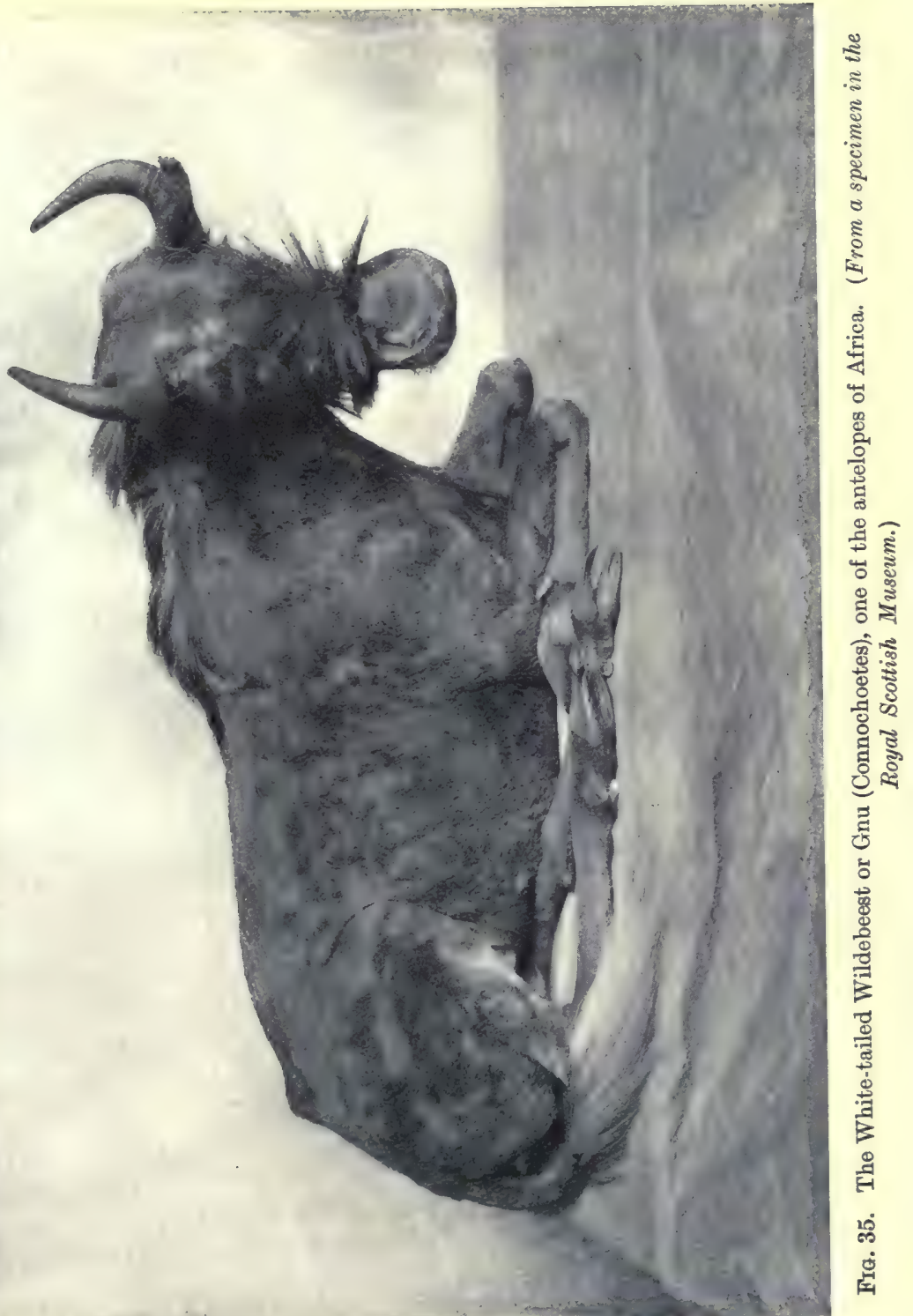




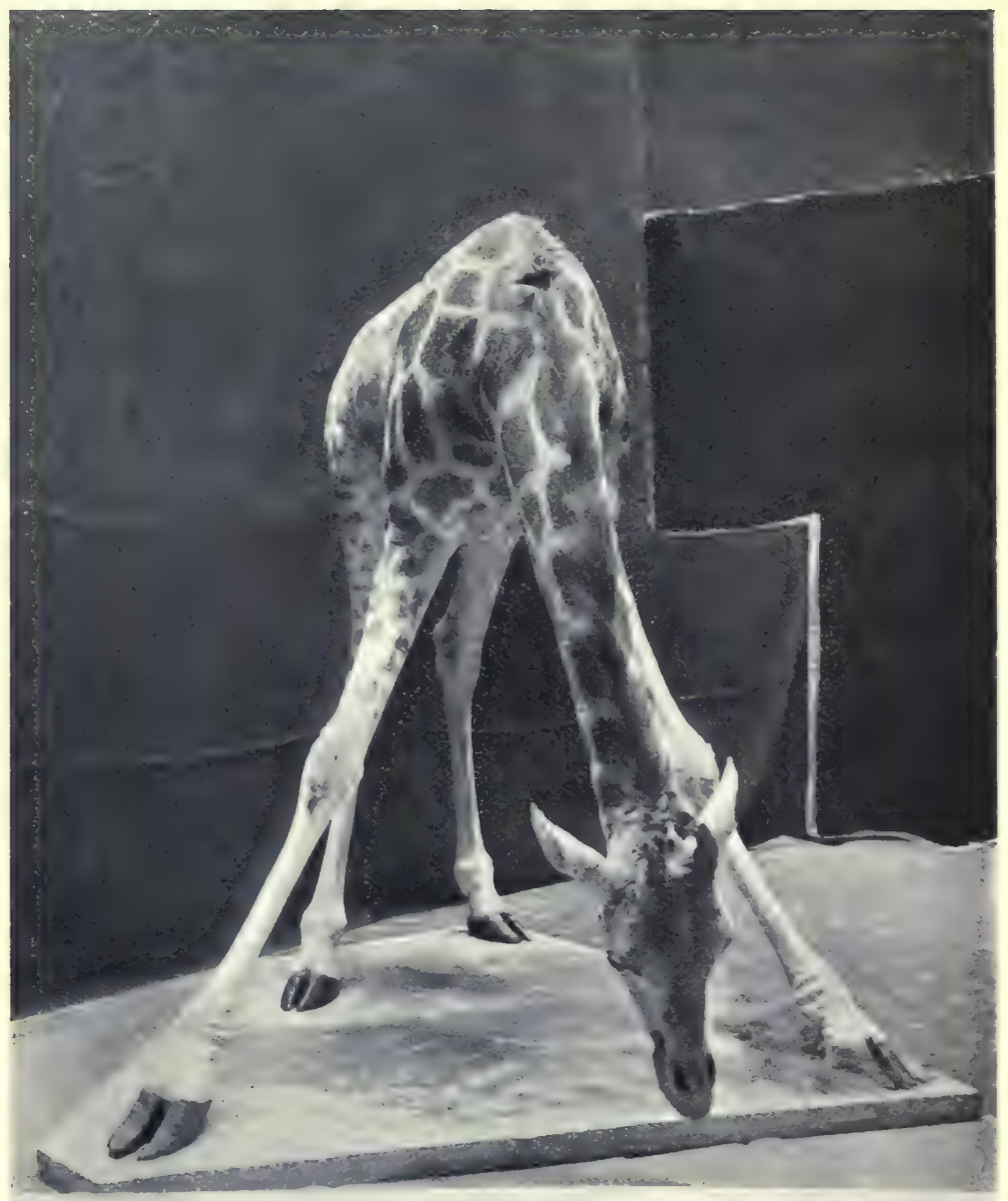

FIG. 36. The Giraffe drinking, showing the great difficulty which the animal has in reaching the ground, in spite of the length of the neck. (From a specimen in the Royal Scottish Museum.) 
Europe meant the absence of such reservoirs of disease, and accounts for the greater ease with which domesticated ungulates were introduced there. It has been suggested as a reason for the disappearance of so many ungulates from South America-for they were once abundant there - that they were killed off by some parasitic disease. If this were so, then with the disappearance of the hosts the parasites must have died also, leaving the field clear for reintroductions later. In Africa we have to notice that the tolerance of minute blood parasites-a tolerance doubtless originally acquired at the price of a fearful death-rate-is a means of protection of the existing forms against the intrusion of new and competing forms. The resistance to the trypanosomes carried by the tsetse-fly has even to some extent protected the antelopes from their great enemy man, for European hunters are constrained to avoid regions much infested by the tsetse on account of the difficulties of transport.

Another very beautiful ungulate which frequents all the open parts of Africa south of the Sahara is the giraffe, which shows a peculiar adaptation to life in the savana. The great elongation of the neck and of the forelimbs enables it to browse upon the leaves of the acacias and other trees of the scrub. Despite the length of the neck, however, drinking presents great difficulties, the animal being compelled to straddle its legs apart before it can reach to the ground. Grazing is similarly difficult, and is rarely practised. The giraffe inhabits arid country, notably the Kalahari desert, and, generally, sandy plains where the scrub on which it feeds occurs. It can apparently go many months without drinking. The animals go about in herds, and are capable of great speed. Only a single young one is 
produced at a birth, and when three days old it can trot by the side of its mother, who protects it from the attacks of carnivores by kicks with her powerful legs. The large eyes and the long neck give the giraffe a very wide range of view, very necessary in an animal which frequents open country.

Deer are usually absent from open plains, and are entirely absent, as we have seen, from Africa south of the Atlas. But in South America, where antelopes are totally absent, the deer extend their range to the plains and swamps. Thus the pampas of the Argentine and Paraguay, together with similar regions further south, are inhabited by the pampas deer (Cariacus campestris), which finds the necessary shelter among the long pampas grass. This deer occurs in pairs or small parties, and the female is particularly ingenious in protecting her fawn. The latter makes off through the grass on an alarm, and then cowers down, while the mother takes herself off in another direction in a slow and limping manner.

We have spoken of the camels of the steppes of the Old World, and have seen also that their allies, the llamas of the New, are intolerant of great heat, so that the tropical savanas, whether in Africa or in America, have no members of this family.

Of the odd-toed ungulates the rhinoceroses, as already mentioned, extend into the plains, this being especially true of Burchell's rhinoceros, a grass-eating form. Of the striped horses of Africa Burchell's zebra and the quagga are (or were) both inhabitants of the open grass-covered plains, but both are chiefly extra-tropical, inhabiting the vast plains of the extreme south of Africa. The African wild ass is similarly an inhabitant of the arid regions of North Africa. While Burchell's 
zebra and the quagga formerly occurred in vast herds, the wild ass, an inhabitant of a region where food is always scanty, occurs in smaller parties. Its sober tint harmonizes with the uniform colour of the desert, and the fact that the domesticated form will eat dry and prickly food points back to the days when its ancestors contented themselves with the thorny herbs of the desert. The stripes of the zebra and quagga apparently harmonize with the light and shade playing through the open bush country of their native haunts. It will be noted that the presence of the various forms of wild horses on the plains to the north and south of Africa, and their limitation chiefly to elevated regions in the tropics (Grévy's zebra), speaks to a relative intolerance of heat, a not uncommon feature in the larger ungulates.

As to the rodents, we note that in Africa those of the savanas are relatively unimportant, while in South America, with the paucity of ungulates, there are many large and important rodents.

We have already spoken of the jerboas, which extend from the steppes of Asia into the deserts of North Africa, and have noted their special adaptations. In the southern half of the continent the place of the jerboas is taken by the so-called jumping hare (Pedetes caffer), very common at the Cape, but extending northwards into Angola and Mozambique. While related to the jerboas the animal resembles the common hare in size and colour, but it has a long hairy tail, and elongated hind-legs. It feeds upon all-fours, but escapes from its enemies by taking long bounds, stated sometimes to cover as much as thirty feet. The animals are burrowers and nocturnal, and frequent arid districts. True hares also occur in Africa, but offer no special features. 
Among the various mole-like forms of Africa mention may be made of the little sand-rats (Heterocephalus) of the sandy deserts of Somaliland. These little animals -which are no bigger than a mouse-are nearly naked, perhaps as an adaptation to life in sandy soil. They resemble moles in having no external ears, and in their almost functionless eyes.

Of the rodents of South America the majority have a wide distribution, ranging from the true savanas southward to the pampas of the Argentine and the plains of Patagonia. The viscacha (Lagostomus trichodactylus), according to Mr. W. H. Hudson the most typical inhabitant of the pampas, extends beyond their limits, though scarcely into the savanas proper. On the other hand the mole-like tucotucos (Ctenomys) are burrowing animals, which occupy sandy regions from Brazil and Bolivia to the extreme south. The coypu (Myopotamus), an aquatic form haunting the banks of rivers and lakes, has an even wider distribution. Many species of cavy also occur, some being partial to moist situations, while others dwell in rocky regions. The largest Jiving rodent, the capivara or capybara (Hydrochoerus capivara) has a very wide distribution, and is aquatic in its habits, frequenting the margins of lakes and rivers, but also feeding on the open plains.

Of the South American Edentates most of the armadillos inhabit open country within the tropics, though some extend into extra-tropical regions. Most prefer arid regions, and feed on insects and carrion, together with some vegetable matter. The tiny pichiciago or fairy armadillo (Chlamydophorus) is found in sandy regions in the western part of the Argentine where the vegetation consists of cactuses and thorny brushwood. It burrows with great rapidity, and is very sensitive 


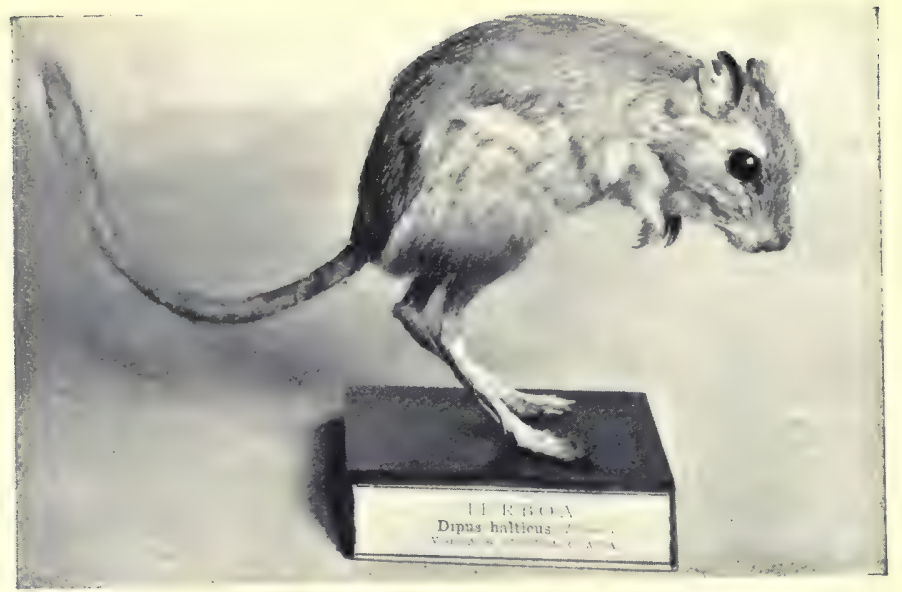

Fra. 37. Jerboa (Dipus) from Central Asia. (From a specimen in the Royal Scottish Museum.)

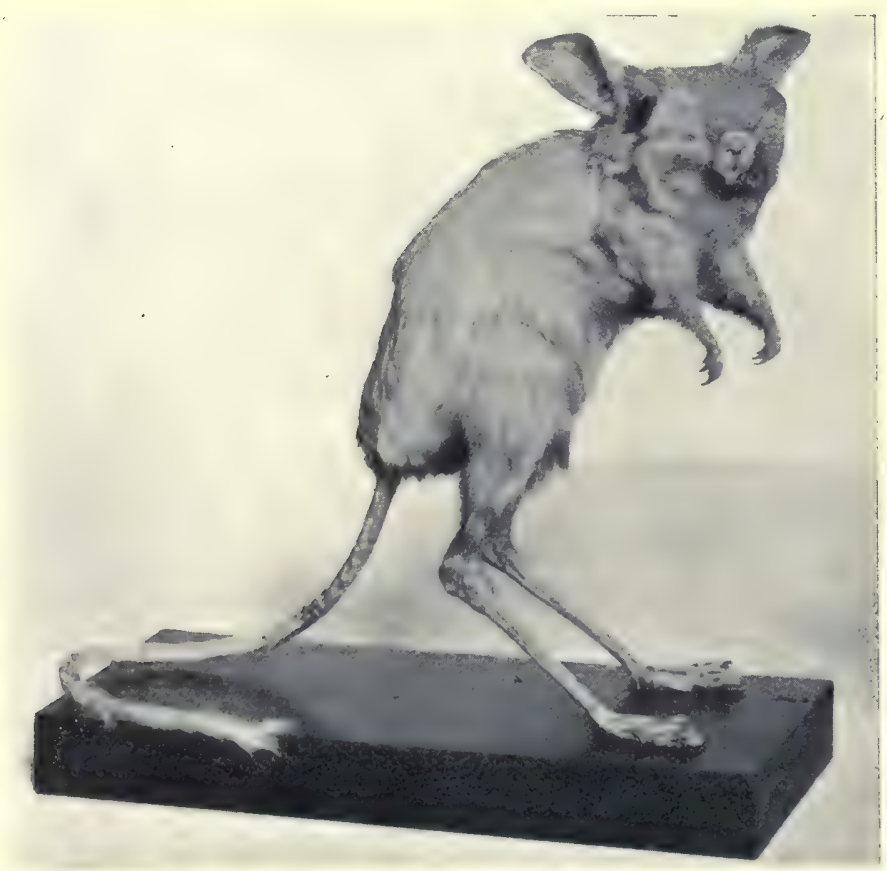

FIG. 38. The Egyptian Jerboa (Dipus). The animal is of a greyishsandy colour which renders it very inconspicuous in the desert regions in which it lives. (From a specimen in the Royal Scottish Museum.) 


\section{.}


to cold or wet. Another species is found in Bolivia. The members of the type genus Dasypus are widely distributed, being especially common in the Argentine. In addition to the protective covering of bony plates, they find security from their enemies in their burrowing habits, and in the fact that they are mostly nocturnal.

In Africa, where armadillos are completely absent, another curious edentate, the aard-vark or ant-bear (Orcyteropus) occurs in open regions, and is also of burrowing nocturnal habits, though it has no armour as the armadillos have. It seems to feed chiefly on termites, the so-called white ants.

Of the marsupials the kangaroos and their immediate allies are exclusively confined to the Australian region, and there they formed the natural fauna of the savanas till the advent of the European with his flocks and herds. The kangaroos and wallabies, with the exception of the tree-kangaroos already mentioned, are ground forms, feeding not only upon grass but also upon shoots of bushes and shrubs, or even in the case of the larger forms, on leaves, \&c., of trees, which they reach by standing in the upright position. The tail is long and strong. It aids the animal in maintaining the upright position, and also in running-that is, in leaping. We have already noticed the essential points of structure in the kangaroo; the elongation of the hind-limbs, without corresponding elongation of either forelimbs or neck, is an adaptive peculiarity which is far from uncommon in animals of the open plains. In the ungulates the other type of adaptation, that which consists in the elongation of both pairs of limbs, and therefore necessarily of the neck to permit feeding to take place, is the usual one. Just as among the rodents 
we have various stages in the elongation of the hindlimbs, and therefore in the development of the power of leaping, so among the kangaroos we have forms like the rat-kangaroos (Potorous) in which the elongation of the hind-limbs is much less marked, and which run on all fours, and cannot deliver the powerful kicks which are so important a part of, e.g., the giant kangaroo's means of defence. In the scrub of Queensland the firetoed kangaroo (Hypsiprymnodon moschatus) occurs, and in the structure and shortness of its hind-feet approaches the phalangers, showing that the true kangaroos have been evolved in response to the special conditions which prevail on the open plains, just as the jerboas on the Asiatic steppes have been evolved from ordinary rodents, or as the long-legged antelopes and giraffe have been evolved from the ancestral short-legged ungulates, in response to similar conditions. The nature of these special conditions has been already emphasized, but we may repeat that if an animal of the open plains cannot burrow, or defend itself passively in some way, it must be swift to escape its enemies, it must hare a wide range of vision in order to note their advance, it must have acute senses. We saw also in connexion with the ungulates that there is a marked tendency to reduction in the number of digits, to a fusion of limb bones, and so on, in order to give the necessary strength and rigidity for rapid movement. That the same need produces the same results is obvious when we note that the kangaroo has four toes on its hind-foot instead of five, and that of those four two are rudimentary, like the useless side toes in antelope or deer, though in the kangaroo the rudimentary toes have apparently a subsidiary use, for they are said to be employed in cleaning the fur. 
In one respect, however, the kangaroo shows a very striking contrast to the ungulates. We have noted that among the swift ungulates the tendency is for the young to be born very fully developed, able after a very short period to run by the side of the parent. The consequent long period of gestation is dangerous to the mother, but has apparently been justified in the struggle for existence by the higher survival rate of the young. Further, as we may note readily among domesticated sheep, the young ungulate, when suckling, is not allowed by the mother to satisfy its appetite completely-it must never be so satiated as to be incapable of flight. In the case of the kangaroo conditions are very different. The period of gestation is very short, and the young one is born in a very imperfectly developed condition, incapable of sucking and quite incapable of voluntary movement. It is placed by the mother in the pouch with which she is provided, and attached to the teat. Milk is then pumped into its mouth, by the action of certain of the muscles of the mother. Owing to this abundant food, growth is rapid, and soon the young one is able to move and leave the pouch. It however always returns to it on an alarm, and is not able to care for itself till it is some eight or nine months old. The mother shows great devotion to her young, but if hard pressed by dogs she will throw the young one out of the pouch into the fern, thus relieving herself of a weight which diminishes her speed. The action has been variously interpreted. According to some authorities the chances are that the dogs will neglect the young one and continue to chase the mother, who, if she escapes, will return to pick up her 'joey'. Others regard the action as equivalent to an abandonment of 
the young. In any case the fact that, with rare exceptions, marsupials have only succeeded in surviving in the Australian region, suggests that the placental method, that practised by the ungulates, has been justified in the struggle for existence as against the marsupial method, despite the greater risk to the mother before birth and at birth in the former method.

Only one kangaroo is produced at a birth. This is an interesting point, because a reduction in the number of young is frequent in animals which must escape with their young by flight when threatened, and do not attempt to defend themselves nor to hide. A similar tendency is well marked in the higher ungulates. But it must not be supposed that the kangaroo is entirely helpless. In the ungulates we find that, though the primary purpose of the elongation of the limb is to give swiftness, yet secondarily, e.g. in the horse, the powerful hind legs can be used as weapons. Similarly the kangaroo can use its long hind-legs to deliver heary blows, capable of killing a dog. Like so many denizens of open country, the animals are markedly gregarious.

In regard to the other marsupials we need only note that Australia contains various forms showing special adaptations to open grassy plains or desert regions, these adaptations exhibiting a curious convergent resemblance to those which appear among the placentals. For example, throughout the greater part of Australia the open grassy plains are inhabited by the so-called pig-footed bandicoot, a small animal with long hind-legs, remarkable in showing an ungulate-like reduction in the number of the toes. The fore-foot has two functional toes, the hind only one; the animals take both vegetable and animal food. The jerboas and jumping mice of other desert regions are represented 
in Australia by small marsupials of similar habit, notably by Antechinomys laniger, a little jerboa-like animal with long hind-legs, a bushy tail, and the habit of progressing by jumps. Again, the banded ant-eater (Myrmecobius fasciatus) shows the long extensile tongue common to ant-eating forms, and is found in sandy regions where ant-hills occur.

Among the inhabitants of savana regions, mention must be made of the running birds, which are specially adapted to these districts. The adaptations are well seen in the African ostrich (Struthio), distributed throughout Africa wherever the open sandy regions suitable to its habits occur, and found also in Syria, Arabia, and Mesopotamia. The great length of the legs and of the neck gives the animals a wide range of vision (cf. giraffe), the length of the hind-legs and the reduction of the number of toes to two gives them speed (cf. again the giraffe). Like the large antelopes with which the ostriches associate in the southern parts of Africa, the ostrich is a social animal, the gregarious habit, as in the ungulates, being associated with polygamy. The males are bigger and stronger than the females, and use their hind-legs as weapons when attacked. The young are active almost immediately after hatching, again recalling the precocious young of the ungulates of the steppes and savanas. Like many savana animals, ostriches can go without water for a prolonged period, but they drink freely if water is available.

In South America the place of the ostrich is taken by the rhea, which has three toes instead of two, and some other structural differences. The habits are somewhat similar. The birds are chiefly found on the pampas, which correspond rather to steppe regions than to savanas in the strict sense. 
In Australia and the neighbouring regions two other types of running birds occur, these being the emus and cassowaries, which resemble the rheas in having three toes, but of these the cassowaries are forest birds, rarely venturing out into the open. The emu, on the other hand, is a savana bird, haunting the plains and open country, where it eats a large amount of grass. The remaining living member of the group, the kiwi of New Zealand, like the cassowary, is an inhabitant of wooded districts.

Another interesting group of birds which inhabit the grassy plains of South America, though extending also into forest regions, are the tinamus, which show certain resemblances to ostriches, but possess the power of flight. They strongly resemble game birds in outward appearance, being popularly called partridges, but they do not fly nearly so well as the game birds, and rise with reluctance, preferring to skulk among the long grass. The flight is swift, but cannot be kept up for long at a time.

Among other birds characteristic of savana regions mention may be made of the bustards, of which many species occur in Africa, just as the common form occurs in the steppe regions of Asia. The curious secretary bird (Serpentarius secretarius) also, with its long legs, is very characteristic of the African savanas. Though it is capable of flying well and strongly, it prefers to run along the ground, like the ostrich. Its structure shows that it is allied to the birds of prey, and the fact that the young are very helpless, and are for long unable to run upon their elongated legs, suggests that the ground-haunting habit is a recent acquisition. The nest is a huge structure and is often placed in a mimosa bush. 


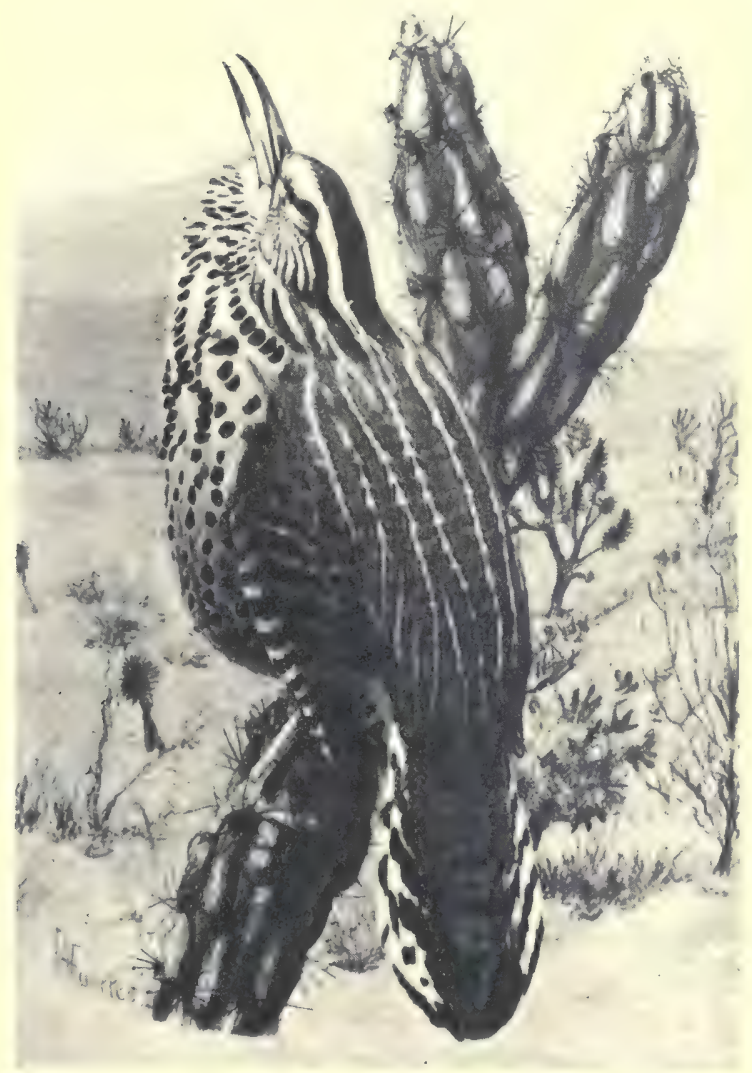

FIG. 39. The Cactus Wren (Campylorhynchus brunneicapillus), a characteristic bird of the desert regions of California and Texas, where it builds a complicated nest in cactus bushes. (Photo by the Biological Survey, U.S.A.)

In South America the place of the secretary bird in nature is taken by the seriemas, birds apparently related to the cranes, but showing a curiously close 
external resemblance to the secretary birds. The Brazilian seriema (Cariama cristata) haunts open districts with scattered bushes, and is a cursorial bird, though it roosts in trees.

There is nothing very characteristic about the reptiles of the savanas and hot deserts, but of the numerous lizards which occur there one or two may be named as showing interesting peculiarities. In the sandy districts of Western and Southern Australia occurs Moloch horridus, a lizard covered with spines and tubercles. It lives upon ants, and has the curious power of being able to absorb water through its rough skin. This is presumably an adaptation to permit the animal to avail itself of the rare showers which fall in the desert regions where it lives.

Somewhat similar in appearance are the 'horned toads' (Phrynosoma) of the desert regions in the warmer parts of the United States and in Central America. They also have a rough and prickly skin, and possess remarkable powers of burrowing. The animals are assisted in the process by a curious fringe at the sides of the body, and are said to appear actually to sink into the sand. They feed upon a variety of insects, and in colouring resemble the sandy soil in which they live. In the hot deserts of Northern Africa and the adjacent regions occur the skinks (Scincus), which are admirably adapted for desert life, their bodies enabling them to move through the soft sand as fish swim through water.

The presence of the lizards named, together with many others, speaks to the abundance of insects in desert and savana regions. These insects do not, as a rule, show any very marked adaptations, but we may mention the termites, or so-called white ants, as being 


\section{AND DESERTS}

very characteristic of the savana regions of Africa and elsewhere.

REFERENCES. All the books mentioned in the previous chapter as giving accounts of African animals, describe the inhabitants of the savanas as well as those of the forests. The books mentioned at the end of Chapter $\mathrm{X}$ also, as giving accounts of the zoological regions, describe among others the savana animals. Mention may also be made of W. H. Hudson's books, especially The Naturalist in La Plata (Londun, 1892); and of 'Tristram's Flort and Futna of Palestine (London). 


\section{CHAPTER VII}

\section{SPECIAL FEATURES OF ISLAND FAUNAS}

ISLANDS present some interesting features as regards their animal life which makes them worthy of special study. We have already seen that mountain areas have special types of animals, because they form isolated regions cut off by the physical conditions from the neighbouring districts. The special conditions in their case include both climate and topography, and in whatever region of the globe the mountains occur, if they are greatly elevated, the climatic conditions are similar. Islands are regions cut off from neighbouring regions by the sea, which forms a barrier to the passage of all but the marine and the flying animals. Even to flying animals a large expanse of sea may constitute a formidable barrier, save in the case of those with exceptional powers of flight. The consequence is that island faunas form a whole, and can be studied with much more ease than the animals of any other natural region. The question whether a particular animal does or does not occur in an island is merely a question of observation; while that as to whether a form found on a mountain does or does not constitute part of the mountain fauna is a much more delicate one, involving an elaborate process of reasoning. In the one case a gradual migration with concurrent adaptation is possible from plain to mountain or vice versa, but no such slow migration is possible in the case of islands.

On the other hand, it is to be noted that while 
mountain animals, like those of steppes or forests, are exposed to virtually uniform conditions of climate, \&c., no such uniformity exists in the case of islands. We speak, it is true, of insular climates, meaning that the proximity of the sea has a certain moderating effect, more especially if there is a large expanse of ocean all round, or if the prevailing winds blow from such an expanse. But even within the same island there may be great variations of climate, and there may be almost all types of surface-mountain, wood, steppe, tundra, and so forth. Thus, while the inhabitants of islands may be readily counted and classified, and form a statistical unity, they do not form a biological unity in the sense that the animals of the other natural regions do, and there are few general statements which can be made of them as a whole.

The special features of island faunas may best be illustrated by a few examples, and we may begin by a consideration of the Galapagos Islands, an interesting group which has been studied by various naturalists, including Darwin.

This archipelago consists of a group of islands lying some seven hundred miles off the coast of Ecuador, and on the equator. They are of volcanic origin, the surface being covered with extinct craters, and are placed upon a submarine bank, which rises steeply from the depths of the Pacific. The climate is singularly cool for the position, this being due to the fact that the islands are washed by the cold Humboldt current. In the lower regions of the islands the rainfall is markedly deficient, rain only falling in small amounts in the earlier months of the year (FebruaryMay). Here the vegetation is scanty, and xerophytio in character, the most important plant from the 
economic point of view being the archil lichen from which the dye called litmus is obtained. Darwin describes this lower zone as uninviting in the extreme, the scanty brushwood leaving the black basaltic lava exposed, and giving the district the appearance of an iron-smelting region in the 'black country' of England. But the clouds hang low, and above an elevation of about eight hundred feet not only is there abundant rain during the rainy season, but even at other seasons a constant mist keeps the vegetation fresh. The plants of the two regions differ fundamentally, and in the upper cultivated plants from many climates thrive. Of the native vascular plants, about one-half are peculiar to the islands. The group consists of five principal and eight small islands, with a total area of nearly 3,000 square miles. The hills range in height from 3,000 to 4,000 feet. The more conspicuous bushes and trees are species of euphorbia, cactus, and acacia, so that the islands generally resemble savanas and desert regions in their vegetation. Palms are entirely absent.

Turning now to the fauna, we find that mammals are practically absent. There are two mice, but of these one belongs to the widely distributed genus Mus, and has doubtless been introduced; the other belongs to a South American genus (Hesperomys), and has also possibly been introduced. That there is nothing in the conditions of the islands to prevent the existence of even large herbivorous mammals is, however, shown by the fact that goats, pigs, horses, \&c., introduced by man, have become wild, and have multiplied exceedingly.

The birds present some interesting features. About seventy species, according to Wallace, have been 
obtained in the islands, and of these forty-one, or considerably more than half, are peculiar to the islands, not being found elsewhere. Most of those which are not peculiar are birds with considerable powers of flight, capable of travelling great distances. Of the true land birds all but one are peculiar, and this one is the common rice-bird (Dolichonyx oryzivorus), which occurs throughout the whole of the American continent. This bird is markedly migratory, spending its winters in the West Indies and Central America, and travelling northwards in vast numbers to breed and spend the summer in the northern United States and Canada. There is, therefore, nothing improbable in the supposition that stragglers from the migrating flocks reach the Galapagos Islands from time to time, and so prevent an island type from establishing itself. The other land birds of the islands show, as Wallace points out, all gradations from close resemblance to forms occurring elsewhere to generic difference. Thus the archipelago contains a special owl-Asio galapagensis-but this is very nearly related to the widely distributed shorteared owl (Asio brachyotus). On the other hand, among the finches peculiar genera occur, e.g. Geospiza, related to genera of restricted range found on the continent of South America. Again, though the islands are relatively so near together, a peculiar genus may be represented by three different species on as many different islands. This is well exemplified in the case of the honey-creepers of the genus Certhidea, the three species of which occur on different islands.

The reptiles of the islands are especially remarkable. The giant tortoises have long been famous, and give the islands their Spanish name. Such giant tortoises occur only on islands, being found in certain islands in 
the western Indian Ocean, and in the Galapagos archipelago. In addition to their large size the animals have as special peculiarities the fact that they show much individual variation, and tend also to split up into species, different species occurring on adjacent islands. No small tortoises occur on the islands containing these large forms. A final peculiarity is that the bony carapace tends to be reduced in thickness, perhaps because till man came the animals had few enemies. The diet is exclusively vegetarian, and the animals occur in both the upper well-watered region and in the lower arid region. The fact, however, that they drink greedily, and are fond of wallowing in muddy water, suggests that they are not native to arid regions. Darwin gives an interesting description of the long journeys made by the low-ground tortoises to the springs of the upper region, in order to obtain water. The cactuses of the arid regions form a favourite food plant. The exact number of species is a matter of doubt, owing to the individual variability already mentioned.

In addition to the giant tortoises, the Galapagos possess both lizards and snakes. Two of the lizards are very large and of very peculiar habits. One (Conolophus subcristatus) is found only on the central islands of the archipelago, and occurs both in the upper and lower regions, but more abundantly in the latter. The forms from the arid districts, however, do not travel upwards to the springs to drink, and are far more numerous than the upland forms. As the diet of these lizards is quite similar to that of the tortoises, it would seem that originally the lizards inhabited the arid ground, and the tortoises the damp upper regions, but each has become partially adapted to the territory of the other. The lizards reach a length of a yard, and 
have stout heavy bodies. They are very partial to cactuses, but also climb the acacia trees to feed upon the foliage.

Closely related to Conolophus, and therefore like it one of the iguana family, is the marine lizard Amblyrhynchus cristatus. It also is entirely peculiar to the islands, and is the only lizard known which is marine in habitat. It inhabits the shores of most of the islands, and feeds upon seaweeds which grow below tide mark, and, as Darwin proved, it can tolerate prolonged immersion without any ill effects. It will be recollected (cf. p. 116) that the typical iguanas are forest animals. The exceptional conditions to which the forms in the Galapagos Islands are exposed has made it necessary for these to adopt modified habits.

The family Iguanidae is further represented in the islands by various peculiar species of the genus Tropidurus, other members of which occur on the continent of South America. Various species of geckoes belonging to the widely distributed genus Phyllodactylus also occur, most of these being peculiar to the islands. There are also two snakes, both being nearly allied to South American forms.

Amphibians are entirely absent. Of the invertebrates the insects are few in number, but show the same characters as the other kinds of animals. In other words, most of the species and many genera are peculiar, and the forms tend to have a limited distribution among the islands, very few being found in all the islands. Further, there are many wingless forms, a common feature in island insects.

It is not necessary to describe the fauna of other islands of the same type as the Galapagos archipelago in detail, for the general characters are the same in 
all. Islands which do not lie very near a continent, and are separated from the nearest continent by deep water, that is, do not lie upon the same continental shelf as the continent, show great general similarity as regards their fauna. In such islands there are no indigenous land mammals, often with the doubtful exception of mice and rats, animals readily introduced by man. Amphibians are also absent, a fact readily explained when we recollect that both the eggs and adults are very intolerant of salt, and therefore could not be readily transported across sea-water by floating logs of wood or any similar means. In such islands generally the commonest land forms are birds and invertebrates, especially insects and land shells. These in all cases tend to run into local races, due apparently to the isolation of the stock. Further, flying forms tend to lose their wings or to possess only limited powers of flight. This is very marked in some birds, thus the flightless dodo, the solitaire, the kiwi of New Zealand, and so forth are all inhabitants of islands. It is noticeable that the power of flight tends specially to diminish in animals found in islands much exposed to hurricanes, for here even short flights might expose the animals to strong winds, which would sweep them out to sea, and thus destroy them, while those which flew little or not at all would be more likely to breed and continue their own type.

Reptiles are not very frequent in islands separated by deep water from continents, and the presence of the large tortoises in the Galapagos Islands is held by some to indicate a connexion, at a remote period, with the continent of America. Wallace, on the other hand, believes that the ancestors of these forms were accidentally introduced, possibly on floating timber. 


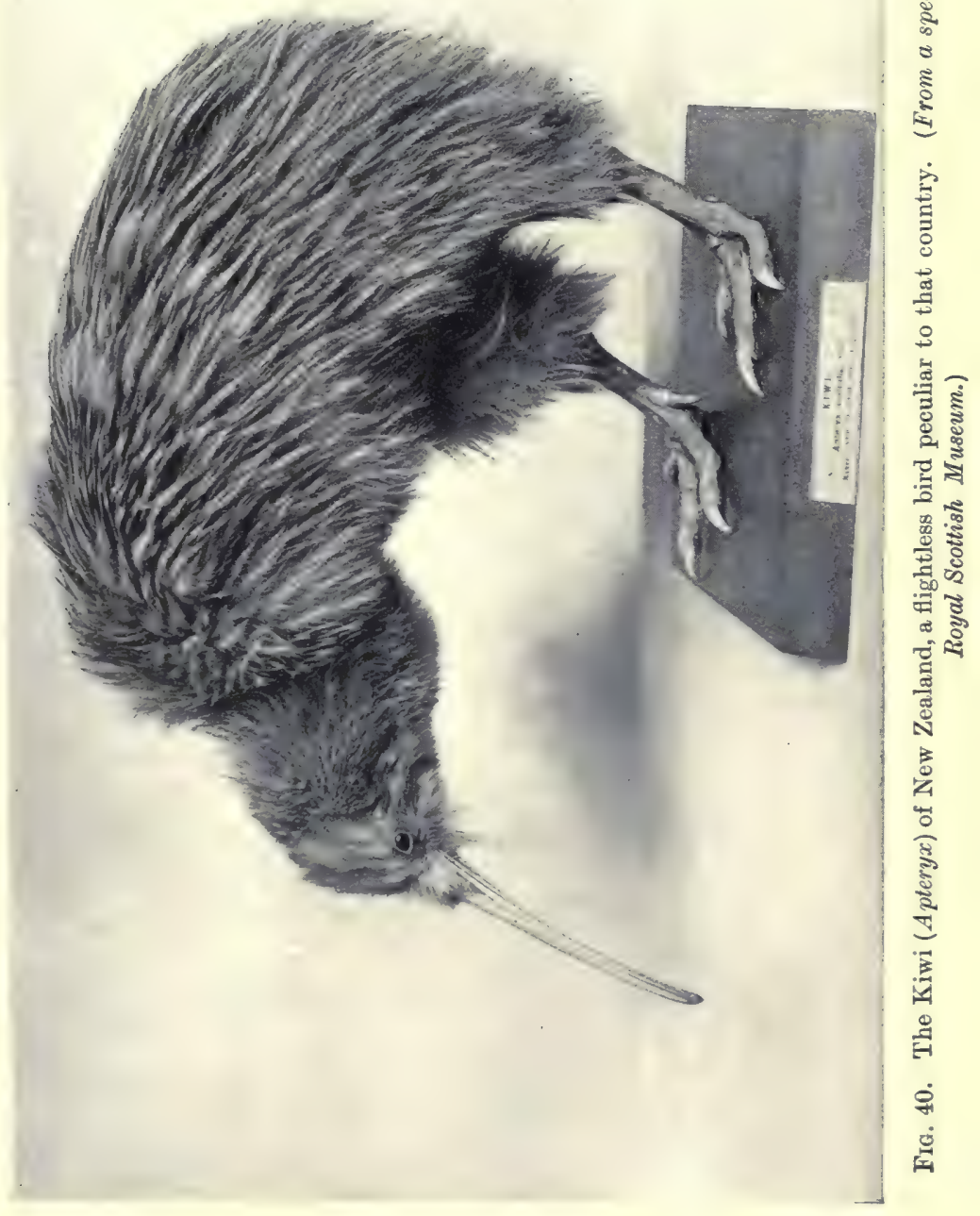



Generally the fauna of islands like the Galapagos, called oceanic by Wallace, is such that its members may be supposed to have been, at least to a large extent, accidentally introduced-by storms carrying winged animals out of their usual course, or by mechanical transportation on floating wood, \&c. Incidentally we may note that the absence of mammals on oceanic islands has often important human consequences, for the paucity of sources of animal food tends to make their human inhabitants cannibals.

As contrasted with oceanic islands we have the islands which are obviously merely separated portions of the adjacent continent upon whose continental shelf they stand. A good example is furnished by the British Isles, whose fauna is very similar to that of the adjacent continent, but shows impoverishment in several respects, apparently as a result of the glacial period. As Ireland was apparently cut off from the continent before Great Britain, and at a stage when many of the animals driven south by the ice had not had time to recover lost ground, we find that iț fauna is poorer even than that of the larger island. The following figures, quoted from Wallace, will help to render the above statements more precise. Scandinavia possesses about 60 species of mammals, Great Britain 40, and Ireland 22; Belgium has 22 species of reptiles and amphibia, Great Britain 13, and Ireland only 4. The question as to the number of peculiar forms in the British fauna has been actively debated. That the red grouse (Lagopus scoticus) of the northern regions is peculiar is generally admitted, though it is nearly allied to the willow grouse of Scandinavia. We have also some peculiar fresh-water fish, most of which occur in lakes. The differences are, however, not very striking, 
and are no doubt due to the fact that the chances of the fish of one loch interbreeding with those of another are very small. There are also a considerable number of peculiar species or varieties of insects, but nothing comparable to the differences which separate the animals of the Galapagos Islands from those of the adjacent mainland. To add point to the contrast we may note that the area of the British Isles is in round numbers, 121,500 square miles, as contrasted with the 3,000 square miles of the Galapagos Islands. Suchislands as the British Islands are called by Wallace continental, in contrast with the oceanic type.

One more example of an island fauna may be given. In this case we shall take Madagascar, which is of the continental type, but is separated from the continent of Africa by a channel so deep and wide that it must be supposed that the connexion between the two was broken at an extremely remote period. The total area of this large island is nearly twice that of the British Isles, and there is much forest. The fauna is remarkably rich, and is as markedly characterized by the animals it includes as by those of which it is devoid. Thus the island has no monkeys in its wide tropical forests, but has some thirty-three species of lemurs, which constitute half the mammalian population of the island. Insectivores are fairly numerous, and include in the tailless hedgehogs (Centetes) primitive forms whose nearest allies appear to be some shrews in the West Indian Islands. There are not many carnivores, and no true cats, but in addition to eight civets there is a relatively powerful animal called Cryptoprocta, about the size of a common cat, which belongs to the civet group. There are few rodents, and the enormous wealth of large ungulates, which is so 
characteristic of the continent of Africa, is here scarcely suggested, for that important order is only represented by a river-hog and a subfossil pygmy hippopotamus. Both the species and genera of mammals are strikingly peculiar; thus it appears that of the twenty-four mammalian genera of Madagascar only two occur in Africa.

The birds are not quite so peculiar, but they also show, though to a less degree, the same feature of the absence of the African forms which would be expected, and the presence of primitive or peculiar forms. Among both snakes and lizards we find the peculiar feature that American forms are represented; among the lizards by two Iguanidae, otherwise peculiar to America. The other lizards are mostly peculiar members of African families, but a special feature is the number of chameleons, and the absence of the monitors, which are abundant in Africa. There are no poisonous snakes. The amphibians are remarkable, for they present affinities both with the Indian region and with South America. The beetles, again, show affinities with those of India, Australia, and the Malayan region.

Without considering in detail the various questions raised by these peculiarities, it may be sufficient to say generally that Madagascar was formerly connected to Africa, and perhaps also through a chain of islands to India. The connexion was broken before the higher forms of life, e.g. the monkeys, the higher ungulates, \&c., had penetrated Africa, and consequently the original mammalian and other fauna of Madagascar was primitive in type. Saved from the competition of higher forms by isolation, and favoured by the abundant food, the absence of enemies, and the great forest area, many forms, notably the lemurs, have reached a high 
degree of specialization along their own lines, and have evolved in many different directions.

If we sum up the more important general points in regard to island faunas, we may note first that Wallace's distinction into oceanic and continental islands is not of very great practical importance, because the progress of geology, since the classification was laid down, has made it difficult to apply. It involves a conception of the permanence of ocean basins which is not now generally accepted. Thus, while Wallace names the Galapagos group as a characteristic oceanic group, others believe that the presence of giant land tortoises is in itself a proof of a former land connexion. For our purpose then it is sufficient to recognize the following three conditions:

1. When an island has never had a connexion with a continent, e.g. many coral and volcanic islands, or has only had such a connexion at a geologically remote period (Galapagos?) before the higher forms living at the present day had originated, or before they had had time to become widely distributed, its fauna contains no mammals, no amphibia, (1) no reptiles, or (2) reptiles of a very primitive type, or (3) such as could be accidentally carried by floating wood, \&c. The most important members of its fauna will be birds, insects, and land shells. Owing to the isolation the animals will tend to exhibit special peculiarities, fitting them for their habitat. Among flying forms the conditions favour those in which the power of flight is moderately developed, or has disappeared. Examples of such islands are the Azores, the Bermudas, St. Helena, the Sandwich Islands, \&c. Where such islands have had a continental connexion, this must have been prior to the deposition of the lower Tertiary beds, for at this 
time mammals were evolving rapidly and spreading widely.

2. When an island has been separated from adjacent land masses for a moderately long time, i. e. since the middle of the Tertiary period, it will tend to have a rich fauna, including representatives of all the chief classes and phyla, but the more modern classes will be represented by primitive forms, their primitiveness depending on the length of the period during which the island has been isolated. Of such islands Madagascar and the adjacent islands of the Indian Ocean are good examples.

3. When the separation of an island from the adjacent continent has taken place within geologically recent times, i. e. in the Pleistocene or Post-Pleistocene period, the fauna will be in all essentials similar to that of the adjacent land mass, though minor differences may occur. Examples are the British Isles, Japan, Borneo, Java, \&c.

In other words, the most satisfactory classification of islands from the point of view of their fauna depends upon the approximate length of time since which they have been isolated.

References. Wallace's Island Life (second edition, London, 1892) is the classical work dealing with the subject, which is also discussed to a minor extent in the same author's Darwinism. A very interesting account of the Galapagos Islands will be found in Darwin's Journal of Researches into the Natural History and Geology of the Countries visited during the Voyage of the 'Beagle' (London, 1843). The subject is also fully treated in Beddard's Text-book of Zoogeography (Cambridge, 1895). See also Dobson's, On Some Peculiarities in the Geographical Distribution and in the Habits of certain Mammals inhabiting Continental and Oceanic Istands (Ann. Nat. Hist. xiv. 1884). 


\section{CHAPTER VIII}

\section{THE DISTRIBUTION OF ANIMAL LIFE IN THE SEA}

WhILE, as we have seen in the previous chapters, the natural regions of the land more or less grade into one another-savana, for example, passing into savana wood, and savana wood into forest, it is very much easier to separate the oceans into natural regions, for here the divisions are relatively sharp. The two great conditions which influence the type of animal to be found within any part of the sea are, first, the presence or absence of light, and, second, the presence or absence of a substratum. At the margin of the sea, where the light penetrates to the bottom, we have the littoral area, peopled by littoral organisms. All these organisms agree in that, in structure or in habit, they show adaptations to the two striking features of the area. Thus a sea anemone, fixed to a rock and containing symbiotic algae, is obviously adapted for life in a region where a substratum is present, and where light penetrates. A plaice, so shaped that it is adapted for lying on a sandy surface and bearing well-developed eyes, is similarly fitted. But the dependence of a mud-haunting animal feeding upon minute algae upon littoral conditions is no less real, if less apparent, for landderived mud only accumulates off shores, and the minute algae must have light before they can live.

In the open water occurs another group of organisms, 
constituting the pelagic forms, which require no substratum, but for the most part demand light, and usually display sensitiveness to it. Finally, at the bottom of the ocean, in the great depths, we have forms entirely independent of sunlight, but directly or indirectly dependent upon the presence of a substratum. These are the abyssal animals, whose existence was first fully demonstrated by the Challenger expedition.

We can thus divide the inhabitants of the ocean into three well-defined classes, each class showing adaptations to a natural region. These three groups are (1) the littoral, (2) the pelagic, and (3) the abyssal, each of which we must consider separately. As we shall see, the members of the different groups do not necessarily restrict themselves throughout their whole life history to one of the natural regions. It is, for example, very common to find that littoral forms have pelagic larvae, or pelagic stages in their life-history, able to take advantage, for purposes of distribution, of the many currents which influence the surface waters of the sea.

(1) The littoral zone extends outwards from the margin of the land to the edge of the continental shelf, or roughly to the one hundred fathom line. Beyond this line the sea-bottom usually slopes rapidly in the Continental Slope to the great depths, where the littoral animals are replaced by the abyssal ones. Shallow seas, such as the North Sea, contain only littoral and pelagic animals. Throughout its extension the littoral area is characterized by its great wealth of food, and its great variations in the physical conditions. The basal sources of food are here three : (1) the waste of the land, (2) the fixed algae of the shore rocks, (3) the minute floating algae or phyto- 
plankton. The importance of the waste of the land may be realized if we think of the number of marine animals which find food in the mud-deposits which accumulate round the mouths of rivers and estuaries. If the water be fairly clear, such estuaries are specially favourable to shell-fish like mussels and oysters ; to many marine worms, which in their turn feed many fishes ; to many small crustacea, which also feed fish; and so forth. This land-waste has only a limited seaward extension, and is not available as a source of supply either for the pelagic or for the abyssal animals.

The fixed algae can only grow where some firm surface to which they can attach themselves exists, and where the sunlight is strongly felt. They are therefore limited to the margin of the lands, but there form rich feeding-grounds. The Laminarian zone, which lies just beyond low-tide mark, has always been known as a rich collecting-ground. It contains many small forms - crustacea, molluses, worms, coelenterates, and so forth-perfectly adapted to life among the long brown fronds and about the branching roots. At high tide this zone is covered with a sufficient depth of water to be available as a pasture ground even for the larger fish, and here therefore shore animals cluster, and the fisherman reaps rich harvests.

Finally, in the shore waters minute algae swarm. In their habits and adaptations most of these are pelagic, that is apparently independent of the presence of a substratum, but the fact that there is considerable difference between the phytoplankton of the shore water and of the open sea, suggests that these forms are in some way indirectly affected by the proximity of the sea-floor, or by the waste of the land. Diatoms, especially, which are eagerly consumed by many 
animals, are represented in the shore waters by many species-by more than in the open ocean. But, it may be asked, if these algae have no attachment to a substratum, how do they contrive to remain in the shore waters, in spite of currents and tides which must tend to sweep them seawards? The answer is apparently that myriads are so swept out into the ocean, but there they degenerate, and probably do not live long. Produced in the shore waters, their destiny may be to serve as food for the pelagic animals of the open seas, but they no more form a true part of the life of the pelagic area than does that shoreborn weed which floats at the surface of the Sargasso Sea for a period, ere it perishes and is replaced by new fragments torn off by the currents.

Of the physical peculiarities of the littoral area the constant movement of the waters is characteristic. Tides and currents, in all the open seas, ensure that no stagnation shall occur, and thus keep the water sweet, and bring constant supplies of food and oxygen. It is this constant movement which helps to give the shores of the oceans so much richer a fauna than the shores of lakes, or of enclosed seas like the Mediterranean or Black Sea. The constant movement brings with it also a danger, whose influence is manifest in several ways. Some of the shore forms are swift swimmers, strong to stem the tide, and yet, notwithstanding their strength, the shore naturalist knows that off many coasts he is sure of a rich harvest when wind enforces tide or current, for the beach at certain seasons is strewn with flotsam and jetsam. Many shore fish, the strong cuttles among molluses, powerful forms like porpoises and dolphins and even whales-there are times when the strength of these avails them nothing 
against the movement of the waters, and they are found dead or stranded on the beach.

The weaker abandon the attempt to struggle against the waters-the lumpsucker and the gobies among fish, the limpet among molluscs, the acorn shells and bar. nacles among crustacea-these do not attempt to resist the tides, but cling tight and allow the danger to pass.

Another danger, quite as real, though not so obvious, which the shore forms must guard against is the constant change of temperature and of salinity in the sea water, which is characteristic of the shore. The temperature of the oceans varies much, and is influenced by local causes, but the shore waters especially are greatly affected by the variations in the temperature of the land, that is by latitude. In tropical waters the range of temperature is small (about $10^{\circ} \mathrm{F}$.), and the mean temperature is high (about $80^{\circ} \mathrm{F}$.). In polar waters, while the range is similarly small, the mean temperature is low (about $28^{\circ} \mathrm{F}$.). Between the two, in temperate regions, the range is considerable, while the mean is neither high nor low. Nowhere, of course, can the ranges of temperature in the sea be compared with those on land, owing to the high specific heat of water. We find, however, that very many land animals, for instance all the warm-blooded ones, have a heatregulating mechanism, whereby they can adjust themselves to changes of temperature. Such a mechanism is absent in all sea animals except those (e.g. whales, \&c.), who are descended from terrestrial ancestors. According as they can or cannot tolerate variations in the temperature of sea water, sea animals may be divided into eurythermal and stenothermal forms. The former are tolerant of great variations, the latter are rapidly killed by them. Speaking generally, the 
littoral animals of temperate latitudes must be eurythermal, while those of tropical and of polar seas may be stenothermal. As the actual temperature in the case of many stenothermal animals seems to matter less than its constancy, the temperate zone must form a barrier between the animals of the two other zones, and more or less prevent their mixing. Further, as sudden changes are always more dangerous than gradual ones, the contact of a cold current with a warm one seems often to lead to a great destruction of animal life, though this perhaps affects pelagic animals more than littoral ones.

Variations in the salinity of the water seem to have similar effects, and Hjort states that of the seventeen species of the cod family found in the North and Norwegian Seas, each one seeks out a special spawningground, having its characteristic depth, temperature, and salinity, a fact which may be partly due to greater susceptibility of the larvae than of the adults to minor variations in pressure, temperature, and salinity.

Something must now be said as to the characters of shore animals. In the chapter on the tundra we mentioned some of the common forms to be found in Arctic regions, and to that account some more general statements may be added. Of the marine mammals we must regard all the seals and the walrus as littoral forms, for though many show a perfect mastery of the water, all come on shore for breeding purposes, and thus are dependent on a substratum, at least at certain seasons. In addition to the seals already mentioned, we have the true fur-seals (Otaria), which occur in the north, outside the Arctic area, and the many seals of the Far South, such as Weddell's seal (Leptonychotes weddelli), Ross's seal (Ommatophoca rossi), the crab- 
eating seal (Lobodon carcinophaga), the sea-leopard (Stenorhynchus leptonyx), which all occur in the region of ice-pack, while the sea-elephant (Macrorhinus leoninus), and the southern fur-seal (Otaria jubata) occur in sub-Antarctic seas as well as elsewhere. The fact that all these different kinds of seals tend to occur in cold regions cannot be ascribed wholly to deliberate choice on their part, for the young of all are born on the land, and the animals seek out places as free as possible from molestation, which are more frequent in polar seas than elsewhere. Since man joined their enemies many species are being driven further and further back into the inaccessible parts of the polar seas, or have been virtually exterminated.

The seals, walrus, and sea-otter, the last named being a fur-bearing animal found off rocky coasts in the North Pacific, are all carnivores which have taken recently to the aquatic life, and are still bound to terra firma at the breeding season. There are, however, two orders of mammals whose members are entirely aquatic, their young being born under water. These are the Cetacea or whales and dolphins, and the Sirenia or sea-cows. The former are powerful swimmers, and are pelagic. Their only connexion with shore is that the greater abundance of fish in shallow water brings many of them to the vicinity of submarine 'banks', while the whalebone whales haunt relatively shallow water in high latitudes, because of the abundance of small marine organisms there.

The Sirenia include only two living animals, the dugong (Halicore) found in the Pacific and Indian Oceans, and extending southwards to the shores of Australia, and the manatee (Manatus) which lives in the estuaries of the great rivers which flow into the 


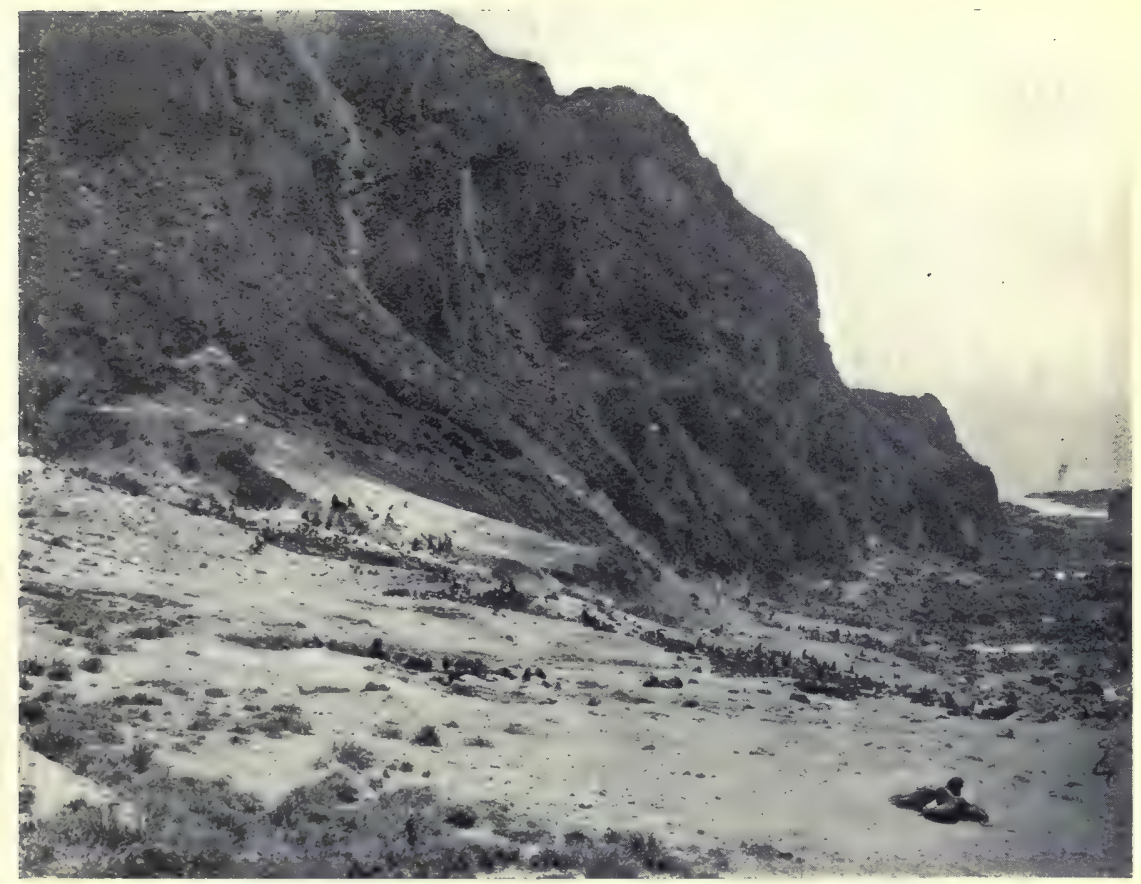

FIG. 41. The shore of Copper Island, in the Bering Sea, showing a Rookery of Fur-seals. The seals prefer the rocky portion of the beach close to the water, and only the weaker forms, unable to obtain a foothold there, haunt the smooth ground at the back of the rookery. (Photo by Prof. D'Arcy W. Thompson.) 


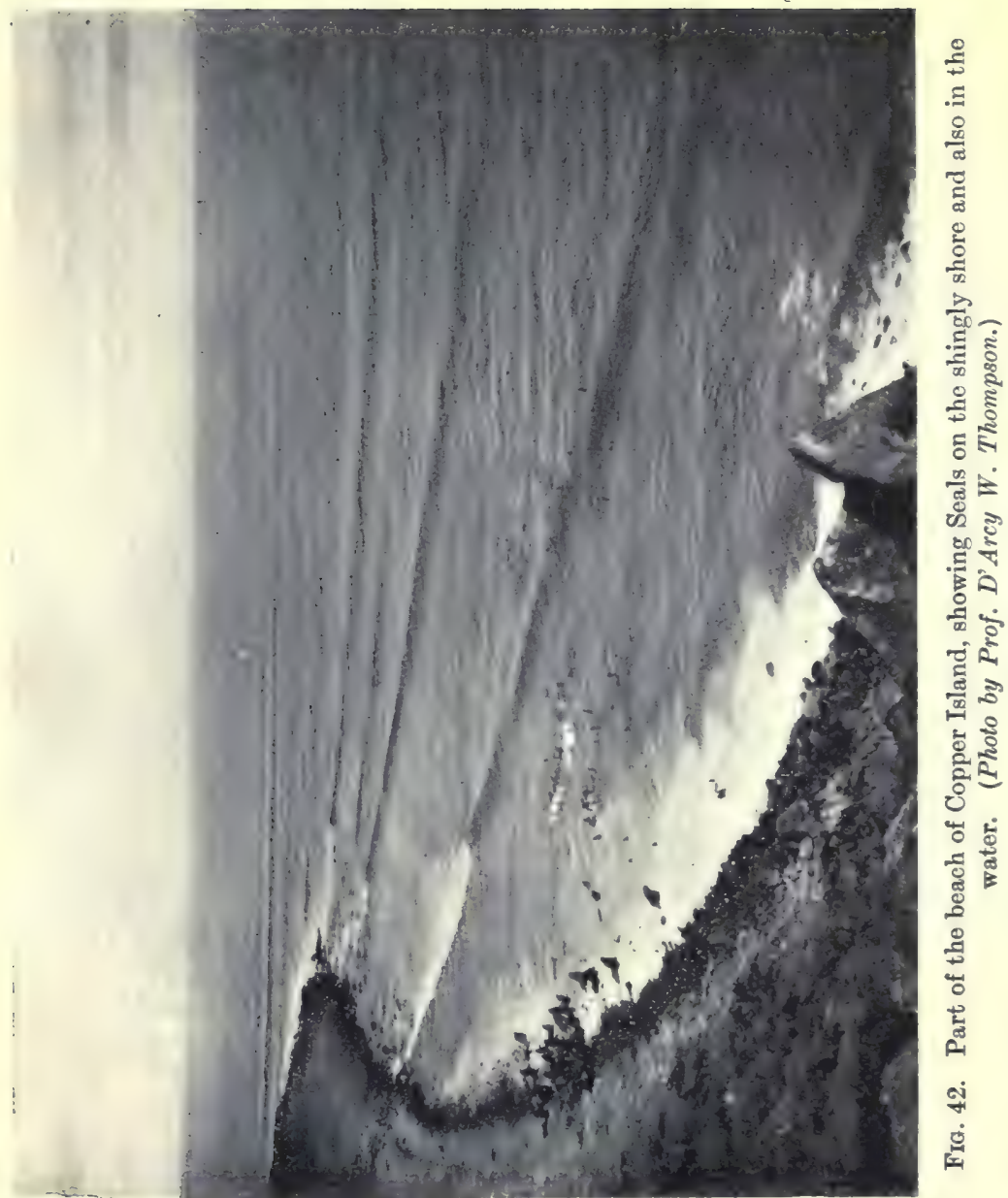


tropical part of the Atlantic, and in shallow bays or lagoons. Though both spend their whole life in the water, and are helpless outside it, yet both are definitely littoral, for they feed upon the large algae, and could therefore find no food in the open sea. The manatee apparently takes a large variety of aquatic plants in addition to algae. The animals are not nearly such good swimmers as the Cetacea, and their heavy bodies and massive bones fit them for life near the bottom. The hind-legs are entirely absent, but the fore-limbs may touch the ground as the animals swim leisurely along the bottom, and are also used in pushing food into the mouth, and in carrying the young, which are suckled above water.

Of the littoral birds perhaps the most interesting are the flightless penguins, which present the same features as the seals in that, though pelagic for much of the year, and having a perfect mastery of the water, they must come on shore for breeding purposes. The absence of any carnivorous land mammals in the Antarctic area, and its inaccessibility, make it a perfect paradise for the penguins, who resort to its rocks and beaches in millions to breed, and have been described by all the Antarctic expeditions (see Fig. 44). Quite comparable in habits, though not related, was the extinct great auk (Alca impennis) of the shores of the North Atlantic, which was similarly incapable of flight, and fell an easy victim to man during the breeding-season.

Of the other birds which feed in the sea and frequent it, some, like certain of the seagulls, forsake it at the breeding-season for inland regions. Others, like little auks, guillemots, puffins, gannets, and so forth, breed on the shore, choosing cold or inaccessible regions for the purpose. Of the various adaptations to such 
breeding-places which they show the commonest is the pointed egg, which does not roll off the rocks readily, while the eggs themselves are frequently protectively

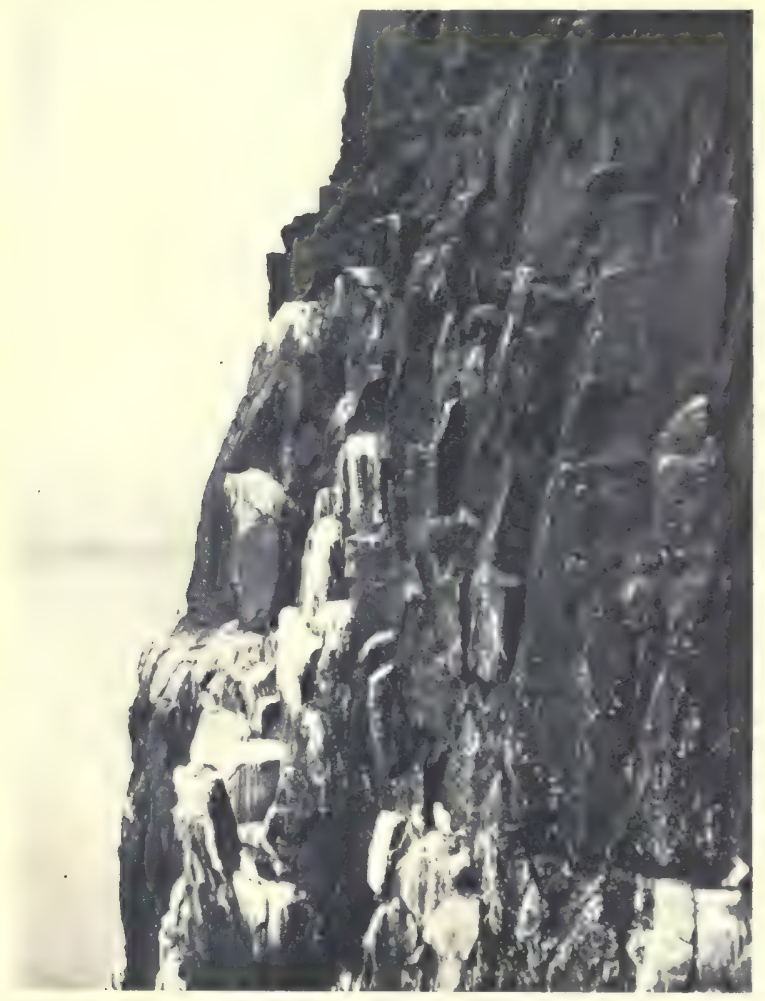

FIG. 43. Kittiwake Gulls nesting on basaltic pinnacles on May Island, ', in the Firth of Forth. (Photo by Mr. George West.)

coloured, except where, like those of the puffin, they are concealed in holes.

Of the reptiles relatively few are marine animals, the habit being most frequent among the turtles and 


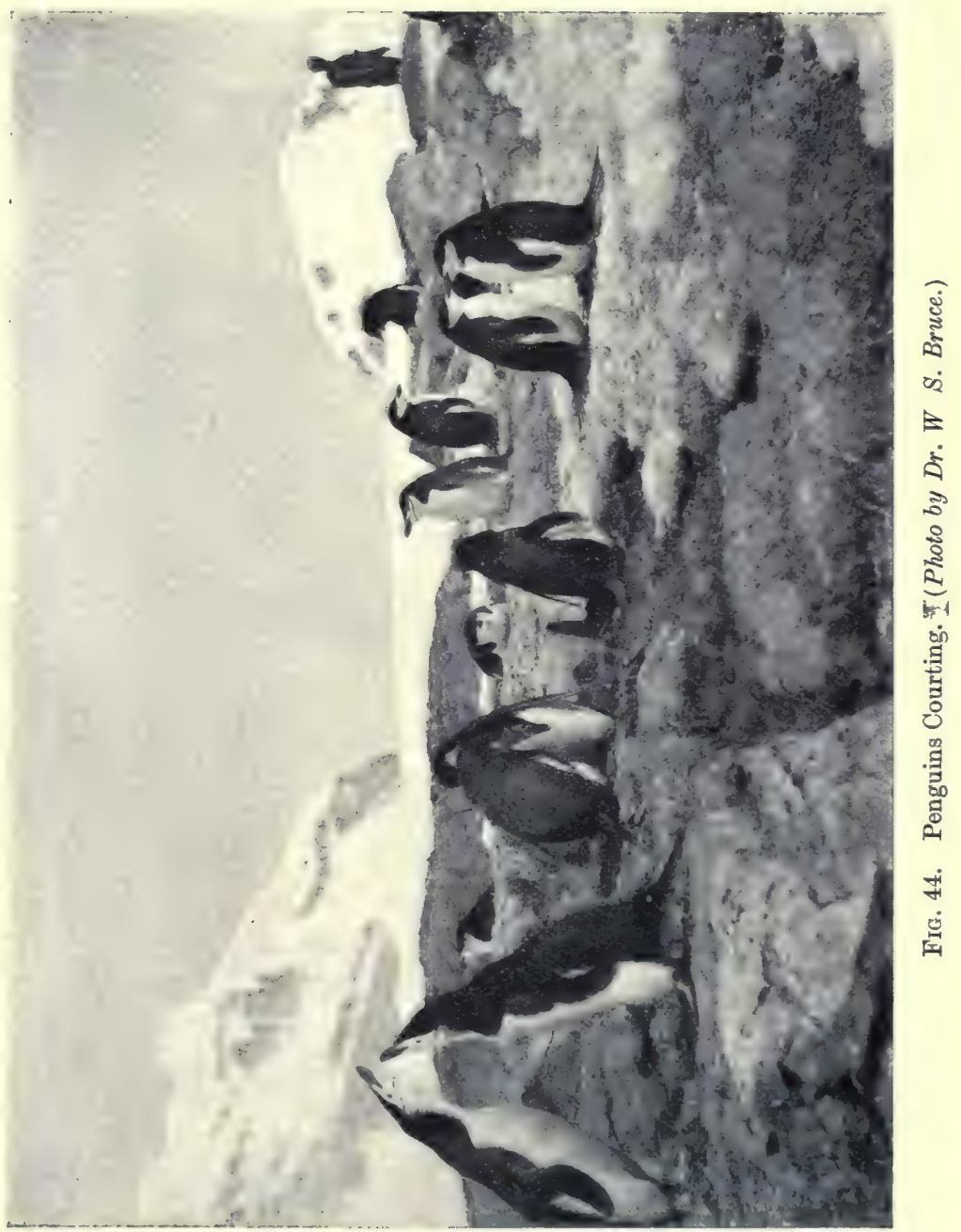



tortoises (Chelonia). The very curious leathery turtle (Sphargis coriacea) is apparently found in all tropical seas, but it is either very rare or its habits make it infrequently seen and caught. It is a large animal, sometimes measuring six and a half feet long, and feeds exclusively on fish, molluses, and crustacea. The limbs are turned into paddles, the anterior ones being very long, and the animal is apparently pelagic in habit and a swift swimmer, though it is tied to the land by the need of breeding there. The eggs are laid on sandy shores, especially on the eastern side of tropical America.

The green or edible turtle of commerce (Chelone $m y d a s)$ is also marine, but the fact that it is vegetarian, feeding upon algae and other aquatic plants, binds it closely to the shore, though the animals are good swimmers. As usual the eggs are laid on sandy beaches. Another species of the same genus is the hawksbill turtle (Ch. imbricata), which supplies the tortoiseshell of commerce, and is carnivorous, feeding upon fish and molluses. Both these forms have a wide distribution in warm seas, while the loggerhead (Thalassochelys caretta) extends into the Mediterranean and Bay of Biscay. This is a carnivorous form, and occurs hundreds of miles from land, floating on the surface. Again, however, it must approach the land at the breedingseason.

We have already spoken of the marine lizard of the Galapagos Islands (p. 149), and there are also seasnakes (Hydrophis) similarly adapted for life in the sea. These animals, which are especially found off the coasts of the Indian Ocean, have compressed swimmingtails, and feed upon fish. As in the case of so many forms which have secondarily returned to the aquatic life, their dependence on the land is especially shown 
at the breeding-season, for the gravid female must come on shore to produce her young. For this purpose she visits the shores of low islands, where she may be found coiled up among the rocks.

The fact that amphibians have unprotected skins, through which salt can pass very easily, makes them intolerant of its presence, and we have thus no marine amphibia.

Littoral fishes are many, and range from forms like the lumpsucker, the gobies, the sea-horses, the pipefish, and so forth, which inhabit rocky pools within or close to tide marks, through forms like plaice, dabs, turbot, skate, fishing frogs, \&c., which haunt the sandy bottom, their shape fitting them for life here, to forms like cod and haddock, whose chief adaptation to littoral life is that they are ground feeders, depending upon animals like hermit crabs, marine worms, shellfish, \&c., which only occur on the bottom.

It is a curious illustration of what has been already said as to the tendency to change from the pelagic to the littoral habitat during the life-history, that the littoral cod and haddock should have floating or pelagic eggs, and should in their early life haunt the surface, often seeking shelter within the bells of the pelagic jellyfish, while the herring, which in adult life is a pelagic fish, feeding on free-swimming crustacea, has heavy or demersal eggs, which sink to the bottom.

The tunicates or sea-squirts mostly attach themselves to the sea-bottom, but have pelagic free-swimming larvae.

Of the molluses a vast number are littoral forms. Many cuttles cower down on the sea-bottom waiting for their prey, or clamber over the rocks by the aid of 
their sucker-bearing arms. The flat creeping surface which forms the foot in most gastropods, such as periwinkles, whelks, and so forth, indicates the dependence of these animals upon a substratum. The bivalves often live buried in the mud, like Mya and Lutraria, or in sand like cockles, or they are attached by a byssus or tuft of silky threads like the common mussel, or they bury themselves in the substance of the rocks like Pholas and Saxicava. Many of these forms, however, have pelagic larvae.

While many of the crustacea are pelagic, like the copepods or water-fleas, and various forms of prawns, others, like crabs, are adapted for life on the bottom. Indeed, we can trace among the shore crustacea the gradual acquirement of the ground-haunting habit, leading by various stages from a form with the power of swift swimming like the lobster, to forms which can only walk like the crabs, these showing many very interesting adaptations to their relatively sedentary life.

The majority of the annelid worms are littoral, relatively few being adapted to the pelagic life. Curiously enough, however, not only have most of them pelagic larvae, but certain forms become temporarily pelagic at the breeding-season. The most striking example of this is the palalo worm of various islands in the Pacific. This worm lives among the coral reefs, but at certain seasons a portion of the body containing the sexual clements is liberated, and leads a brief free-living life at the surface, before death occurs. The liberation of these sexual portions takes place at night, simultaneously in thousands of worms, so that the whole surface of the water becomes filled with the animals, which off Fiji, the Friendly Islands, and elsewhere, 
are eaten by the natives as food. The portion of the worm which remains behind in the coral reefs regenerates the missing segments, and a year later the process is repeated. A similar process is suggested in certain British annelids, and is a device to ensure that the eggs are carried to a distance from the parent.

The littoral annelids show many beautiful adaptations to shore life. We can only name the sea-mouse (Aphrodite), which lives buried in mud; Serpula, which secretes lime from the sea water and fashions a tube, which it attaches to rocks or to the hard parts of other animals or to weed; Terebella, which builds up tubes from the sand, and implants them deeply in the sand so that it is safe from the wash of the wares; a Nereis, which lives inside the shell inhabited by a hermit crab, and thus finds protection from its enemies, and so forth. Very many of these annelids are greatly prized as food by fishes, and it is their abundance in the shore waters that attracts so many fish there.

Very many of the echinoderms also are littoral, and manifest obvious adaptations to this mode of life. The sea-urchins burrow in the sand or mud, or else climb about the rocks by means of their suctorial tube feet. Starfish and brittle-stars similarly clamber over the bottom, while the holothurians either live buried in the sand or attach themselves by their tube feet.

Not a few unsegmented worms are littoral, a pretty example being the turbellarian called Convoluta, which possesses symbiotic algae, a common feature of shore animals of simple structure.

Perhaps the most interesting forms are, however, the Coelentera, which often show a double adaptation to littoral and to pelagic life. The fronds of the shore 
algae are often covered with the delicate tracery of the sea-firs, colonial coelenterates of sedentary habit. Among the branches of the 'fir' special cups may be seen in which buds form. These buds drop out and float away, becoming swimming-bells-sexual forms which carry eggs and sperms to a distance, so that the fertilized egg may find a home far from the parent stock. This, which the biologist calls alternation of generations, is of common occurrence among the coelenterates. We find, however, that frequently one of the two modes of life is emphasized at the expense of the other. Those delicate bells which we call Ctenophora, or comb-bearers, have no littoral stage at all, but are pelagic throughout their life. On the other hand, sea-anemones, sea-pens, and their allies, the corals of warm seas, and so forth, are littoral, save in their earliest stages, and are fixed save in those very early stages. No swimming-bell floats away from the coral as it does from the sea-fir colony. Between the two extremes all stages exist. For example, many of the great jellyfish are shore-born, spending a considerable part of their lives attached to rocks. Others are pelagic throughout, while still others remain permanently attached to the rocks, like larvae which have never grown up. Somewhat similar conditions occur in the tunicates already mentioned (p. 166).

The sponges, which all require the presence of $\mathrm{a}_{\mathrm{s}}$ substratum, are necessarily either littoral or abyssal. A great number occur in shallow water, all these being attached to some solid body. But there are no very obvious adaptations to littoral life, save perhaps that shallow-water sponges seem to be always attached, while some abyssal forms lie loosely on the surface of the ooze. 
The protozoa are as well represented on the shore as in other parts of the sea, but present no special adaptations to life here.

(2) We come next to the pelagic region, where there is no substratum, but where many at least of the organisms are fully exposed to the action of light. With regard to the movements of the water here, we must notice first that, in contrast to the littoral area, tides are of little importance. On the other hand, currents are very important. As is well known, the difference in the amount of heat which streams down from the sun upon the surface of the sea gives rise to differences in temperature and density, which cause the surface waters to move in great whirls, the ocean currents. As the surface in the different latitudes is exposed to different types of winds, and therefore to differential evaporation, we have also differences of salinity. Roughly speaking, the salinity is greatest in warm regions exposed to the drying trades, e.g. in the Red Sea and in the Mediterranean, and least towards the poles. In not a few parts of the globe we find that currents bringing cold water of relatively low salinity meet warm currents of highly saline water. When this occurs the warmer water floats on the surface of the colder, and there is a junction layer where a sudden change in temperature, salinity, and specific gravity occurs. Such a meeting of warm and cold currents is found, for instance, in the Norwegian Sea, where the Polar drift meets the warm currents of that sea; it occurs also off the eastern coast of North America, where the Labrador current meets the Gulf Stream; it occurs off the Cape of Good Hope, where the cold Benguela current meets the warm Agulhas one, and so on. Now, as has been already suggested, such regions 
are regions of great mortality among the pelagic organisms, for the stenothermal forms are killed by the sudden changes of temperature which occur. But there is something more than this. The delicate organisms which float in the surface waters of the sea are necessarily very sensitive to changes of density. They must be able to float without effort--that is, their specific gravity must be that of the water in which they float. Very many possess certain powers of adjustment-that is, they can vary their specific gravity in harmony with variations in the specific gravity of the water. But this power of adjustment has its limits. When warm, light water is floating on cold, dense water, it is apparently impossible for the more delicate forms at least to pass through the junction layer of the two, which thus forms what Dr. Hjort calls a 'false bottom', a region where living and dead plankton animals accumulate. By a series of very ingenious investigations he has shown that, in many parts of the ocean, not only does such a junction layer between the surface and lower layers of water occur, but that this layer is a region of great wealth of life. It is a false shore-line in mid-ocean, and Dr. Hjort has shown that many of the littoral fish at certain seasons leave the shore, and swim out into the open ocean, following this line of change of density, where food accumulates-where it is as abundant as it is near the land. There seems some reason to believe that such an accumulation of pelagic organisms in an area of sudden change of density occurs in the vicinity of all the great fishing regions of the world, and thus, as it were, prolongs the plenty of the shore out into the open, and helps to account for the abundance of fish.

As to the actual temperature of ocean water, the 
statements made above in regard to the temperature of littoral waters hold good here also. In important point, however, is that nowhere-not even under the Equator-does the warmth of the surface layer extend far downwards. In practically all parts of the ocean the temperature at depths exceeding 1.000 fathoms is permanently low, and varies but little throughout the year.

The conditions as to light demand detailed consideration. Very careful experiments show that all rays of light are present at depths of 50 fathoms. It 300 fathoms the red and green rays have disappeared, but blue and violet rays remain. Some of the violet rays are still present at 500 fathoms, for photographic plates are slightly affected here. At 900 fathoms they remain absolutely unaffected after long exposure, and here we must suppose that absolute darkness reigns.

These statements are true for middle latitudes, but another point has also to be considered. Obviously, the direction of the rays is not the same in all latitudes, and therefore they will penetrate to different depths in different latitudes. Dr. Hjort gives the following figures in regard to the depths at which the same intensity of light is found in different latitudes :

In $33^{\circ} \mathrm{N}$. lat. at about 430 fathoms depth.

In $50^{\circ} \mathrm{N}$. lat. at about 270 fathoms depth.

In $67^{\circ} \mathrm{N}$. lat. at about 100 fathoms depth.

This is important, because, as we shall see directly, the intensity of light greatly influences the bathymetrical (i.e. depth) distribution of marine animals.

The basal food-supply of marine animals-in the open as off the shore-consists of algae, so that we must add to the above consideration of the conditions of life in the open some account of the pelagic algae. 
In the first place it is noticeable that the larger algae are unrepresented in the open sea. The weed which floats at the surface of the Sargasso Sea is an apparent exception, but it is apparent only, for this weed is torn off the shores, especially off the Bahamas, and though it proliferates vegetatively in the open, and can live there for a time, it is not a truly pelagic form. The swarms of animals which live among the floating masses of weed in the Sargasso Sea show what an important addition to the food-supply of the ocean the weed is.

The basal food-supply of the pelagic animals is, therefore, the phytoplankton, the minute algae which float at the surface. Necessarily these algae, as lightdemanding organisms, are limited to the surface layers of the water, being especially abundant in the uppermost 25 fathoms. They occur, though in diminished quantity, down to 50 fathoms. Those found in greater depths are resting stages or dead forms. The dead forms, as we have already suggested, tend to accumulate, at least temporarily, at levels where a sudden increase of density occurs. As regards quantity, the water of the open ocean seems to be poorer in algae than coastal waters, but, as has been already suggested, currents may carry the shore forms out to the ocean, and there is reason to believe that then the fish of the shore may follow them.

The next point to be considered is the distribution of pelagic animals. There is a tendency among many writers, at least tacitly, to confine the term 'pelagic' to those forms which live sufficiently near the surface for light to penetrate. There is, however, no real justification for this use. An animal living at a depth of 2,000 fathoms is as truly pelagic as one living at 
a depth of 50 fathoms, if it can be proved that neither has any dependence on the proximity of a substratum. But here, obviously, a difficulty occurs. A sponge with an attaching stalk, taken in deep water, is obviously an abyssal form, for it was attached to the bottom. But. if a net which has been dragged along the bottom at a depth of say 2,000 fathoms proves, when examined, to contain fish, how can we tell whether these fish were truly abyssal forms, or were merely caught as the net was hauled up? The difficulties in coming to a decision are great, and until recently there has been a tendency to assume that all fish obtained in deep water, and having a bizarre form and colouring, large eyes or no eyes, and so on, were abyssal fish, feeding on the bottom. Dr. Hjort, however, believes that the recent (1910) expedition of the Michael Sars, taken in conjunction with some previous observations, has yielded evidence which proves that many of these curious fish are truly pelagic, living at or below the light limit. If he is right, then pelagic animals may be divided into at least three groups : (1) surface forms, most abundant in the upper 100 fathoms or so ; (2) mesopelagic or intermediate forms, found about the light limit, which varies with the latitude ; (3) bathypelagic forms, which occur below the limit to which the rays of light penetrate, but yet not upon the sea-floor, of which they are independent.

We must now consider some of the characters of pelagic organisms, beginning with the plankton. Plankton animals are those able to float in water without exertion, and have usually flattened and expanded bodies. Sometimes, as in the very abundant copepods, a globule of oil makes the body light. At other times, as in some protozoa, and such forms as the sunfish, 
the lightness is due to the presence of air or another gas. In the surface forms the body is often transparent and colourless, so that it is invisible as it floats in the clear water, while in other cases it is blue or violet, so that it will equally be invisible when seen from below against the sky. That these peculiarities are adaptive is suggested by the way in which they appear in unrelated forms. Thus while the shore annelids are brightly coloured, Tomopteris, a pelagic form, is colourless, and has an expanded body. The same peculiarities appear in Sagitta, a worm of uncertain affinities; in Phyllirhöe, a curiously modified and shell-less gasteropod; in Salpa, a pelagic tunicate, and so on. The surface jellyfish are blue or violet or almost colourless, while in deep water bright-red forms occur. Many of the pelagic forms of the surface are phosphorescent. We see this in the protozoon called Noctiluca, in the beautiful tunicate called Pyrosoma, in some pelagic crustacea, and so forth. Surface pelagic forms are so numerous that no useful purpose would be served by giving a list, but it may be interesting to note those groups which have no pelagic representatives. While, as already suggested, very many types of Coelentera are pelagic, there are no pelagic alcyonarians (sea-pens, $\& c$.$) , and there are no pelagic sponges. With one$ exception, to be considered later, there are no pelagic echinoderms, though their larvae are often pelagic. There are no pelagie bivalve molluses, though many different kinds of gasteropods are adapted to life in the open sea, the sea-butterflies (Pteropods) being good examples. Some other less familiar groups are also unrepresented in the open sea.

On the other hand, there are enormous numbers of pelagic larvae. As young animals have often delicate 
translucent bodies it would seem as though they could be very readily adapted to the pelagic life. As two interesting forms mention may be made of the transparent larva of the eel, called Leptocephalus, because its relation to the parent was for long unknown, and the glass crab (Phyllosoma), which is the larva of the rock lobster, but was similarly for long regarded as an independent organism.

Very remarkable is the presence in the open sea of the members of an insect genus, Halobates, a kind of bug, related to the forms which skim over the surface of fresh-water ponds. Some fifteen species of Halobates are known from the warmer parts of the oceans. The insects appear to be perfectly pelagic in that even the eggs are produced in the open, but they may also approach shores, for what reason is not known. The female carries the eggs for a time attached to her own body, and the young have been found on floating solid bodies in the sea. Wings are completely absent, and the body is covered with a greyish pubescence, which shines in the sunlight. The animals breathe air, and belong rather to the surface of the ocean than to its waters.

In contrast with these plankton or drifting forms, we have in the open sea a number of powerful swimmers (nekton) able to make headway against the currents. The most important of these are the whales and their allies, whose distribution is tied to that of the animals upon which they prey. Thus the huge cachalot or sperm whale (Physeter macrocephalus) is found especially in warm seas, where it finds the large cuttles upon which it feeds. The related bottle-nose (Hyperoodon), which also lives on cuttles, occurs in colder seas, and is found especially in the North Atlantic. The whalebone whales 
(Balaena, \&c.) feed on the floating plankton, especially on sea-butterflies (Pteropods), and are very common in cool and cold waters, though widely distributed. On the other hand, the fish-eating dolphins and porpoises especially frequent shallow waters, where the fish on which they prey are most frequent.

With the exceptions already given, purely pelagic fish are not very abundant, at least in the surface waters. The reason is apparently that food near the surface is not sufficiently abundant. Professor Bouvier notes that the Princesse Alice, the Prince of Monaco's yacht, while cruising in mid-Atlantic, found practically no surface fish, except when some floating wreckage, with a burden of attached invertebrates, such as crustacea, \&c., drew them to the surface. Among the surface forms may be noted the flying-fish (Exocoetus), the beautiful 'dolphin' (Coryphaena), and its allies, the bonito (Thynnus pelamys), another flying form, related to the mackerel, which is also pelagic. All these forms, however, despite their obvious adaptations to pelagic life, are more abundant as the land is approached than far away from land.

The above forms may be regarded as characteristic of the upper 100 fathoms or so of water. We have next to consider the mesoplankton and mesonekton-that is, the forms which occur between the surface layers of water and the bottom, near the light limit. The study of these is necessarily a difficult matter, involving the use of complicated methods not hitherto used at very great depths. Provisionally, however, the following statements may be made, these being based especially on the results obtained by the Michael Sars expedition.

At depths between 200 to 300 fathoms, but varying 
with the latitude for the reasons already discussed, there seems to be a fauna of silvery or iridescent animals, of which the fish have been chiefly investigated, though medusae, and doubtless other forms also occur. The fish living at these depths inhabit an environment where a considerable amount of sunlight penetrates, especially blue and violet rays. They have often large eyes, which sometimes protrude at the end of short stalks, and are then called telescopic. Large light organs are present, which perhaps catch the last rays of sunlight. An example is the silvery fish Argyropelecus affinis, which lives in the Atlantic at depths of somewhere about 200 fathoms; at night, when the light conditions are the same near the surface as in the depths where it habitually dwells, this fish has been found within some 80 fathoms of the surface. Its young have the same colouring as their parents, and live in the same depths. Another form with the same colouring and characters is Cyclothone signata, which lives at a depth of about 300 fathoms.

Still deeper, at depths of from 300 to 500 fathoms, where all trace of red and green rays have completely disappeared, occur forms in which the colouring is black or red. In the absence of any red rays both these colours must look the same, and either will protect the animal. At these depths occur deep-red or chocolate-coloured medusae, the only pelagic echinoderm (Pelagothuria), bright-red prawns, such as Acanthephyra multispina, and red or black fish, Sebastes norvegicus being an example of the former and Goniostoma elongatum of the latter. The last-named fish is purplish-black, with small light organs and small eyes. It has huge jaws, a common feature in these deep-water fish. A very curious point about it 
is that in the daytime it lives at about 300 fathoms, but at night it rises to within 80 fathoms of the surface. Its young are crystal clear, and are surface forms living in the upper 80 fathoms. On the other hand, some members of the genus Alepoeephalus live as far down as 1,100 fathoms, and have no light organs. Their young are the same black colour as the parents, and live also in the great depths.

To sum up, so far as we know at present, forms which live in the surface waters of the ocean are crystal clear or pale violet or blue. Those which live in layers where only blue and violet rays penetrate freely tend to be silvery and to have large eyes and large light organs. Still deeper, where no red and no green rays, even in some instances no rays at all, penetrate, the colour becomes red or black, and light organs are small or disappear. That there is an intimate relation between the characters and colouring of the organism and the amount of light present is shown by the fact that when the larva inhabits the same depth as the parent it has the same colours. When it inhabits another zone it takes on the normal colouring of the inhabitants of that zone. Further, the fact that the forms from deeper water occur in different layers of water in different latitudes-the level corresponding to the degree of penetration of light in the particular latitude, so that the animals live higher up in high latitudes than in low-suggests that the life of the animals is strongly influenced by the amount of light present.

One other point is interesting in regard to the life of these depths. Just as the littoral fishes often send pelagic larvae out to the open sea, so some of the abyssal fishes seem to have bathypelagic larvae, i.e. larvae living in the open water, but at considerable 
depths. Thus the members of the genus Macrurus, believed to be true abyssal, that is ground-living, forms, have apparently such eggs and larvae. The abyssal hermit crabs, also, have bathypelagic larvae, just as the littoral forms have larvae which form part of the surface plankton.

(3) The abyssal region of the oceans is contrasted with both the other regions in that its waters must be permanently calm. It is in harmony with this calm that we find, as already stated, some deep-sea sponges which have no attachment to the substratum, upon which they seem to lie loosely. The pressure must be enormous, for the animals of the depths support a weight of several miles of sea-water upon their bodies. Though there are no plants, oxygen seems to be abundant. But this is a consequence of the welldeveloped circulation of the great oceans, and is not a feature of enclosed seas. Thus the Black Sea has no animals in its depths, and the waters there are impregnated with sulphuretted hydrogen, and contain but little oxygen. In the Mediterranean the conditions are less extreme, but the deep-sea fauna is scanty. Light is, of course, entirely absent in the depths. The water is permanently cold. The basal food-supply must consist of the dead animals of the upper zone, which fall downwards through the water as they die. In consequence we find that many of the abyssal forms are mud-eaters. To what extent the floor of the ocean is peopled still remains a difficult question. As already noted, Dr. Hjort believes that genuine abyssal fish, in the sense of ground forms, are few, most of the so-called abyssal forms being bathypelagic and having been obtained in the process of hauling in the dredge. But there can be no doubt that many 
invertebrates do occur on the sea-floor in the greatest depths, especially over regions covered by Globigerina ooze. Among these invertebrates sponges and echinoderms preponderate, molluses and crabs among crustacea being rare. Of the sponges the old-fashioned siliceous forms are numerous, and calcareous sponges are absent. A few corals occur. Among the echinoderms all the classes are represented, and the oldfashioned crinoids, rare in shallow water, are relatively abundant. Among the sea-urchins the special feature is the abundance of old-fashioned irregular forms, which occur so abundantly as fossils. Annelids occur especially in the red clay. In harmony with the great uniformity of the conditions over wide areas, the abyssal animals are widely distributed. Further, as the conditions of temperature, and during the long Arctic night the conditions regarding illumination, show resemblance in polar and abyssal regions, there is apparently some resemblance between polar animals and abyssal animals.

REFERENCES. The forty-two volumes of the 'Challenger' Reports (188091) give the results of the epoch-making cruise of that vessel. More popular accounts of its work are to be found in Mosely, Notes by a Naturalist on the 'Challenger' (London, 2nd ed., 1892), and Wyville Thomson, The Depths of the Sea (London, 1873), and Narrative of the Voyage of the 'Challenger' (London, 1885). 'The following may also be consulted: Ortmann, Grundzüge der marinen Tiergeographie (Jena, 1896); Chun, A us den Tiefen des Weltmeeres (Jena, 1900); Marshall, Die Tiefsee und ihr Leben. For the more recent work discussed in the present chapter, see Hjort, The 'Michael Sars' North Atlantic Deep-sea Expedition (Geographical Journal, April and May, 1911); Hjort, Die erste Nordmeerfahrt des norwegischen Fischdampfers 'Michael Sars' im Jahre 1900 (Petermann's Mitteilungen, IV, 1901), and The Depths of the Ocean, by Sir John Murray and Dr. Johann Hjort (London, 1912). Two interesting popular articles on the work of the Princesse Alice are Les Vertébrés de In Surface and La Faune Pélagique des Invertébrés, by Professor Bouvier (Revue Générale des Sciences, 1906). 


\section{CHAPTER IX}

\section{THE ANIMALS OF LAKES AND RIVERS}

THE water of rivers and of very many lakes differs from that of the sea in the absence of any considerable quantity of common salt, making it 'fresh' instead of salt. Such bodies of water contain a special fauna, which, as contrasted with the fauna of the ocean, may be described as impoverished; but in addition to this negative character, this fauna possesses also some positive ones, which we shall consider later. Certain other lakes, either because they had a former connexion with the sea, or because they have no outlet, contain saline water. Such masses of water may contain some animals with distinctly marine affinities, e.g. in the Caspian are found a seal and a kind of herring. But the Caspian is far from being as salt as the sea, and in addition to animals of marine type it contains some typically fresh-water fishes. On the other hand, masses of very salt water, such as the Great Salt Lake of Utah, contain peculiar brine-shrimps (Artemia) not found in the sea. A still further complication is introduced by the fact that certain lakes, though their waters are perfectly fresh, contain animals of distinctly 'marine ' facies. Thus Lake Baikal, though its waters are not salt, lodges a seal allied to the Caspian seal, and a marine worm; Lake Tanganyika, in Central Africa, contains several animals of marine type, and so on. In consequence we cannot sharply separate freshwater animals from marine ones, in the sense of imply- 


\section{THE ANIMALS OF LAKES AND RIVERS 183}

ing that all the latter live only in the ocean, and that lakes and rivers contain only the former; nor can we assume that all aquatic animals can be divided into marine and fresh-water types, for this would exclude forms like the brine-shrimps, characteristic of salt lakes and brine pools. But, at the same time, it is convenient to recognize a general distinction between the animals of the oceans, the marine forms, and those characteristic of lakes and rivers, which are for the most part fresh-water animals.

Using the terms in this general sense, we may note that the poverty of the fresh-water fauna is due to the relatively unfavourable conditions. Among these unfavourable conditions we probably need not include the absence of considerable amounts of salt dissolved in the water, for the presence of an appreciable amount of salt, e.g. in the Caspian, does not give rise to a marked increase in the fauna as compared with freshwater lakes, and the presence of a large amount of salt, e.g. in the Great Salt Lake, is distinctly inimical to animal life.

Before proceeding to discuss the especially unfavourable conditions, we may note that it is generally believed that life originated in the sea, not in fresh water, and that therefore all the animals now found in rivers and lakes must have originated in one of two ways: (1) they may have been derived directly from marine forms, or (2) they may have been derived from land animals which have reacquired the aquatic habit of their remote ancestors.

Of the first group, fresh-water fishes may be taken as examples. They have certainly had marine ancestors, and in some cases, e.g. the eel and the salmon, the existing forms have retained the power of living in 


\section{THE ANIMALS OF LAKES AND RIVERS}

the sea as well as in fresh water. Similarly, the bivalve molluses of the lakes and streams have certainly had marine ancestors. Most of the higher crustacea live in the sea, and the few crayfish and prawns which live in fresh water are certainly descended from ancestors which lived in the open ocean.

It is otherwise with most of those numerous forms which, though they live in water, are yet adapted for breathing air. The otter which haunts the salmon rivers has lungs no less than its distant relative the polecat; the water-tortoises have lungs like the land forms; the water-beetles and the many insect larvae found in pools, the water-spider, the water-mites, the pond-snails, are all air-breathers, and their peculiar respiratory organs would be inexplicable if we could not assume that their immediate ancestors lived on land. In these cases there is no reason to believe that the animals have ever sought the sea since the time when their far-off ancestors acquired terrestrial characters. Therefore in possessing some of these forms the fresh-water fauna is not poorer but richer than the sea, which has hardly any insects (cf. p. 176), no air-breathing molluses, no true spiders, and so on. Again, while most amphibians have a fresh-water larval stage, and some pass much of their life in water, no living amphibian is ever found at any period of its life in the sea.

But when we come to consider the groups which are richly represented in the sea, the tale is different. The echinoderms are exclusively marine-no starfish, seaurchin, brittle-star, nor sea-lily is known from fresh water. No cuttle hunts its prey in the depths of the great lakes, nor creeps along river bottoms. The polychaete worms are almost exclusively marine, and the 
higher crustacea largely so. The great group of the Coelentera is very scantily represented in fresh water, where also there are but few sponges. Fresh-water fish also are few in number as compared with their marine allies, though they include some peculiar forms, like the ganoids (e.g. sturgeon, bony pike, \&c.), and the dipnoi or double-breathers. It is, however, interesting to note that of these peculiar fish all the three living dipnoi, and at least one ganoid (Polypterus) have accessory breathing organs which enable them to breathe air, as well as gills. This fact, taken in conjunction with the relatively large numbers of air-breathing invertebrates, suggests that one difficulty in colonizing fresh water has always been its relative deficiency in oxygen. In the general case this applies, of course, to lakes and inland seas rather than to rivers, whose water is oxygenated by its motion. But where a marked dry season occurs, as in many parts of the globe, the rivers may periodically cease to flow, and be represented by a series of stagnant pools, whose waters become very fetid-conditions highly unfavourable to animal life.

In the lakes of temperate regions, where the surfacewater periodically cools below the point of maximum density of water, a vertical circulation is produced which carries down oxygen to the deeper layers of the water, at least at certain seasons. This makes life in the deeper layers possible, though some American experiments suggest that the oxygenation of these deeper layers occurs only in spring and autumn, as the ice melts in the former case, and before it is formed in the latter. In the summer the heating of the surfacewater gives rise to a stratification into two layers, when the warm oxygenated surface-water lies upon a 


\section{THE ANIMALS OF LAKES AND RIVERS}

deeper, colder layer, whose oxygen is only renewed very slowly. This relative paucity of oxygen naturally checks life in the deeper parts of the lake.

In tropical lakes the fact that the surface-water does not cool in the same way in autumn, and that there is no spring melting of ice, makes the vertical circulation much less marked, and leads to a virtual absence of a deep-water fauna. In brief, then, the deep-water fauna of lakes is always poor, because of the absence of a well-marked circulation of the water, and the deficiency in the amount of oxygen, with the resultant paucity of life, increases towards the Equator.

The second unfavourable condition in fresh water is its frequent turbidity. Rivers are powerful eroding and transporting agents, lakes are great filter-beds on the course of rivers; necessarily, therefore, the waters of both must often contain fine particles in suspension, which would form a deposit on the surface of the breathing organs of animals living in them, and greatly retard respiration. The importance of this may be illustrated by an example. The Firth of Forth is a great estuary swept by the tides, once inhabited by great numbers of marine animals tolerant of estuarine conditions, notably by oysters. There is much evidence to show that its waters are becoming muddier year by year, apparently because drainage of the 'mosses ' in the upper regions of the river has made the run-off there more rapid. As a result of the increasing muddiness many animals have disappeared - the oyster-beds long ago ceased to be productive, and other forms also are diminishing. Now if an increase in the amount of mud in the water kills estuarine animals, which are naturally tolerant of some suspended matter, even a small amount of suspended matter will prevent the 
growth of the more delicate animals, and must be a great bar to the passage of marine animals up estuaries and rivers. Almost any coast-line will illustrate the same thing on a smaller scale. The shore collector knows that to get the rarer and more delicate animals he must seek rocks or beaches remote from the mouths of streams, for at the immediate outlets of these only the hardiest forms occur. This statement is not inconsistent with that already made, that the waste of the land is an important part of the food of the seaanimals, for oxygen is a prime necessity which precedes even the need of food, and few animals can take in oxygen if their respiratory organs are choked with mud.

But it is not only the suspended matter in the water of lakes and rivers which is inimical to animal life. The presence of large amounts of lime or manganese salts, or of humic acid, may render the water unsuitable to certain forms.

Still another point of great importance is the enormous variation in temperature to which lakes and rivers are subject. These variations are normally so great that they render the water absolutely unsuited to stenothermal animals. All fresh-water forms must be eurythermal (cf. p. 160), and temperate and polar forms must have special means of protecting themselves, or their offspring, against the cold of winter. In the 'lakes' of Victoria Land, which are almost permanently frozen, the naturalists of Sir Ernest Shackleton's expedition found rotifers which can apparently tolerate being frozen into the ice for years, and will yet hatch out if the temperature rises and the ice melts. This is an extreme case, but it suggests the adaptations necessary before animals can thrive in small masses of water. Low temperatures are not, however, the only 


\section{THE ANIMALS OF LAKES AND RIVERS}

danger. High temperatures, with resultant desiccation, are just as dangerous, and must also be provided against. The amoebae in a waterspout can be dried to dust, and will lie unharmed within their protective cysts until the rain comes, and the spout once again becomes suitable for their active life. In the swamps of the Paraguay or of the Central African rivers, the lung-fishes lie in their mud cases, waiting till the wet season again permits them to become active. Drought and freezing, high temperatures and low, are risks which every fresh-water organism must face, and the lessons learnt in the conflict with them are stamped deep on all the inhabitants of stream and lake. In these, as on dry land, life in the temperate and frigid zones is markedly seasonal, and it is interesting to note that where the problem of seasonal adaptation cannot be directly faced, it may be avoided. For example, those shallow bodies of water which are favoured by frogs as spawning-places are very apt to dry up in full summer, but the tadpole avoids the risk of drought by adjusting its time of metamorphosis to the time of drought, so that it is ready to leave the water at the time when the pond would naturally dry up. Every summer one may find cases where the adjustment has not been sufficiently delicate, so that thousands of tadpoles die because the drought comes before they are ready for their land life. In autumn the ponds fill again, and the little frogs return again to them to pass the winter in their mud.

One other unfavourable feature of rivers and lakes is found in the strength of their currents. The waters of the ocean are swayed also by currents, but within considerable limits, and with the exceptions already given (p. 161), such currents cause little harm to 
marine animals. Tides and currents sweep the members of the plankton hither and thither, but the regions into which they are swept may be more suitable than those they have left-in the case of the littoral animals the currents are the great distributors. But for a lake or river animal to be swept out to sea must in the general case mean death, for it means the passage from a specialized environment to which the animal has become adapted through progressive variation, to another to which it has no adaptations.

In the nature of things littoral animals must have always had special facilities - that is, facilities in regard to space-for conquering fresh water. So far as their relations in space go, it is relatively easy for them to progress, actively or passively, from the shore up rivers and estuaries. But we have already seen that it is one of the great peculiarities of littoral animals that they tend to produce free-swimming young, or free-swimming stages, whose purpose it is to ensure distribution along the shore, and the existence of these free-swimming stages or young offers a serious obstacle to the colonization of fresh water. For example, in some artificial ponds at the mouth of the Ganges a very curious fauna has been described (Records Indian Museum, i. (1907) p. 35). These ponds are sometimes connected with the sea, and sometimes shut off from it, and are sometimes filled with water rendered very salt by evaporation, while at the rainy season the water is nearly fresh. In spite of these variations in salinity, a number of marine forms occur, including a seaanemone, a kind of sea-fir (Hydromedusan), and a polychaete worm, showing that it is not its freshness alone which prevents such forms from colonizing fresh water. Now sea-anemones produce usually free- 
swimming larvae called planulae; Hydromedusae produce free-swimming medusoids; polychaete worms have free-swimming larvae called trochospheres, all delicate forms incapable of swimming against currents. These particular ponds have at intervals a connexion with the sea, and so can be peopled afresh from it, but if we suppose that at some future period the connexion with the sea were to be reduced to a swift-flowing stream, could we suppose that the animals would persist? Obviously not, for the medusoids, the planulae and the trochospheres would tend to be swept out to sea by the stream, and there would be thus no young forms to replace the parents when death took place. So real is this danger that, with rare exceptions, fresh-water organisms have no free-swimming stage in their life-history. Only those marine animals could colonize fresh water which had no plankton stage in their life-history, or which managed somehow to survive until this free-living stage could be suppressed by progressive variation. This perhaps gives us a second reason why so many animals with a terrestrial ancestry have succeeded in colonizing fresh water, for these forms would not have a free-swimming stage. Thus while most marine gasteropods have freeswimming larvae, fresh-water snails, like land snails, hatch as miniature adults, which makes life in ponds and streams easy for them. These arguments of course only apply to those delicate organisms which are incapable of swimming against currents. Relatively powerful swimmers, like many insect larvae, can resist moderate currents, though they avoid regions where the water is in rapid movement.

But, it may be said, in a large lake the need for distribution is as great as in the sea, how do the lake 
animals succeed in spreading from one part of the lake to another if they have no free-swimming stage? The answer is apparently that the distribution is largely passive, being assisted by sudden freshets, which may produce currents of unusual violence, capable of carrying adults, or, more likely, resting eggs to a distance. In addition there are some curious special adaptations. We may take two examples of familiar forms. The fresh-water hydra as contrasted with the marine seafirs has no free-swimming stage. While the weather is warm it reproduces itself by buds; towards autumn it produces coated eggs which survive the winter, and produce fresh hydrae in spring. These shelled eggs are doubtless easily transported by currents. More remarkable are the conditions in the fresh-water mussel (Anodon). Here the mother retains the young within her body till sticklebacks approach the mud in which she is living. She then discharges the young, who fix themselves to the fish, and are thus carried about for a time, and so distributed. Later they drop from the stickleback to the mud, and develop into mussels like the parent.

With this preliminary account of the conditions of life in lakes and rivers, and of the resultant adaptations, we may proceed to consider the animals which constitute the fauna.

A considerable number of mammals show at least a partial adaptation to fresh-water life. Thus we have many kinds of otters, which have webbed feet and feed upon fish; not a few insectivores, such as the common water-shrew and the Russian desman; various rodents, such as the beaver and the water-vole; a monotreme, the curious duck-mole or Ornithorhynchus of Australia, and so on. In most of these cases the modifications are 


\section{THE ANIMALS OF LAKES AND RIVERS}

not very profound, not sufficient to cause the animals to diverge very markedly from their terrestrial allies. This suggests that in most cases the modification is relatively recent. Among the more frequent modifications are webbed feet, used in swimming, close dense fur which prevents the water reaching the skin and so chilling it, and a broad flattened tail used as a rudder. Of mammals with more profound adaptations to aquatic life, few occur in inland waters. We have already spoken of the Lake Baikal seal (Phoca sibirica) and the Caspian seal (Phoca caspica), both closely related to the Ringed seal of northern waters. The Baikal seal also occurs in Lake Oron, on the course of the river Vitim, and in addition to its seal Lake Baikal shows certain 'marine' features in its molluscan fauna. The explanation is perhaps that the lake had once a connexion, direct or indirect, with the great inland sea of Tertiary times. Among the Sirenia the manatee is largely fresh-water, ascending such rivers as the Amazon almost to their sources. But these animals thrive equally well in the ocean, and their presence in large rivers requires no special explanation.

The large Cetaceans are exclusively marine, but certain dolphins occur in fresh water. The one which is most definitely adapted for this habitat is the blind dolphin of the Ganges, Brahmaputra, and Indus (Platanista gangetica). This animal occurs from tidal waters to the upper reaches of the rivers, as high up as the depth of the water permits, but it has never been seen in the sea. These dolphins feed upon freshwater fish and river prawns, and are apparently primitive forms which, like Ganoid fish, have found a refuge in fresh water. Other fresh-water dolphins occur in the large rivers of South America, especially the Amazon. 


\section{THE ANIMALS OF LAKES AND RIVERS 193}

A very large number of birds haunt the vicinity of fresh water, being attracted to it, especially at certain seasons, by the relative abundance of food there. Such forms, however, live on the surface rather than in the water.

In regard to reptiles it is interesting to note that among the Chelonia, as among mammals, the adaptations to the aquatic life are much more marked in marine than in fresh-water forms. Marine turtles have their limbs turned into paddles; fresh-water Chelonians swim by limbs which are only slightly modified as compared with terrestrial forms. This is quite parallel to the conditions which occur in mammals. Such typically marine mammals as seals, Cetaceans, and Sirenians have their limbs (when present) turned into paddles. Such fresh-water carnivores as otters, fresh-water rodents like water-voles and beavers, fresh-water insectivores like water-shrews, have only slightly modified limbs, retaining many features found in terrestrial types. This is equivalent to saying that for an airbreathing animal the modifications which fit an animal for life in the sea must necessarily be more profound than those which fit it for life in fresh water, which usually occurs in relatively small masses, and where the animal inhabitants often retain considerable dependence upon the land.

Among the Chelonia a considerable number spend at least a great part of their time in the water. As two examples we may take the American Snapping Turtle (Chelydra serpentina), a form reaching a considerable size, which is found in lakes, ponds, and rivers throughout the greater part of North America. It has strongly webbed feet and is carnivorous. As might be deduced from its limbs, which are but little modified, 


\section{THE ANIMALS OF LAKES AND RIVERS}

it leaves the water, should want of food or any other cause render this necessary, and is capable of (awkward) progression on land, in a way that would be impossible for a marine turtle. In Central and Southern Europe the ponds and swamps are inhabited by the pretty little pond tortoise (Emys europea), which has also webbed feet. These little creatures are fond of coming out of the water to bask, and migrate from one pond to another if the first shows signs of drying up.

The same tale of partial adaptation to aquatic life can be told of the various kinds of crocodiles, which, like the forms just mentioned, seem to seek the water for the sake of the food to be obtained there. The living crocodiles are still so far bound to the land that they leave the water voluntarily, either to bask in the sun, or in order to migrate from one region to another, or to lay their eggs.

None of the snakes show such definite adaptations to life in fresh water as do the sea-snakes to life in the sea, but certain forms enter the water freely in search of food. This is especially true of the common grasssnake (Tropidonotus natrix), which sometimes spends the greater part of its life in water, in which it swims easily.

The amphibians show some very curious conditions in connexion with adaptations to the aquatic life. The normal condition, as already suggested, is that the young live in the water and breathe by gills, while the adults live on land and breathe by lungs. But there are some interesting exceptions. Throughout much of North America, and especially in Mexico, there occurs a salamander (Amblystoma tigrinum), which when adult is normally terrestrial, except at the breeding-season, and is of a brownish colour, with yellow spots and 
blotches. The larvae, known as axolotls, have large external gills, slender limbs, and a tail fringed with a swimming membrane. Now, at times, under natural conditions, but for causes not clearly understood, these larvae may become sexually mature and lay eggs, while remaining in the water, and while retaining larval characters. That is, of the Amblystoma eggs laid in a lake some may give rise to the salamander-like adult, while others may breed while retaining tadpole characters. As a much rarer phenomenon this may occur in the common newts, which sometimes breed while retaining the characters of the tadpole.

In a more advanced form the same condition occurs in certain other amphibia, which, as it were, never grow up, but remain permanently in the tadpole stage. In the lakes and swamps of the eastern part of the Mississippi basin, and in some of the Canadian lakes, there occurs an amphibian of about one foot in length, with three pairs of external gills and a fringed tail, called Necturus maculatus. This animal uses both its lungs and its gills for breathing purposes, and retains its gills throughout life. The same statements may be made of Siren lacertina, the mud-eel of parts of the United States. These are examples of the reacquisition of the exclusively aquatic habit by animals whose ancestors had become adapted for life both on land and in water. Amphibians, it may be noted, have probably been derived from fishes of the 'ganoid' type - that is, originated from fresh-water forms (see p. 202).

This brief account of the air-breathing vertebrates found in lakes and rivers enables us to draw some general conclusions in regard to these. Obviously we can classify them under three headings: (1) The amphibians, which possess gills at some stage in their 


\section{THE ANIMALS OF LAKES AND RIVERS}

life-history as well as lungs, illustrate the transition from the fresh-water to the terrestrial life, some forms showing a tendency to revert to the aquatic life; (2) such forms as otter and desman among mammals, water-tortoise and crocodile among reptiles, show land animals in the process of reacquiring aquatic characters, either because food is easier to get in water than on land, or because life is safer there for relatively helpless animals; (3) the fresh-water dolphin of the Ganges, the manatee, \&c., exemplify the acquisition of the fresh-water habit by animals adapted to life in the sea, but driven from the sea by the competition of more advanced forms, or quitting it voluntarily in search of food. The seals found in Lake Baikal and the Caspian Sea are truly marine forms, more or less accidentally cut off from their natural habitat.

The remaining animals of lakes and rivers, including fishes and invertebrates, are of more ancient origin, and have had more time to become fundamentally modified. The manatee is still a marine animal, the fresh-water dolphin of the Ganges became fluviatile at a period which is geologically but of yesterday, but the fresh-water hydra, the fresh-water crayfish, the freshwater mussels have had time to become greatly modified.

The fauna of swift rivers must in the general case consist only of powerful swimmers like fish and freshwater crayfish, or of animals which can so fix themselves as to avoid the force of the currents. In lakes and ponds, on the other hand, there is a greater wealth of life, and it is possible, as in the sea, to divide this life into littoral, pelagic, and abyssal groups. But of these groups the littoral is by far the largest, because it is enriched by many forms, like the larvae of insects, which retain some dependence upon the land. The 
abyssal fauna is sometimes virtually absent, e.g. in the Caspian, owing to the paucity of oxygen, and its members rarely if ever show the specialization seen in the animals of the ocean abysses. This seems to be partly because lakes are necessarily temporary phenomena, destined to be filled up after a longer or shorter period, and therefore there is no time for a special abyssal fauna to develop. As considerable differences exist in the fauna of different lakes, it seems better to give some account of a few types rather than to make general statements in regard to lakes as a whole.

The fauna of the lochs of Scotland has been studied in great detail by the members of the Scottish Loch Survey, so that it is possible to make a considerable number of general statements in regard to it.

The members of the Survey studied in all 562 lochs, and, exclusive of vertebrates and of insects and their larvae, 440 species of animals were found. Most of the lochs studied are shallow, but Loch Morar has a maximum depth of over 1,000 feet, and Loch Ness of over 750 feet, rendering an abyssal fauna possible. The members of the Survey did not especially investigate the fishes. We know, however, from other sources that the special feature is the number of members of the salmon family, which run into many species or varieties; ef. the Loch Leven trout, which is peculiar to that lake.

Of the invertebrates the majority may be described as littoral in that they occur in shallow water, near the margins of the lochs. Here are found many insect larvae, and not a few adult insects adapted for life in the water, e.g. water-beetles and water-boatmen. Here, too, are found nearly all the few molluses, including the large mussels and the small fresh-water snails. Small 
crustacea are numerous, especially those forms popularly called water-fleas, from their jumping movements. Many rotifers occur, together with such small animals as water-mites, water-bears (Tardigrada), and so forth.

Only some thirty species are typically pelagic and thus constitute the plankton. These comprise fourteen small crustacea, twelve rotifers, and four protozoa. Of these thirty species most are very widely distributed, the animals which constitute the fresh-water plankton being all but cosmopolitan, and believed to form 'the oldest community of organisms on the earth' (Sir John Murray). The special feature, however, is the presence here of some Arctic crustacea, and the absence of certain forms found in other European lakes, both no doubt due to the northern position of the lochs.

As has been just stated, the lochs are mostly shallow, and therefore an abyssal fauna is rarely developed. Of the two deep lochs, only in Loch Ness were successful deep-water dredgings made. Here it was found that at depths greater than 300 feet the majority of the littoral species disappear, leaving a small group of animals, including one mollusc (a small bivalve called Pisidium pusillum), three crustacea, three worms, an insect larva, and a few infusoria. These occur also in the littoral region, and the forms from deep water show no special feature, so that it would be more correct to say that a few only of the littoral forms can live in depths greater than 300 feet than to say that a special deepwater fauna exists.

Before leaving the fauna of these lakes, one interesting point may be noticed. In certain of them, especially those which lie but little above sea-level, a marine crustacean called the opossum shrimp (Mysis) occurs. In the Scottish lochs the species of Mysis found is that 
which also occurs round the coasts in salt and brackish water, and its presence is doubtless to be explained on the supposition that it is a recent migrant from the sca. But in certain continental lakes, especially those in Denmark and on the North German plain, another variety or species occurs, called Mysis relicta. The modifications which this form displays are believed to indicate that the bodies of water in which it occurs were once connected with the sea, but have been long separated from it. Such organisms are said to constitute a relict fauna, and the lakes in which they occur are called relict lakes (German, Reliktenseen), to indicate their supposed former connexion with the sea.

With the Scottish lochs may be contrasted Lake Balaton or Platten See, a large shallow body of water in Hungary, connected with the Danube drainage system. The area of this lake is about 250 miles, but its average depth is only 10 feet, and the maximum 36 feet. Its fauna has been subjected to detailed investigation.

As its shallowness makes Lake Balaton a mere pool, we find that here the fauna forms a unity. Necessarily there is no deep-water fauna, and it is not possible to discriminate accurately between littoral and pelagic faunas, as the bottom is everywhere so close to the surface. The total number of species does not differ greatly from that of the Scottish lochs, being about 475 , including 38 kinds of fish, but exclusive of insects and air-breathing vertebrates. The fish show some interesting peculiarities. There are no trout, but the lake contains such common fresh-water forms as perch, gobies, pike, eels, roach, tench, gudgeon, \&c., and in addition two forms of special interest. One is the catfish called 'Wels' by the Germans (Silurus glanis), 


\section{THE ANIMALS OF LAKES AND RIVERS}

and the other the sterlet (Acipenser inthenus). The cat-fish constitute a large family of fresh-water fish especially characteristic of the equatorial region. The wels is found only in Eastern Europe, and is the only. member of its family in European waters. The sterlet is a near ally of the sturgeon, and is a member of a small group of old-fashioned fishes which used to be called ganoids. The name has been abandoned in more recent classifications of fish, for the ganoids are not a homogeneous group, but their interest for us is that they are fish of a primitive type, which once lived in the sea, but have been driven into fresh water (though the sturgeon also occurs in the sea) by the competition of the more highly organized bony fish.

of the invertebrates it is sufficient to say that with considerable general resemblance to those of the Scottish lochs, they display certain minor differences. Thus, the Arctic types of crustacea are absent, and such forms as the fresh-water crayfish (Astacus), found in England, but not in Scotland, are present here. Similarly there is a greater wealth of molluses, a considerable number of genera of more or less southern facies being here represented, though they are absent from the lochs of Scotland. On the other hand, the rotifers are far less abundant than in the Scottish lochs, but comparisons of this sort do not profit very much, as it is difficult to be sure that the investigations have been conducted along exactly similar lines in the two cases.

As a third example of a lake fauna we may take that of Lake Tanganyika in tropical Africa, which has been the object of careful study by Mr. J. E. S. Mnore and others.

Tanganyika has an area of 12,700 square miles. It 
has never been systematically sounded, but depths of 1,200 to 2,100 feet have been recorded at various localities. The elevation is 2,624 feet above sea-level.

The fish fauna show some curious features. In the first place the lake contains a species of Protopterus, one of the three living genera of dipnoi or lung-fishes. The two other living genera inhabit the one (Lepidosiren) the rivers of tropical America, and the other (Ceratodus) those of Queensland. As well as occurring in Lake Tanganyika, the species of Protopterus have a wide distribution in the lakes and rivers of the middle portion of the African continent. All the dipnoi possess, as we have seen, both lungs and gills, but the two sets of breathing-organs are not in use simultaneously. The fish normally inhabit regions where a periodical dry season occurs, when the water in which they live either becomes very foul or dries up. The first condition is frequent in the natural habitat of the Queensland Ceratodus, the second in that of the two other genera. At this period, therefore, Lepidosiren and Protopterus make themselves nests of mud, in which they lie dormant, breathing by their lungs till the water returns. In the case of Ceratodus the lungs are used when the water is too foul for the gills to be of any use, but the animal does not make mud nests. All three genera show certain very primitive characters in combination with this specialized mode of breathing. Their ancestors were certainly marine, many fossil forms having been found. Thus the dipnoi must be looked upon as the fresh-water survivors of a highly primitive group of marine fishes, owing their persistence to the acquisition of specialized breathingorgans. Their 'discontinuous distribution' over the surface of the globe is another point of interest in 
regard to them. Such discontinuity is common with old-fashioned animals, which owe their local persistence to their adaptation to special environmental conditions. The tapir in the swampy forests of the Malay region and in South America, but nowhere else, is another example.

Another very peculiar fish-type in Tanganyika is Polypterus congicus, a member of a 'ganoid' genus, which is restricted to tropical Africa. Like Protopterus this fish has an accessory respiratory organ, for the organ which forms the air-bladder in many other fish seems here to be used in respiration, perhaps because the fish inhabits the same regions as Protopterus, i.e. rivers whose waters become periodically foul. In very many points of structure, however, the species of Polypterus differ markedly from those of Protopterus. Into these points we cannot go here, but it may be sufficient to say that many zoologists are of opinion that they show that terrestrial vertebrates arose from a stock common to them and to Polypterus. Though the lung of the dipnoi is much more like the lung of a terrestrial vertebrate than is the air-bladder of Protopterus, it is not believed that dipnoi are near the line of descent of terrestrial vertebrates, largely because of the structure of their limbs. It seems as if the limb of Polypterus could more easily give rise to that of a land vertebrate than that of Protopterus. We have already considered several cases of land animals reacquiring modifications of structure which fit them for life in the water, but Polypterus is interesting as suggesting one way in which land animals arose from aquatic ones. Its ancestors were certainly marine; but were driven into fresh water by the competition of better-organized forms which appeared in the sea. 


\section{THE ANIMALS OF LAKES AND RIVERS 203}

The relatively unfavourable conditions which exist in rivers made it necessary to develop accessory breathingorgans, and these apparently led the way to the acquisition of purely terrestrial characters, in the allies of the ancestral Polypterus.

Another peculiarity of the fish fauna of Tanganyika is the enormous number of fish belonging to the family Cichlidae. The lake is characterized by its very large number of fish, nearly a hundred different species having been described. Of these, more than half belong to the family Cichlidae, and, more remarkable still, of the fifty-eight species of this family described in the lake only one is known outside the lake. We have already noted, in speaking of the Scottish lakes, that it is not unusual to find peculiar varieties or species of fish in lakes, but the fact that many peculiar genera occur in Tanganyika speaks to long isolation.

The other fish of the lake are for the most part similar to those which occur in the remaining African lakes. For instance, there are a considerable number of cat-fish, very usual inhabitants of equatorial lakes. As we shall see directly the invertebrates show the same general peculiarities as the fish-that is, we find a combination of forms found in other African lakes, and of quite peculiar forms of primitive type, the result being to give the lake an unusually large fauna. Moore believes that this shows that the lake had once a direct connexion with the sea to the west, through what is now the Congo basin. He places the rupture of this connexion so long ago as the period called by geologists the Jurassic, and believes that at the time of the rupture the lake was peopled by Jurassic forms. These in course of time evolved into the peculiar types now found in the lake, which retain many archaic 


\section{THE ANIMALS OF LAKES AND RIYERS}

characters. Later, the ordinary fresh-water fauna of Africa gradually reached the lake, giving the presentday mingling of special types with marine affinities (halolimnic forms) and ordinary fresh-water types. This hypothesis has not been universally accepted, and the evidence upon which it is based depends upon detailed anatomical points which cannot be considered here.

As the figures already given suggest, Tanganyika is an enormous lake when compared with the lochs of Scotland, and it is of course very inaccessible. We cannot, therefore, hope to have the detailed information in regard to its fauna which is available for the Scottish lochs or for Lake Balaton. It has never been systematically sounded, so that it is not possible to distinguish between the faunas of the different depths in detail. The great point of interest is the occurrence of invertebrate animals of definitely 'marine' type, notably of a fresh-water jellyfish. Invertebrates of marine type are of course not confined to Tanganyika. We have already mentioned their occurrence in other lakes, e.g. in Lake Baikal, but they seem to be especially numerous and peculiar in Tanganyika, and, as already stated, they coexist there with ordinary fresh-water forms.

No less than fifty species of molluses have been described from Lake Tanganyika. Of these a considerable number belong to the genera commonly represented in masses of fresh-water elsewhere. Thus we have species of Limnaea, Planorbis, Bithynia, Cnio, \&c., the first two genera being cosmopolitan and very old. But in addition there are a number of gastropods of peculiar and primitive characters, with strong marine affinities, constituting part of Moore's 'halolimnic " fauna. Some of these live at depths of 600 feet and upwards, which is in itself an exceptional feature, for, 
as we have already explained, there appears to be a deficiency of oxygen in the depths of equatorial lakes, and in Lake Nyasa no life has been found at depths greater than 100 to 150 feet. The occurrence of deepwater forms in Lake Tanganyika is perhaps associated with the antiquity of the lake, which has given time for the evolution of a special deep-water fauna.

The crustacea include the usual small copepods of fresh water, and also two crabs and two prawns, all peculiar to the lake. One of these crabs extends downwards from 500 to 600 feet, and is thus another example of the deep-water fauna. Among the other interesting forms are a peculiar polyzoon, three fresh-water sponges, and the jellyfish (Limnocnida) already mentioned. A closely related fresh-water jellyfish has been described from Rhodesia, and another apparently very similar form has been found in the tributaries of the Krishna in India, but none of these is well known.

The protozoa of Tanganyika seem to resemble generally those of other African lakes, and indeed those of lakes in general.

To these accounts of characteristic lake-faunas, a word or two may be added on the fauna of the Great Salt Lake of Utah. Here the conditions are extraordinarily unfavourable to animal life. Only one organism can be said to have solved completely the problem of adaptation to life in the brine. This is the Brine-shrimp (Artemia salina), which in summer is excessively abundant (cf. Scottish Geographical Magazine, vol. xvii. (1901) p. 617). It is very tolerant of cold and of variations in the salinity of the water, and the fact that the eggs can develop parthenogenetically-that is, without previous fertilization-enables the animals to reproduce themselves very rapidly when the conditions 
are at all favourable. During the warm season the larvae of two flies, a Tipula and a Chironomus, also occur in the shore waters, and a water-boatman (Corixa) is also found in the lake. Otherwise it is singularly barren of animal life.

Cave Faunas. As caves usually contain a considerable amount of water, something may be said here of the more characteristic animals found in them. Cave animals live in conditions which in many respects resemble those prevailing in the ocean abysses. Thus there is often complete darkness, and the temperature, though it may be low, is remarkably uniform. Green plants, also, are necessarily absent. Some of the characters of abyssal forms therefore reappear here; for example, the eyes tend to disappear or become minute. But as the light conditions are quite different from those which obtain in the ocean depths, where as we have seen (p. 172) certain rays penetrate deeply, we find that cave animals tend to be white, instead of showing the deep-red or black coloration found in many animals which live in the ocean near the light limit.

An interesting example of a cave animal is Proteus anguinus, found in the caves of Carniola, Dalmatia, and Carinthia. This animal is one of the permanentlygilled amphibians already described, and reaches a length of about a foot. The skin is without pigment, and the eyes are below the skin. The animal remains permanently within the water, though it rises to the surface to breathe if the water is not quite pure. Curiously enough, if the white body is exposed to light pigment develops in the skin, and perfectly black specimens can be produced by gradual exposure. In the caves of Texas there is an allied form (Typhlomolge 
rathbuni) of similar characters. The same type of adaptation also reappears among the cave fish, which have been especially studied in the Mammoth Cave of Kentucky. One of the most interesting found there is Amblyopsis spelaea, which is white in colour, and has concealed eyes. To make up for the loss of the eyes the head is furnished with a great number of tactile papillae.

Of other cave animals the most important are crustacea, especially isopods, e.g. Titanethes albus, which has no eyes, and insects, notably beetles, e.g. Adelops and Bathyscia, also some spiders, myriapods, and a few molluses, the tendency to lose eyes and the pigmentation of the skin being well marked.

ReFERExces. The first volume of the scientific results of the Bathymetrical Survey of the Scottish Fresh-water Lochs, conducted under the direction of Sir John Murray and Laurence Pullar (Edinburgh, 1910), contains several articles dealing with the fauna of lakes, as well as detailed lists of the organisms found in the Scottish Lochs. This volume gives also a detailed bibliography of limnological literature. The account of the fauna of Lake Balaton given in the text is based upon the Resultate der wissenschaftlichen Erforschung des Balatonsees, herausgegeben von der Balatonsee-Commission der Ungarischen Geographischen Gesellschaft (Vienna, 1906). A full account of the fauna of Lake Tanganyika is given in The Tranganyika Problem, by J. E. Moore (London, 1903). Other references to the same subject will be found in the bibliography mentioned above. Many of the general works already mentioned also discuss fresh-water faunas, and to them may be added Forel's Handbuch der Seenkunde (Stuttgart, 1901), and the same author's large work on Lake Geneva (Le Léman: Monographie limnologique, 1892-1904, Lausanne), and Die Tier-und Pflanzenwelt des Süsswassers, by Dr. Otto Zacharias and others (Leipzig, 1891). See also articles on the river mussels, \&c., of South America in Archhelenis u. Archinotis, by Hermann von Ihering (Leipzig, 1907). Kobelt's book (cf. p. 35) has an interesting chapter on cave faunas. See also Semper's Conditions of Existence as they affect Animal Life (London, 1881). The blind fish of the Kentucky cave are discussed by Putnam (Amer. Nat. 1872). 


\section{CHAPTER X \\ ZOOGEOGRAPHICAL REGIONS}

WE have now surveyed those natural regions of the earth described in the Introduction, and have noted their more important occupants, and the adaptations which these show to their particular habitats. In the course of these descriptions it has become obvious that what may be called the raw material upon which adaptation has worked is not the same in all parts of the globe. We have found that animals inhabiting dense forest generally show certain arboreal adaptations, such as the prehensile tail, the opposable thumb and great toe, and so forth, found wherever the forest occurs. But in New Guinea, for example, certain kangaroos have taken to the trees and become arboreal; in Madagascar lemurs swarm in the forests; in South America particular kinds of monkeys, the opossums, and the sloths, as well as other animals, people the selvas, and so on. In other words, each isolated forest, or other area, has its own types of adapted animals.

The only possible explanation of these conditions is the hypothesis that the specialized forms in each separate region have been evolved from pre-existing unspecialized forms inhabiting the region. In South America we find fossil representatives of ground sloths. These have long since become extinct, and the existing sloths have apparently been saved from a like fate by the acquisition of marked arboreal characters, which protect them from many possible enemies. In the continent of Australia, and parts of the adjacent 
regions, kangaroos are abundant, and are for the most part savana animals. But where tropical forests occur, as in North Queensland and New Guinea, there certain forms have taken to the arboreal life, and have thus protected themselves from the competition of groundliving forms no less than from the attacks of some possible enemies.

The same statements might be made of desert animals, of savana animals, or, generally, of any forms inhabiting a natural region. We may say, then, that when any stock of terrestrial animals reaches a new region, and is there isolated from any cause, that stock will tend to give rise to specialized groups, more or less perfectly adapted to all the possible varieties of habitat which the region affords. In order that a particular stock may give rise by specialization and differentiation to many such groups, some degree of isolation seems to be necessary, for otherwise new incoming stocks may colonize the vacant places before the first stock has had time to become differentiated. For example, in Australia almost all habitats suited to terrestrial mammalia are occupied by marsupial animals. Living marsupials also occur in South America, but there they are represented by a very limited number of types, because they have had to face the competition of placentals, practically absent in Australia. Similarly, in Madagascar the lemurs are very numerous and very diverse, being adapted for different modes of life. Lemurs also occur in Africa and India, but there, where they have to face the competition of the more intelligent monkeys, and the attacks of more powerful carnivores than any which are found in Madagascar, they are few in number, small in size, and less diverse. 
Such isolation of portions of the earth's surface is caused by the existence of barriers to the distribution of terrestrial animals. Necessarily these barriers must be supposed to have a definite date of origin, and this origin must always be supposed to be later in time than that of the ancestral stock of the group under consideration, but to precede the differentiation of the stock into many divisions as the result of the isolation. As an example of the origin in time of such a barrier let us take a progressive climatic change. The animals of temperate Europe and Asia show a marked difference from those of tropical Asia and of tropical Africa. To some extent this difference is doubtless due to the existence of transverse mountainchains, such as the Himalayas and the Andes, but it is also largely due to the existence of a great band of deserts and wastes across Asia and Northern Africa, for both the mountains and the deserts prevent intermixing. Now there is much evidence to show that there has been a progressive desiccation in this region within geologically recent times. One effect has been to favour the development of the many steppe and desert animals of the region, but another has certainly been to separate an originally homogeneous fauna into three parts, and by isolating much of Africa on the one hand and the peninsula of India with Further India on the other, to favour evolution in these two areas, now protected from the incursion of northern forms, save on a very limited scale. We have seen, for example, how scantily represented in temperate Europe and Asia are the abundant antelopes of Africa, and similarly how the numerous deer of the north are shut out from Africa by the, to them, impassable desert.

To the zoogeographer, however, the greatest barrier 
is undoubtedly the sea, for a broad channel offers an insuperable barrier to the passage of most land animals, save those small enough, or resistant enough, to be carried passively by winds and waves or an animal host. Here, obviously, we approach difficult questions. Geological research, especially in recent years, has familiarized geographers with the idea that great changes in the distribution of land and water have taken place on the surface throughout geological time. Now to consider this distribution in its relation to animal life and evolution from the Cambrian period onwards would obviously be a Herculean task, though it is one which has been attempted, e.g. by Arldt. Without such a consideration, however, we cannot hope to explain in its entirety the distribution of animals at the present time. But without attempting to do this, it is of interest to note the main features of the distribution of the higher forms of life in the existing continental masses. As we saw in the Introduction, such a division of the globe into zoogeographical regions is primarily of interest to the zoologist rather than to the geographer. This is especially true when the subject is treated in detail, as in most of the works on the subject. At the same time for historical reasons, if for no other, the subject is too important to be entirely omitted, and in this concluding chapter we shall consider briefly the classical ' regions' into which the globe has been divided by zoologists, on the basis especially of the distribution of birds and mammals.

In dividing up the globe in this way the first point to be emphasized is that, though the geographers are accustomed to lay great stress upon the distinction between the American and Eurasiatic continents, between the Old and the New Worlds, no such distinction 
exists between the animals, at least of the northern regions. We have already pointed out that the tundra animals of the east and west show very marked resemblances to one another; that similarly there is considerable resemblance as regards both the plants and animals of the belt of coniferous forest in both hemispheres, and that only as we travel southwards does differentiation appear. There is much evidence, both geological and zoological, to show that not long ago there was free land communication between the Old and New Worlds in the northern hemispheres, across what is now the Bering Strait, as well as possibly across parts of the North Atlantic. Further, though parts of what are now the continents of Africa and of India were, in early Tertiary times, probably separated by stretches of sea from the land-masses to the north, and though they are now functionally separated from the great land-mass in the eastern temperate and frigid zones by belts of deserts and by transverse mountain-chains, yet, before the progressive formation of these belts of desert, there was apparently a time when it was physically possible for land animals to spread from the far north of Europe and Asia to the far south of Africa and India, and south-eastwards to parts of the Malay Archipelago. With this great eastern landmass North America, as already suggested, was in free communication, though it seems to have been long separated from South America.

We thus have to consider as forming one great REALM of the earth's surface the whole Eurasian continent with parts of the Malay Archipelago, the continent of Africa with the isolated region of Madagascar, and North America. In this great land-mass evolution, as we would expect from its great extent, has been 
rapid. Here we find the highest mammals and the most specialized birds. Where the tropical forest is dense a few primitive forms linger, and some also have been saved by isolation, e.g. in Madagascar. But as a general rule the primitive forms have been crushed out of existence by higher forms. No marsupial (save one opossum in North America) now lives within this great area, and no monotreme. No primitive reptile, like the Hatteria of New Zealand, points us back to an earlier age. Here and here alone do we get the highest of the primates apart from man-the anthropoid apes and the dog-faced baboons. Here and here alone do we get the highest and most specialized of the ungulates, and so on.

For this great area various names have been proposed. Thus it has been called Aretogaea, or the Northern World, because of its mainly northern position, though Africa extends far to the south.

In regard to the boundaries of this realm it may be said that over much of the area they are formed by the sea. In two regions, however, difficulty occurs. One is in the south-east, where a boundary line has to be drawn through that mass of islands which stretches between Further India and the northern shores of Australia. Wallace drew the line which separates his Oriental (or Indian) region and the Australian region between the islands of Bali and Lombok. A narrow but deep strait separates these islands, and Wallace believed that all the islands to the east of this strait (Wallace's line) possessed faunas with a distinctively Australian facies, while those to the west had faunas of Indian type. Recent detailed research has thrown some doubt upon this statement. A mingling of faunas certainly occurs in this region, and any hard 
and fast line must necessarily be of a more or less artificial character. The difficulty is sometimes got over by the erection of a transitional region. It is enough for our purpose to know that such a transition exists.

The other area where a line is difficult to draw is in the American continent. There are many striking differences between the faunas of North America and South America, but the two regions are now in free communication. Necessarily, therefore, a certain amount of mingling occurs. That this mingling is not greater than it is is doubtless due to climatic differences, to the occurrence of desert regions, e.g. in Mexico and the west, and so on. Here again the difficulty is usually got over by the erection of a transitional region to include a considerable part of the south-western United States.

The rest of the globe is sometimes included in one Realm, forming the Notogaeic Realm, or Southern World, and including on the one hand Southern and Central America, with Mexico and the West Indian islands, and on the other the continent of Australia with Tasmania, New Guinea, the islands of New Zealand, and some of the islands of the Malay Archipelago, as well as the scattered groups of Polynesia. This union of Australia and South America, despite their considerable separation in space, seems to be justified by the increasing proofs of the affinities of their faunas, and the increasing probability that they were connected, at a not very remote period, through the Antarctic continent.

The Notogaeic realm so defined is characterized by the presence of monotremes (in Australia) and marsupials; by the presence of running birds and dipnoi (these being characters shared with Africa), and by the absence of the highly differentiated forms named above. 
Now it is obvious that these two realms are large and unwieldy divisions. They are therefore in their turn subdivided into regions. Taking the Arctogaeic realm first, we find that it may be subdivided into the following regions: (1) the Holarctic, including the whole of temperate Europe, Asia, and North America; (2) the Oriental, including India south of the Himalayas, Further India, and parts of the Malay Archipelago; (3) the Eтhiopian, including Africa south of the Atlas and Sahara desert. To these many would add a fourth region for the island of Madagascar, whose fauna is so strikingly different that it may well form (4) the Malagasy region. But while the fauna of the Oriental region shows many resemblances to that of the Holarctic region, the differences being largely attributable to differences of climate, Africa, in the characters already mentioned, is strikingly dissimilar, and approaches the South American and Australian regions. Without pursuing this point further, we may note that some authorities separate it on this account from the Arctogaeic realm.

Again, the Notogaeic realm obviously falls into two regions: (5) the western or Neotropical, and (6) the eastern or Australian.

This classification may be summed up in tabular form as follows :

\section{ARCTOGAEIC REALM.}

(1) Holarctic Region [sometimes divided into an eastern (Palaearctic) and a western (Nearetic) subregion].

(2) Oriental region.

(3) Ethiopian Region.

(4) Malagasy region. 


\section{NOTOGAEIC REALM.}

(5) Neotropical REgion.

(6) Australian Region.

Each of these regions may now be considered in a little detail.

Beginning with the Holarctic region, we find that the western or Nearctic section has no primates, and the eastern or Palaearctic only those species of Semnopithecus and Macacus already mentioned (pp.77-8). In the Palaearctic section the sheep and goats are well represented, but to the west they are few (cf. p. 82). Both sections have oxen. The antelopes are scantily represented in both, while deer are abundant. To the east, but not in the west, camels and horses occur. Elephants do not occur in either division, but both are rich in carnivores. Among the special forms it is noticeable that the badger is peculiar to the Old World, while the Nearctic section shares the skunk and raccoon with the Neotropical region. In' both divisions rodents are very numerous, but this is a fact which has already been sufficiently discussed. Among the insectivores the mole (Talpa) is a form peculiar to the Old World, where it extends into the Oriental region.

The bird faunas of the two regions differ from each other somewhat markedly, but this is partly because both regions receive many seasonal immigrants from the hotter land-masses lying to the south of them. The differences also chiefly affect genera or even species, rather than orders or families. Two familiar families of the Old World are, however, absent in the New. Thus North America has no true starlings, their place being taken by the hang-nests or Icteridae, to which the rice-bird or bobolink (Dolichonyx) belongs. The 
flycatchers (Muscicapidae) of the Old World are also absent in the New, their place being taken by the tyrant shrikes (Tyrannidae). Reptiles are somewhat scantily represented, but we have already touched upon the abundance of tailed amphibians, the majority of which are peculiar to the region. Something has also been said of the fresh-water fish fauna, which is remarkable for its development of salmon, carp, pike, perch, sticklebacks, \&c. There is nothing specially worthy of note as regards the invertebrates.

The animals of the ORIENTAL region show so marked a general resemblance to those of the Ethiopian, that some naturalists would unite the two as a Palaeotropical region. There are, however, certain welldefined differences in addition to basal resemblances.

Beginning with the Primates, we find that the Oriental region has two peculiar kinds of anthropoid apes, the orang of Sumatra and Borneo, and the gibbons of the Malay region. There are also many kinds of monkeys, belonging to the genera Macacus and Semnopithecus. The genus Cynopithecus includes only one species, the so-called black ape, peculiar to the island of Celebes, usually included in the Oriental region. We have already mentioned the peculiar proboscis monkey (Nasalis) of Borneo. There are four lemurs, including two species of the very peculiar genus Tarsius. In the continent of Africa there are eight species, and in Madagascar about thirty-six species-a very interesting contrast.

The Oriental region is rich in bats, having many representatives both of the insect-eating and the fruiteating forms, with some peculiar genera.

Among the insectivores the very peculiar flying lemurs (Galeopithecus) of the Philippine Islands are 
confined to the region, as are also the tree-shrews (Tupaia).

Camivores are numerous, and among the interesting contrasts with the Ethiopian region is the presence of bears, believed to have originated within the Oriental region. The tiger, whose presence in India affords another point of contrast with Africa, does not reach Ceylon, and is believed to be a relatively recent immigrant into India. Like the Ethiopian region, the Oriental one is rich in civets and their allies. True cats of the family Felidae are also numerous.

Among the ungulates we note the presence of oxen, the paucity of antelopes, the abundance of deer, the presence of chevrotains, of many pigs, of rhinoceroses, of a tapir, and an elephant, and the fact that wild asses just reach the region.

Rodents, especially squirrels and mice, are abundant, and include peculiar genera. The Edentates are represented by members of the genus Manis, the pangolins, represented elsewhere only in the Ethiopian region.

Birds are very numerous, the region being especially characterized by the number and beauty of its pheasants. On the other hand, parrots are relatively few, compared with their abundance in the Australian region. The babbling thrushes (Timelidae) have their headquarters in the region, and are very numerous. Very striking also are the bulbuls (Pycnodontidae), green bubuls (Phyllornithidae), and the hill-tits (Leiotrichidae). There are many reptiles; we have already spoken of the flying lizard (Draco) and the crocodiles. The longsnouted forms of the latter (Gavialis) are restricted to the region, where there is one species in the Ganges.

A good many of the peculiarities of the ETHIOPIAN region have been alluded to incidentally in the fore- 


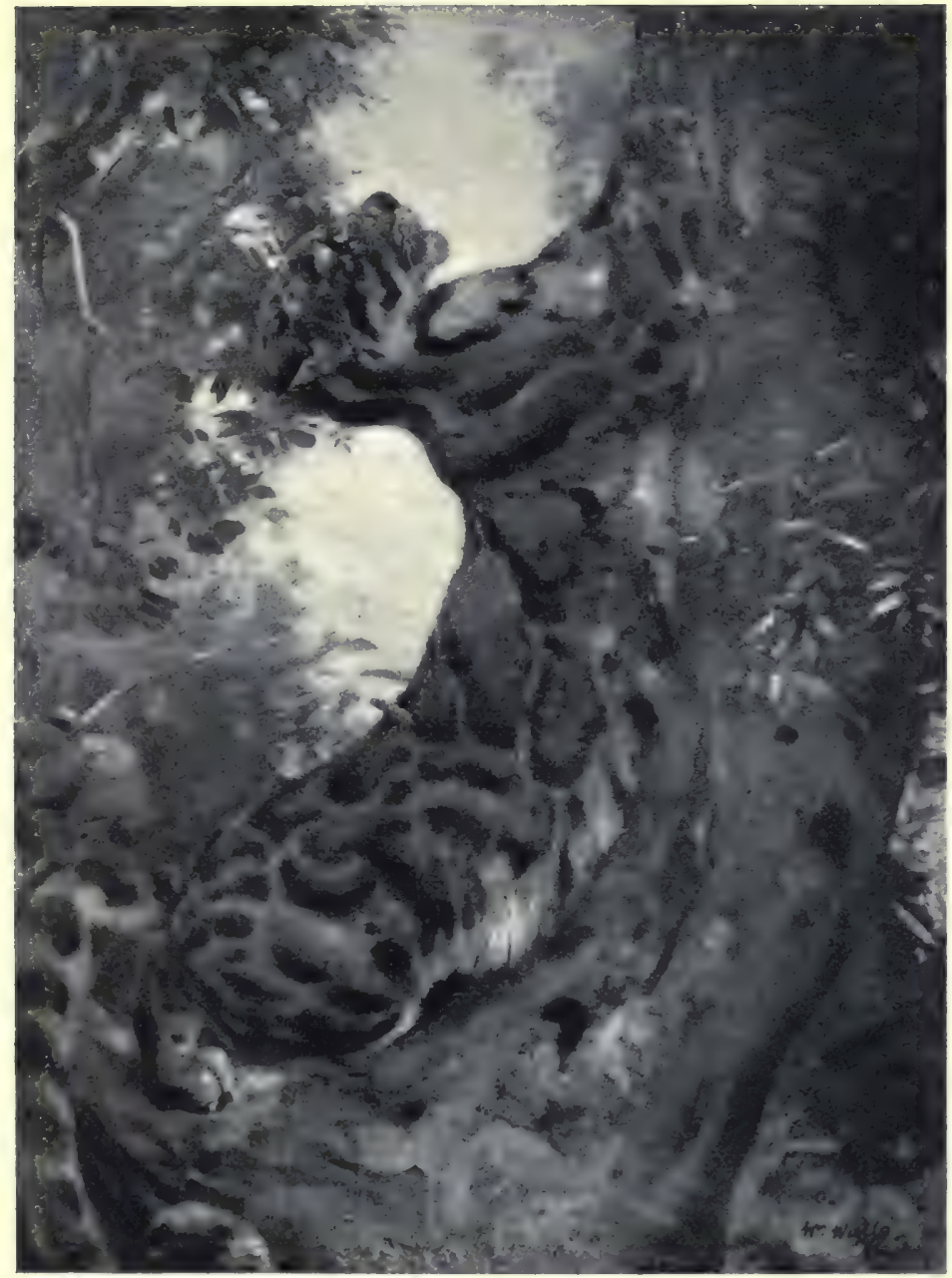

Fic. 45. Clouded Leopard of S.E. Asia. (From the picture by W. Walls.) 


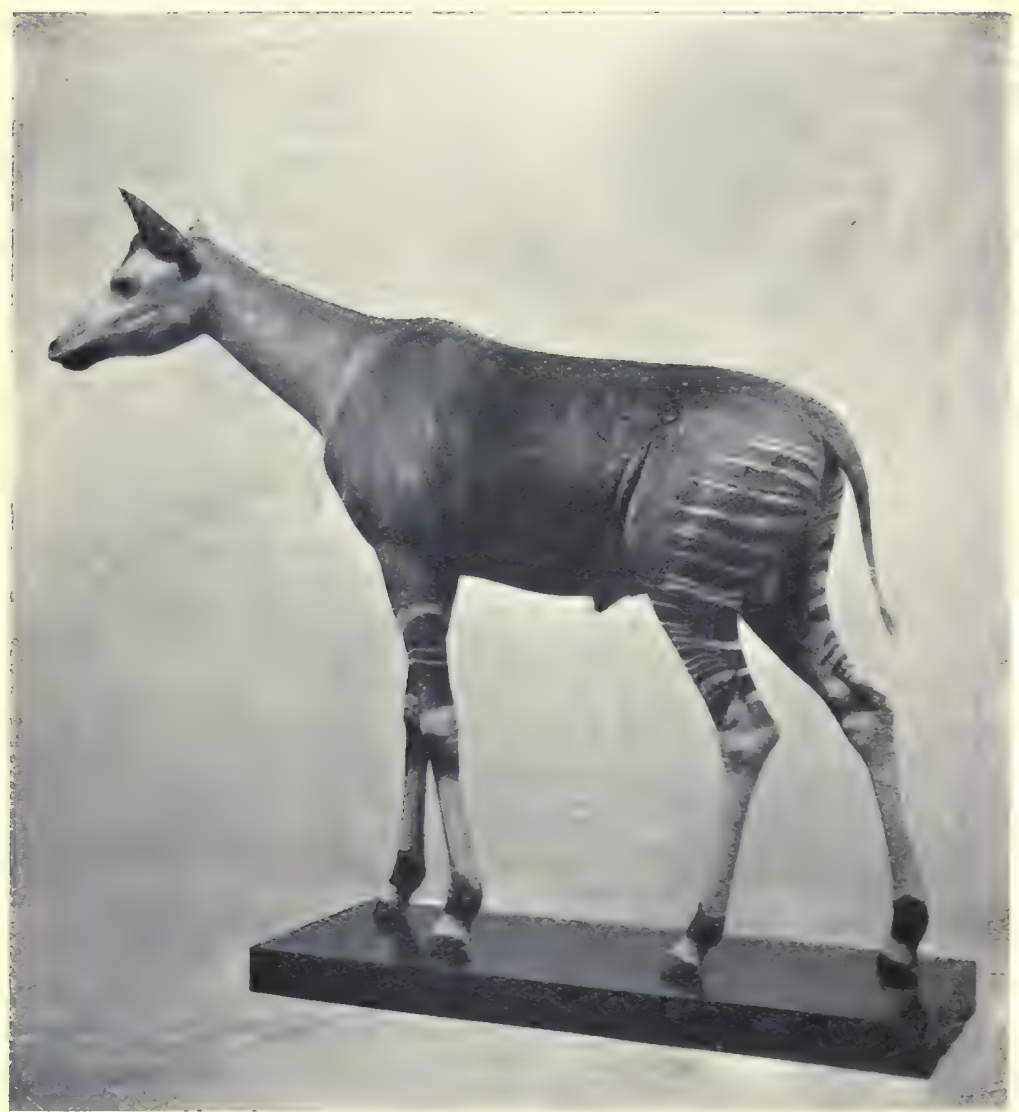

Frg. 46. The Okapi. (From a specimen in the Royal Scottish Museum.) 
going description, but some further details may be added. The region is almost equally characterized by the forms which are present, and by those which are absent. Among the Primates it possesses the gorilla and the chimpanzee, two peculiar forms confined, as we have seen, to a relatively small part of the continent. Monkeys are represented by five peculiar genera with many species, lemurs by two or three genera and some eight species. Fruit-bats are fewer than in India. Insectivores are peculiar and primitive. Thus we have jumping-shrews, the aquatic potamogale and the golden mole, the latter believed to be allied to the curious tailless hedgehog or tenrec of Madagascar. Among the carnivores an interesting feature is the presence of two peculiar dogs, belonging to the two genera of Lycaon and Otocyon, the latter having very primitive teeth. We have already spoken of the absence of bears, and it is noticeable that the weasel alliance is scantily represented.

So much has been already said of the ungulates (p. 129 et seq.) that a few general statements may suffice. Goats and sheep are practically absent, and with one exception so are true pigs of the genus Sus, though wart hogs, bush pigs, river hogs, and the hippopotamus occur. There is no tapir and no camel, but rhinoceroses, elephants, chevrotains, and several kinds of horses occur, as well as the curious hyrax and peculiar forms like the giraffe and okapi; antelopes are abundant.

In regard to the rodents a peculiar feature is the absence of the true flying squirrels and their replacement by the peculiar family of Anomaluridae (ef. p. 109). The Edentates are represented by the curious aard-vark (Orycteropus), as well as by pangolins.

The birds are not so abundant nor so beautiful as 
those inhabiting the Oriental region. The plantaineaters (Musophagidae) and the colies (Coliidae) are among the peculiar families. Though the beautiful sun-birds (Nectarinidae) are represented in the Oriental and Australian regions, they are especially characteristic of Africa, where they take the place of the humming-birds of South America, which they somewhat resemble in beauty of plumage and in habits. Parrots are not very numerous. The true ostrich, though not confined to the region, is very characteristic. Reptiles are numerous, and among the fish we have to note the presence of the dipnoan genus Protopterus, and the curious 'ganoids' known as Polypterus and Calamoicthys. Some other peculiarities of the fresh-water fauna have been already alluded to.

The Malagasy region or sub-region (p. 152) shows some very striking differences from the mainland, these differences testifying to its long isolation. Thus there are no anthropoid apes nor monkeys, but some thirty-six species of lemurs occur, all belonging to peculiar genera. The insectivores are somewhat numerous, for there are over twenty species. The relative abundance of these and of lemurs, both helpless forms, must be associated with the paucity and small size of the carnivores. Of the insectivores all save one species of musk-shrew (Crocidura) belong to peculiar genera, and most belong to a peculiar family, that of the tenrecs or Centetidae, which is entirely confined to the island, and shows many primitive characters. The musk-shrews are widely distributed in the old World, and the genus is one of the three which Madagascar shares with the adjacent mainland. The other two are hippopotamus (with one extinct species) and Potamochoerus, the river hog (with one species) 
Rodents are represented by five peculiar genera belonging to the mouse section; carnivores by some seven members of the civet family, of which the largest is the cat-like animal called Cryptoprocta. All the genera of carnivora are peculiar to the island. The absence of the true cats of the genus Felis, elsewhere so widely distributed, is a remarkable feature.

The above include all the non-flying mammals of Madagascar, and it will be noted that they form a striking contrast with those of Africa. The characteristic African birds, e.g. the plantain-eaters and colies, are similarly absent, while the reptiles are very remarkable in that some show affinity with those of South America rather than with those of Africa. The chameleons present some interesting features. These lizards occur in Africa and in India, but are more abundant in the island of Madagascar than anywhere else, thus showing a curious parallelism with the lemurs.

Turning now to the Notogaeic Realm we may begin with the Neotropical Region, which is both highly peculiar and very rich in species. Here are no anthropoid apes, no dog-faced (Catarrhine) monkeys, and no lemurs, but on the other hand a peculiar family of broad-nosed (Platyrrhine) monkeys, and another of small, also broad-nosed, furry forms called marmosets, both families differing in a number of respects from all the Old World forms. The bats are very peculiar. Here only (with a slight extension into North America) do we find the vampire bats, while the fruit-bats of the Old World are completely absent, as well as another family called the horse-shoe bats (Rhinolophidae). Insectivores are practically absent, though in the West Indian Islands there occur two shrews of the genus Solenodon, believed to be related to the Centetidae of 
Madagascar. Of the carnivores it is only necessary to say that bears are represented by only one species, while raccoons are plentiful, and like the skunks are common to this region and the Nearctic.

Very remarkable conditions are exemplified by the ungulates. Tre find peculiar deer, peculiar pigs (peccaries), tapirs (shared with the Malayan region), llamas (allies of the Old World camels), but no antelopes, sheep, goats, oxen, nor horses. There are many peculiar fossil forms, but these are beyond our range.

We have already spoken of the number and peculiar nature of the rodents, and nothing need here be added to what has been said on pp. 56 and 87. The peculiar nature of the Edentates has also been pointed out, and the presence of many kinds of opossums. In South America there occur also other marsupials, known as selvas (Coenolestes), which are of great interest because they are believed to belong to the herbivorous or diprotodont section, that of which the kangaroo is the most familiar representative. The discovery of these little animals in South America is of great theoretical importance, because it was formerly believed that the diprotodont marsupials had originated within the Australian area, and had never occurred outside it. Their existence, therefore, is another link in the increasing chain of evidence which points to a former connexion between South America and Australia.

The birds of South America are almost as peculiar as the mammals, though, as was to be expected, many of the characteristic forms extend also into North America. Among the important families are the humming-birds, the macaws (Conurinae), the toucans, the jacamars, the motmots, the chatterers, the tanagers, the tinamus (cf. p. 140), the curassows (Cracidae), \&c. 
The so-called American ostrich (genus Rhea), is characteristic, and is represented by several species. Among the negative characters we may note the absence of crows and ravens, which do not extend south of Guatemala. As in Australia there are many parrots. Among the reptiles interesting forms are the rattlesnakes, the boas and anacondas, and the lizards of the family Iguanidae, while there is a large number of toads and frogs, especially tree-frogs (Hylidae). Among the fish the dipnoan called Lepidosiren is important.

Finally we must consider the markedly peculiar Australian region. Here the higher or placental mammals are absent, with the exception of bats, a few rodents of the mouse section, the dingo or native dog of Australia, and the pig of New Guinea, which is probably an introduced animal. As already explained, the region further includes the only living monotremes, Ornithorhynchus being found in Australia and Tasmania, Echidna in Australia, Tasmania, and New Guinea, and Proechidna in New Guinea only.

The marsupials are extraordinarily numerous and very diverse, and a peculiar feature is that the more specialized forms, e.g. the certainly modern treekangaroos, occur towards the north, in Queensland and New Guinea, \&c., whereas the more primitive forms, e.g. the Tasmanian wolf and Tasmanian devil, occur to the south, in the island of Tasmania. This is another link in the chain of evidence which suggests that Australia received its original marsupials from the south, through a connexion with South America, rather than from the north, through the islands of the Austro-Malayan region. We need not consider further the marsupials of the region beyond noticing that there are forms adapted to almost every kind of 
habitat, and showing curious adaptive resemblances to the placentals. An interesting form, discovered not many years ago, is the marsupial mole (Notoryctes), with a curiously close resemblance to the typical mole of the Old World.

The birds of the region are interesting and peculiar. There are no true finches, no woodpeckers, no pheasants, and no vultures. New Guinea is especially remarkable for its beautiful birds of paradise, represented on the mainland chiefly by the bower-birds. Mound-turkeys and lyre-birds occur both on the mainland and in the islands, and the parrots are exceedingly numerous and very characteristic, while the related cockatoos are almost peculiar. New Zealand, with many peculiar birds, has some remarkable parrots, notably Nestor, which has become carnivorous, preying upon sheep, and the nocturnal owl parrot (Stringops) with a degenerate keel on its sternum, and but little power of flight. Pigeons are also very abundant, and include the most brightly coloured members of the order. The honeyeaters (Meliphagidae) are peculiar to the region.

Very striking also are the Running birds. New Zealand has the curious little Apteryx, as well as the extinct moa (Dinomis), Australia the emu and cassowary.

The reptilian fauna is less peculiar, but New Zealand has a very primitive lizard (Hatteria, p. 228) and no snakes. Queensland and New Guinea share with America an abundance of tree-frogs of the family Hylidae. The type genus Hyla occurs all over Australia, and the presence of many members of the family in the Australian continent is the more remarkable in view of its complete absence from Africa and India (cf. p. 118).

The fish fauna of the streams and lakes is somewhat 


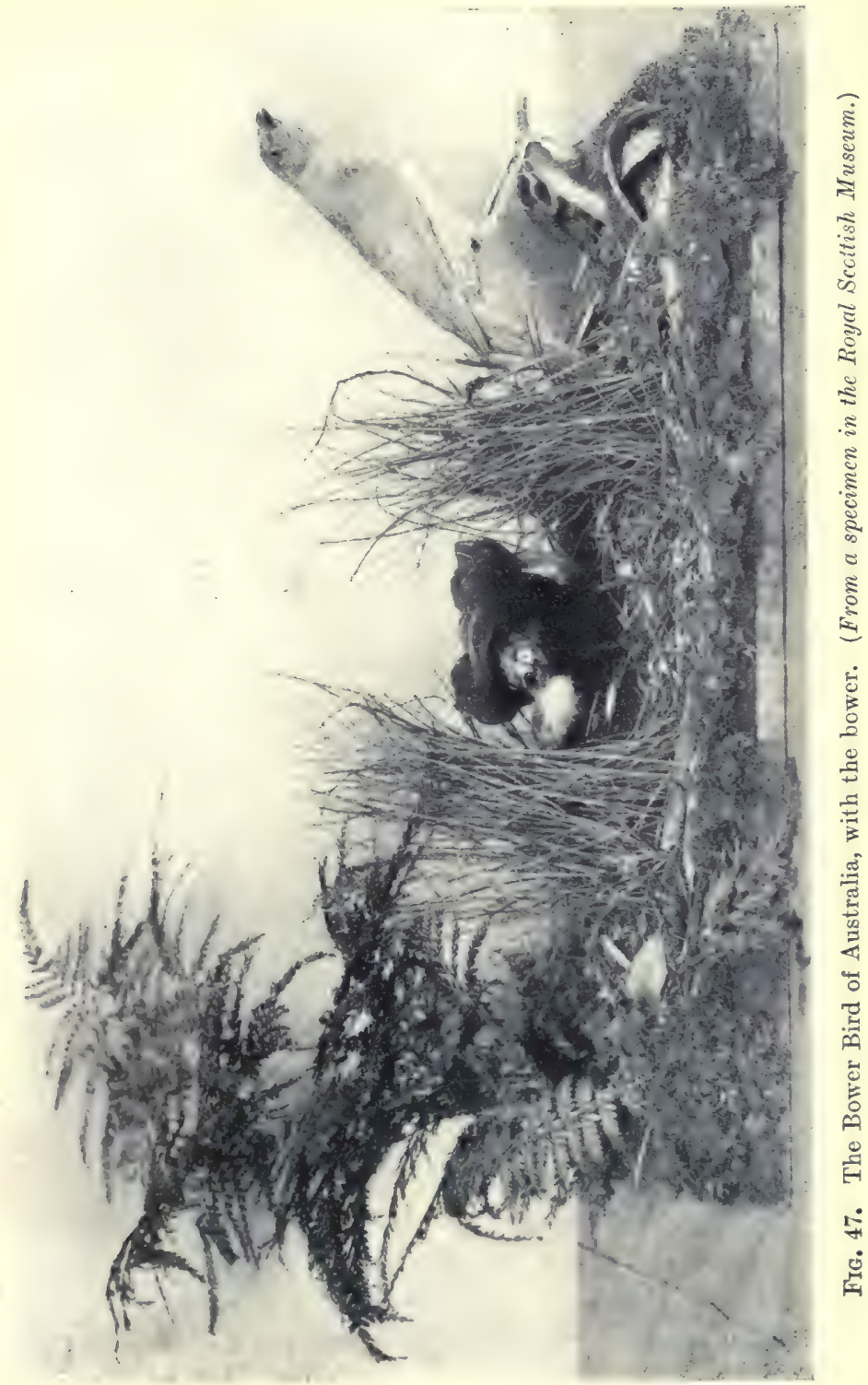




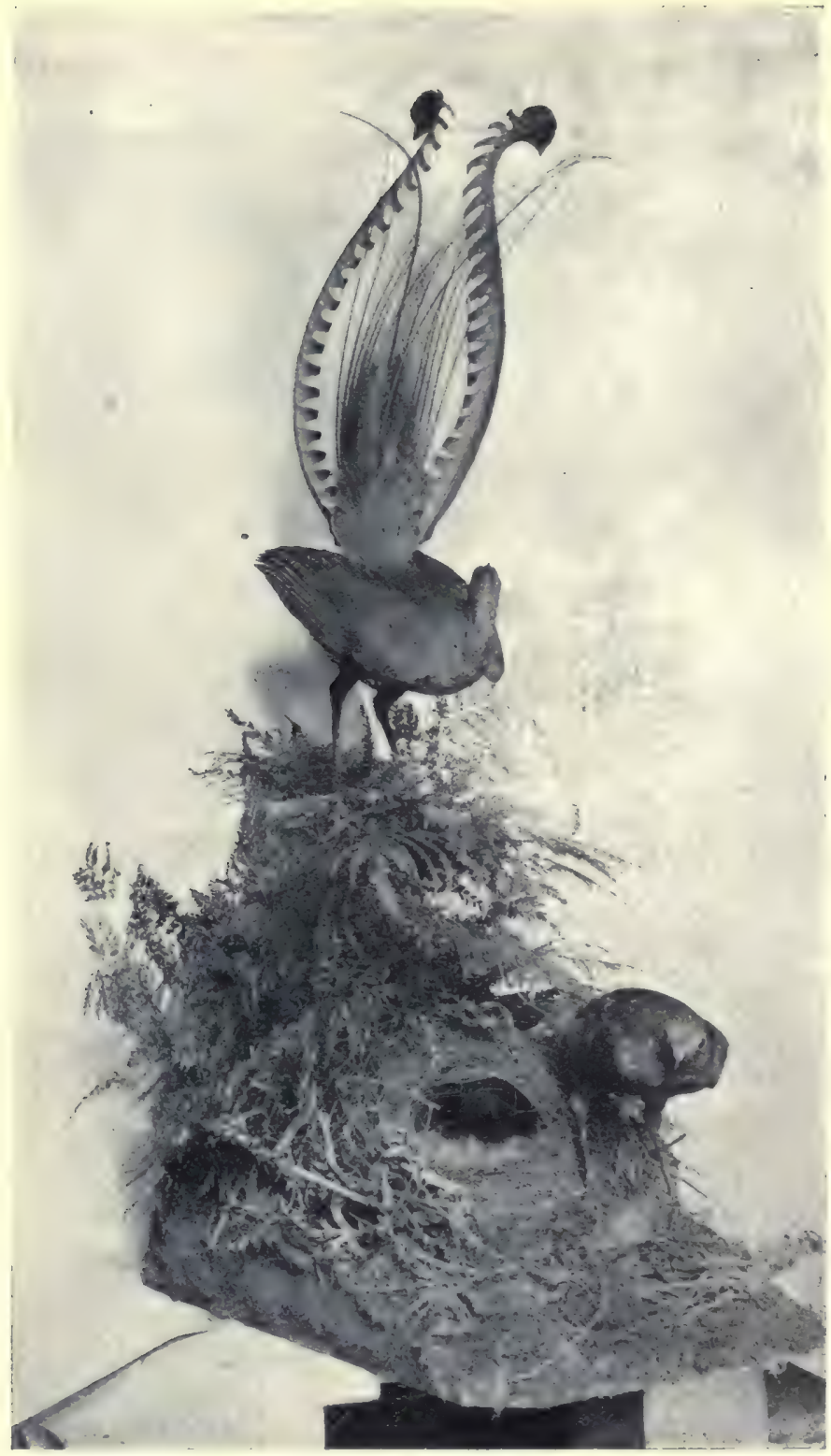

Frg. 48. Lyre Birds with nest and eggs. (From a specimen in the Royal Scottish Museum.) 
poor, but the presence of the very primitive dipnoan fish Ceratodus is important. This fish, now found only in the rivers of Queensland, lived in the far-off Devonian period in the seas of the northern hemisphere, and is one of the curious relics of the Australian continent. Another is a mussel called Trigonia, now found only off Australian coasts, but once abundant in the Jurassic and Cretaceous seas of Europe. Still another curious relic is the mountain shrimp (Anaspides), a primitive type of crustacean found only in the mountain region of Tasmania, and apparently closely related to forms found fossil in Carboniferous and Permian beds in Europe and North America. These old-fashioned forms are perhaps in some respects even more striking than the marsupials in suggesting the long isolation of Australia, and the extraordinary differences between its fauna and that of the rest of the world.

References. The following are the more important books on the subject of this chapter: Wallace, Geographical Distribution of Animals (London, 1876) ; Sclater, The Geography of Mammals (London, 1899); Lydecker, A Geographical History of Mammals (Cambridge, 1896); Beddard, A Text-book of Zoogeography (Cambridge, 1895); Trouessart, La Géographie Zoologique (Paris, 1890); Heilprin, The Geographical and Geological Distribution of Animals (London, 1887); Arldt, Die Entwicklung der Kontinente und ihrer Lebewelt (Leipzig, 1907). See also (reoffrey Smith, A Naturalist in Tasmania (Oxford, 1909), for a discussion of the origin of the Australian fauna. A very elaborate series of plates, with a considerable amount of text and a full bibliography, will be found in the Atlas of Zoogeography, by Bartholomew, Clarke \& Grimshaw (Edinburgh, 1911). 


\section{APPENDIX}

\section{OUTLINE CLASSIFICATION OF ANIMALS}

READERS who are not well acquainted with modern zoology may find the following outline classification useful for reference. Fuller details will be found in any of the zoological text-books, e.g. Thomson's Outlines of Zoology (Edinburgh), or the more systematic Natural Histories, e.g. The Royal Natural History (London).

Of the terms used in modern classification, the word phylum is important. A phylum includes a group of animals whose members are characterized by a common ground-plan of structure, and are believed to have been descended from a common ancestor. Thus we distinguish the members of the phylum of vertebrates from all the varied phyla of invertebrates by the fact that all have at some period of life a dorsal supporting rod called the notochord, possess a tubular nervous system, and have their respiratory organs, whether lungs or gills, originating from the anterior end of the food-canal. This phylum is divided into a number of smaller units or classes as follows:

\section{PHYLUM VERTEBRATA.}

Class Mammalia, including warm-blooded hairy animals whose young are nourished by milk after birth, with three sub-classes :

Sub-class I, Eutheria or Placentalia, the highest and most intelligent mammals, whose young are nourished before birth by an organ called the allantoic placenta, and are therefore born with the form of the adult; including nine orders.

1. Primates, including monkeys, apes and man, as well as 
the more primitive lemurs, forms with usually opposable thumb and great toe, mostly arboreal in habitat.

2. Chiroptera, or bats, insect-eating or fruit-eating forms with the power of flight, the fore-limbs being greatly modified.

3. Insectivores, generalized and usually small animals, with affinities both with primates and with marsupials, usually feeding on insects, and having cusped teeth. Examples: mole, shrew, hedgehog.

4. Carnivora, or flesh-eaters, a large order of often powerful animals, with strong teeth, adapted either for life on land or in water, having four to five toes. Examples: cat, dog, bear, \&c.

5. Ungulata, herbivorous animals, often of large size, with a reduced number of toes, and teeth adapted for a vegetarian diet. In one sub-order (Perissodactyla) the third or middle toe tends to predominate, and may be the only one present, e.g. horse ; in the other sub-order (Artiodactyla) the third and fourth toes are equally developed, e.g. sheep and cow. The elephant and the rock-conies (Hyrax) of Syria show certain primitive characters, absent in other ungulates.

6. Rodentia, the gnawing animals, usually small, and having characteristic chisel-edged incisor teeth, by means of which they obtain their food. Rabbits, rats and mice are examples.

7. Cetacea, or whales and dolphins, mammals very perfectly adapted for life in water.

8. Sirenia, or sea-cows, an old-fashioned group, including only two living forms, also adapted for life in the water.

9. Edentata, an old-fashioned heterogeneous order, including sloths, ant-eaters, armadillos, \&c., all with relatively simple brains.

Sub-class II, Metatheria or Marsupialia, including mammals whose young are born imperfectly developed, and are carried by the mother after birth in a pouch, or marsupium; comprising two orders:

1. Polyprotodontia, carnivorous forms, with numerous incisor teeth, including the opossums and the Tasmanian wolf. 


\section{OUTLINE CLASSIFICATION OF ANIMLAL}

2. Diprotodontia, herbivorous forms, with only two incisor teeth in the lower jaw, including kangaroos, the wombat, \&c.

Sub-class III, Prototheria, egg-laying primitive mammals, with one living order, Monotremata, which contains only three living kinds of mammals, the duck-mole (Ornithorhynchus), and the two spiny ant-eaters (Echidna and Proechidna).

Class Ares or Birds, including warm-blooded forms clothed with feathers. The living forms may be divided into two divisions :

1. Carinatae, or flying birds, with many orders, having a keel on the sternum, and usually the power of flight.

2. Ratitae, or running birds, long-legged forms, with no keel on the sternum and rudimentary fore-limbs, including only a few living forms, e.g. the ostrich, cassowarr, emu, \&c.

Class Reptilia or Reptiles, cold-blooded scaly animals with five living orders, and many extinct ones:

1. Crocodilia or crocodiles and alligators.

2. Chelonia or turtles and tortoises.

3. Ophidia or snakes.

4. Lacertilia or lizards.

5. Rhynchocephalia, including only the New Zealand lizard called Hatteria, with many primitive characters.

Class Amphibia or Amphibians, smooth-skinned forms with gills in the early stages, and lungs in the later, including forms like frogs and toads, without tails in adult life, and those like newts and salamanders, which keep the tail throughout life.

Class Pisces or Fishes, permanently aquatic forms with gills and scales. The classification is a matter of difficulty, owing to the vast number of fossil forms. It is sufficient to note here that most living fishes are Teleosteans, forms with a completely bony skeleton and a swim-bladder used as hydrostatic organ. Sharks and skates, \&c., are Elasmobranchs, and have a cartilaginous skeleton, the living forms being the specialized remnants of a large and primitive group. As Ganoids we may group a few living forms, very different from each other, but sharing with the Elasmobranchs certain primi- 
tive features, though they have a swim-bladder like the Teleosts. Such are sturgeons, bony pike, the polypterus of the Nile, and so forth. Finally, the Dipnoi or double-breathing fish include only three living forms (Ceratodus, Protopterus, and Lepidosiren), interesting because they possess both lungs and gills.

The phylum vertebrata includes in addition some other sinall groups, such as the Cyclostomes or round-mouths (hag and lamprey), the Tunicates or Sea-squirts, degenerate when adult, but almost tadpole-like when young, and so forth.

Though we commonly use the term invertebrate as a convenient contrast with vertebrate, there are many phyla of invertebrates not nearly related to each other. The highest is the PHYLUM MOLLUSCA, including forms breathing by gills, usually furnished with a limy shell, having a loose fold of skin called the mantle, and a muscular protrusion, on which, e.g., the snail creeps, called the foot. There are three important classes:

1. The Cephalopoda or cuttles, marine forms in which the shell is usually lost, active and carnivorous in habit.

2. Lamellibranchiata or bivalves, forms like oyster and mussel, with a double shell, usually sedentary in habit.

3. Gasteropoda or univalves, including snails, slugs, periwinkle, \&c., in which the shell is present or absent, and when present has but one valve.

The very large PHYLUM ARTHROPODA includes animals in which some at least of the segments of the body are furnished with jointed appendages: There are three main classes :

1. The Crustacea, mostly aquatic forms, with a hard coat, two pairs of antennae, and gills, including large forms like crab and lobster, and the small copepods or water-fleas, \&c.

2. Antennata Tracheata, including insects, millipedes, and centipedes, and the curious worm-like Peripatus, all breathing by air-tubes, and having one pair of feelers or antennae. Most live on land. 


\section{OTTLINE CLASSIFICATION OF ANIMALS}

3. ArachxordeA, including spiders, scorpions, the kingcrab, \&c., as well as many parasites. They have no antennae, and the breathing organs are very diverse.

The PHYLUM ECHINODERMI includes a great number of marine animals, of radiate form, often with limy skeletons. The living classes comprise the sea-urchins (Echinoids), starfish (Asteroids), brittle-stars (Ophiuroids), sea-cucumbers (Holothuroids), and sea-lilies (Crinoids).

The Phylum of ANNELIDS includes all the different kinds of segmented worms, including both the sea-worms and the earthworms. Among worm-like types we have also many parasitic forms, of minor importance so far as distribution is concerned, and such free-living forms as Rotifers.

The PHYLUM COELENTERA includes a great number of aquatic, usually marine, organisms, often of great beauty and of great diversity. Among them we have sea-firs and their allies, and the fresh-water hydra (HrdrovedesAE); the seaanemones, corals, alcyonarians, large jellyfish and related forms, all of somewhat more complicated structure (ScrPHOzOA); and finally those delicate iridescent bells which float in the open waters of the ocean, and constitute the CTExopHORA, because of the delicate combs by means of which they swim. The sponges, all aquatic and mostly marine, constitute the PHYLUM PORIFERA, and the minute PROTOZOA, of great importance in that many parasitic forms are included, form a large phylum of very simple animals. 


\section{INDEX}

Lard-wolf, 125.

vark, 135, 219.

Abyssal fauna of sea, 157 , $158,169,179-81,206$.

of lakes, 197, 204-5.

Abyssinia, 83, 84 .

Acacias, 129, 146.

thorny, $122,123$.

Acanthephyra, 178.

Accentor, 90 .

Acorn shells, 160.

Acipenser, 200.

Acrobates, 112.

Adansonia. 122.

Addax, 128.

Adelops, 207.

Aelurus, 81.

Aepyceros, 129.

Africa, $9,11,12,32,34,40$, $56,72,80-3,86,98,100-25$, $126-40,145-52,153,182$, $200-24$.

Africa, Central, 188.

Eastern, 128, 129, 130.

North, 88, 128, 129, 133, 142, 210.

South, $55,128,129,130$.

South-western, 98, 99, 102. $106,115,118,119,128$.

tropical, 210.

African lakes, 188.

Agriophyllum, 68, 69 .

Agulhas, 170.

A gutis, 110, 115 .

Alactaga, 65.

Alashan, 69.

Alaska, 22.

Alca, 163 .

Alces, 10.

Aleyonarians, 175.

Alders, 19.

Alepocephalus, 179 .

Algae, 158, 159, 163, 165, 168, $169,172,173$.

Alpine regions, 62.

Alps, 49, 72, 74, 87, 88, 89, 90.

Amazon, R., 110, 192 .

Amblyopsis, 207 .

Amblyrhynchus, 149.

Amblystoma, 194, 195.

America, $21,40,49,62,81$, $81,106,107,110,116,117$. $132,150,153,165,201,224$.

Central, 101, 106, 142, 147. 214 ; see North America. South America.

American continent, 211, 214.

Amoebae, 188.
Amphibians, 90, 149, 151, $166,184,194,195,206,217$. Amphipods, 30.

Amu Daria, 58, 59.

Anabas, 119.

Anaconda, 117, 223.

Anaspides, 225 .

Andes Mts., 9, 80, 85, 87, 88, $126,210$.

Angola, 124, 133.

Annelids, 167, 168, 175, 181.

Anodon, 191.

Anomaluridae, 109, 210.

Antarctic area, 15, 21, 32. 163.

continent, 214.

Ant-eaters, 13, 94, 111.

banded, 139.

hairy, 111.

scaly, 111.

two-toed, 111.

Antechinomys, 139

Antelope, 11, 32, 40, 60, 75, $80,83,81,106,123,126,127$. $128,131,132,136,139,210$, 218.

African sable, 107 .

harnessed, 107.

pala, 129 .

saiga, 59 .

water-buck, 129, 130.

Anthropoid apes, 98, 213, 217.

Antilocapra, 61.

Ants, 119, 142.

driver, 119.

Apteryx, 224.

Aphrodite, 168.

A pes, 102.

black, 217 .

Aquila, 88 .

Arabia, 86, 118, 128, 139.

Aral, Sea of, 58 .

Arctic America, 16,23,25,27. Asia, 23.

Circle, 34, 50 .

fox, 23,26 .

hare, $18,20,22,88$.

regions, $22,31,32,161$.

sea, 12 .

waters, 33.

wolf, 21,22 .

Aretictis, 106

Arctogaea, 213, 215.

Aretogaeic realm, 215.

Aretomys, 62, 86.

Argali, 82.

Argentine, 9, 55, 64, 113, 123, $132,134,135$.
Argyropelecus, 178.

Armadillos, 13, 134, 135.

Artemia, 182, 205.

Artemisia, 69 .

Arvicola, 87 .

Asia, 11, 12, 21, 22, 32, 38, ㄴ, $43,47,50,51,54,56,58,61$, $62,82,101,107,119,129,140$, 210,215 .

Central, 52, 54, 82, 83, 85, 89,98 .

Northern, 46.

South-eastern, 77, 98, 99 . $106-8,115,117$.

steppes of, $34,52,133,136$. tropical, 210.

Asio, 147.

Ass, 61 .

wild, 132, 133, 218.

Astacus, 200.

Atlantic, 163, 178.

Atlas Mts., 10, 80, 82, 126, $132,215$.

Ateles, 100.

Auk, 24.

great, 163.

little, 163.

Australia, 34, 55, 56, 102 , $103,105,114,115,121,138$ $40,153,162,191,208,209$, $213,214,215,220-5$.

Eastern, 112.

North, 112.

South, 142

West, 112.

Australian region, 135, 138. 218.

Austro-Malayan region, 223.

Axolotls, 195 .

Azores, 154.

Babbling thrushes, 218.

Babirusa, 107.

Baboons, 98, 100, 124.

African, 124.

Arabian, 78.

dog-faced, 213.

Bactrian camel, 60 .

Badger, 44, 46, 216.

Baftin Land, 16.

Bahrmas, 173.

Baikal, Lake, 182, 196, 204.

seal, $182,192,196$.

Balaena, 33, 177.

Balaenoptera, 33.

Balaton, Lake, 199, 204.

Bali, island of, 213 .

Baobab, 122. 
Barnacles, 160.

Bathy pelagic animals, 174, $179,180$.

Bathyscia, 20\%.

Bats, 223.

fox 102 .

fruit, $102,103,217,219$.

horse-shoe, 221 .

insect-eating, 217.

vampire, $103,221$.

Bas of Biscay. 165 .

Bear, 44, 80, 106, 126, 222.

black, 45 , 80 .

brown, 45, 80.

cat, 106.

grizzls, 45, 80 .

Malayan, 106.

parti-coloured, 81.

sloth, 106.

spectacled, 80.

Beaver, 42, 43, 191, 193.

Bees, 28.

Beetles, 150, 20\%.

water, 181.

Belgium, 59, 151.

Benguela current, 170 .

Bering Strait, 16, 82, 212 .

Bermudas, 154.

Birds, 113, 146, 193, 216, 218, $219,222,224$.

of paradise, $113,221$.

rice, 147, 216.

Bird cherry, 38.

Bison, 61.

Bithynia, 204.

Bivalres, 167.

Black Sea, 159, 180.

Blessbok, 130 .

Boa, 117, 223.

tree, 116.

Bobac, 63, 65, 87

Bog moss, 19.

Bolivia, 85, 134, 135.

Bonasa, 47.

Bonito, 177

Bontebok, 130.

Bony pike, 185.

Borneo, 98, 104, 1อ๊5, 21\%.

Bos, 61, 81, 127 .

Bower-birds, 224 .

Bradypus, 110.

Brahniaputra, R. 192.

Brazil, 9, 11, 110, 131.

Brine-shrimps, 182, 183, 205.

British Isles, 69, 151, 152, 151.

Brittle-star, 168, 184.

Bubalis, 1:30.

Buffalo, 127 .

short-horned, 127 .

Bufo, 90.

Bulbuls. 218.

Bull-frog, 49.

Burma, 104. 117.

Upper, 109.

Buru, island of. $10 \%$.

Bustards, 68, 69, 140 .

Butterfies, 28, 29, 119 .
Caccabis, 89.

Cactus, 123, 146, 148, 179.

Cactus wren, 141.

Calamoicth 5,220 .

California, 13, 141.

Camel, 60, 61, 68, 85, 132 .

Campylorbynchus, 111.

Canachites, 47 .

Canada, 38, 40,42, 147.

Canadian lakes, 195.

C'anis, 23, 45, 67. 80, 126.

Cape Colons, 125, 133.

Cape of Good Hope, 170.

Capercaillie, 47, 84.

Capivara, 134.

C'apra, 75, 83.

Capreolus, 41.

Capuchin monkeys, 100.

Carjacus, 40, 132.

C'ariama, 112.

C'arinthia, 306.

Carniola, 206.

C'arnivores, $38,44,67,76,79$, $81,124,162,193,209,216$, $218,219,220,221,222$.

Carp, 217.

Caspian Sea, 58, 182, 183, 196.

Cassowary, 140, 224.

C'astor. 42.

Cat-fish, 199, 200, 203.

Cats, 41, 67, 79, 105, 12t. 218 .

('attle, 81.

Caucasus, 63, 72, 83, 87.

Cave faunas, 206.

Cayy, 88, 134.

Celebes, island of, $10 \%$, 217.

C'emas, 83.

Cembra pine, $38,47,49$, 96.

Centetes, 152.

Centetidae, $220,221$.

Central Europe, 31.

Centroeercus, 69 .

C'ephalophus, 107.

C'eratodus, 118, 201, 225.

C'ercoleptes, 106.

Cercopithecus, 99.

Certhidea, 147.

Cervulus, 107.

Cervus, 40; see Deer.

C'etacea, 162, 163, 192, 193.

Ceylon, 115, 116, 218.

Chameleon, 94, 113, 116. $153,221$.

Chamois, 84.

('hatterers, 222.

Chelone, 165.

Chelonia, 165, 193.

Chelydra, 193.

Chenopodiaceae, 68.

Chevrotains, 107, 110, 115, $218,219$.

water, $10 \%$.

Chickaree, 42

Chili, 9.85.
Chimarrogale, 78

Chimpanzee, 98, 219.

China, $58,77,78$.

Chinchilla, 87 .

C'hipmunks, 42.

Chirogale, 102.

Chironomus, 206.

Chiru, 84.

Chlamydophorus, 134.

Choloepus, 110.

Chough, Alpine, 89.

Chough-thrushes, 69.

('hrysomitris, 89.

C'ichlidae, 203.

Cirets, 44, 102, 105, 152,218. 221.

nalm, 106 .

Cladonia, 19

Climbing perch, 119 .

C'louded leopard, 105.

Coatis, $81,106,126$.

Cockatoos. 224.

Cockles, 167.

Cod, 161, 166.

Coelentera, 168, 164, 185.

Coelogenys, 88, 110.

Coenolestes, 222.

Colies, 220.

Colíidae, 220.

Colobus, 99.

('olombia, 85.

Condor, 88.

Congo basin, 203.

prgmies, 96.

Connochoetes, 130 .

Conolophus, 148, 149.

Continental Islands. 15้‥

Continental Slope, 157.

Conurinae, 222.

Convoluta, 168.

Corals, 181

Corixa, 206.

Corsica, 82

Corvus, 27.

Coryphaena, 177.

Copepods, 174, 205.

C'оррu, 134.

Crabs, 120, 167, 181, 205.

hermit, 180.

Cracidae, 222.

Cranberries, 38.

Crane, 141.

Cray fish, 196, 200.

Crested cockatoos. 114 .

Cricetus, 16.

Crinoids, 181.

Crocidura, 220 .

Crocodiles, 115, 116, 194. 196,218 .

Crossbill, 47, 49.

Crowberries, 19, 38.

Crustacea, 158, 160, 167, 198 . $305,207$.

Cryptobranchus, 91.

Cryptoprocta, 152, 221.

Ctenomys, 134.

Ctenophora, 169

Curassows, 2y? 
('urlews, 69.

Cuttles, 159, 16\%, 176, 181.

C'yclothone, 178.

('ynomss, 64

(ynopithecus, 217 .

cystophora, 33 .

1) bas, 166

1)almatia, 216.

Danube, R., 199.

Darwin, 9, 145 .

I)

Jasypus, 135.

Deer, 32, 37, 40, 41, 75, 131, 210, 216,218, 222; sec Reillleer. Roedeer.

Asiatic, 106.

pampas, 132

red, $40,12$.

Virginian, $40,42$.

Delphinapterus, 34.

Demoiselle crane. 70.

Jendrobatinae, 117.

I)endrophis, 117.

lemmark, 199.

lesert of Gobi, 58, 69.

Desman, 79, 191, 196.

Diatoms, $15 \%$

I)idelphys, 113.

l)ingo, 223 .

I)inornis, 221.

l)ipnoi, 185, 201, 202, 214, $240,223,225$.

liprotodont marsupials, 222 .

I)ipus, 66 .

J) odo, 150 .

I $\log , 106,125,219$.

(ape hunting, 126.

siskimo, 23.

Indian wild, 80.

Molichony $x, 147,216$.

Dolphin, 159, 162, $1 \%$.

blind, 192

fish-eating, 177.

fresh-water, 192. 19\%

1)rmouse, 37.

I)

Invophis, 11 .

I) k, 69.

Duck-mole or Oruithorhynchus, 191, 22:3.

1)urong, 162 .

Duikerboks, 107,130 .

I)zungarian Gate, 58 .

Figle, Golden, 68.

hawk, 88 .

Fchidna, 223.

Wchinoderms, 168, 175, 178, 181, 184.

Feuador, 85, 145.

fidentates, $110,134,218,219$. w2.

Ecl, 176, 183, 199.

mud, 195.
Eider-duck, '2t.

Fland, 128.

Filephant, 108, 109, 216,218, 219.

Elk, 40, 41.

Elymus, 64

Finu, 67, 140, 224.

Emys, 194.

Fingland, 200 .

kquus, 59.

Eremias, 70.

Erethizon, 43.

Frmine, 23, 26, 46 .

Fryx, 70.

Fskimo, 28.

Ethiopian region, 215, 217, 218.

Euneces; 117

Fuphorbia, 122, 146.

Eurasiatic continent, $\mathbf{1 0}$, $49,211$.

Gurope, 13, 21, 50, 63, 68, 72, $83,81,88,89,116,130,210$, $214,225$.

Central, 78, 194.

Eastern, 200 .

Northern, 47.

South, 89, 194.

Furopean Russia, 16.

Exocoetus, 17\%.

Ealco, 27.

Felidae, 218

Felis, 22, 44, 79 .

Fiber, 42.

Fiji, 167 .

Finch, 147 .

citril, 189.

snow, 89

Firth of Forth, 16t, 186 .

Fish, 119, 120, 152, 178, 196, $199,223$.

cave, $20 \%$.

deep-sea, 174, 178.

flying, 177 .

fresh-water, $118,151,183$, $185,200,201,203,21 \%, 24$. Flies, 119, 206.

Flycatchers, 217.

Flying lenur, $93,104,217$.

Fox, 37, 44, t5, 80.

Arctic, 23, 26 .

corsac, 67.

long-eared, 126.

Franz Josef Land, 16.

Friendly Islands, $16 \bar{t}$.

Frog, 90, 83.

fishing, $166^{\circ}$

flying, 93, 117 .

tree, $49,118,224$.

Fruit-pigeon, 115.

Galago, 93, 10 ${ }^{*}$

Galapayos Islands, 14j-54, 165.

Galeopithecus, 104, 217.
Ganges, R., 189, 192, 196. 218.

Gannet. 16:3.

Ganoids, 185, 192, 200, 202. 220.

Gastropods, $167,175,190$.

Gavialis, 218.

Gazelle, 59, 84, 129 .

Gecinus, 47.

Gecko, 70, 149 .

Geese, 69.

Gemsbok, 128, 129, 130.

Geospiza, 147.

Gerfalcon, 27.

Germany, 63.

Gibbon, 98, 99, 217.

Giraffe, 122, 129, 131, 136, 139. -19.

Glass crab, 176.

Globigerina, 181.

Glutton, 24, 4 .

Gnu, 130.

Goat, 39, 40, 75, 76, 79, 83, 84, $128,116,216$.

Arabian, wild, $8: 3$.

Rocky Mts., 84.

Gobies, 160, 166, 199.

( iolden mole, 219.

Goniostoma, 178.

Gopher, 62

Goral, 83.

Gorilla, 98, 219

Graculus, 89.

Grasshopper, 71 .

Great Salt Lake, 182, 183 , 205.

Greece, 71.

Greenland, 16-29, 32.

Grinnell Land, 22,23 .

Grosbeak. 47.

Grouse, black, 17 .

Canadian, 47 .

hazel, 47 .

Pallas's sand, 68, 69 .

red, 151 .

ruffed. 47.

willow, 151.

Grus, 70

Guanaco, 85.

Gudgeon, 199.

Guillemots, 24, 163.

Guinea-fowl, 115.

Gulf of Mexico, 55.

Stream, 170.

Gulo, 24, 46.

Gypaétus, 88.

Haldock, 166.

Hairmoss, 19.

Halicore, 162

Halobates, 176

Halolimnic fauna, 204.

Hamster, 66 .

Hangnests, 216.

Hale, Anierican, 42.

Arctic, 18, 20, 22, 88; see also Polar hare. 
Hare, jumping, 133.

mountain, 88 .

tailless, 66, 88 .

Hartebeests, 130.

Hatteria, 213, 224.

Hedgehog, tailless, 152,219.

Hemitragus, 83.

Hermit crabs, $166,180$.

Herpetodryas, 117 .

Herring, 166, 182.

Hesperomys, 116 .

Heterocephalus, 134.

Hill-tits, 218.

Himalayas, $10,72,76,-7$ $80-9,210,215$.

Hippopotamus, 219, 220.

Hjort, 161, 171, 172, 17 .

Hoatzin, 115 .

Hog, river, 219, 220.

wart, 219.

Holarctic region, 215, 216.

Honey creepers, 147 .

Honey eaters. 224.

Horses, 60, 61, 65, 68, 108, 146. $216,219$.

Hubara, 68 .

Humming-birds, 220, 씰.

Hungary, 55, 58, 199.

Hyaenas, $125,12 \%$.

Hydra, 191, 196.

Hydrochoerus, 134.

Hrdromed usae, 189, 190.

Hydrophis, 165.

Hvla, 22.

Hylidae, 49, 118, 2223, 224.

Hyperodon, 176.

Hypsiprymnodon. 136.

Hyrax, 86, 219.

Ibex, 83 .

Iceland, 16.

Icteridae, 216.

Ietony x, 127.

Iguana, 116, 149 .

India, $77,80,83,100,104-7$. $109,111,114,115-19,153$.

India, Further, 210, 213, 215.

Indian Ocean, 118, 148, 155 . 162,165 .

Indies, West, 116, 221.

Indo-Malayan region, 112, 116.

Indus, R., 192.

Insectivores, $78,79,152,191$, $193,216,217,219,220,221$.

Insects, 119, 142.

leaf, 120 .

Ireland, 151.

Isopods, 207 .

Iynx, 47.

Jacamars, 114, 222:2

Jackal, 125 .

Jaguar, 105, 108.
Japan. 155.

Java, 155.

Jays, 47, 49.

Jellyfish, 169.

fresh-water, 204. 205 .

Jerboa, 62, 64, 65, 66, 124, 133, $13 \%, 138$

five-toed, 65.

Jumping mouse, 62, 138.

Jumping shrew, 124, 219.

Jungle fowl. 115.

Juniper, 38.

Kalahari desert, 123, 124, $128,129,131$.

Kamchatka, 82.

Kangaroo, 56, 61, 65, 111. 112. 123, 135-8, 208, 204, 1.2.?

five-toed, 13i.

giant. 136 .

rat, 136 .

tree, 111, 135, 22:33.

Kansu, 78 .

Kea, 88.

Khingan Mts.,5\%.

Kiang, $60,85$.

Kilimanjaro. 86.

King Oscar Land, 16, 21, 22, 23.

Kinkajou, 91, 106.

Kirghiz, 59,

Kittiwake, 24, 164.

Kiwi, 140, 150.

Klipspringer, 81, 129, 130.

Koala, 113

Kordofan desert, 12).

Kudu, 128.

Kuku Nor, Lake, 7 .

Labrador, 16, 17'.

Lacerta, 90.

Ladak, 79 .

Laemmergeier, 88.

Lagidium, 8i.

Lagonys, 66.

Lagopus, 20, 25, 151

Lagostomus, 134.

Laminarian zone, 158.

Langur, $7 \overline{7}, 99$; see also Semnopithecus.

Himalayan. 78 .

Tibetan, 78,80 .

Larch, Siberian, 38

Lark, Siberian, 69.

steppe, 66 .

Leiotrichidae, 218.

Lemming, $20,22,23,2 \bar{\tau}, 64$. Aretic, 87 .

Norwegian, 22.

Lemur, 95, 101, 102, 152. 153, $217,219,220,221$.

flying, $93,104,21 \%$.

mouse, 102.

ring-tailed, $10^{\circ}$.

Leopard, 105.
Lepidosiren, 118, 201, 22:3.

Leptocephalus, 176.

Leptonychotes, 1 til.

Lepus, 22, 88.

Lerwa, 89

Leven. L.. 19i.

Limmaca, 204.

Limnocnida. 205.

Limpet. $16 \%$.

Linota, ?11.

Lion, $105,125,12 y$.

Lithocranius, 1:4.

Littoral animals. 161. 167. $18 y$.

annelidss, 168.

area, 170 .

birds, 163.

fauna, $196,199$.

tishes, 166, 179.

Lizard, 69, 90. 94, 116, 11:

$142,148,153,221,22,2$

flying, 218.

marine. 149, 165.

Llamas, 132, 22:2.

Lobelias, 72

Lobodon, 16?.

Lobster, 167 .

Locusts, 71, 1.23.

Loggerhead turtle. 16.5 .

Lombok. 21:3.

Lophyrus, 50 .

Loxia, 49.

Lumpsucker, 1600, 166t.

Lung-fishes, $18 x$.

Lutraria, $16 \%$.

Lycaon, 126, 219.

Lynx, 37, $44,78,81$.

Lyre-birds, 224 .

Lyrurus, 47.

Macacus, 7 , $78,216,217$

Maciaques, $78,100$.

Tibetan, 78,80 .

Macaws, 114, 坐르.

Mackenzie R., 21 .

Mackerel, 17\%。

Macrorhinus, $16^{\circ}$

Macroseelides, 124.

Macrurus, 180 .

Madagascar, 101, 102, 105. $117,152,153,155,208,209$. $212,213,215,217,219,2211-2$.

Magpie, 19.

Malagasy region, 215, 2231).

Malay Archipelago, 212 , $214,215$.

Peninsula, 102, 104, 109.

region, 115, 153, 202, 217. 22 ?

Mammoth, 22

Mammoth Cave of Kentucky, 207.

Manatee, 16\%, 163, 192, 196.

Manis, 111, 218.

Maral stag, 40.

Mark hor, 83.

Iarmosets, 11, 101, 221. 
Marmot, 46, 62, 86, 8\%.

Alpine, 63, 87 .

Himalayan, 87.

Prairie, 64.

Rocky Mountain. 87.

Mamupials, $56,123,135,138$, $209,214,222,223,225$.

Marsupial mole, 224.

Marten, 44, 45.

Mediterranean, 10, 159, 165. 170,180 .

Medusa. 178.

Medusoids. 190.

Meerkat, 125.

Melanocorypha, 69.

Meles 46.

Meliphagidac, 224 .

Melursus, 106.

Mephitis, 14.

Mesonekton, 177.

Mesoplankton, $17 \%$.

Mesopotamia, 139.

Mexico, 43, 100, 110,194, 214.

Mice, 146, 218.

Michael Sars Expedition. 174, 177.

Microchiroptera, 103.

Micropus, 90.

Minx, $44, \pm 6$.

Mistisippi, R., 55, 195.

Moa, 24.

Mole, 216.

Mollusce, 166, 181, 184, 197 . $198,204,207$.

Moloch, 142.

Mongolia, 41, 66, 82.

Mongolian gazelle, 59.

Mongoose, 125

Monkey, 11, 76, 77, 78, 93, 94 . $95,97-100,102,105,153,209$, 219.

broad-nosed, 100, 221.

howling, 100 .

proboscis, 217.

spider, 100.

thumbless, 93, 100 .

Monodon, 33.

Monotreme, 191, 214.

Monticola, 90.

Montifringilla, 89 .

Morar, L. 197.

Moschus, 41, 8.5.

Mosquitoes, 27, 28, 119.

Motmots, 222.

Mound turkeys, 224.

Mountain ash, 38.

Mountain shrimp, 225.

Mt. Kenia, 72.

Mouse, 221, 223.

Mozambique, 133.

Murlskippers, 118.

Muntjacs, $10 \%$.

Muк, 146;.

Muscicapidae, 217.

Musk deer, 41, 85 .

ox, 17, 20, 21, 23, 81 .

shrew, 220 .

Musophagidae, 220.
Musquash, 42 .

Mussel, 167, 191, 196, 197, 2.25.

Mustela, 23, 45.

Mya, $30,167$.

Mycetes, 100 .

Myodes, 22.

Myogale, 79.

Myopotamus, 134.

Myrmecobius, 139.

Myrmecophaga, 111.

Myriapods, 207.

Mysis, 198, 199.

Nansen, 18, $26^{\circ}$.

Narwhal, 33.

Vasalis, 217.

Nasua, 81, 106.

Nearctic region, 215, 216 , 222.

Nectarinidae, 220.

Necturus, 195.

Nekton, 176.

Nemorhoedus, 83.

Neotropical region, 216, 221.

Nereis, 168.

Nestor, 88, 224.

Ness, L., 197, 198.

Newfoundland, 16.

New Guinea, 96, 111, 113, $208,209,214,223,224$.

New Siberian Islands, 16.

Newts. 195.

New Zealand, 102, 140, 150, $212,214,224$

Nilgiri Hills, 83.

Nisaëtus, 88.

Noctiluca, 175.

Nordenskióld, 17, 20, 31.

North America, 11, 12, 13, $34,38,41-51,56,61,64,87$, $170,193,194,213,215,216$, $221,222,225$.

North Atlantic, 163,176,212.

North Pacific, 162.

North Sea, 157, 161.

Northern Asia, 15, 25, 27.

Northern Russia, 19.

Norway, 72.

Norwegian Sea, 161, 170.

Notogaeic realm, 214, 215, 216.

Notoryctes, 224.

Nova luembla, 16, 22, 27, 31 .

Nucifraga, 49 .

Nuterackers, 47, 49.

Nyasa, L., 205.

Nyctea, 27.

Oceanic islands, 151 .

Okapi, 107. 219.

Ommatophoca, 161.

Opisthocomus, 115.

Opossum, 95, 113, 213, 222.

(1rang, 98, 217.

Orca, 34.
Orcyteropus, 135, 219.

Oreotragus, 84.

Oriental region, 215 , 216 , $217,218,220$.

Ornithorhynchus, 191, 223.

Oryx, 128, 129.

Ostrich, 67, 139, 140, 220, 223.

Otaria, 161.

Otis, 68.

Otocyon, 219.

Otter, 184, 191, 193, 196.

Ounce, 79 .

Ovibos, 21

Ovis, 75,82 .

Owl, 27, 147.

Owl parrot, 221.

Oxen, 128, 216, 218 .

Pacas, 88, 110.

Pacific Ocean, 118, 145, 162, 167.

Palaearctic region, 216.

Palacotropical region, 217.

Palalo worm, 167.

Palms, 122.

Pamirs, 57, 58.

Pampas, 134.

Panda, 81.

Pangolins, 218, 219.

Pantholops, 84.

Papio, 124.

Paradoxurus, 106.

Paraguay, 132, 180.

Parakeets, 114.

Parrots, 94, 114, 218, 220, 223. 224.

Partridge, 140.

Greek, 89.

snow, 89.

wood, 115.

Patagonia, 55, 85, 134.

Peccaries, 107, 117.

Pedetes, 133.

Pedioccetes, 69.

Pelagic animals, 157, 158, $159,161-7,173-80,198$.

Pelagic fish, 177.

larvae, 167, 179 .

region, 170.

Pelagothuria, 178.

Pelea, 84.

Pelias, 90.

Penguins, 163.

Perch, 199, 217.

Periophthalmus, 118.

Perisoreus, 49.

Periwinkles, 167.

Persia, 58.

Persian gazelle, 59

Petauroides, 112.

Petaurus, 112.

Petrels, 24.

Phyllirhöe, 175.

Picas, 66, 67, 88 .

Pichiciago, 134.

Pigeon, 224.

Pig-footed bandicoot, 138. 
Pigs, 107, 108, 146, 117, 218, Proteles, 125.

$219,222,223$.

bush, 10\%, 219 .

wild, 107, 108.

Pike, $199,217$.

Pine grosbeak, 49.

Pine-marten, 45.

Pine saw-fly, 50.

Pinicola, 49 .

Pipefish, 166.

Pisidium, 198.

Phacochoerus, 107

Phalangers, 93, 94, 112, 113, 136 .

flying, 112.

Phascolarctos, 113.

Pheasant, 68, 89, 115, 218.

Philippine Islands, 104, 217.

negritos, 96.

Phoca, 33, 192.

Pholas, 167.

Phrynocephalus, 69.

Phrynosoma, 142.

Phyllodactylus, $\mathbf{1 4 9}$.

Phyllornithidae, 218.

Phyllostomatidae, 103.

Physeter, 176.

Phytoplankton, 158, 173.

Plaice, 166.

Plankton, $174,176,177,180$, 198.

Planorbis, 204.

Plantain-eaters, 114, 2200.

Planulae, 120 .

Platanista, 192.

Plateaux, 73, 75, 78, 82 .

Platyrrhine monkeys, 100 , 221 .

Plectrophenax, 26.

Plovers, 67.

Podoces, 69.

Poecilogale, 127.

Polar bear, $24,32$.

hare, 42 ; see also Hare, Aretic.

Polecat, 46, 12\%, 181.

Polychaete worms, 184. 189. 190 .

Polynesia, 214.

Polypterus, 185, 202, 203. 220.

Polytrichum, 19.

Pond snails, 184.

Porcupine, 43.

Canadian, 42, 110.

tree, 43, 94, 110.

Porpoises, 159, 177.

Potamochoerus, 220 ,

Potamogale, 219.

Potorvus, 136.

Prairie-chicken, 69. -hen, 69.

Prawus, 178, 184, 205.

Prejevalski's horse, 59, 60 .

Primates, $76,78,94,97,124$, 219.

Proechidna, 223.

Prongbuck, 61 .

moss, 18 .
Proteus, 206.

Protopterus, 118, 201, 202

220 .

Protozoa, 170. 17t. 198, 205.

Ptarmigan, 19, 20, 23, 25, $26,27,47,89$.

Pteromys, 109.

Pteropods, $17 \%$.

Pudua, 85.

Puffins, 163, 164.

Puma, 44, 79, 105.

Punjab, 82.

Prenodontidae, 218.

Pygmy hippopotamus, 153.

Prrenees, 63, 78, 8\%, 90.

Pyrosoma, 175.

Pythons, 116.

Quagga, 132, 133.

Queensland, 11, 112, 118, 136, 201, 209, 쏘, 224 , 225 .

Raccoons, $81,166,126,216$, 242.2.

Rana, 49, 90.

Rangifer, 21 ; see also Reindeer.

Rat, 66.

Rattlesnake, 씩.

Raven, 27.

Realms, zoological, 212.

Redpoll, 20.

Red Sea, 170.

Reindeer, 17, 20, 21. 26,41 .

Reitbok, 129.

Reptiles, 90, 115, 142, 147. $150,151,164,193,196,218$. $220,221,223$.

Rhacophorus, 93, 117.

Rhea, $6 \overline{7}, 139,223$.

Rhebok, 81, 129 .

Rhinoceros, 108, 132, 218. 219.

Rhinolophidae 221 .

Rice-bird, 147, 216.

River-hog, 153.

Roach, 199.

Rock coney, 86.

Rock lobster, 176.

Rock thrush, 90.

Rocky Mountains, 44, 79, $80,82,84$.

Rodents, $38,60,64-7,78$. $86,89,108,110,112,124$. 125, 133-6, 152, 191, 193, 216, 218, 219, 221-3.

Roedeer, 41.

Rorqual, 33.

Rotifers, 181, 187, 198, 200. 217.

Running birds, 224.

Rupicapra, 84.

Russia, Southern. 55, 58.
Russian Turkestan, 58 .

Ruwenzori. 72.

Satge-brush, 69

cock, 69, 70 .

-iagitta, 175.

Sahara, 68, 80, 106, 118, 121. $126,131,215$.

- 'aiga antelope, 59, 84.

Salamander, $90,91,194,14 \%$.

Salmon, $183,21 \%$.

Salpa, 175.

Nambar. 107.

Sand piper, 24.

sand-rat. 134.

-snake, 70 .

Sand wich Islands, 154.

Sarcorhampus, 88.

Sardinia, 82.

Sargasso Sea, $159,173$.

Saxicava, 30, 167.

Sayansk divide, 11.

Scaudina via, 16, 151.

Seincus, 142.

Sciuropterus, 42.

Sciurus, 42.

Scorpion, 120.

scotland, 72 .

lakes of, $197,203,204$.

Seals, 24, 30, 32, 33, 161, 163 . $182,192$.

seal, bearded. 33.

crab-eating, 161 .

crested, 33.

earless, 31 .

fur, $161,163,182$.

Greenland, 33.

ringed, 33, 192.

Ross's, 161.

Veddell's, 161.

sea-anemone, 169, 184

-butterfl $5,175,177$.

-cow. 162.

-elephant, 162.

-fir, 169, 189, 191.

horse, 166.

-leopard, 162.

-otter, 162

-pen, 169.

-suake, 165.

-squirt, 166.

-urchin, 31, 168, 181, 181.

Sebastes, 178

Sechwan, 78.

Secretary bird, 140, 141.

142.

Selras, 22.

Semnopithecus, $7 \pi, 216,21 \%$.

vienecios, 72

Seriemas, 141, 142.

Serow, 83, 84 .

Serpentarius, 140.

Serpula, 168

Sheep, 39, 40, 75, 76, 79, 지. $82,89,128,137,216$.

Barbary, 82.

Bighorn, 82. 
Shell-fish. Ithi.

shrews, 152, 21.

Alpine, 78 .

flying, 112.

Himalayan swimming. is.

jumping, 124, 219.

musk. 220 .

'Tibetan nole, 79 .

tree, $104,105,218$.

water, 191, 193.

Siberia, 13, 16, 44, 4i, 4t, 49 . (t)i, 85.

Siberian fir, 38.

silurus, 199.

Sind. 82 .

Giren, 195.

sirenia, 16\%, 142, 193.

sirex, 50.

- ikate, 166.

sikink, 142.

sikula, 24.

Skunk, 44, 127, 216, 222

sloth, 11, 13, 93, 95, 110, 111.

ground, 208.

sinail, fresh-water, 190, 197.

Snake, I16, 148, 149, 1533.

grase, 194.

sea, 165.

tree, 117

whip, 11\%.

wood, 11\%.

snipe, 69.

Snow-bunting, 19, 26.

-cock, 89.

Sinowy owl, 27

solenodon, 221.

solitaire, 150.

Somaliland, 125. 134.

siorex, 78 .

South America, 9, 12, 34, $43,55,56,80,85,87,88,93$, 101, 106, 108, 111, 113-23. $130-4,139-47,149,153,192$, $202,208,209,214,215,220$. $221,222,223$.

Gowthern Fingland, 59.

France, ov.

hemisphere, 15.

spain, 73, 116.

sipernophilus, fiz.

siphagnum, 19.

spiders, 120,207 .

Sipitsbergen, 16, 21, 22, 23, 25.27.

śnonges, 169, 17t, 175, 180. 181,185

fresh-water, 205.

śpotted cuscus, 112.

inringbok, 129.

Sipur-fowl, 115.

Squirrel, 13, 37, 42, 43, 62, $105,108,218$.

flying, 42,43, 98, 104, 108 , $109,112,219$.

pygmy flying. 112.

sliktr. 112.
Starfish, 31.

Starling, 216.

Steinbok, 129.

Stenorhynchus, 16 i2

sterlet, 200.

stickleback, 21 .

Stoat, 26, 14.

Strepsiceros, 122x.

strepsiptera, 28.

stringops, 221

struthio, 139.

Sturgeon, 185, $3(x)$.

sudan, 121, 124.

Sumatra, 98,217 .

siun-birds, 220.

Sunfish, 174.

Suricata, 125.

sัuะ, 39, 219.

Suslik, 62.

Sverdrup Expedition, 16, 18, 21, 26.

Swift, Alpine, 90.

Switzerland, 63, 74.

viyntheres, 110.

Syr Daria, 58.

Syria, 86, 130, 139.

syrrhaptes. 68.

Tahr, 83.

Tailless hedgehog, $152,219$.

Takin, 83.

Talpa, 216.

Tamias, 42.

Tanagers, 222.

Tanganyika, Iake, 182, $200-5$.

Tapir, 85, 108, 218, 220, 222.

Tardigrada, 198.

Tarin basin, 58 .

Tarsier, 102 .

Tarsipes, 112.

Tarsius, $102,21 \%$.

Tasmania, $102,214$.

Tasnuanian devil, 223.

wolf, 223.

Taxidea, 46.

Tench, 199.

Tenrec, 219, 220.

Teratoscincus, 70 .

Terebella, 168.

Termites, 120, 125, 135, 112.

Terns, 24.

Tetrao, 47.

Tetraogallus, 89.

Tetrastes, 47.

Texas, 141, 296.

Thalassochelys, 165 .

Thynnus, $17 \%$.

Tibet, $57,73,74,77,80-4$. $87-9$.

Tichodroma, 89 .

Ticks, 120, 130 .

Tiger, 44, 67, 105, 218 .

Timelidae, 218.

Tinamus, 140, 222.

Tipula, 206.

Titanethes, 207 .
Toad, 90, 22:3.

horned, 142 .

Tomopteris, 175.

Tortoise, 165.

giant, 147, 148, 150, $15 t$.

pond, 194.

water, 184. 196.

Toucans, 114, 222.

Tragelaphus, $10 \%, 12 \%$.

Tragulus, 107.

Tree-creeper, 37.

-frog, 37, 49, 223, 22t.

-heath, 72 .

-shrew, 104, 105, 218.

Trichechus, 32 .

Trigonia, 225.

Trigonocephalus, 71 .

Trimeresurus, 117.

Trochospheres, 190.

Tropidonotus, 194.

Tropidurus, 149.

Trypanosomes, 131.

Tsetse flies, 119, 130, 131

Tucotucos, 134.

Tunicates, 175.

'Tupaia, 104, 218.

T'urbot, 166 .

Turkestan, 70.

Turtle, 164.

American snapping, 193. green, 165.

hawksbill, 165.

leathery, 165.

loggerhead, 16.

marine, 193, 194.

Tympanuchus, 69.

Typhlomolge, 206.

Tyrant shrikes, 217 .

Tyrol, 89.

Cngulates, 35, 576, 60, 61, 65, $75,76,81,84,86,89,97,106$, $108,110,123,127,130,131$, $133,136,137,152,153,213$, $218,219,222$.

Unio, 204.

United States, 55, 113, 142. $147,195,214$.

Upper Egypt, 83.

U ropsilus, 79 .

Ursus, 24, 45, 80, 106.

Victoria, 112.

Victoria Land, $18 \pi$.

Vicuna, 85.

Viper, 90.

tree, 117 .

Viscacha, 64, 134.

Viverridae, 105.

Voles, 87.

Vultures, 76.

Wallabies, $123,135$.

Wallace, 146, 147, 150, 151 . 152,154

Wallace's line, 213. 
Wall-creeper, 89.

Walrus, 24, 30, 31, 32, 101, 162.

Wapiti, 39, 40, 42.

Wart-hogs, 107.

Water bears, 198.

beetles, 197 .

boatmen, 197, 206.

chevrotain, 107.

fleas, 167, 198.

mites, 181, 198.

shrew, 191, 163.

spider, 181.

vole, 191, 193.

Weasel, 44, 16, 127, 219.
Welwitschia, 124.

West Indies, 147, 152, 214 . 221.

Whales, 31, 159, 162.

bottle-nose, 176 .

Greenland, 33.

killer, 32,34 .

sperm, 176.

whalebone, $30,162,176$.

white, 34 .

Whelks, 167 .

Whortleberries, 20, 38.

Wild cat, 44.

boar. 39 .

dog, 44.
Villows, 19.

IVolf, $23,37,44,45$.

Wolverene, 46.

Woodpeckers, 37, 47, 109, 113.

green, 47

spotted, 47.

three-toed, 48.

Wood wasp, 50.

Wryneck, 47 .

Yak, 81, 82.

Zebra, 60, 132, 133. 


$$
\text { , }
$$


OXFORD: HORACE HART M.A. PRINTER TO THE ONIVERSITY 




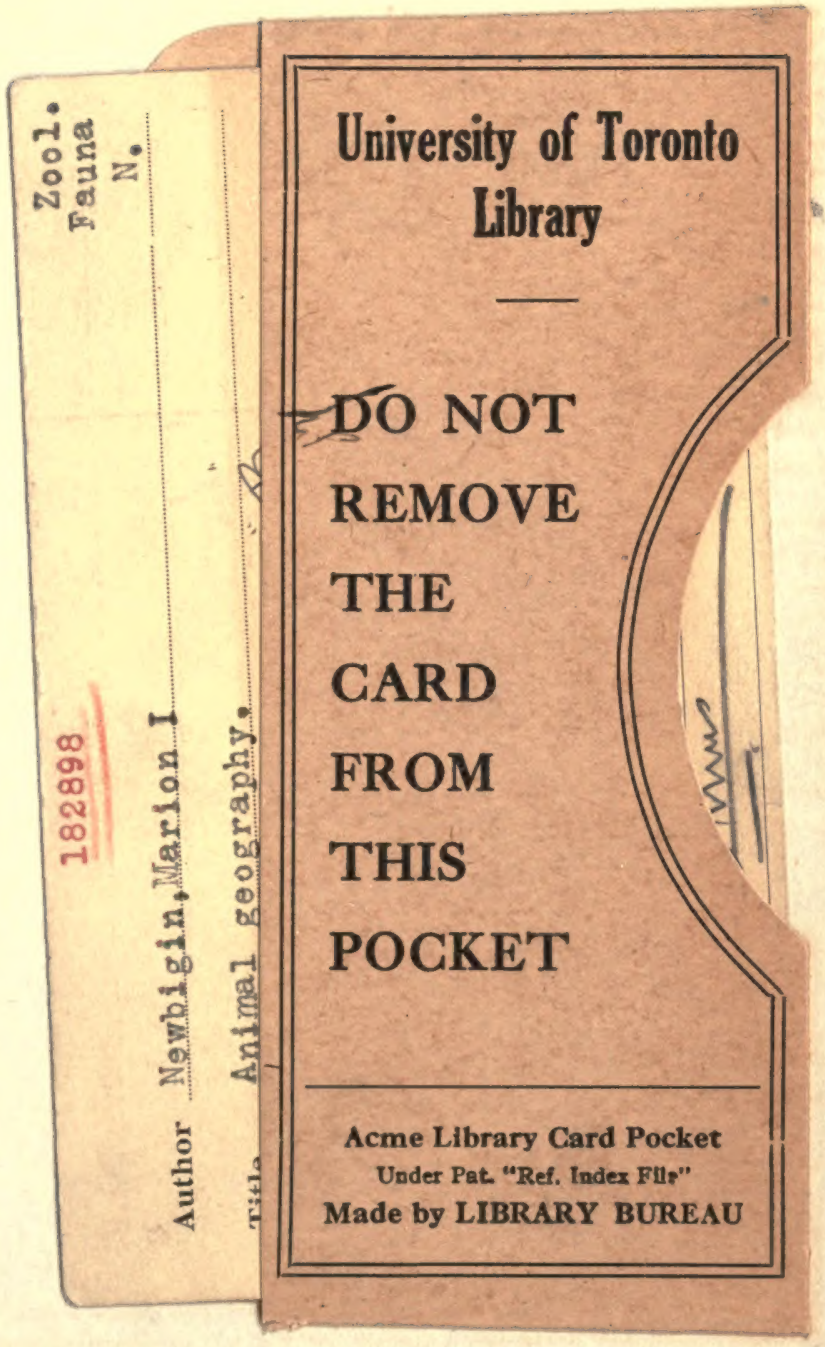




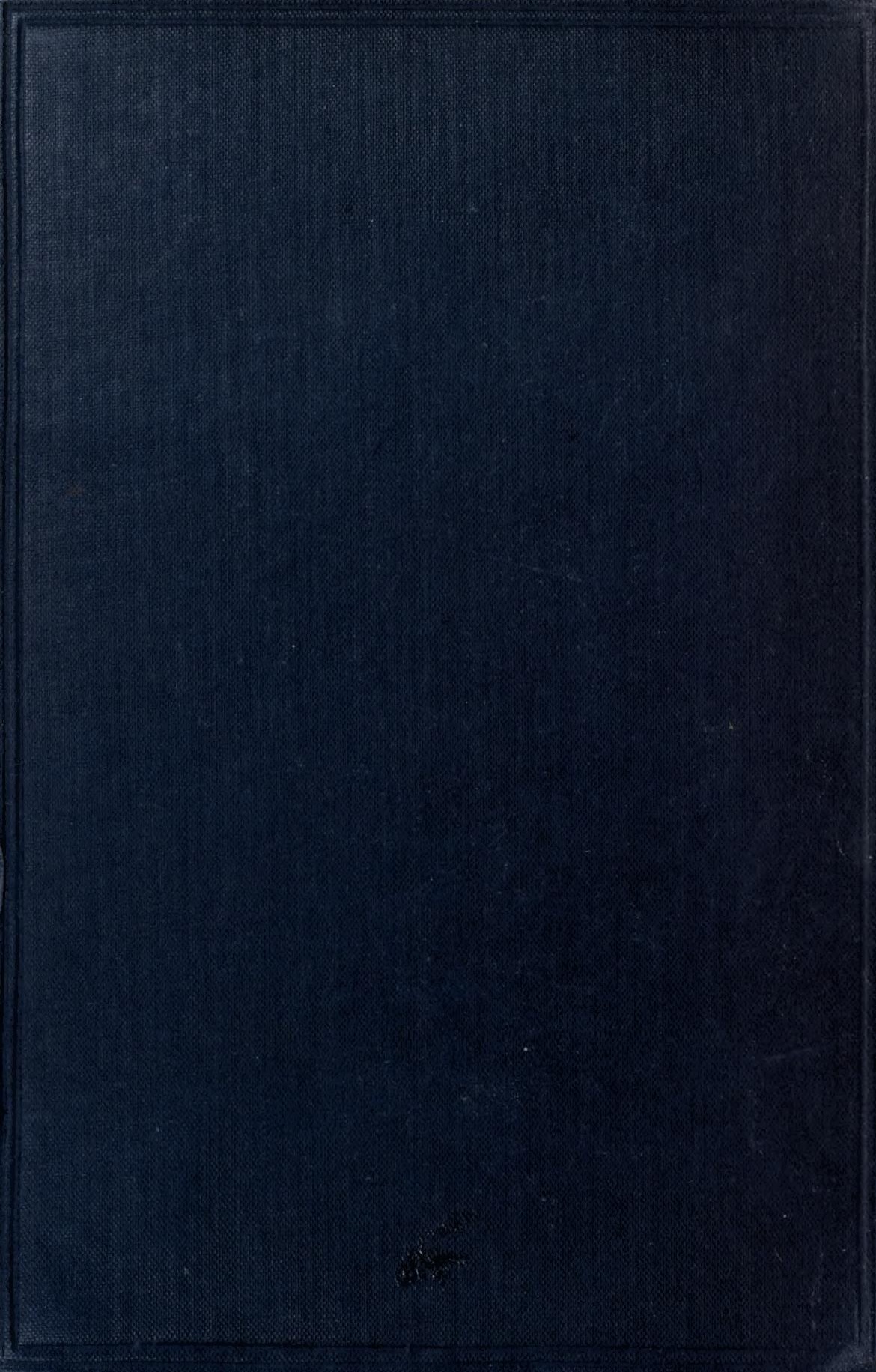

